\title{
INTERACTION OF CALCIUM WITH SUGAR TYPE Ligands IN SOLUTiOnS RELATED TO THE BAYER PROCESS
}

Ph.D. Dissertation

CONFIDENTIAL TO SPONSORS

Attila Pallagi

Supervisors:
DR. PÁl Sipos
DR. ISTVÁN PÁLINKÓ
DR. STEVEN ROSENBERG

Doctoral School of Chemistry

Material and Solution Structure Research Group | Department of Inorganic and Analytical Chemistry and Department of Organic Chemistry | Faculty of Science

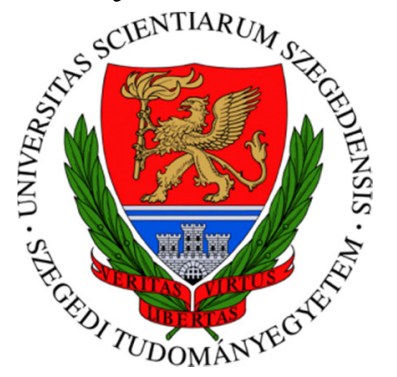
and Informatics | University of Szeged

Szeged

2011

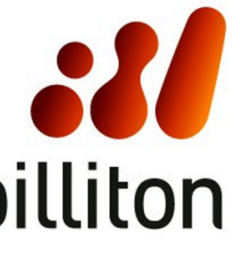




\section{Table of contents}

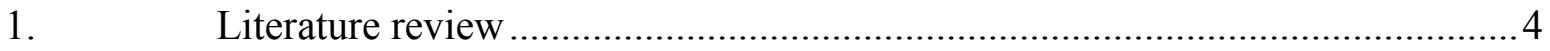

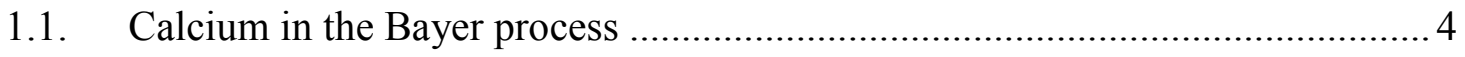

1.2. Solubility of $\mathrm{Ca}^{2+}$ in strongly alkaline solutions ............................................. 5

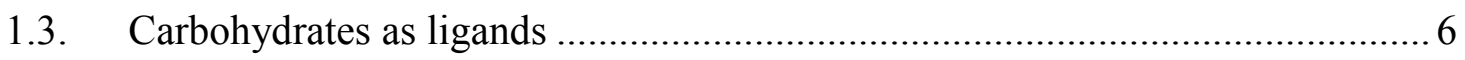

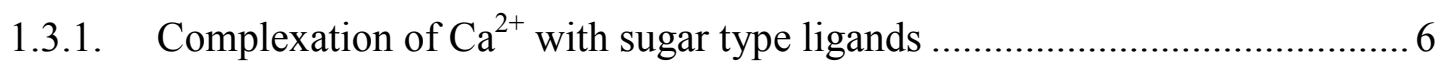

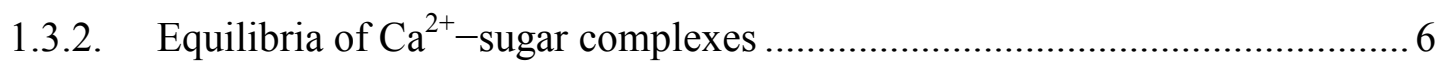

1.3.3. The structure of $\mathrm{Ca}^{2+}$ sugar complexes ................................................... 7

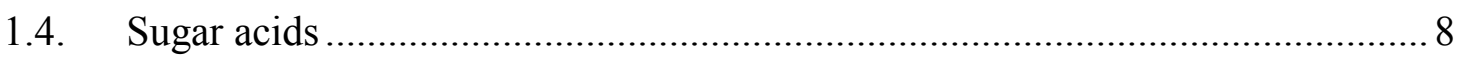

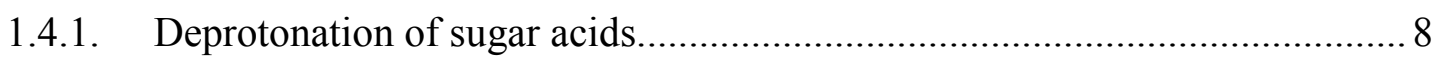

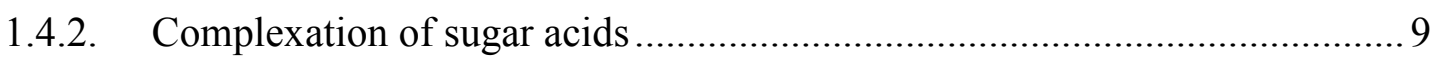

1.5. Interaction of $\mathrm{Ca}^{2+}$ with polyhydroxy carboxylates, in particular with $\mathrm{Gluc}^{-} . .11$

1.6. Solution equilibria in the $\mathrm{Al}^{3+} / \mathrm{Gluc}^{-}$system ............................................... 12

1.7. Solution equilibria in ternary systems containing $\mathrm{Ca}^{2+}$, three- or fourvalent cations $\left(\mathrm{B}^{3+}, \mathrm{Al}^{3+}, \mathrm{Fe}^{3+}\right.$ and $\left.\mathrm{Th}^{4+}\right)$ and sugar carboxylates........................... 14

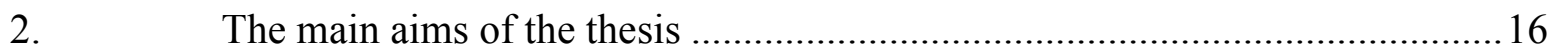

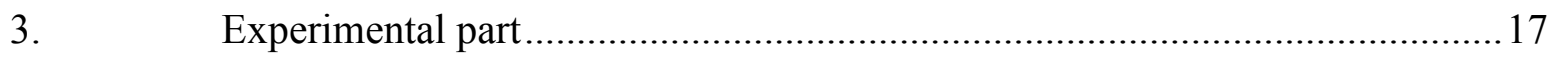

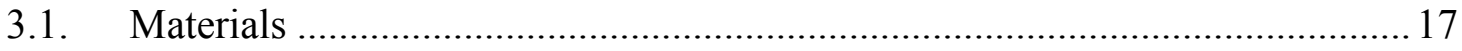

3.1.1. Preparation of the carbonate-free $\mathrm{NaOH}$ solutions ..................................... 17

3.1.2. Preparation of Na-aluminate solution .................................................. 17

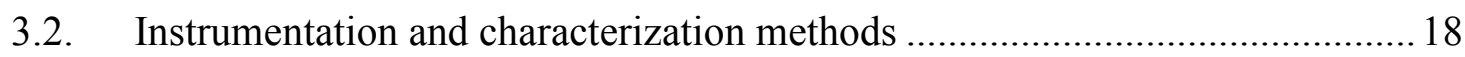

3.2.1. Multinuclear NMR spectroscopic measurements .................................... 18

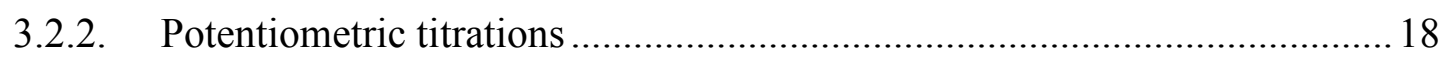

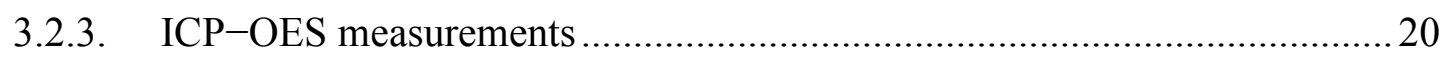

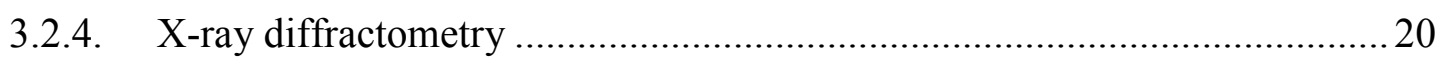

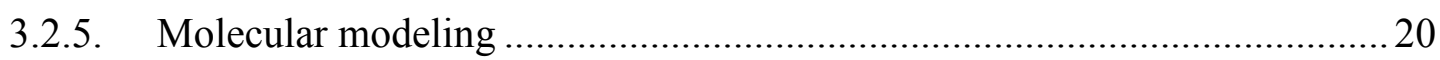

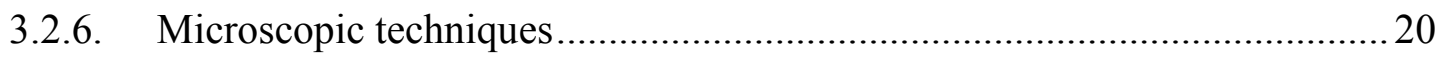

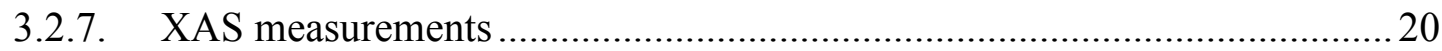

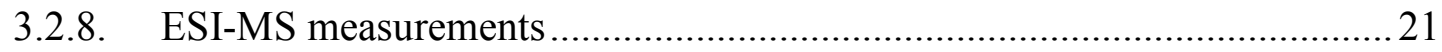

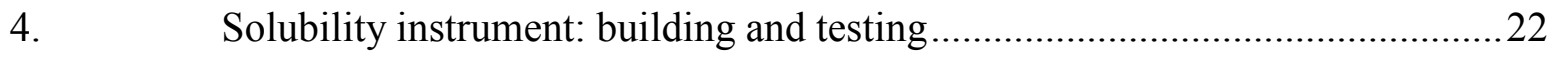

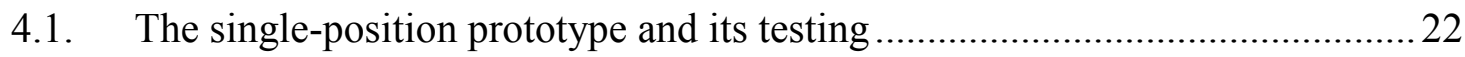

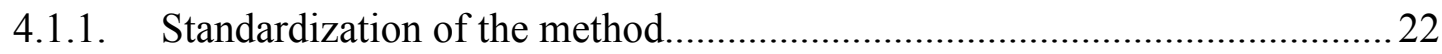

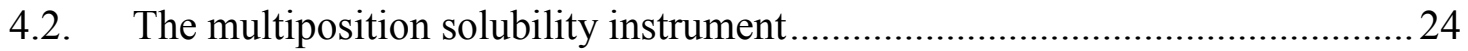

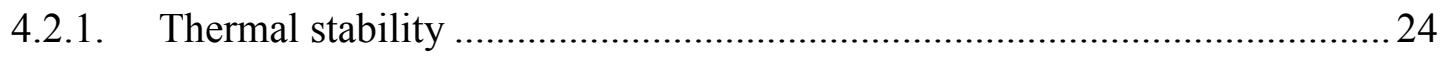

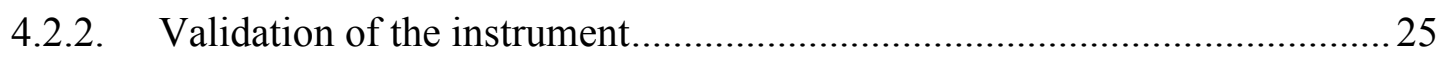

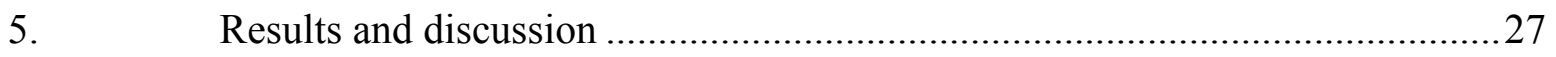


5.1. Binary systems containing Gluc ${ }^{-}$: protonation and interaction with $\mathrm{Ca}^{2+}$ 27

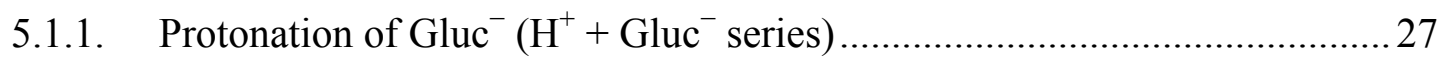

5.1.1.1. Multinuclear NMR measurements on the $\mathrm{H}^{+} / \mathrm{Gluc}^{-}$system ....................... 27

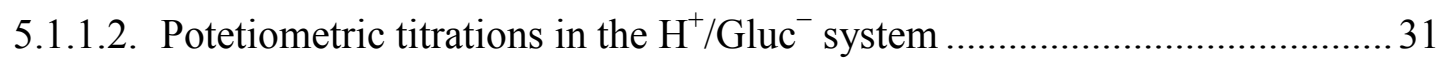

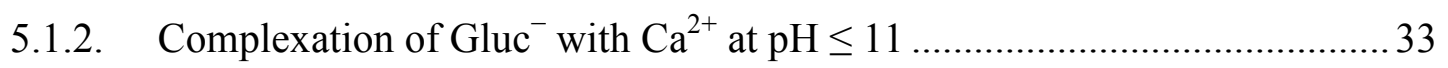

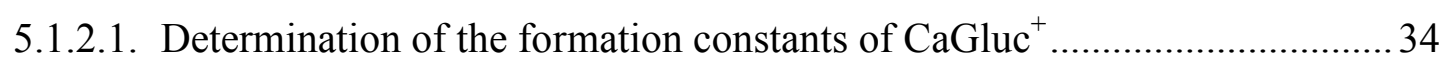

5.1.2.2. The structure of the $\mathrm{CaGluc}^{+}$complex ........................................................ 38

5.2. Binary systems containing other sugar derivatives........................................... 41

5.2.1. Complexation of $\mathrm{Ca}^{2+}$ with D-glucose $(\mathrm{Glu})$............................................ 41

5.2.2. Complexation of $\mathrm{Ca}^{2+}$ with sorbitol (Sor) ................................................ 45

5.2.3. Protonation of muconate $\left(\mathrm{Muc}^{2-}\right)$ and interaction with $\mathrm{Ca}^{2+}$...................... 47

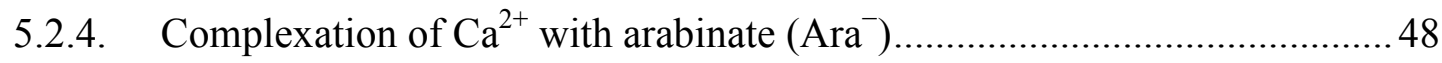

5.2.5. Complexation of $\mathrm{Ca}^{2+}$ with heptagluconate $\left(\mathrm{Hglu}^{-}\right)$................................... 49

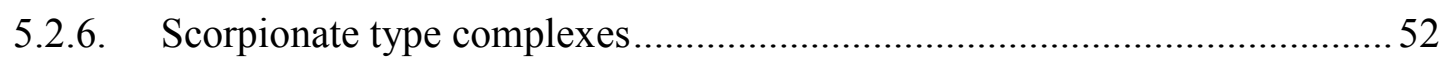

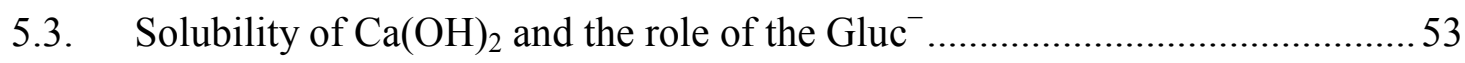

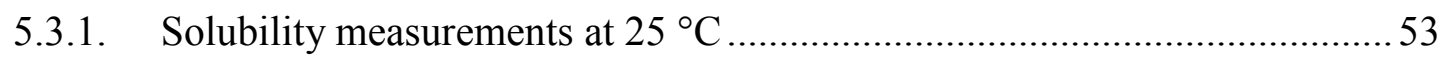

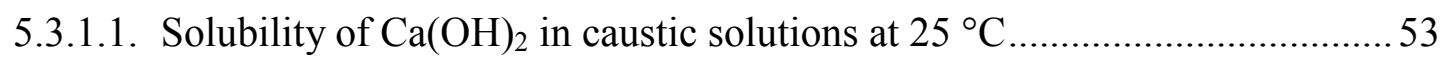

5.3.1.2. The solubility product of $\mathrm{Ca}(\mathrm{OH})_{2}$ and the stability constant of $\mathrm{CaOH}^{+}$at

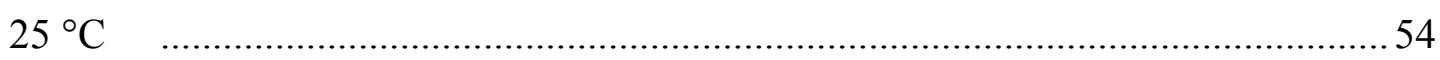

5.3.1.3. The conditional stability constant of the high-pH calcium gluconate

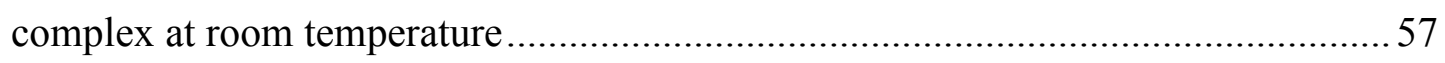

5.3.2. Solubility measurements under superambient conditions...........................5 58

5.4. Equilibria in solutions approaching real Bayer conditions .................................. 60

5.4.1. Complexation of $\mathrm{Gluc}^{-}$with $\mathrm{Ca}^{2+}$ in caustic solutions ...............................6 60

5.4.1.1. Multinuclear NMR measurements on the $\mathrm{Ca}^{2+} / \mathrm{Gluc}^{-}$binary systems in

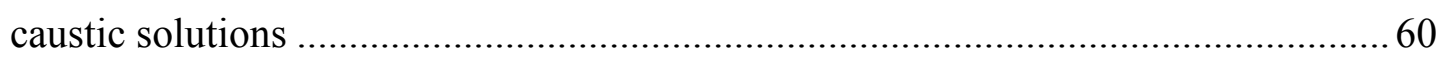

5.4.1.2. Potentiometric titrations on the $\mathrm{Ca}^{2+} / \mathrm{Gluc}^{-}$binary systems..........................6 64

5.4.1.3. ESI-MS measurements on the high-pH $\mathrm{Ca}^{2+} / \mathrm{Gluc}^{-}$binary systems ...........66 66

5.4.1.4. X-ray absorption (XAS) measurements on the $\mathrm{Ca}^{2+} / \mathrm{Gluc}^{-}$binary system .. 68

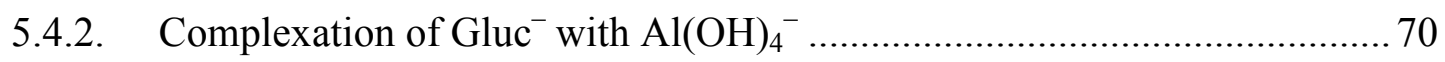

5.4.3. The role of the carbonate ion: Does it interact with $\mathrm{Al}(\mathrm{OH})_{4}{ }^{-}$or $\mathrm{Gluc}^{-}$?..... 77

5.4.4. Ternary system containing $\mathrm{Ca}^{2+}, \mathrm{Al}(\mathrm{OH})_{4}^{-}$and $\mathrm{Gluc}^{-}$................................ 78

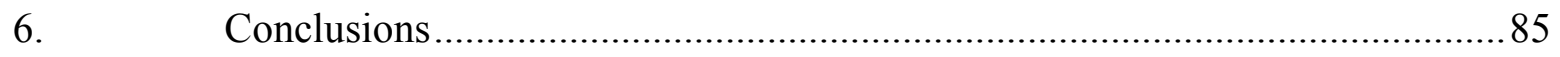

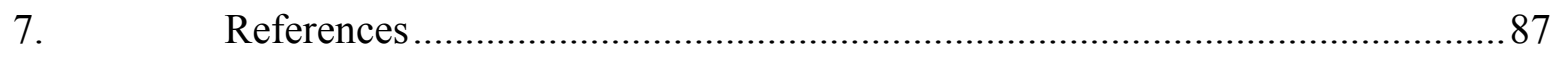




\section{Literature review}

The Bayer process is the principal industrial method of refining bauxite to produce $\mathrm{Al}_{2} \mathrm{O}_{3}$. It was invented in 1887 and patented ${ }^{1}$ in 1894 by Carl Josef Bayer. It may be considered as the recrystallization of the of the alumina content of bauxite in the presence of various inorganic and organic compounds. Since organic compounds, like humic acid, oxalate, or sugar carboxylates have important role in the Bayer process (e.g. via influencing calcium solubility) understanding the solution chemistry of these ligand types is highly desirable.

\subsection{Calcium in the Bayer process}

$\mathrm{Ca}(\mathrm{OH})_{2}$ is one of the most useful processing aids available to alumina refinery operators, primarily for its application in recausticising the liquor streams. In some cases the benefits arise directly from the reactions of the $\mathrm{Ca}(\mathrm{OH})_{2}$; in others they are more likely to be brought about through the actions of some soluble form of the calcium cation. Rosenberg et al. ${ }^{2}$ described the behavior of the calcium ion in virtually all of its common applications related to the Bayer process as presented on Figure 1.

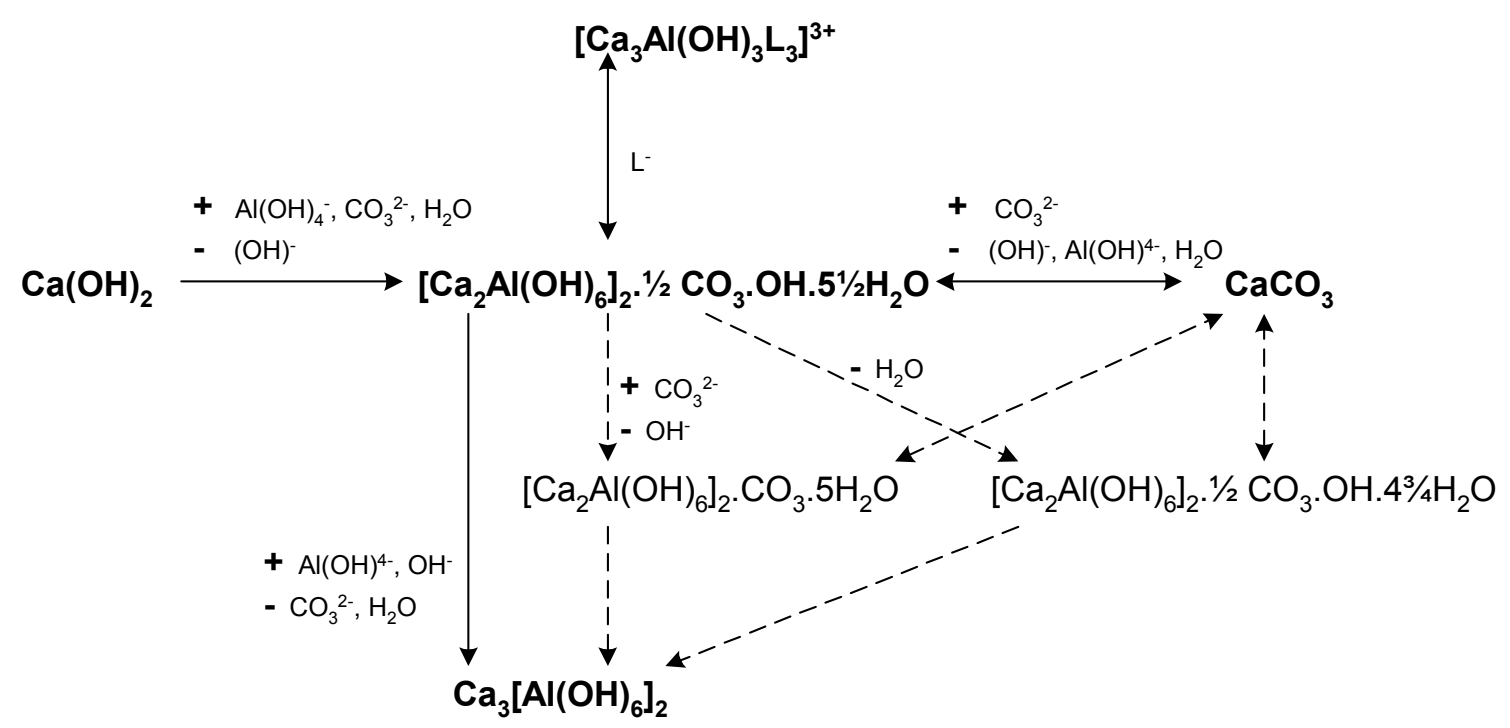

Figure 1: The reaction map of the calcium ion from ref. 2.

The and Sivakumar ${ }^{3}$ found that NaGluc and humic acid increase the solubility of the calcium ion in Bayer liquors, suggesting the formation of $\mathrm{Ca}^{2+}$-complexes with these ligands. Rosenberg et al. ${ }^{2}$ believe that the major soluble species in Bayer liquors is a kind of calcium aluminate monomer. They stated that addition of NaGluc had minor effect on the calcium solubility in $\mathrm{Al}(\mathrm{OH})_{4}{ }^{-}$-free systems, but a linear increase in calcium concentration took place with increasing $\mathrm{Gluc}^{-}$concentration in $\mathrm{Al}(\mathrm{OH})_{4}{ }^{-}$containing solutions. Investigation of these 
systems led to the conclusion that the complex species was of the form $\left[\mathrm{Ca}_{3} \mathrm{Al}(\mathrm{OH})_{3} \mathrm{Gluc}_{3}\right]^{3+}$, however Gluc ${ }^{-}$could equally be replaced with some other organic anion or $\mathrm{OH}^{-}$.

\subsection{Solubility of $\mathrm{Ca}^{2+}$ in strongly alkaline solutions}

The solubility behavior in alkaline solutions of some $\mathrm{Ca}^{2+}$ salts relevant to our research is depicted in Figure 2. The solubility of $\mathrm{Ca}(\mathrm{OH})_{2}$ decreases with increasing $\mathrm{NaOH}$ concentration, because the high $\mathrm{NaOH}$ concentration prevents the dissociation of $\mathrm{Ca}(\mathrm{OH})_{2}$. The solubility of $\mathrm{Ca}(\mathrm{OH})_{2}$ decreases with the temperature too. ${ }^{4}$
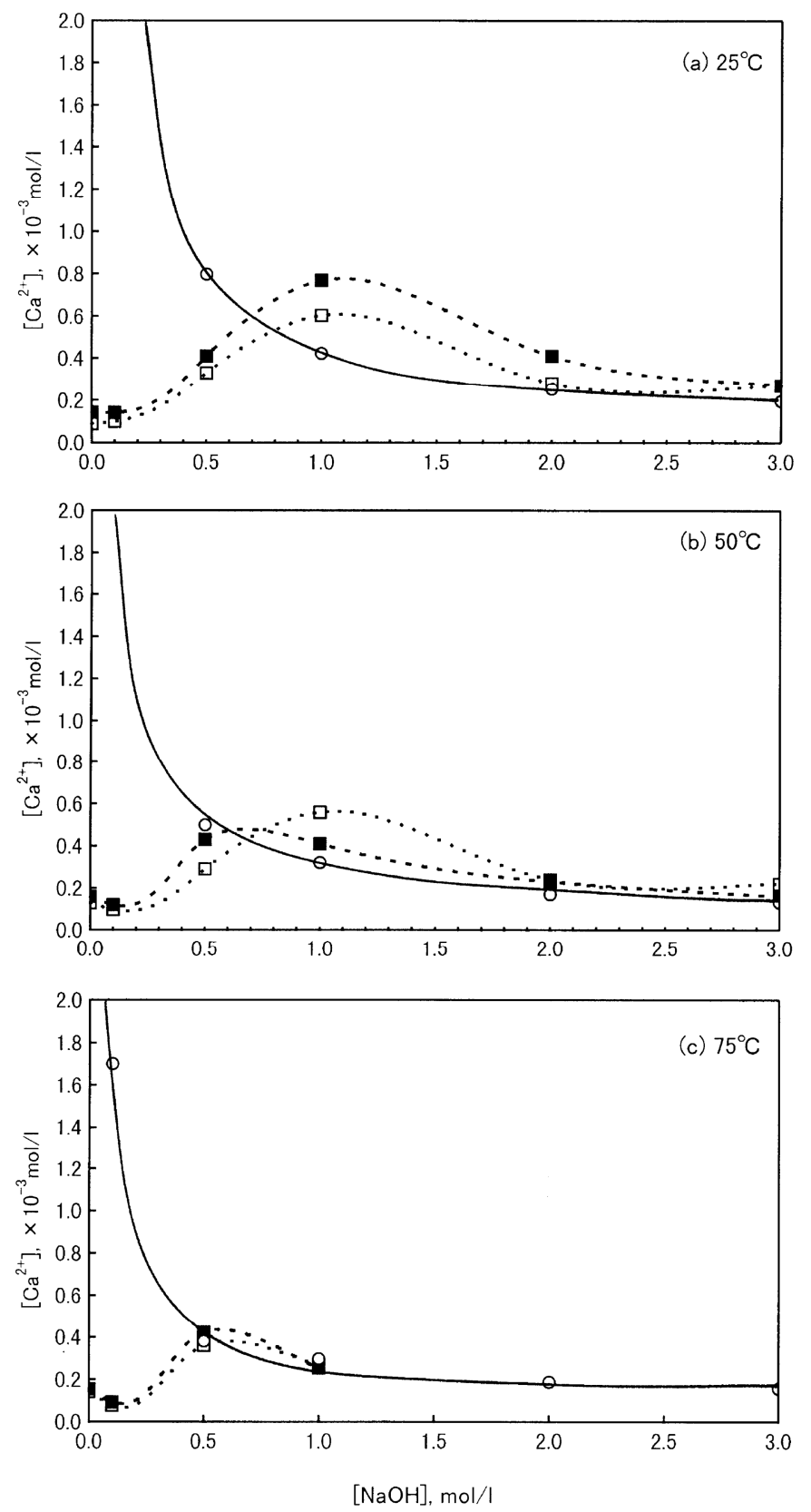

Figure 2: Solubility of $\mathrm{Ca}(\mathrm{OH})_{2}$, calcite and aragonite in $\mathrm{NaOH}$ solution at 25, 50 and $75{ }^{\circ} \mathrm{C}$ $\circ: \mathrm{Ca}(\mathrm{OH})_{2}$; $\square$ : calcite; $\mathbf{\square}$ : aragonite from ref. 4. 
The solubilities of calcite and aragonite change according to a maximum curve with increasing $\mathrm{NaOH}$ concentration. In the $25-50{ }^{\circ} \mathrm{C}$ range and under $1 \mathrm{M} \mathrm{NaOH}$ the solubility of $\mathrm{CaCO}_{3}$ becomes higher than that of $\mathrm{Ca}(\mathrm{OH})_{2}$. Above $2 \mathrm{M} \mathrm{NaOH}$, however, the solid phases of calcite and aragonite are unstable and are easily converted to $\mathrm{Ca}(\mathrm{OH})_{2}$. At $50{ }^{\circ} \mathrm{C}$, aragonite is less stable than calcite and it transforms to $\mathrm{Ca}(\mathrm{OH})_{2}$. At $75^{\circ} \mathrm{C}$, the solubilities of both crystals decrease above $0.5 \mathrm{M} \mathrm{NaOH}$. It is expected that both calcite and aragonite are unstable at the higher $\mathrm{NaOH}$ concentration and the solubilities of calcite and aragonite are much higher than that of $\mathrm{Ca}(\mathrm{OH})_{2}$. The equilibrium solubilities of calcite and aragonite are not influenced by the temperature under causticizing reaction conditions.

In the presence of $\mathrm{Na}_{2} \mathrm{CO}_{3}$ the solubilities of calcite and aragonite decrease with increasing $\mathrm{Na}_{2} \mathrm{CO}_{3}$ concentration. The solubility of calcite at $75^{\circ} \mathrm{C}$ and that of the aragonite at $50{ }^{\circ} \mathrm{C}$ and $75^{\circ} \mathrm{C}$ in $\mathrm{NaOH}$ solution without $\mathrm{Na}_{2} \mathrm{CO}_{3}$ cannot be investigated due to their conversion to $\mathrm{Ca}(\mathrm{OH})_{2}$.

\subsection{Carbohydrates as ligands}

Simple sugars and their derivatives (with oxygen, nitrogen, sulphur or phosphorous coordinationg groups) form metal ion complexes of various compositions and stabilities. The quantitative characterization of the coordination equilibria is difficult due to the low stabilities of the complexes in neutral or acidic aqueous solutions. With increasing $\mathrm{pH}$, however, the hydrolysis of some metal ions prevents the coordination of the organic ligands, thus complex formation can only be expected in strongly alkaline solutions, after deprotonation of the alcoholic hydroxy group(s). ${ }^{5}$

\subsubsection{Complexation of $\mathrm{Ca}^{2+}$ with sugar type ligands}

$\mathrm{Ca}^{2+}$ forms weak complexes with cyclic sugar type ligands in aqueous solutions ${ }^{5,6,7,8,9,10}$. From ${ }^{13} \mathrm{C}$ NMR measurements it was suggested ${ }^{10,11}$ that the prerequisite of the formation of reasonably stable calcium complexes (i.e., the formation constant of which can experimentally be determined) with this family of compounds is the presence of three hydroxyl groups in an ax-eq-ax sequence in the molecule with chair conformation.

\subsubsection{Equilibria of $\mathrm{Ca}^{2+}$-sugar complexes}

Metal ions with appropriate ionic radii [that is ca. $1.0 \AA$ and $r\left(\mathrm{Ca}^{2+}\right)=0.99 \AA$ ] form relatively stable complexes (with $\mathrm{Ca}^{2+}$ up to the value of $20 \mathrm{dm}^{3} \mathrm{~mol}^{-1}$ for the stability constant of 1:1 complexes) with these ligands, because they can comfortably fit in the cavity 
of the three adjacent donor groups. Other cyclic sugars with no such sequence (e.g., Dglucose) form much weaker $\mathrm{Ca}^{2+}$ complexes. ${ }^{12}$ It was reported ${ }^{11}$ that complexing with cations (among others with $\mathrm{Ca}^{2+}$ ) causes a downfield shift of the signals of some protons in the ${ }^{1} \mathrm{H}$ NMR spectra of several glycosides. This complexing was weak $\left(\mathrm{K} \sim 0.1 \mathrm{dm}^{3} \mathrm{~mol}^{-1}\right)$ and was attributed to coordination with two adjacent oxygen atoms of the glycosides. Upon addition of calcium ions no substantial changes in the NMR spectra of sugars lacking the required $a x-e q-a x$ sequence of hydroxyl groups (e.g. D-glucose, D-mannose, and D-arabinose) were observed. $^{11}$ By other methods, the formation of the complexes is plausible: using thermodynamic methods, the formation constant of the $\mathrm{Ca}^{2+}$ complex of $\mathrm{D}$-glucose was found to be $5 \mathrm{dm}^{3} \mathrm{~mol}^{-1}\left[\mathrm{Ca}^{2+} \text {-ion selective electrode (Ca-ISE) }\right]^{13}$ or $8.7 \mathrm{dm}^{3} \mathrm{~mol}^{-1}$ (calorimetry). ${ }^{14}$ Note that these values are significantly larger than expected on the basis of the structural features of $\mathrm{D}-$ glucose.

Calcium complexes of the linear polyol, D-sorbitol, in aqueous solutions are also known to be weak. ${ }^{15}$ From the variation of the ${ }^{13} \mathrm{C}$ NMR signals upon $\mathrm{Ca}^{2+}$ addition the formation constant of the complex with 1:1 composition was estimated to be $\mathrm{K}_{1,1}=0.6 \mathrm{dm}^{3} \mathrm{~mol}^{-1}$ $\left(36{ }^{\circ} \mathrm{C}\right)$ and $1.2 \mathrm{dm}^{3} \mathrm{~mol}^{-1}\left(4^{\circ} \mathrm{C}\right) .{ }^{15}$ From conductance measurements at $30{ }^{\circ} \mathrm{C}, \mathrm{K}_{1,1}=$ $0.16 \mathrm{dm}^{3} \mathrm{~mol}^{-1}$, while from solubility determinations at $25^{\circ} \mathrm{C}, \mathrm{K}_{1,1}=1.5 \mathrm{dm}^{3} \mathrm{~mol}^{-1}$ and $0.8 \mathrm{dm}^{3} \mathrm{~mol}^{-1}$ were derived. ${ }^{16,17,18}$ Note that all these measurements were performed in solutions with varying ionic strengths.

\subsubsection{The structure of $\mathrm{Ca}^{2+}$ sugar complexes}

The majority of the studies to reveal the structure of the $\mathrm{Ca}^{2+}$-sugar complexes was performed in the solid phase, and the complexes were characterized mainly by FTIR spectroscopy.

Interaction between the D-glucose and $\mathrm{Ca}^{2+}$ in solid phase was investigated by $\mathrm{H}$. A. Tajmir-Riahi. ${ }^{19}$ Strong interaction was found between D-glucose and alkaline-earth metal cations in the solid state and in non-aqueous solutions, whereas, in aqueous solution such interaction is less significant. In 1:1 solid-state metal-D-glucose adducts, the $\mathrm{Ca}^{2+}$ may have a coordination number of seven, binding to a D-glucose (possibly through $\mathrm{O}(1)-\mathrm{H}, \mathrm{O}(2)-\mathrm{H}$ and other sugar donor atoms) and to four water molecules. In the solid-state adducts of 1:2 ratio, the $\mathrm{Ca}^{2+}$ may have a coordination number of eight, binding to two sugar units bidentately via $\mathrm{O}(1)-\mathrm{H}$ and $\mathrm{O}(2)-\mathrm{H}$ and four $\mathrm{H}_{2} \mathrm{O}$. In non-aqueous solutions $\left(\mathrm{Me}_{2} \mathrm{SO}\right)$ there is strong interaction between $\mathrm{Ca}^{2+}$ and D-glucose, in particular with the anomeric $\mathrm{O}(1)-\mathrm{H}$ group, but there is no major interaction in aqueous solutions. The interaction of $\mathrm{Ca}^{2+}$ with ribose has also 
been studied. ${ }^{20}$ All five oxygen atoms of the ribose molecule are involved in calcium binding. Each $\mathrm{Ca}^{2+}$ is shared by two ribose molecules, coordinating through $\mathrm{O}(1), \mathrm{O}(2), \mathrm{O}(3)$ of one molecule and $\mathrm{O}(4)$ and $\mathrm{O}(5)$ of the other. The crystal structure of the $\mathrm{Ca}^{2+}$ complex formed with galactitol is monoclinic. ${ }^{21}$ Galactitol provides $\mathrm{O}(2)$ and $\mathrm{O}(3)$ to coordinate to one, and $\mathrm{O}(4), \mathrm{O}(5)$ to another $\mathrm{Ca}^{2+}$, and a chain structureis formed. Hereby the $\mathrm{Ca}^{2+}$ is coordinated to eight oxygen atoms, four from two galactitol molecules and four from water molecules.

\subsection{Sugar acids}

Sugar acids are monosaccharides containing one or more carboxylic groups. The main classes of sugar acids are as follows: aldonic acids, ulosonic acids, uronic acids and aldaric acids. Aldonic acids are formed by oxidation of the aldehyde functional group of an aldose to form a carboxylic acid [e.g., glyceric acid, gluconic acid (Gluc $\left.{ }^{-}\right)$, heptagluconic acid $\left(\mathrm{Hglu}^{-}\right)$, ascorbic acid]. Ulosonic acids are $\alpha$-keto acids, and can be obtained by oxidation of the hydroxyl group at position 1 of a ketose to a carboxylic group. In uronic acids (e.g., glucuronic acid, galacturonic acid) beside the formyl group a carboxylic group is also present. Aldaric acids contain carboxylic groups at both ends.

\subsubsection{Deprotonation of sugar acids}

The protonation processes of different sugar acids were investigated by G. M. Escandar and L. F. Sala. ${ }^{22}$ The chemicals studied were the gluconic acid, heptagluconic acid, galactonic acid, ribonic acid, glucuronic acid and galaturonic acid. The protonation constants were determined by potentiometric titrations in $0.1 \mathrm{M} \mathrm{NaNO}_{3}$ at $20.0 \pm 0.1{ }^{\circ} \mathrm{C}$ and are shown on the Table 1 .

Table 1: The protonation constants of sugar acids at $20^{\circ} \mathrm{C}\left(\mathrm{I}=0.10 \mathrm{M}, \mathrm{NaNO}_{3}\right)$ from ref. 22.

\begin{tabular}{lc}
\hline \multicolumn{1}{c}{ Ligand } & $\log \mathbf{K}$ \\
\hline Gluconic acid & $3.40 \pm 0.01$ \\
Heptagluconic acid & $3.38 \pm 0.008$ \\
Galactonic acid & $3.49 \pm 0.01$ \\
Ribonic acid & $4.02 \pm 0.03$ \\
Glucuronic acid & $2.98 \pm 0.01$ \\
Galaturonic acid & $3.19 \pm 0.01$ \\
\hline
\end{tabular}

The acidity and the ability of mucic $\left(\mathrm{H}_{2} \mathrm{Muc}\right.$; also known as galactaric) acid to form complexes with different metal ions have been reported. ${ }^{23}$ In the study the protonation 
constant of the mucic acid was determined at various temperatures in the $15-45{ }^{\circ} \mathrm{C}(\mathrm{I}=0.1$ $\mathrm{M}, \mathrm{NaNO}_{3}$ ) range. At $25^{\circ} \mathrm{C} \log \mathrm{K}_{1}$ and $\log \mathrm{K}_{2}$ were found to be 3.05 and 4.04, respectively.

Little is known about the deprotonation of an alcoholic $\mathrm{OH}$ of sugar acids at high $\mathrm{pH}$. Zhang et al. ${ }^{24}$ have found by NMR studies that the chemical shifts of the individual Gluc carbons show an inflexion point at high $\mathrm{pH}$. They have given two possible explanations for this observation. One is that deprotonation occurs on a hydroxyl group of the Gluc ${ }^{-}$and the second is the occurrence of an interaction between the $\mathrm{Na}^{+}$and $\mathrm{Gluc}^{-}$ions. The protonation constant of the alcoholic $\mathrm{OH}$ is found to be $\log \mathrm{K}_{\mathrm{a}}{ }^{\prime}=13 \pm 1$ and they suggest that the deprotonation occurs on the $\mathrm{C} 4$ hydroxyl group due to its largest displacement in the chemical shift.

\subsubsection{Complexation of sugar acids}

Sugar acids form various complexes with different metal ions. The stability constants of the $1: 1 \mathrm{Cu}^{2+}$ complexes formed with the conjugated bases of gluconic acid, galactonic acid and ribonic acid were found to be $\log \mathrm{K}_{110}=3.02,3.04$ and 3.52 (at $20{ }^{\circ} \mathrm{C}$; I $=0.10 \mathrm{M}$, $\mathrm{NaNO}_{3}$ ), respectively. ${ }^{22}$ The stability constants of these ligands with $\mathrm{Cu}^{2+}$ with different ratio and/or deprotonation of the ligands is presented in Table 2. They suggest that these polyhydroxy carboxylates coordinate the $\mathrm{Cu}^{2+}$ through the $\mathrm{O}(1)$ and $\mathrm{O}(3)$ oxygen atoms.

Table 2: Stability constants and deprotonation constants of chelates between sugar acids and $\mathrm{Cu}(\mathrm{II})$ at $20^{\circ} \mathrm{C}\left(\mathrm{I}=0.10 \mathrm{M}, \mathrm{NaNO}_{3}\right)$ from ref. 22.

\begin{tabular}{lccc}
\hline \multirow{2}{*}{ Quotient } & \multicolumn{3}{c}{$\log \mathrm{K}$} \\
\cline { 2 - 4 } & Gluconic acid & Galactonic acid & Ribonic acid \\
\hline$\left[\mathrm{CuL}^{+}\right] /\left[\mathrm{Cu}^{2+}\right]\left[\mathrm{L}^{-}\right]$ & 3.02 & 3.04 & 3.52 \\
{$\left[\mathrm{CuH}_{-2} \mathrm{~L}^{-}\right]\left[\mathrm{H}^{+}\right]^{2} /\left[\mathrm{CuL}^{+}\right]$} & -11.96 & -11.33 & -11.85 \\
{$\left[\mathrm{CuH}_{-3} \mathrm{~L}^{2-}\right]\left[\mathrm{H}^{+}\right] /\left[\mathrm{CuH}_{-2} \mathrm{~L}^{-}\right]$} & - & -10.86 & -10.30 \\
$\left.\left[\mathrm{Cu}_{2} \mathrm{H}_{-3} \mathrm{~L}_{2}^{-}\right]\left[\mathrm{H}^{+}\right]^{3} \mathrm{Cu}^{2+}\right]\left[\mathrm{L}^{-}\right]$ & -6.58 & -7.54 & -7.26 \\
\hline
\end{tabular}

${ }^{1} \mathrm{H}$ NMR studies of the Gluc ${ }^{-}$complexes formed with $\mathrm{Pb}^{2+}$ and $\mathrm{Bi}^{3+}$ were performed by D. T. Sawyer and J. R. Brannan. ${ }^{25}$ By recording the ${ }^{1} \mathrm{H}$ NMR spectra of the complexes formed by Gluc ${ }^{-}$with $\mathrm{Mg}^{2+}, \mathrm{Al}^{3+}, \mathrm{Zn}^{2+}, \mathrm{Mo}(\mathrm{VI}), \mathrm{Pb}^{2+}$ and $\mathrm{Bi}^{3+}$ under alkaline conditions, they found that only the $\mathrm{Pb}^{2+}$ and $\mathrm{Bi}^{3+}$ complexes exhibited chemical shifts for the $\mathrm{C}-\mathrm{H}$ protons. The pronounced downfield shift for the $\mathrm{O}(2)$ and $\mathrm{O}(4)$ oxygen atoms indicate that these alcoholic oxygen atoms are involved in bonding to $\mathrm{Pb}^{2+}$. The formation of the $\left[\mathrm{Pb}_{3} \mathrm{Gluc}_{2}(\mathrm{OH})_{6}\right]^{2-}$ complex is assumed on the basis of potentiometric titrations and ${ }^{1} \mathrm{H}$ NMR 
measurements. Beside the carboxylic oxygen the $\mathrm{O}(2), \mathrm{O}(3)$ and $\mathrm{O}(4)$ alcoholic oxygens are also involved in bonding interactions. In the $\mathrm{Bi}^{3+}$ and Gluc ${ }^{-} 1: 1$ and $1: 2$ complexes are formed. Titrations indicate that their formulas are $\left[\operatorname{BiGluc}(\mathrm{OH})_{4}\right]^{3-}$ and $\left[\operatorname{BiGluc}_{2}(\mathrm{OH})_{4}\right]^{3-}$, respectively. Beside the carboxylic oxygen of the $\mathrm{Gluc}^{-}$the $\mathrm{O}(2)$ and the $\mathrm{O}(3)$ alcoholic oxygen bonds to the $\mathrm{Bi}^{3+}$. G. M. Escandar et al. studied the complexation of trivalent metal ions $\left(\mathrm{Al}^{3+}, \mathrm{Ga}^{3+}\right.$ and $\left.\mathrm{In}^{3+}\right)$ with Gluc ${ }^{-}$and lactobionic acids. ${ }^{26}$ The stability constants of these and the $\mathrm{Fe}^{3+}$ complexes are listed in Table 3. The $\mathrm{Al}^{3+}$ forms complexes with the Gluc by binding to the $\mathrm{O}(1)-\mathrm{O}(4)$ oxygen atoms at both $\mathrm{pH} 4.7$ and 10. In the case of lactobionic acid, the $\mathrm{O}(1)-\mathrm{O}(3)$ and the $\mathrm{O}(6)$ atoms participate in $\mathrm{Al}^{3+}$ binding at $\mathrm{pH} 4.7, \mathrm{O}(5)$ is also bonded at $\mathrm{pH}$ 10. The oxygens involved in complex formation with $\mathrm{Ga}^{3+}$ and $\mathrm{In}^{3+}$ are $\mathrm{O}(1)-\mathrm{O}(4)$ of both ligands.

Table 3: Stability constants of trivalent metal ions $\left(\mathrm{Al}^{3+}, \mathrm{Ga}^{3+}\right.$ and $\left.\mathrm{In}^{3+}\right)$ with $\mathrm{Gluc}^{-}$and lactobionic acids at $20{ }^{\circ} \mathrm{C}\left(\mathrm{I}=0.10 \mathrm{M}, \mathrm{NaNO}_{3}\right)$

\begin{tabular}{|c|c|c|c|c|}
\hline \multirow[b]{2}{*}{ Quotient } & \multirow[b]{2}{*}{$M^{3+}$} & \multicolumn{2}{|c|}{$\log K$} & \multirow[t]{2}{*}{ Ref. } \\
\hline & & HGluc & $\begin{array}{l}\text { Lactobionic } \\
\text { acid }\end{array}$ & \\
\hline \multicolumn{5}{|c|}{$\left[\mathrm{MH}_{-1} \mathrm{~L}^{+}\right]\left[\mathrm{H}^{+}\right] /\left[\mathrm{L}^{-}\right]\left[\mathrm{M}^{3+}\right]$} \\
\hline & $\mathrm{Fe}^{3+}$ & 2.43 & 2.03 & 27 \\
\hline & $A l^{3+}$ & -0.84 & & 26 \\
\hline \multicolumn{5}{|c|}{$\left[\mathrm{MH}_{-2} \mathrm{~L}\right]\left[\mathrm{H}^{+}\right]^{2} /\left[\mathrm{L}^{-}\right]\left[\mathrm{M}^{3+}\right]$} \\
\hline & $\mathrm{Fe}^{3+}$ & -0.80 & -1.86 & 27 \\
\hline & $\mathrm{Ga}^{3+}$ & -2.83 & -3.02 & 26 \\
\hline \multicolumn{5}{|c|}{$\left[\mathrm{MH}_{-3} \mathrm{~L}^{-}\right]\left[\mathrm{H}^{+}\right]^{3} /\left[\mathrm{L}^{-}\right]\left[\mathrm{M}^{3+}\right]$} \\
\hline & $\mathrm{Fe}^{3+}$ & -5.18 & -11.79 & 27 \\
\hline & $\mathrm{Al}^{3+}$ & -10.70 & -11.98 & 26 \\
\hline & $\mathrm{Ga}^{3+}$ & -8.94 & -8.95 & 26 \\
\hline & $\ln ^{3+}$ & -9.21 & -9.53 & 26 \\
\hline \multicolumn{5}{|c|}{$\left[\mathrm{MH}_{-4} \mathrm{~L}^{2-}\right]\left[\mathrm{H}^{+}\right]^{4} /\left[\mathrm{L}^{-}\right]\left[\mathrm{M}^{3+}\right]$} \\
\hline & $\mathrm{Ga}^{3+}$ & -16.45 & -16.40 & 26 \\
\hline
\end{tabular}

Aldaric acids form various complexes with different $\mathrm{M}^{2+}$ metals. $^{23,28}$ The stability constants of the complexes formed with $\mathrm{Ca}^{2+}, \mathrm{Mg}^{2+}$ or $\mathrm{Zn}^{2+}$ are presented in Table 4. Beside the 1:1 complexes of $\mathrm{Muc}^{2-}$ and $\mathrm{M}^{2+}$ metals Saladini et al. ${ }^{23}$ reported the deprotonation of the ligand and the formation of 1:2 complexes. They were as follows: $\left[\mathrm{MMucH}_{-1}\right]^{-},\left[\mathrm{M}(\mathrm{Muc})_{2}\right]^{2-}$ and $\left[\mathrm{M}(\mathrm{Muc})_{2} \mathrm{H}_{-1}\right]^{3-}$. 
Table 4: The stability constants of 1:1 complexes of aldaric acid or its salt with $\mathrm{Ca}^{2+}, \mathrm{Mg}^{2+}$ and $\mathrm{Zn}^{2+}$

\begin{tabular}{lllll}
\hline \multirow{2}{*}{ Ligand } & \multicolumn{3}{c}{$\log \mathbf{K}$} & \multirow{2}{*}{ Ref. } \\
\cline { 2 - 4 } & $\mathbf{C a}^{2+}$ & $\mathbf{M g}^{2+}$ & $\mathbf{Z n}^{2+}$ & \\
\hline Tartonic acid & 2.27 & 2.17 & 3.22 & 28 \\
Tartaric acid & 1.80 & 1.36 & 2.68 & 28 \\
Muc $^{2-}$ & 2.45 & 2.37 & 3.04 & 28 \\
& 2.45 & 2.32 & 3.04 & 23 \\
\hline
\end{tabular}

\subsection{Interaction of $\mathrm{Ca}^{2+}$ with polyhydroxy carboxylates, in particular with Gluc}

Polyhydroxy carboxylates are known to sequester calcium ions in solution. ${ }^{5}$ Under hyperalkaline conditions high stability $\mathrm{Ca}^{2+}$ complexes may be formed (e.g., with isosaccharinate), where the metal ion is claimed to be bound via the alcoholate group(s) of the carbohydrate. ${ }^{29,30}$ However, at intermediate $\mathrm{pH}$ such deprotonation does not take place and the contribution of the alcoholic $\mathrm{OH}$ to the coordination (if any) is expected to be relatively little. Therefore, the stabilities of the calcium complexes formed are very low and the formation constant of the first stepwise complex, $\mathrm{K}_{1,1}$ defined as

$$
K_{1,1}=\frac{\left[\mathrm{CaL}^{+}\right]}{\left[\mathrm{Ca}^{2+}\right]\left[L^{-}\right]}
$$

(where $\mathrm{L}^{-}$denotes the polyhydroxy carboxylate anion) is in the order of $10-80 \mathrm{dm}^{3} \mathrm{~mol}^{-1}$. As a result of this low stability, the experimental determination of the corresponding formation constants is inherently difficult and accurate stability data are scarce. ${ }^{32}$ Not at all surprisingly, even less is known about the structure of these solution complexes. ${ }^{5}$

Calcium gluconate is a widely used gluconic acid derivative. In pharmaceutical use it is applied in treating calcium(II) deficiency, and hydrofluoric acid burns are treated with water based gel containing $2.5-5 \%$ calcium gluconate ${ }^{33,34}$. It is also widely used in the food and general industrial chemical fields. In aqueous solutions the stability constant of the solution complex comprising calcium and D-gluconate is considerably low.

Literature data indicate that the $\mathrm{CaGluc}^{+}$complex (or ion pair) is very weak. ${ }^{31,35,36,37,38}$ From $\mathrm{H}^{+} / \mathrm{Pt}$ electrode potentiometry $\log \mathrm{K}_{1,1}=1.21$ was obtained $\left(20{ }^{\circ} \mathrm{C}, \mathrm{I}=0.20 \mathrm{M}, \mathrm{KCl}\right)^{35}$, while from ionic exchange measurements under similar conditions $\log \mathrm{K}_{1,1}=1.22$ was found $\left(25{ }^{\circ} \mathrm{C}, \mathrm{I}=0.16 \mathrm{M}, \mathrm{KCl}\right) .{ }^{37} \mathrm{Ca}^{2+}$-ISE potentiometry yielded $\log \mathrm{K}_{1,1}=1.31\left(25^{\circ} \mathrm{C}, \mathrm{I}=\right.$ $\left.0.70 \mathrm{M}, \mathrm{KNO}_{3}\right)^{31}$ and $1.05\left(25^{\circ} \mathrm{C}, \mathrm{I}=0.50 \mathrm{M}, \mathrm{NaCl}\right) .{ }^{36}$ At reasonably high $\left[\mathrm{Gluc}^{-}\right]_{\mathrm{T}}:\left[\mathrm{Ca}^{2+}\right]_{\mathrm{T}}$ ratios (where the lower index $\mathrm{T}$ denotes total or analytical concentrations) noticeable 
formation of the $\mathrm{Ca}(\mathrm{Gluc})_{2}{ }^{0}$ complex was also reported ${ }^{36}$ (hence the difference between the formation constants published in refs. 31 and 36). Potentiometric titrations ${ }^{38}$ resulted in $\log$ $\mathrm{K}_{1,1}=1.21\left(25^{\circ} \mathrm{C}, \mathrm{I}=1 \mathrm{M}, \mathrm{NaClO}_{4}\right)$ - the latter value is somewhat higher than expected, possibly due to complications caused by lactonisation of HGluc in acidic solutions ${ }^{39,40}$ (see also below). From these data and also on the basis of analogies with isosaccharinic acid, the formation constant at $\mathrm{I} \rightarrow 0 \mathrm{M}$ has been estimated to be $\log \mathrm{K}_{1,1}^{0}=1.7$. $^{29,41,42}$

The metal binding site in $\mathrm{CaGluc}^{+}$(i.e., the structure of the complex in solution) has not been clarified yet. It is plausible that the (deprotonated) carboxylate moiety is involved in the complexation. However, on the basis of the formation constants, monodentate carboxylate coordination is highly unlikely as simple monocarboxylates under similar conditions form much weaker complexes with $\mathrm{Ca}^{2+}$ than Gluc ${ }^{-}$does. ${ }^{43}$ Participation of alcoholic OH groups at C2 (five-membered chelate ring), C3 (six-membered chelate ring) or C6 (head-to-tail coordination or macro-chelate formation) in the complexation of the calcium are all possible but cannot be deduced from the data published so far in the literature.

$\mathrm{Ca}^{2+}$ forms stable complexes with D-glucuronate. ${ }^{44}$ These solid complexes were found to be of the type $\mathrm{Ca}\left(\mathrm{D} \text {-glucuronate) } \mathrm{X} \cdot 3 \mathrm{H}_{2} \mathrm{O} \text { and } \mathrm{Ca} \text { (D-glucuronate }\right)_{2} \cdot 4 \mathrm{H}_{2} \mathrm{O}$, where $\mathrm{X}=\mathrm{Cl}^{-}$ or $\mathrm{Br}^{-}$. The $\mathrm{Br}^{-}$containing complex was structurally identified, showing that the octacoordination of each $\mathrm{Ca}^{2+}$ is facilitated by three D-glucuronate residues and two water molecules. The D-glucuronate binds to the $\mathrm{Ca}^{2+}$ via three chelation sites. One that involves carboxylate oxygen combined with $\mathrm{O}(5)$, one includes the second carboxylate oxygen combined with $\mathrm{O}(4)$, and one involves the $\mathrm{O}(1)-\mathrm{O}(2)$ pair of hydroxyl groups.

As described before, $\mathrm{Muc}^{2-}$ forms stable complexes with $\mathrm{Ca}^{2+}$. The stability constant of the 1:1 complex can be seen in Table 4. Beside this [CaMuc] $]^{0}$ complex the formation of the $\left[\mathrm{CaMucH}_{-1}\right]^{-},\left[\mathrm{Ca}(\mathrm{Muc})_{2}\right]^{2-}$ and $\left[\mathrm{Ca}(\mathrm{Muc})_{2} \mathrm{H}_{-1}\right]^{3-}$ complexes have also been reported. ${ }^{23}$ The stability constants of these complexes at $25^{\circ} \mathrm{C}\left(\mathrm{I}=0.1 \mathrm{M}, \mathrm{Na} \mathrm{NO}_{3}\right)$ are $\log \mathrm{K}_{11-1}=-5.93, \log$ $\mathrm{K}_{120}=4.37$ and $\log \mathrm{K}_{12-1}=-1.73$, respectively. The $\log \mathrm{K}$ values of the $1: 1$ complex of $\mathrm{Ca}^{2+}$ with tartronic or tartaric acid are presented in Table 4.

\subsection{Solution equilibria in the $\mathrm{Al}^{3+} /$ Gluc $^{-}$system}

$\mathrm{Al}(\mathrm{III})$, as a typical hard metal ion, prefers coordination to oxygen donors, especially negatively charged ones, such as carboxylates, phosphates and alcoholates ${ }^{45}$.

The complexation of Al(III) with D-gluconic acid was widely studied in solution from $\mathrm{pH}$ 2 to $10^{46}$. In earlier publications only formation of mononuclear complexes are assumed. Motekaitis and Martell ${ }^{47}$ proposed the formation of species $[\mathrm{AlL}]^{2+},\left[\mathrm{AlLH}_{-1}\right]^{+}$and $\left[\mathrm{AlLH}_{-3}\right]^{-}$ 
whereas Escandar et $a l .{ }^{26}$ assumed an even simpler complexation model involving the species $\left[\mathrm{AlLH}_{-1}\right]^{+}$and $\left[\mathrm{AlLH}_{-3}\right]^{-}$. The speciation models for other trivalent metal ions interacting with gluconic acid indicate the formation of bis (1:2) complexes, besides mononuclear $1: 1$ complexes $^{48,49,50}$, similarly to other metal ions such as $\mathrm{Cu}(\mathrm{II})^{5}$ and $\mathrm{VO}(\mathrm{IV})^{51}$. Lakatos et al. ${ }^{46}$ reveal the formation of six complexes in aqueous solutions between $\mathrm{pH} 2$ and 10: $[\mathrm{AlL}]^{2+}$, $\left[\mathrm{AlLH}_{-1}\right]^{+},\left[\mathrm{AlLH}_{-2}\right],\left[\mathrm{AlLH}_{-3}\right]^{-},\left[\mathrm{AlL}_{2} \mathrm{H}_{-1}\right]$ and $\left[\mathrm{AlL}_{2} \mathrm{H}_{-2}\right]^{-}$. The stability constants of these complexes are listed in Table 5, and the distribution of the complexes as a function of $\mathrm{pH}$ are shown in Figure 3.

Table 5: Stability constants for proton and Al(III) ion complexes [log $\beta]$ of gluconic acid at $25^{\circ} \mathrm{C}$ and $\mathrm{I}=0.2 \mathrm{M}, \mathrm{KCl}$ from ref. 46

\begin{tabular}{cc}
\hline Species & $\log \beta$ \\
\hline $\mathrm{HL}$ & $3.36(2)$ \\
{$\left[\mathrm{AlL}^{2+}\right.$} & $2.38(3)$ \\
{$\left[\mathrm{AlLH}_{-1}\right]^{+}$} & $-1.49(6)$ \\
{$[\mathrm{AlLH}-2]$} & $-5.59(15)$ \\
{$\left[\mathrm{AlLH}_{-3}\right]^{-}$} & $-11.94(3)$ \\
{$\left[\mathrm{AlL}_{2} \mathrm{H}_{-1}\right]$} & $1.48(6)$ \\
{$\left[\mathrm{AlL}_{2} \mathrm{H}_{-2}\right]^{-}$} & $-3.70(15)$ \\
\hline
\end{tabular}

Lakatos et $a l^{46}$ also demonstrated that the alcoholic/alcoholate groups of $\mathrm{C} 2, \mathrm{C} 3$ and $\mathrm{C} 4$ participate in metal chelation. They assumed that in the bis complexes the tridentate $\left(\mathrm{COO}^{-}\right.$, $\left.\mathrm{C}(2)-\mathrm{O}^{-}, \mathrm{C}(4)-\mathrm{OH}\right)$ coordination of one of the ligand molecules and a bidentate $\left(\mathrm{COO}^{-}\right.$, $\mathrm{C}(2)-\mathrm{OH})$ coordination of the other one is the most favoured.
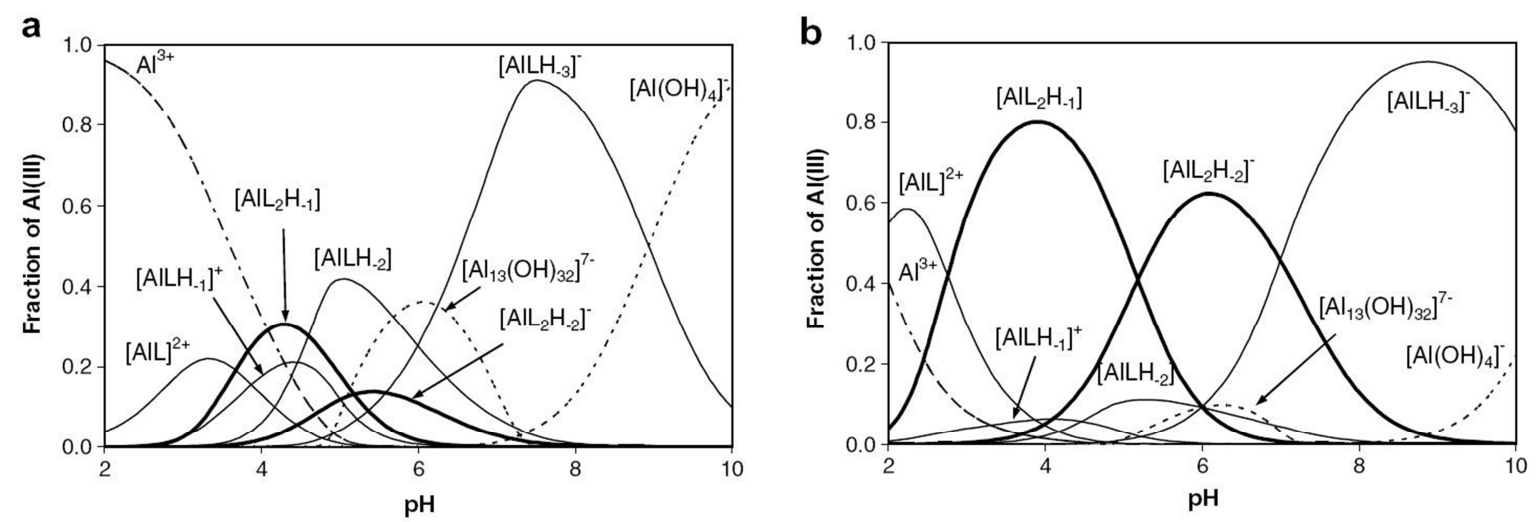

Figure 3: Species distribution curves as the function of pH in the Al(III)-D-gluconic acid system at a metal ion to ligand ratio of $1: 2$ and at (a) $c_{A l(I I I)}=0.002 \mathrm{M} ;\left(\right.$ b) $c_{A l(I I I)}=0.1 \mathrm{M}$. Solid lines indicate the 1:1, bold lines the 1:2 and dashed lines the binary hydroxo complexes from ref. 46. 
In Bayer liquors gluconate ion is a well-known inhibitor of gibbsite $\left[\mathrm{A} 1(\mathrm{OH})_{3} \cdot 3 \mathrm{H}_{2} \mathrm{O}\right]$ precipitation. ${ }^{52}$ Rossiter et al. claimed that sodium gluconate poisoning was a surface process and not a solution one, i.e. the effect of sodium gluconate was equivalent to "shutting down" parts of the precipitating surface. ${ }^{53}$ Lack of aluminium complexation via gluconate in solutions of $\mathrm{pH}>13$ was suggested noted by Motekaitis and Martell. ${ }^{44}$ Although it seems likely that in caustic liquors aluminium-gluconate complex is not formed, and the aluminium is present in $\left[\mathrm{Al}(\mathrm{OH})_{4}\right]^{-}$form, the notion, that equilibrium is established slowly in these solutions $^{50}$ warrants further experimental work. For such studies, multinuclear NMR (including ${ }^{27} \mathrm{Al},{ }^{1} \mathrm{H}$ and ${ }^{13} \mathrm{C}$ ) appears to be the method of choice and inclusion of ligands structurally related to gluconate could yield further insight into this phenomenon.

\subsection{Solution equilibria in ternary systems containing $\mathrm{Ca}^{2+}$, three- or fourvalent cations} $\left(\mathrm{B}^{3+}, \mathrm{Al}^{3+}, \mathrm{Fe}^{3+}\right.$ and $\left.\mathrm{Th}^{4+}\right)$ and sugar carboxylates

It is well known that certain cations (both non-metals, e.g., B(III), and metals, e.g., Fe(III), $\mathrm{Al}(\mathrm{III}), \mathrm{Th}(\mathrm{IV})$, etc.) form stable chelate complexes with sugar carboxylate type ligands (e.g., gluconate, glucarate, glucuronate, etc.) in aqueous solutions. There are indications that the stability of these complex species (i.e., the extent of their formation) is significantly enhanced by the presence of $\mathrm{Ca}^{2+}$ ions via the formation of ternary $\mathrm{Ca}_{\mathrm{p}} \mathrm{M}_{\mathrm{q}} \mathrm{L}_{\mathrm{r}}$ complexes. The effect of $\mathrm{Ca}^{2+}$ is so pronounced, that the ternary complexes thus formed are stable even under strongly alkaline conditions (that is, they do not decompose to form $\mathrm{M}(\mathrm{OH})_{3(\mathrm{~s})}$ or $\mathrm{M}(\mathrm{OH})_{4}{ }_{(\text {aq) }}{ }^{-}$note that in the absence of $\mathrm{Ca}^{2+}$, the appropriate binary $\mathrm{M}_{\mathrm{q}} \mathrm{L}_{\mathrm{r}}$ complexes tend to decompose). Only scattered examples are found in the literature with regard to the equilibria and structure of such ternary complexes. On using Th(IV), the formation of a very stable complex, $\mathrm{CaTh}(\mathrm{OH})_{4} \mathrm{~L}_{2}(\mathrm{~L}=$ gluconate and isosaccharinate $)$ has been described. ${ }^{54}$ The structures of $\mathrm{CaAl}_{2} \mathrm{~L}_{2}$ and $\mathrm{Ca}_{2} \mathrm{Al}_{2} \mathrm{~L}_{2}$ complexes $\left(\mathrm{L}=\right.$ glucarate) have been described ${ }^{55}$ and it was found that Al(III) was coordinated to two adjacent alcoholate oxygens, while the carboxylate and alcoholate were coordinated to the $\mathrm{Ca}^{2+}$ (Figure 4). 

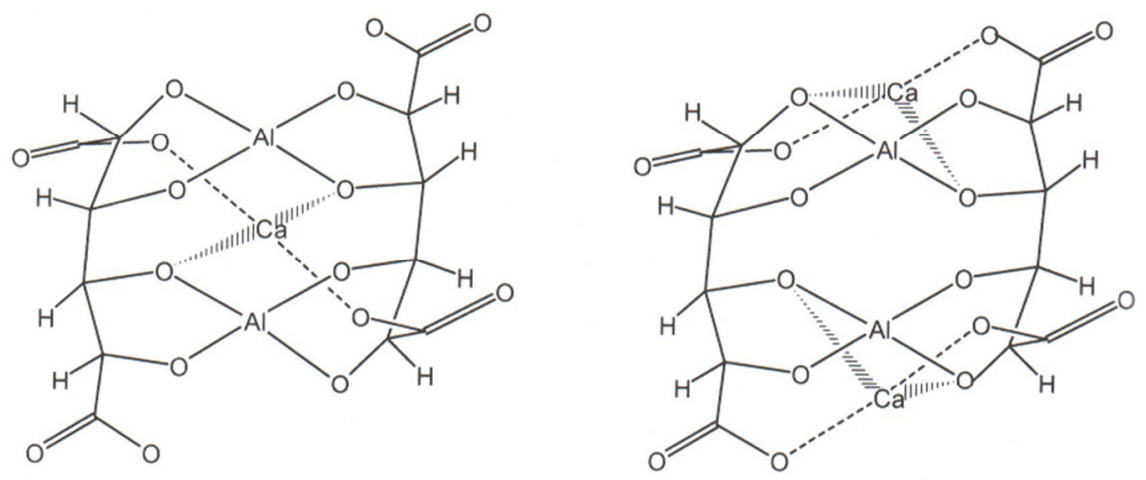

Figure 4: Coordination modes of $\mathrm{Ca}^{2+}$ and $\mathrm{Al}^{3+}$ glucarate ions from ref. 55.

The equilibria yielding the $\mathrm{CaFe}(\mathrm{III}) \mathrm{L}_{\mathrm{n}}$ ternary complex $(\mathrm{L}=$ gluconate, $\mathrm{n}=1$ and 2 ) have recently been described from $\mathrm{pH}$ potentiometric and cyclic voltammetry experiments ${ }^{50}$, and it was found that the ternary complexes dominate in solution in the presence of $\mathrm{Ca}^{2+}$ ions even at $\left[\mathrm{Ca}^{2+}\right]_{\mathrm{T}}:[\mathrm{Al}(\mathrm{III})]_{\mathrm{T}}:[\mathrm{L}]_{\mathrm{T}}=1: 1: 2$. The ternary complex species $\mathrm{Ca}_{3} \mathrm{Al}(\mathrm{OH})_{3} \mathrm{~L}_{3}(\mathrm{~L}=$ gluconate) has been suggested ${ }^{2}$ to be formed in Bayer liquors in the presence of gluconate upon addition of $\mathrm{Ca}^{2+}$. Ternary complexes comprising of $\mathrm{Ca}_{\mathrm{p}} \mathrm{B}(\mathrm{III})_{\mathrm{q}} \mathrm{L}_{\mathrm{r}}(\mathrm{L}=$ gluconate $)$ are also known from the literature. From this short overview it seems plausible that highly stable ternary complexes are expected to be formed in ternary systems containing $\mathrm{Ca}^{2+}$, hard (metal) cations and certain sugar carboxylate type ligands and they are formed in $\mathrm{pH}$-sensitive processes even in the $\mathrm{pH}$ range routinely studied in solution (i.e., $\mathrm{pH}=2-12$ ). 


\section{The main aims of the thesis}

The Gluc ${ }^{-}$is known to form complexes in solution with various metal ions. It is well known that $\mathrm{Ca}^{2+}$ forms weak Gluc complexes of $1: 1$ composition in the usual $(2<\mathrm{pH}<12)$ range. Complexes with $\mathrm{Al}^{3+}$ and $\mathrm{Gluc}^{-}$in the same $\mathrm{pH}$ range are also well established.

Relatively little is known about the complexes forming in strongly alkaline solutions (those relevant to the Bayer process) in $\mathrm{Ca}^{2+} / \mathrm{Gluc}^{-}, \mathrm{Al}^{3+} / \mathrm{Gluc}^{-}$binary and $\mathrm{Ca}^{2+} / \mathrm{Al}^{3+} / \mathrm{Gluc}^{-}$ ternary systems. Hereby the main propose of my work is:

- Investigation of the $\mathrm{Ca}^{2+} / \mathrm{Gluc}^{-}$system in solutions under $\mathrm{pH} 11$. Determination of the stability constant and identification of the binding sites of the Gluc ${ }^{-}$.

- Investigation of other sugar derivatives related to the Gluc ${ }^{-}$.

- Determination of the solubility of calcium in strongly alkaline solutions in the absence and presence of Gluc ${ }^{-}$.

- Investigation of the $\mathrm{Ca}^{2+} / \mathrm{Gluc}^{-}$binary system in strongly alkaline solutions. Determination of the particles being present in these solutions, calculation of their stability constants and identification of the binding sites of the Gluc ${ }^{-}$.

- Investigation of the $\mathrm{Al}(\mathrm{OH})_{4}{ }^{-} / \mathrm{Gluc}^{-}$binary system in strongly alkaline solutions $(\mathrm{pH}>13)$.

- Investigation of the ternary system containing $\mathrm{Ca}^{2+} / \mathrm{Al}(\mathrm{OH})_{4}{ }^{-} / \mathrm{Gluc}^{-}$. Determination of the particles being present in these solutions and their stability constants. 


\section{Experimental part}

\subsection{Materials}

All materials used for experiments [calcium chloride (Molar Chemicals, puriss), hydrogen chloride, sodium hydroxide (VWR, a.r grade), sodium gluconate (NaGluc, Sigma-Aldrich, $\geq 99 \%$ ), sodium heptagluconate (NaHglu, Sigma-Aldrich), Glucose (Gls, Sigma-Aldrich, ACS reagent), calcium heptagluconate (CaHglu, Sigma-Aldrich, $\geq 98.0 \%$ ), sorbitol (Sor, Sigma-Aldrich, $\geq 98 \%$ ), Arabic acid (HAra, Sigma-Aldrich), mucic acid $\left(\mathrm{H}_{2} \mathrm{Muc}\right.$, Sigma-Aldrich, $\geq 97 \%$ ), aluminium wire (J. M. \& Co, 99.99\%) ] were used as received without further purification. Millipore MilliQ water was used throughout the experiments.

\subsubsection{Preparation of the carbonate-free $\mathrm{NaOH}$ solutions}

The preparation of the carbonate-free sodium hydroxide solution was carried out by dissolving solid $\mathrm{NaOH}$ in distillated water (1:1 mass ratio). After precipitating the sodium carbonate following a literature recipe ${ }^{56}$, the solution was filtered on polysulfone Nalgene filter. The exact density of the sodium hydroxide solution was determined by a $10 \mathrm{~cm}^{3}$ volume pycnometer at $25^{\circ} \mathrm{C}$. The concentration of the solution was calculated from the known density $v$ s. concentration curve ${ }^{57}$ of $\mathrm{NaOH}$ at $25.0 \pm 0.1{ }^{\circ} \mathrm{C}$.

\subsubsection{Preparation of Na-aluminate solution}

The $\mathrm{Al}(\mathrm{OH})_{4}{ }^{-}$solutions were prepared according to well-established procedures, ${ }^{58}$ i.e., by dissolving $99.99 \%$ pure aluminium wire in standardized and carbonate-free $\mathrm{NaOH}$ solution. The aluminium wire $(50.964 \mathrm{~g})$ was slowly added to the thermostated carbonate-free $\mathrm{NaOH}$ solution $\left(500 \mathrm{~cm}^{3} ; 8.0 \mathrm{M}\right)$ and the mixture was continuously stirred with magnetic stirrer under Allihn condenser equipped with soda lime containing drying tube. The dissolving of the aluminium wire needed 4-5 days under these conditions. The mass loss was found to be 7-8 g including $6.0 \mathrm{~g}$ of $\mathrm{H}_{2}$ formation. The prepared Na-aluminate solution was filtered on polysulfone Nalgene filter, and the exact density of the Na-aluminate $\left(1.4045 \mathrm{~g} / \mathrm{cm}^{3}\right.$; $4.1219 \mathrm{M}$ ) solution was determined by a $10 \mathrm{~cm}^{3}$ volume pycnometer at $25.0 \pm 0.1{ }^{\circ} \mathrm{C}$. 


\subsection{Instrumentation and characterization methods}

\subsubsection{Multinuclear NMR spectroscopic measurements}

NMR experiments were carried out using a BRUKER Avance DRX 500 NMR spectrometer equipped with a $5 \mathrm{~mm}$ inverse broadband probe-head furnished with $z$ oriented magnetic field gradient capability.

Experimental protocol for the NMR spectrometer to record ${ }^{43} \mathrm{Ca}$ NMR spectra was built. In Figure 5 the ${ }^{43} \mathrm{Ca}$ NMR spectrum of a calcium chloride solution with a concentration of $\sim 8 \mathrm{~mol} \mathrm{dm}{ }^{-3}$ containing $0.20 \%(\mathrm{v} / \mathrm{v}) \mathrm{D}_{2} \mathrm{O}$ is shown. The reference chemical shift $(0.000 \mathrm{ppm})$ was set to this octahedral form of $\mathrm{Ca}(\mathrm{II})$. Under these conditions the ${ }^{43} \mathrm{Ca}$ NMR spectrum can readily be recorded without any enrichment of the ${ }^{43} \mathrm{Ca}$ isotope. This measurement showed that recording of a ${ }^{43} \mathrm{Ca}$ NMR spectrum required approximately 4 hours in the targeted concentration range (i.e., around $0.1 \mathrm{M}$ ).

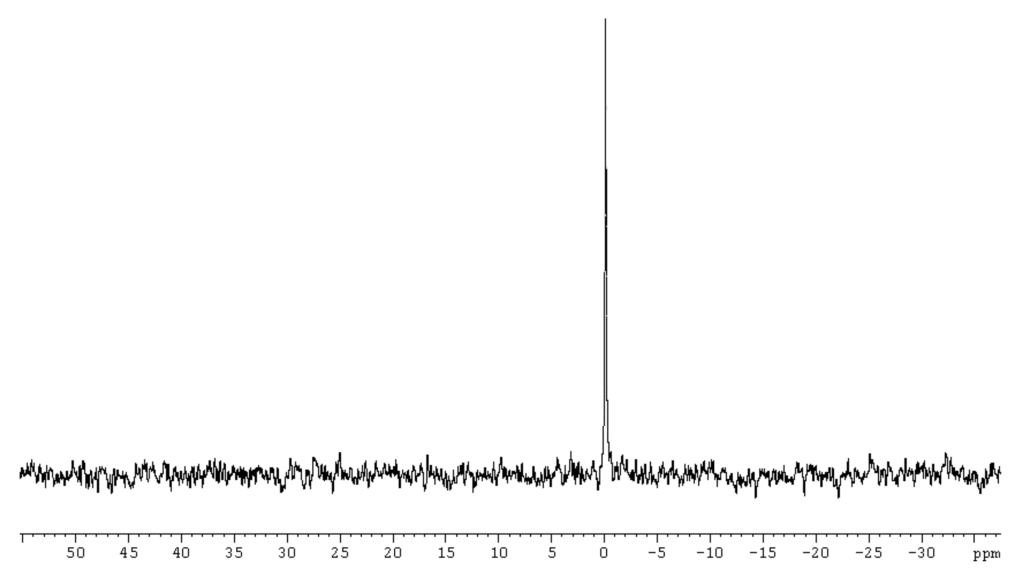

Figure 5: The NMR spectrum of a $8 \mathrm{M} \mathrm{CaCl}_{2}$ solution

To obtain ${ }^{27} \mathrm{Al}$ NMR spectra of our target solutions, a suitable experimental protocol was built for the NMR spectrometer. The reference chemical shift $(0.000 \mathrm{ppm})$ was set to the octahedral form of $\mathrm{Al}(\mathrm{III})$ with $0.3000 \mathrm{M} \mathrm{AlCl}_{3}$ in $3.000 \mathrm{M} \mathrm{HCl}$ containing $0.19 \%(\mathrm{v} / \mathrm{v}) \mathrm{D}_{2} \mathrm{O}$. These measurements will be suitable to determine Al(III) concentrations by keeping the number of recorded scans and the value of the receiver gain constant. Recording of a ${ }^{27} \mathrm{Al}$ NMR spectrum takes $c a .3$ min under these conditions.

\subsubsection{Potentiometric titrations}

Potentiometric titrations were performed with a Metrohm 888 Titrando instrument. The titroprocessor was controlled by Tiamo 2.1 control and database software. Glass cells (max. 
volume: $120 \mathrm{~cm}^{3}$ ) for the titrations were custom made in the glass blowing workshop of the department and are externally thermostated. During all titrations the temperature was set to $25.00 \pm 0.04{ }^{\circ} \mathrm{C}$ with a Julabo F12-MB thermostat.

Initially, commercial glass electrodes were tested, but they were found to be unsuitable to perform precise measurements in alkaline $(\mathrm{pH}>12)$ media containing $\mathrm{Na}^{+}$ions. Interestingly, aqueous solutions containing $\mathrm{KCl}$ Electrode Plus and Unitrode electrodes (both are Metrohm products) follow the Nernstian electrode behavior up to $\mathrm{pH}$ 13. To produce measurements above this $\mathrm{pH}$, in industrially relevant (that is: $\mathrm{Na}^{+}$containing) solutions, we decided to construct a platinised-platinum hydrogen $\left(\mathrm{H}_{2} / \mathrm{Pt}\right)$ electrode. ${ }^{58}$

The $\mathrm{H}_{2} / \mathrm{Pt}$ electrode was prepared according to the instructions described by P. May et al. in 1993. ${ }^{59}$ The full electrochemical cell contains a platinised-platinum hydrogen electrode and a thermodynamic $\mathrm{Ag} \mid \mathrm{AgCl}$ reference electrode which may be represented schematically as

\section{$\mathrm{Ag} / \mathrm{AgCl} \mid 5 \mathrm{M} \mathrm{NaCl}\|5 \mathrm{M} \mathrm{NaCl}\|$ test solution, $\mathrm{I}=1 \mathrm{M}(\mathrm{NaCl}) \mid \mathrm{H}_{2} / \mathrm{Pt}$.}

The electrode was first calibrated in the $-2.7<\log \left[\mathrm{OH}^{-}\right]<-0.7$ range (that is $2 \times 10^{-3} \mathrm{M}<\left[\mathrm{OH}^{-}\right]<0.2 \mathrm{M}$ ) (Figure 6 ). The maximum deviation of the observed value from the calculated (ideal) Nernstian potential value is $1.5 \mathrm{mV}$ and it is most probably due to minor variations in the liquid junction potential.

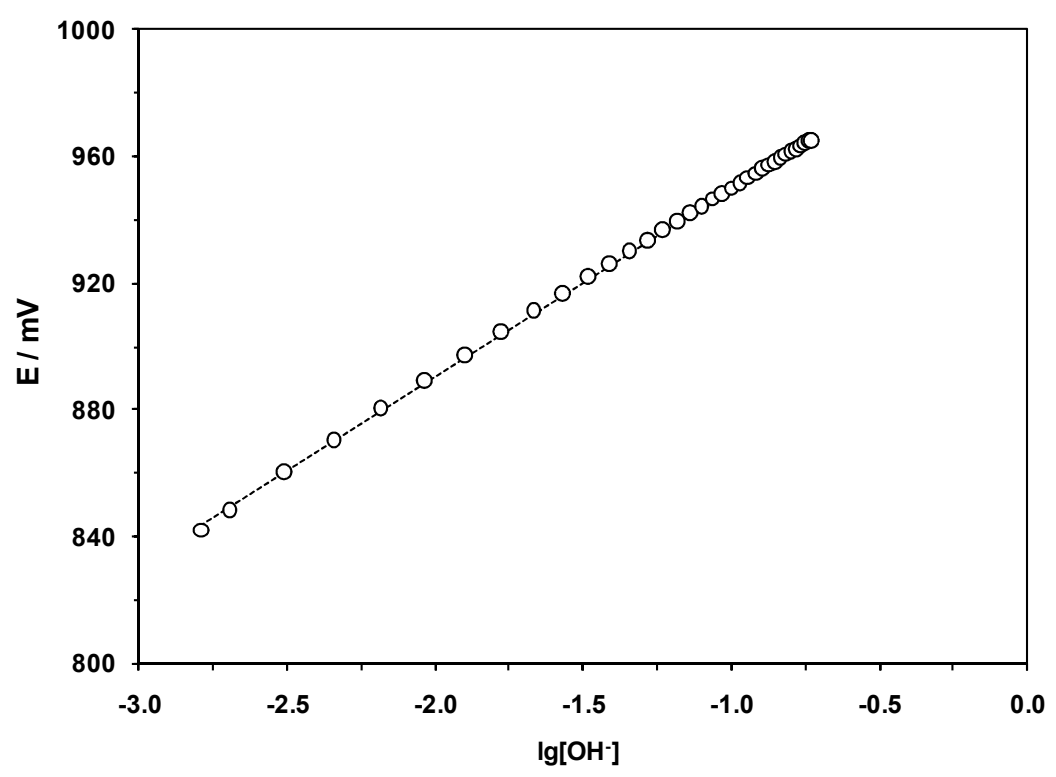

Figure 6: A representative calibration plot of the $\mathrm{H}_{2}$ /Pt electrode: the observed electrode potential as a function of the logarithm of the $\mathrm{OH}^{-}$concentration (circles: observed potentials; dotted line: ideal Nernstian behavior with $59.16 \mathrm{mV}$ slope) 


\subsubsection{ICP-OES measurements}

Determination of the $\mathrm{Ca}^{2+}$ concentration was done using a Thermo's IRIS Intrepid II ICP-OES spectrometer. The instrument was externally calibrated with a calibration solution series prepared from ICP Multi element standard solution XXIII made by CertiPUR, and the calcium concentration was determined at three different wavelengths $(315.887 \mathrm{~nm}$, $317.933 \mathrm{~nm}$ and $393.366 \mathrm{~nm}$ ) for each sample. The calibration curve was fitted to the target concentration range and the parameters were set to obtain the best available fit.

\subsubsection{X-ray diffractometry}

The powder X-ray diffraction (XRD) patterns of the solid samples were registered on a Philips PW1710 instrument, using $\mathrm{CuK} \alpha(\lambda=1.5418 \AA)$ radiation. The samples were pasted (generally $150 \mathrm{mg}$ ) onto the quartz sample holder.

\subsubsection{Molecular modeling}

Full geometric optimisations were performed by Hartree-Fock $a b$ initio calculations applying the $6-31 \mathrm{G}^{* *}$ basis set included in the Hyperchem program package. ${ }^{60}$ Calculations were considered to be converged when the gradient norm reached 0.1 . The obtained minima were checked with frequency calculations.

\subsubsection{Microscopic techniques}

The morphologies of the substances obtained were studied using a Hitachi S-4700 scanning electron microscope (SEM) at various magnifications (1,000-90,000). Acceleration voltage was set to $10 \mathrm{kV}$. The samples were ground before fixing them on a double-sided adhesive carbon tape. They were coated with gold in order to obtain images with more contrast, using a sputter coater (Quorum Technologies SC7620). The thickness of the gold layer was a few nanometers.

The relative quantities of the ions in the solid samples were determined with a Röntec QX2 energy dispersive X-ray fluorescence (EDX) spectrometer coupled to the microscope.

\subsubsection{XAS measurements}

The Ca K-edge X-ray absorption spectra spectra were recorded in the Advanced Photon Source (APS) of Argonne National Laboratory (Argonne, IL USA). According to the literature ${ }^{61}$, the coordination number $(\mathrm{N})$ of the $\mathrm{Ca}^{2+}$ in solutions is 6 or 8 , representing an octahedral or square antiprism structure, respectively. 


\subsubsection{ESI-MS measurements}

ESI-MS measurements were made using a Finnigan TSQ-7000 triple-quadrupole mass spectrometer (Finnigan-MAT, San Jose, CA, USA) equipped with a Finnigan ESI source. Spectra were produced by infusing the sample with a Harvard Apparatus 22 syringe pump (South Natick, MA, USA) driving a $250 \mu \mathrm{L}$ glass syringe with a stainless steel needle attached to a $50 \mathrm{~mm}$ i.d. fused-silica capillary tubing via a teflon coupling at the syringe needle. The electrospray needle was adjusted to $4.5 \mathrm{kV}$ and $\mathrm{N}_{2}$ was used as nebulizer gas. The computer program used to simulate the theoretical isotope distributions is included in the ICIS 8.3 software package. The temperature of the heated capillary was $200{ }^{\circ} \mathrm{C}$. 


\section{Solubility instrument: building and testing}

Our experimental setup to perform solubility measurements consists of a multiposition magnetic stirrer with 15 stirring positions and a self-designed a one-piece multiposition waterjacketed glass pot externally thermostated with a Julabo F12-MB thermostat. This is fitted to the size of the magnetic stirrer and is capable of accommodating 15 individual polyethylene vessels with a volume of $50-100 \mathrm{~cm}^{3}$. Before building the multipositon instrument a prototype of such glass-made device with only one position was made and tested.

\subsection{The single-position prototype and its testing}

Preliminary experiments were performed to confirm that our experimental setup was capable for accurate solubility measurements. The measurements were performed in screwtop polyethylene flasks fitted in a thermostated glass cell and continuously stirred with magnetic stirrers with the slowest possible rate $(\sim 80 \mathrm{rpm})$, to minimize attrition (Figure 7$)$.

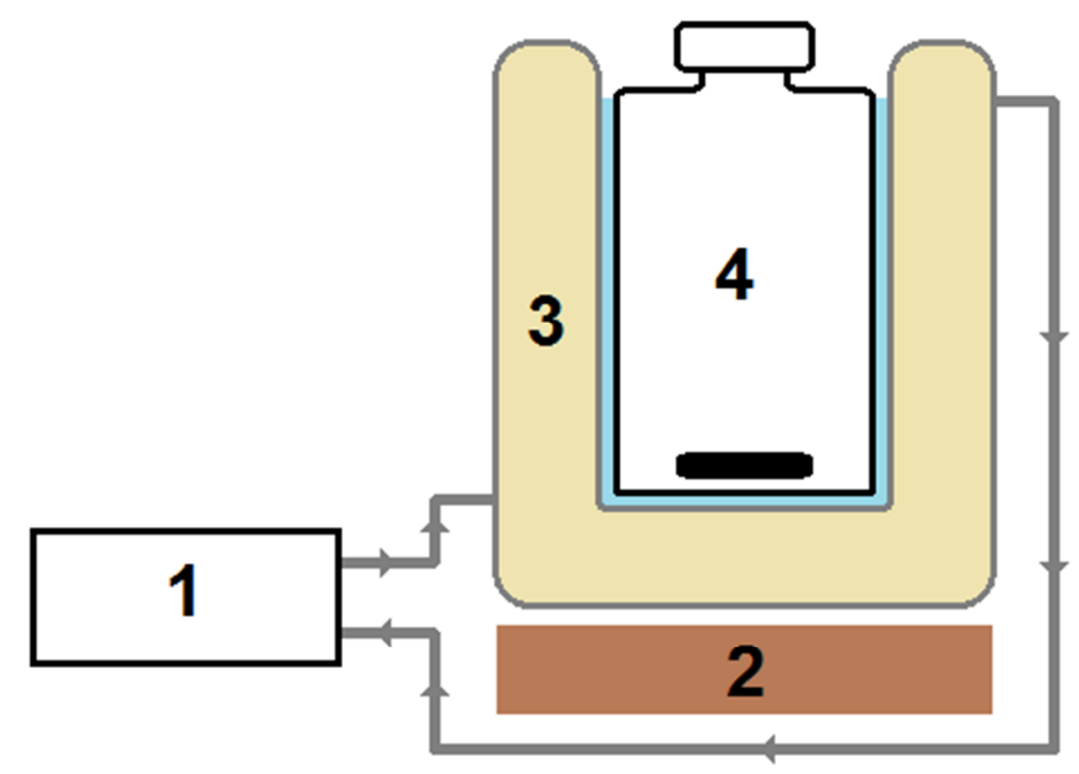

Figure 7: The schematic figure of the experimental setup used for preliminary experiments 1: thermostat; 2: magnetic stirrer; 3: glass cell; 4: screw-top polyethylene flasks

\subsubsection{Standardization of the method}

The solubility measurements were performed by saturating distilled water with calcium oxalate monohydrate $\left(\mathrm{CaC}_{2} \mathrm{O}_{4} \cdot \mathrm{H}_{2} \mathrm{O}\right)$. This compound was chosen, because the equilibrium concentration of calcium in a solution in equilibrium with $\mathrm{CaC}_{2} \mathrm{O}_{4} \cdot \mathrm{H}_{2} \mathrm{O}(6.700 \mathrm{ppm})^{62,63}$ is close to the expected range of the calcium concentration in our target solutions, and the 
preparation of calcium oxalate monohydrate is quite simple and exact. It was prepared following a standard procedure found in any analytical chemistry lecture notes. ${ }^{64}$

Saturated solutions were prepared by and were withdrawn twice from each solution: from solution no. 1 after allowing 6 and 18 hours and from the solution no. 2 after allowing 5 and 12 hours for equilibration. The supernatant was withdrawn through a WHATMAN, Anotop $25(0.02 \mu \mathrm{m})$ syringe filter and analyzed with an ICP-OES spectrometer.

The results are summarized in Table 6. Disregarding the first row in Table 6, the difference between our data and those found in the literature is around $2 \%$.

Table 6: The concentration of the calcium oxalate monohydrate in the supernatant ( $t_{\text {eq. }}$ refers to the time of equilibration)

\begin{tabular}{cccc}
\hline solution & $\mathbf{t}_{\text {eq. }} / \mathbf{h}$ & $\mathbf{c}_{\mathrm{Ca} \text { (avg.) }} / \mathbf{m g} \cdot \mathbf{d m}^{-3}$ & Diff*$/ \%^{*}$ \\
\hline 1 & 6 & $2.171 \pm 0.028$ & 3.59 \\
1 & 18 & $2.050 \pm 0.011$ & 2.19 \\
2 & 5 & $2.077 \pm 0.033$ & 0.89 \\
2 & 12 & $2.052 \pm 0.038$ & 2.08 \\
\hline \multicolumn{4}{r}{${ }^{*}$ Difference from the data found in literature }
\end{tabular}

The initial and the equilibrium solid phase after solubility experiments were analyzed with powder XRD. The results show that no changes took place during equilibration and the equilibrium solid phase is also $\mathrm{CaC}_{2} \mathrm{O}_{4} \cdot \mathrm{H}_{2} \mathrm{O}$ (Figure 8).

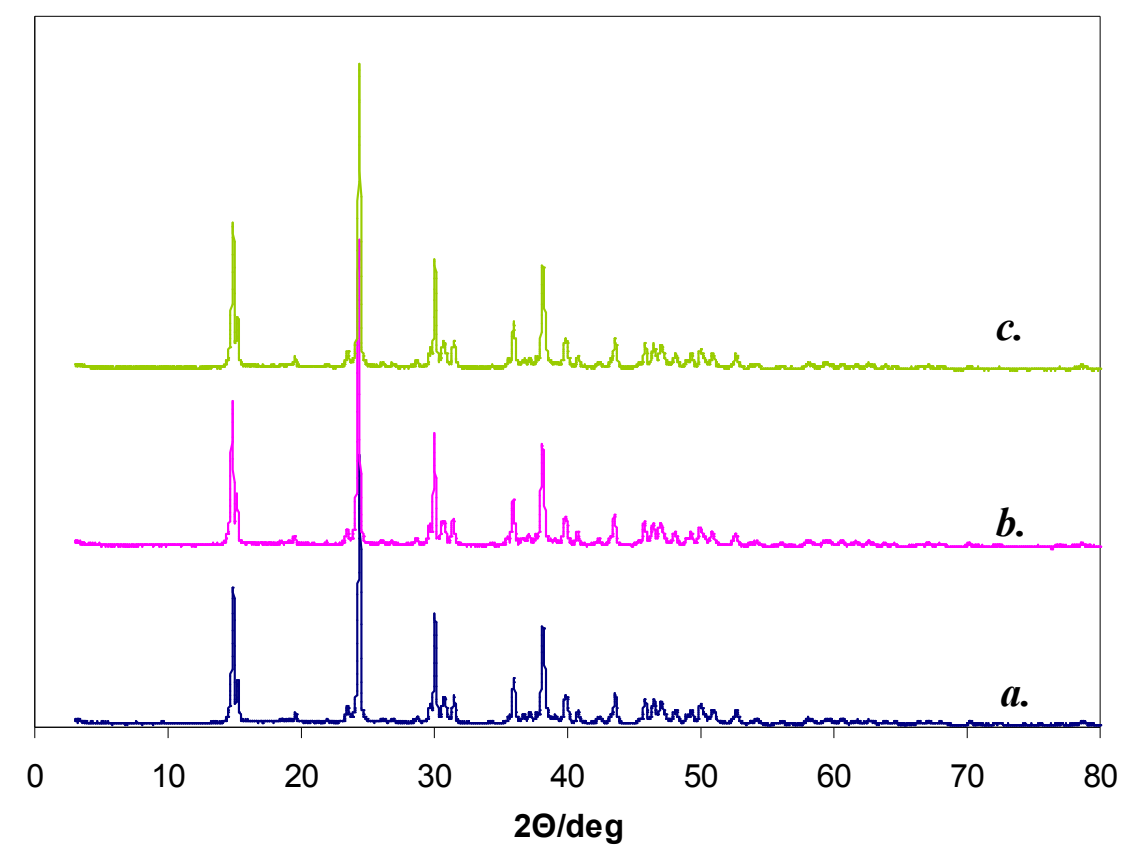

Figure 8: The powder XRD spectra of the initial calcium oxalate monohydrate (a.) and of two solid phases (b., c.) obtained from the vessels of the solubility experiment 


\subsection{The multiposition solubility instrument}

The multiposition solubility instrument consists of a Multistirrer 15 multiposition magnetic stirrer (product of VELP) a self-designed a one-piece multiposition water-jacketed glass pot (custom made by the Glass Blowing Workshop of the Chemistry Department) externally thermostated with a Julabo F12-MB thermostat On the basis of the technical description of the various parts, it is expected that solubility measurements up to $80{ }^{\circ} \mathrm{C}$ will be possible to be performed. The apparatus built is shown in the Figure 9.

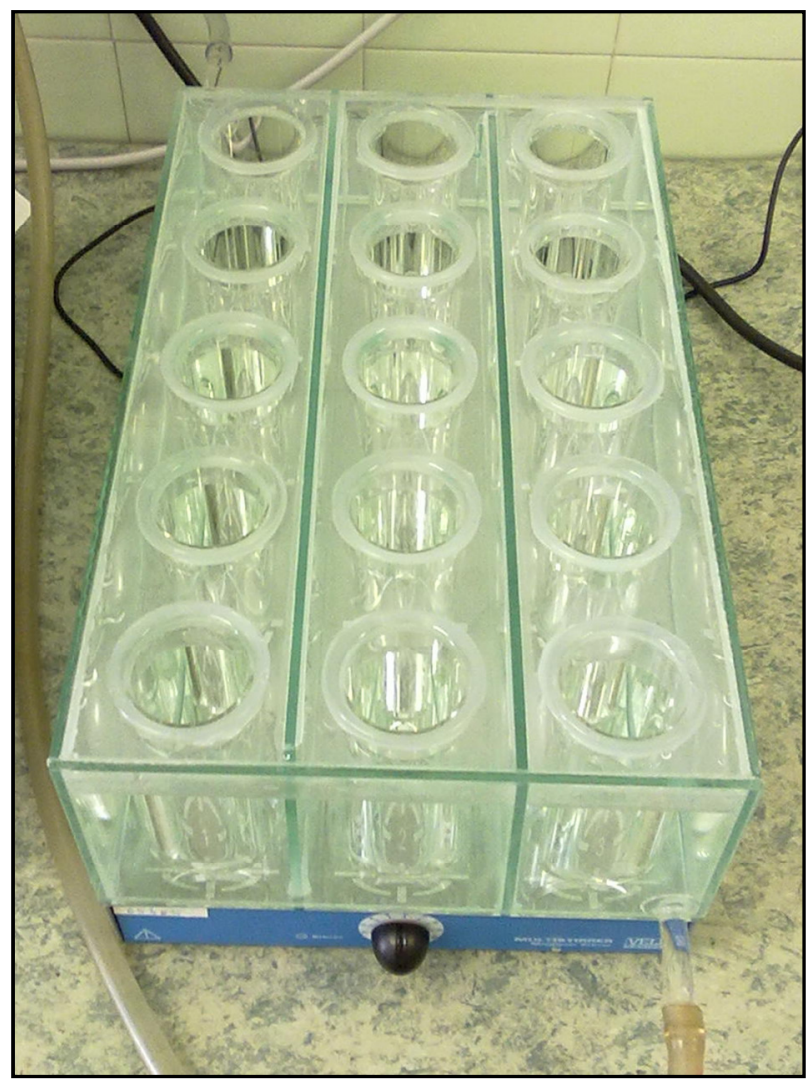

Figure 9: The custom-made solubility apparatus

\subsubsection{Thermal stability}

The temperature at $25^{\circ} \mathrm{C}$ was monitored with a mercury-in-glass thermometer with $0.01{ }^{\circ} \mathrm{C}$ precision (operational in the $22-27^{\circ} \mathrm{C}$ region). The results of the thermal stability measurements at $25^{\circ} \mathrm{C}$ can be seen in Figure 10. The fluctuation of the temperature as a function of time was smaller than $\pm 0.03{ }^{\circ} \mathrm{C}$ in every three monitored positions of the 15 position water bath. We consider this as a satisfactory stability at room temperature.

At elevated temperatures the results of the thermal stability measurements can be seen in Figure 10 too. At 50 and $60{ }^{\circ} \mathrm{C}$ the fluctuation of the temperature as a function of time after reaching the target temperature was smaller than $\pm 0.04{ }^{\circ} \mathrm{C}$ in every three monitored positions 
of the 15-position water bath. We consider this as a satisfactory stability at these elevated temperatures. At $75^{\circ} \mathrm{C}$ the mercury-in-glass thermometer showed a temperature smaller by $1.0-1.6{ }^{\circ} \mathrm{C}$ than the nominal value on all the three monitored positions. The fluctuation of the temperature as a function of time after reaching the target temperature was smaller than $\pm 0.07{ }^{\circ} \mathrm{C}$. From this we concluded, that the bath can be used as is up to $60{ }^{\circ} \mathrm{C}$, but will need further thermal insulation at temperatures above $60{ }^{\circ} \mathrm{C}$. By using a thermal insulation jacket (Styrofoam) the difference between the real and nominal temperature was practically eliminated.

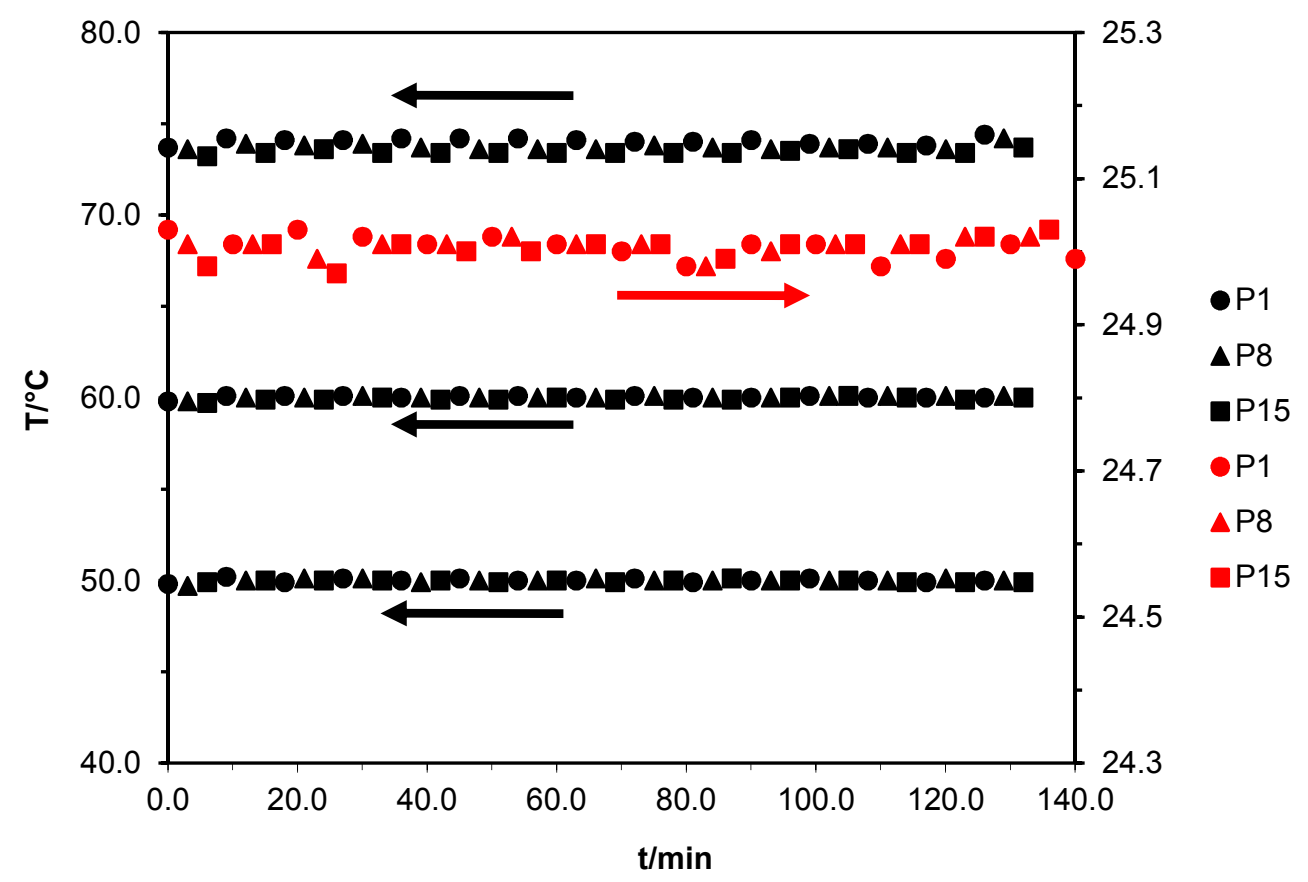

Figure 10: The thermal stabilities of the solubility apparatus at 25.0, 50.0, 60.0 and $75.0^{\circ} \mathrm{C}$ nominal temperature in three different positions

(closest to the water inlet: P1, in the middle: P8, last: P15)

\subsubsection{Validation of the instrument}

Solubility test measurements at $25.00 \pm 0.03{ }^{\circ} \mathrm{C}$ were performed in the usual way, i.e., by saturating distilled water with calcium oxalate monohydrate $\left(\mathrm{CaC}_{2} \mathrm{O}_{4} \cdot \mathrm{H}_{2} \mathrm{O}\right)$. Three parallel measurements were performed in three different positions of the thermostated bath: closest to the water inlet (P1), one in the middle (P8) and the last (P15). Solutions were allowed to equilibrate for two hours, the supernatant was withdrawn through a WHATMAN, Anotop 25 $(0.02 \mu \mathrm{m})$ syringe filter and analyzed with ICP-OES spectrometer. The results are summarized in Table 7. Disregarding the first row in the table, the difference between our 
data and those found in the literature $e^{62,63}$ is around $1 \%$. Now, we are certain that our solubility apparatus is suitable to measuring our target solutions at room temperature and also at elevated temperatures.

Table 7: The concentration of the calcium oxalate monohydrate in the supernatant

( $t_{\text {eq. }}$ refers to the time of equilibration)

\begin{tabular}{|c|c|c|c|}
\hline pos. & $t_{e q} / \mathrm{min}$ & $\mathrm{c}_{\mathrm{Ca} \text { (avg.) }} / \mathrm{ppm}$ & $\operatorname{diff}^{*} / \%$ \\
\hline 1 & 30 & $2.057 \pm 0.014$ & -1.86 \\
\hline 8 & 45 & $2.106 \pm 0.029$ & 0.45 \\
\hline 15 & 60 & $2.089 \pm 0.055$ & -0.33 \\
\hline 1 & 90 & $2.110 \pm 0.021$ & 0.67 \\
\hline 8 & 105 & $2.114 \pm 0.065$ & 0.86 \\
\hline 15 & 120 & $2.083 \pm 0.008$ & -0.64 \\
\hline \multicolumn{2}{|c|}{ average } & $2.093 \pm 0.021$ & -0.14 \\
\hline
\end{tabular}




\section{Results and discussion}

\subsection{Binary systems containing Gluc ${ }^{-}$: protonation and interaction with $\mathrm{Ca}^{2+}$}

An exemplary ${ }^{1} \mathrm{H}$ NMR spectrum of Gluc ${ }^{-}$with appropriate peak assignations is shown in Figure 11. The double doublet of H6 at $\sim 3.6$ ppm, the H4 and H5 signals cannot be used in any kind of evaluation, because in most cases (except for alkaline solutions, see Figure 11) the overlapping peaks cannot be resolved.

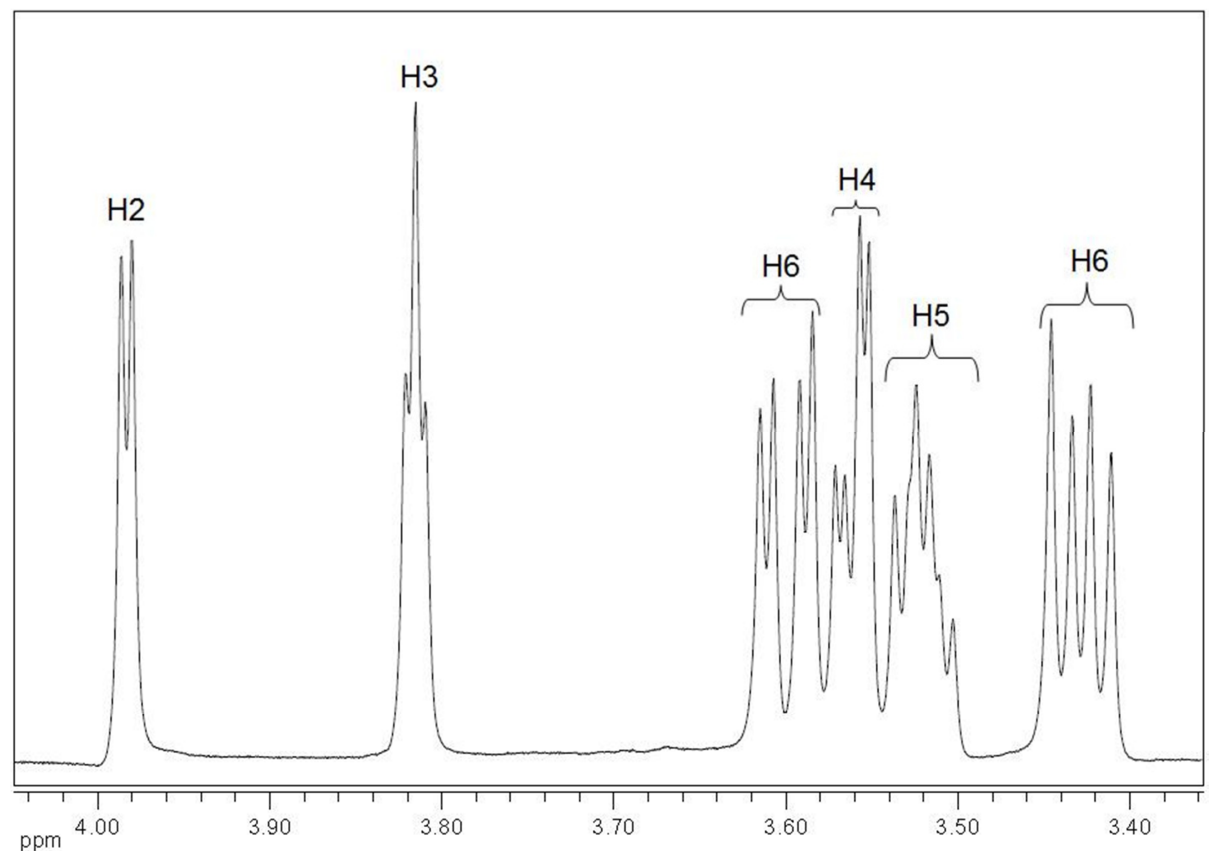

Figure 11: The ${ }^{1} \mathrm{H}$ NMR spectrum of a solution with $[\mathrm{NaGluc}]_{T}=0.200 \mathrm{M}$ in $1.00 \mathrm{M} \mathrm{NaOH}$ medium with peak assignments

\subsubsection{Protonation of $\mathrm{Gluc}^{-}\left(\mathrm{H}^{+}+\mathrm{Gluc}^{-}\right.$series $)$}

\subsubsection{Multinuclear NMR measurements on the $\mathrm{H}^{+} / \mathrm{Gluc}^{-}$system}

The $\mathrm{H}^{+}+$Gluc $^{-}$system was studied to decide whether the variation in the chemical shifts on carbon atoms 3-6 (Figure 12) upon $\mathrm{Ca}^{2+}$ addition was associated with the direct interaction (binding) of the calcium ion to some of the alcoholic OHs. These experiments are also suitable to prove, whether the NMR method is accurate enough to derive good quality stability constants. 


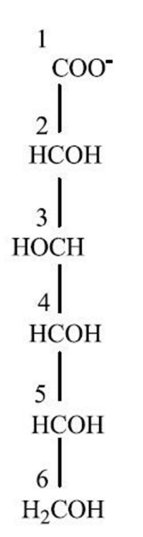

Gluconate

$\left(\mathrm{GH}_{4}^{-}\right)$

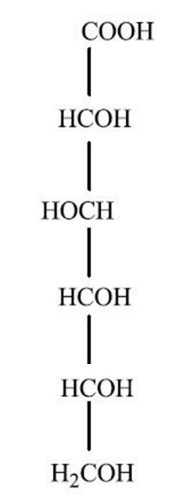

Gluconic acid

$\left(\mathrm{HGH}_{4}\right)$

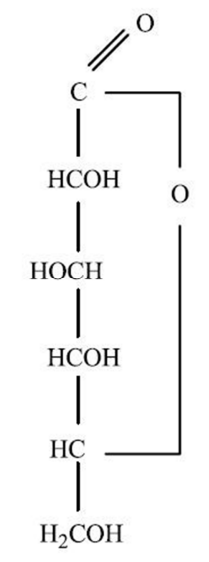

$\delta$ - Lactone

$(\delta-\mathrm{L})$

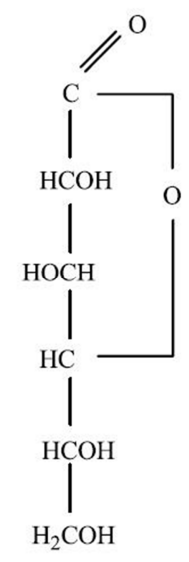

$\gamma$ - Lactone

$(\gamma-\mathrm{L})$

Figure 12: The structures of Gluc ${ }^{-}$ion, gluconic acid, $\delta$ - and $\gamma$-lactone from ref. 24

In the $\mathrm{H}^{+}+$Gluc $^{-}$series the concentration of Gluc ${ }^{-}$was held constant at $0.2000 \mathrm{M}$, the ratio of the $\mathrm{HCl}$ to $\mathrm{Gluc}^{-}$was systematically raised from 0.00 to 1.00 . The ionic strength was set to $1.0 \mathrm{M}$ with $\mathrm{NaCl}$. The $\mathrm{pH}$ of the solutions was determined with a calibrated $\mathrm{pH}$ sensitive glass electrode. The chemical shifts in the function of $\mathrm{pH}$ fall on a sigmoid curve for each carbon and hydrogen atom. From the $\mathrm{pH} v s$. $\delta$ curves, the proton dissociation constant was determined using the PSEQUAD software package. ${ }^{65}$

The normalized chemical shifts of each carbon in the function of $\mathrm{pH}$ are shown in Figure 13.

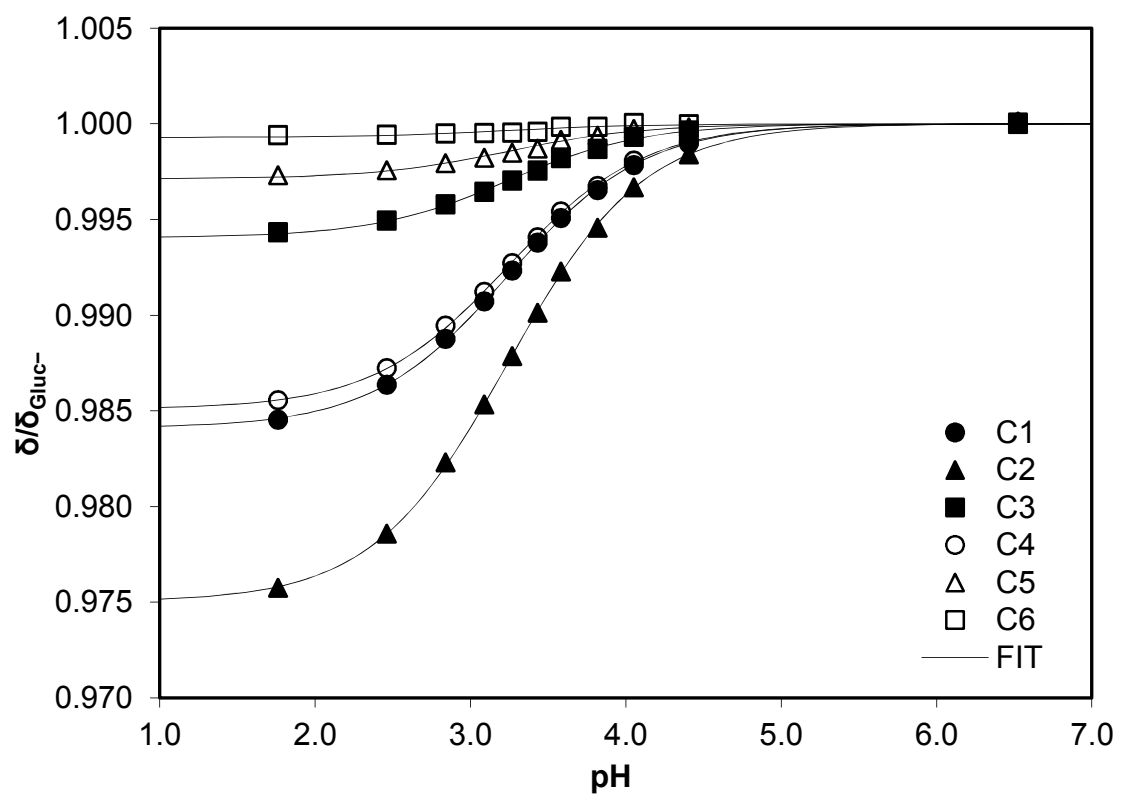

Figure 13: The observed (symbols) and calculated (solid lines) ${ }^{13} \mathrm{C} N \mathrm{NR}$ chemical shifts on each carbon atom of gluconate as a function of $\mathrm{pH}$. For better visualization limiting chemical shifts for the carbons of gluconic acid were set to $1.00 \mathrm{ppm}$. 
The proton dissociation constant, calculated using the chemical shift variation of every carbon atom was found to be $\log _{10} \mathrm{~K}_{\mathrm{a}}=3.24 \pm 0.01$ (the value found in the literature ${ }^{24}$ is as follows: $\log _{10} \mathrm{~K}_{\mathrm{a}}=3.30 \pm 0.02$ at $\mathrm{I}=0.1 \mathrm{M}, \mathrm{NaClO}_{4}$ ), and the calculated limiting chemical shifts are shown in Table 8 . The difference between our and the literature ${ }^{24}$ data $\left(\log _{10} \mathrm{~K}_{\mathrm{a}}=\right.$ $3.30 \pm 0.02$ at $\left.\mathrm{I}=0.1 \mathrm{M}, \mathrm{NaClO}_{4}\right)$ is most likely due to the difference in ionic strengths and the possible differences in the calibration protocol of the glass electrode. It is noteworthy that the variation in the chemical shifts caused by protonation (i.e., $\Delta \delta$ ) does not change monotonously with the increasing distance from the site of protonation.

Table 8: The limiting chemical shifts and the variations in the chemical shifts on each carbon atom for the $H^{+}+$gluconate system (carbon atoms are numbered starting at the carboxylate end, as shown in the structural formulae given in Figure 12)

\begin{tabular}{ccccccc}
\hline & C1 & C2 & C4 & C5 & C3 & C6 \\
\hline $\boldsymbol{\delta}_{\text {Gluc }}-/ p p m$ & 178.370 & 73.796 & 72.310 & 71.010 & 70.730 & 62.414 \\
$\boldsymbol{\delta}_{\text {HGluc }} / \mathbf{p p m}$ & 175.536 & 71.952 & 71.232 & 70.806 & 70.310 & 62.370 \\
$\boldsymbol{\Delta} \mathbf{\delta} / \mathbf{p p m}$ & 2.834 & 1.844 & 1.078 & 0.204 & 0.420 & 0.044 \\
\hline
\end{tabular}

The assignation of protons was done with the aid of the two-dimensional ${ }^{1} \mathrm{H}-{ }^{13} \mathrm{C}$ NMR spectrum shown in Figure 14.

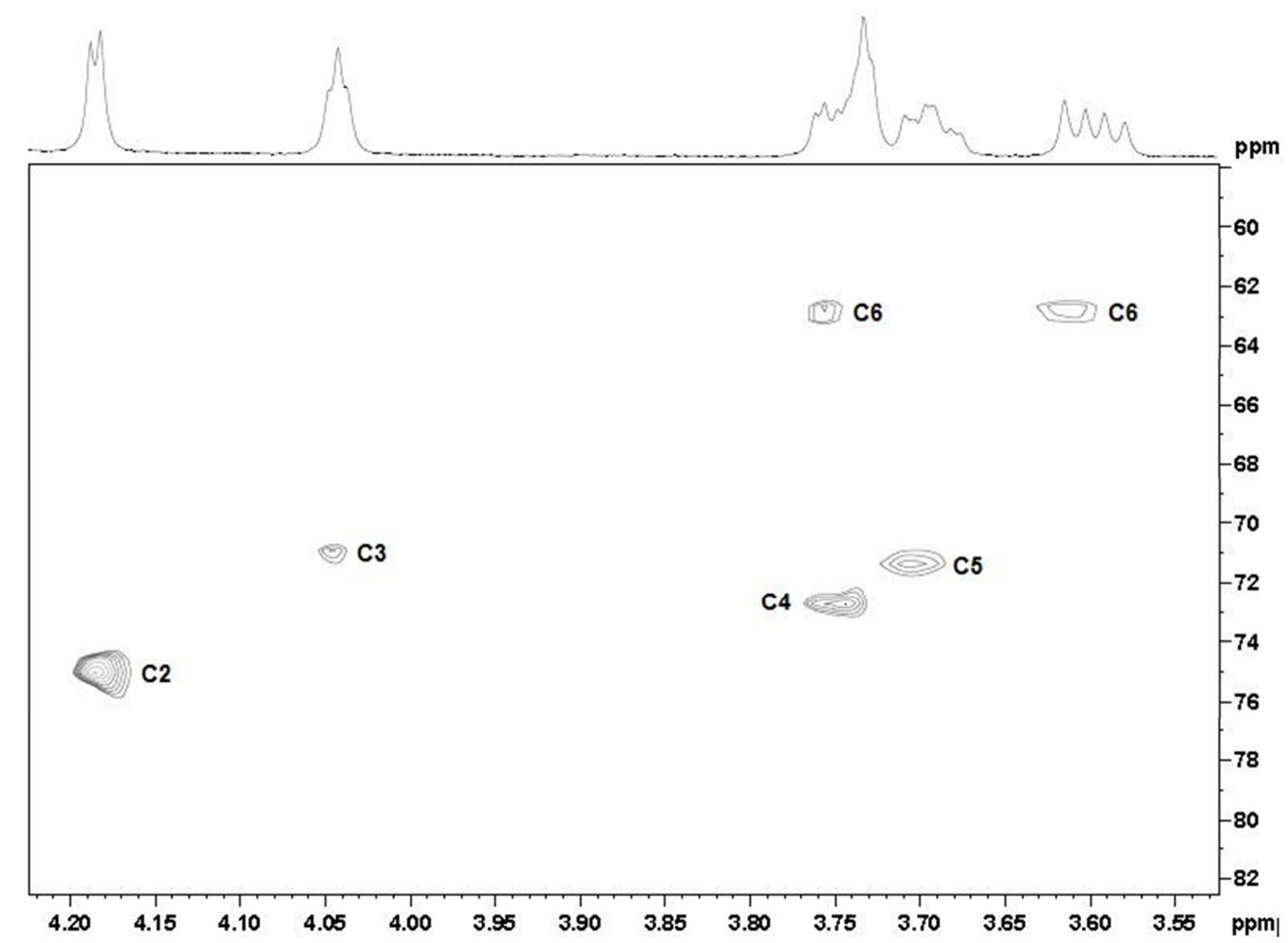

Figure 14: The two-dimensional ${ }^{1} \mathrm{H}^{-}{ }^{13} \mathrm{C}$ NMR spectrum of NaGluc $\left(\left[\mathrm{Gluc}^{-}\right]_{T}=0.200 \mathrm{M}\right)$. 
Since it is too complicated to extract chemical shift variations for the H4-H6 atoms from Figure 14 unambiguously, curve fittings (Figure 15) to obtain acidity constant were performed on the basis of the ${ }^{1} \mathrm{H}$ NMR chemical shift variations on $\mathrm{H} 2$ and $\mathrm{H} 3$ hydrogen atoms, respectively. Both peaks of the $\mathrm{H} 2$ doublet were used separately. The acidity constant thus calculated was found to be $\log _{10} \mathrm{~K}_{\mathrm{a}}=3.23 \pm 0.01$. The fit is very good and the obtained results are practically identical with those gained from the ${ }^{13} \mathrm{C} N M R$ data.

The limiting chemical shifts obtained for $\mathrm{H} 2$ (both members of the doublet) and $\mathrm{H} 3$ in the Gluc $^{-}+\mathrm{H}^{+}$system are shown in Table 9.

Table 9: The limiting chemical shifts and the variations in the chemical shifts of the

\begin{tabular}{|c|c|c|c|}
\hline & $\mathrm{H} 2 \mathrm{a}$ & $\mathrm{H} 2 \mathrm{~b}$ & H3 \\
\hline$\delta_{\text {Glud }} / p p m$ & 4.156 & 4.149 & 4.047 \\
\hline$\delta_{\text {HGluc }} / p p m$ & 4.467 & 4.459 & 4.129 \\
\hline$\Delta \delta / p p m$ & 0.311 & 0.310 & 0.082 \\
\hline
\end{tabular}

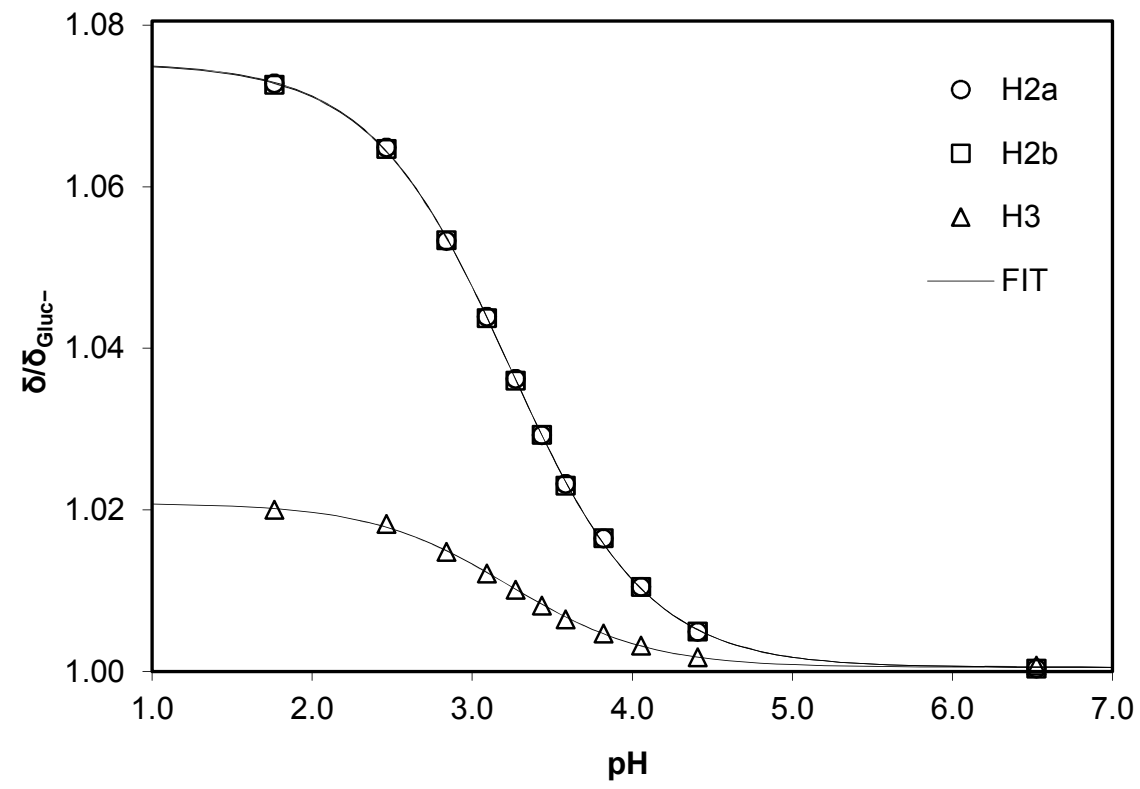

Figure 15: The observed (symbols) and calculated (solid lines) ${ }^{1} H$ NMR chemical shifts of the H2 and H3 protons of the gluconate ion as a function of $\mathrm{pH}$. For better visualization, limiting chemical shifts for the protons of the gluconate ion were set to $1.00 \mathrm{ppm}$.

Beside the six primary carbon peaks for the six carbons of the Gluc ${ }^{-}$additional peaks were seen in the ${ }^{13} \mathrm{C}$ NMR spectrum upon the decrease of $\mathrm{pH}$ (Figure 16). 


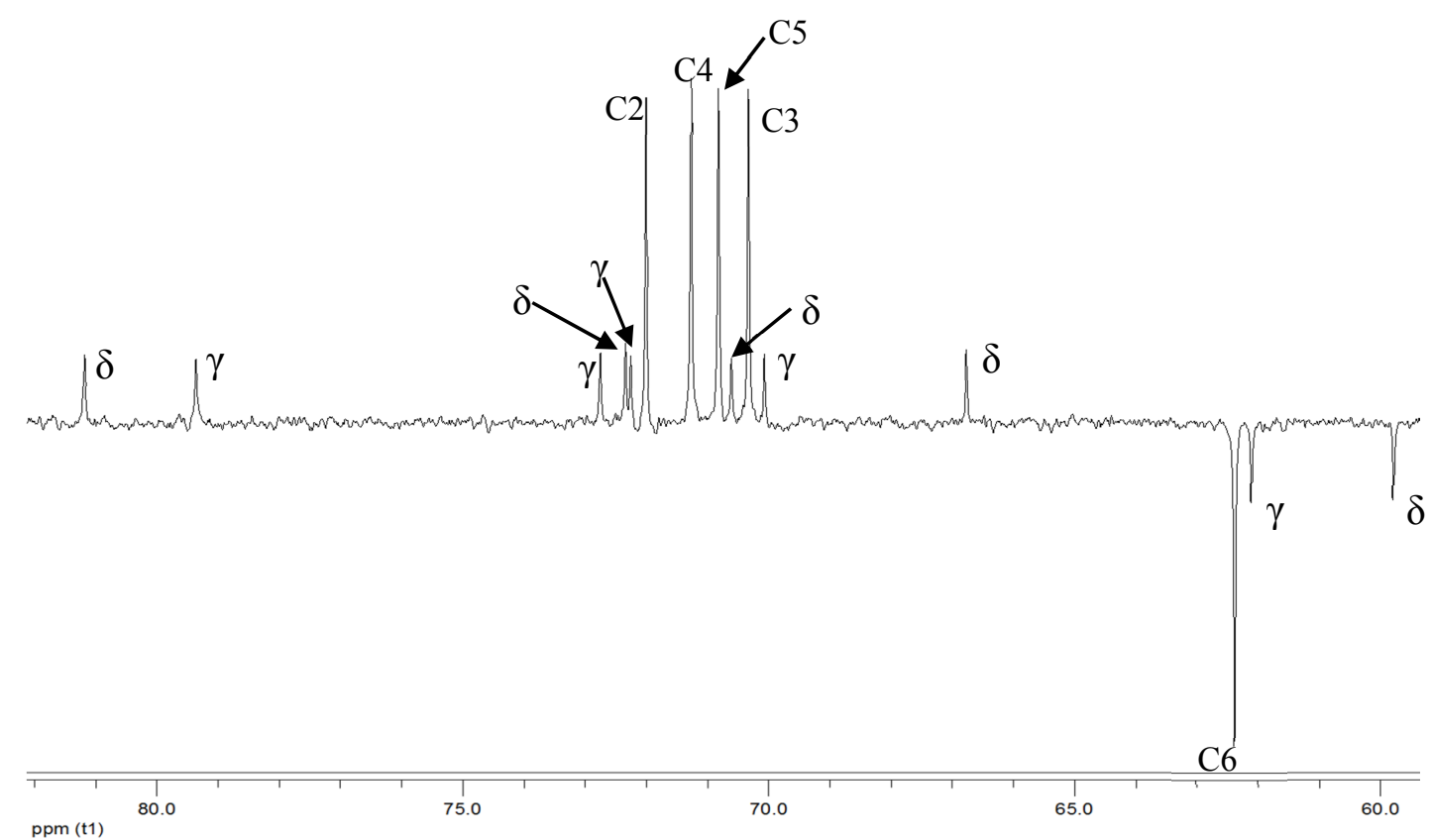

Figure 16: The appearance of the $\delta$ - and $\gamma$-lactone in the ${ }^{13} \mathrm{C} N \mathrm{NR}$ spectrum at $\mathrm{pH} 1.76$

As described in the literature, the reason for the appearance of these small extra peaks is the lactonization of the protonated gluconate ion, i.e. the gluconic $\operatorname{acid}^{24}$. Upon the decrease in $\mathrm{pH}$, the sequential formation of two lactones ( $\delta$ and $\gamma$ ) occurred. It is known and we have observed as well that the formation of the $\delta$-lactone is more pronounced than that of the $\gamma$ lactone $^{24}$. Lactonization takes place under $\mathrm{pH} \sim 3.8$ and the intensities of the relevant peaks increased with the decrease in $\mathrm{pH}$, however, the chemical shifts remained almost constant. Lactonization does not occur in solutions of $\mathrm{pH}>5$, thus, it does not affect the accuracy of the protonation constant derived from the measurements.

\subsubsection{Potetiometric titrations in the $\mathrm{H}^{+} / \mathrm{Gluc}^{-}$system}

Potentiometric titrations on the $\mathrm{H}^{+} / \mathrm{Gluc}^{-}$(and $\mathrm{Ca}^{2+} / \mathrm{Gluc}^{-}$) binary systems have been performed. For the former, a one-step deprotonation process (associated with alcoholic $\mathrm{OH}$ group(s) of the $\mathrm{Gluc}^{-}$) has been established; it commences around $\mathrm{pH}=13$. This is suitable for determining the protonation constant of the gluconate ion. Six titration curves were fitted simultaneously using the PSEQUAD software package. The initial $\mathrm{NaOH}$ concentration of each titrated solution was around $0.00125 \mathrm{M}$, the titrant was $0.9273 \mathrm{M} \mathrm{NaOH}$ and the ionic strength was set to $1.0 \mathrm{M}$ with $\mathrm{NaCl}$. The $\left[\mathrm{Gluc}^{-}\right]_{\mathrm{T}}$ concentration varied between $0.1875 \mathrm{M}$ and $0.3750 \mathrm{M}$ (the high Gluc concentration was necessary because of the very small dissociation constant of the ligand). 
Three fundamental $\left(\mathrm{H}^{+}, \mathrm{Na}^{+}, \mathrm{Gluc}^{-}\right)$and four derived $\left(\mathrm{NaOH}, \mathrm{GlucH}_{-1}{ }^{2-}, \mathrm{GlucH}_{-2}{ }^{3-}\right.$ and $\mathrm{OH}^{-}$) solution species were included in the calculations. All of the particles listed were systematically included in the calculations to reach the best available fit.

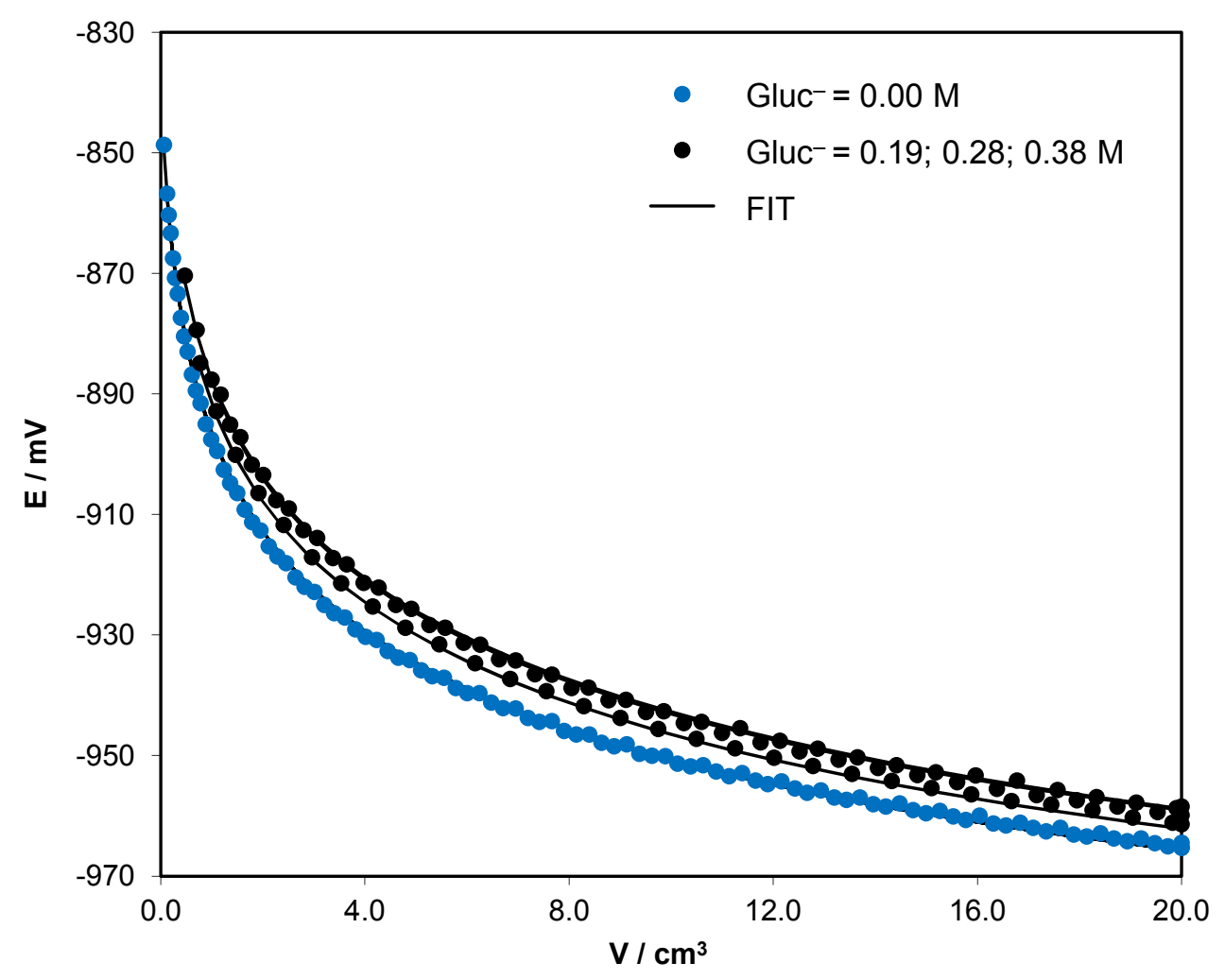

Figure 17: Potentiometric titration curves of the $\mathrm{H}^{+} / \mathrm{Gluc}^{-}$systems.

Dots represent observed EMF values, solid lines were fitted on the basis of the model discussed in the text. (Titrant: $1.00 \mathrm{M} \mathrm{NaOH}$ )

Results show a deprotonation process associated with alcoholic $\mathrm{OH}$ group of the Gluc ${ }^{-}$, forming $\mathrm{GlucH}_{-1}{ }^{2-}$ particle. No further deprotonation step (i.e., formation of $\mathrm{GlucH}_{-2}{ }^{3-}$ ) can be observed. As the calculation reaches a minimum on the fitting parameter $(0.60 \mathrm{mV})$ the protonation constant of the $\mathrm{GlucH}_{-1}{ }^{2-}$ is found to be $\log \mathrm{K}_{01-1}=-13.684 \pm 0.005$ $(=0.076-13.76)$, using the autoprotolysis constant of water $\left(\mathrm{pK}_{\mathrm{w}}=13.760 \pm 0.003\right)$ determined from independent potentiometric titrations. This $\mathrm{pK}_{\mathrm{w}}$ value is found to be in reasonable agreement with literature data. ${ }^{66}$ The agreement between the observed and calculated EMF values is presented in Figure 17.

Zhang et al. ${ }^{24}$ have found that the protonation constant of the alcoholic $\mathrm{OH}$ is $\log \mathrm{K}_{\mathrm{a}}{ }^{\prime}=13 \pm 1$. To the best of our knowledge, our data is the first accurate value for the high-pH proton dissociation constant of Gluc ${ }^{-}$. 


\subsubsection{Complexation of $\mathrm{Gluc}^{-}$with $\mathrm{Ca}^{2+}$ at $\mathrm{pH} \leq 11$}

Two types of measurements were performed with this system. In the first, the ionic strength was systematically varied (from 1.0 to $4.0 \mathrm{M}$ ) without setting the $\mathrm{pH}$ of the solution (this means $\mathrm{pH} \sim 6$ throughout), while in the second, the ionic strength was held constant at 1.0 $\mathrm{M}$ and the $\mathrm{pH}$ value of the solutions were set to 9 and 11 within the two series, respectively.

In the first measurement type, three series were planned for the ${ }^{1} \mathrm{H}$ and ${ }^{13} \mathrm{C} \mathrm{NMR}$ measurements. In each series the concentration of $\mathrm{Gluc}^{-}$was held constant at $0.0200 \mathrm{M}$, the concentration of calcium chloride was systematically varied from $0.0200 \mathrm{M}$ to $0.4000 \mathrm{M}$, and the ionic strength was set with sodium chloride in the ionic strength range of $1-5 \mathrm{M}$.

During the experimental work the ionic strengths have been modified to $1.0 \mathrm{M}, 2.0 \mathrm{M}$, 3.0 $\mathrm{M}$ and 4.0 M, because solid material precipitated at 5.0 M. EDX measurements indicated (Figure 18) that the solid was $\mathrm{NaCl}$. EDX signals corresponding to calcium are not detected and the Al signal $(\sim 1.5 \mathrm{keV})$ was stemming from the sample holder and the $\mathrm{C}$ signal $(\sim 0.3 \mathrm{keV})$ is from the tape used as sample support. This observation indicates that the solubility of $\mathrm{NaCl}$ (which is $c a .5 .8 \mathrm{M}$ at room temperature) significantly decreases in the presence of $\mathrm{Ca}^{2+}$ and/or Gluc ${ }^{-}$. This limits the ionic strength range to be used.

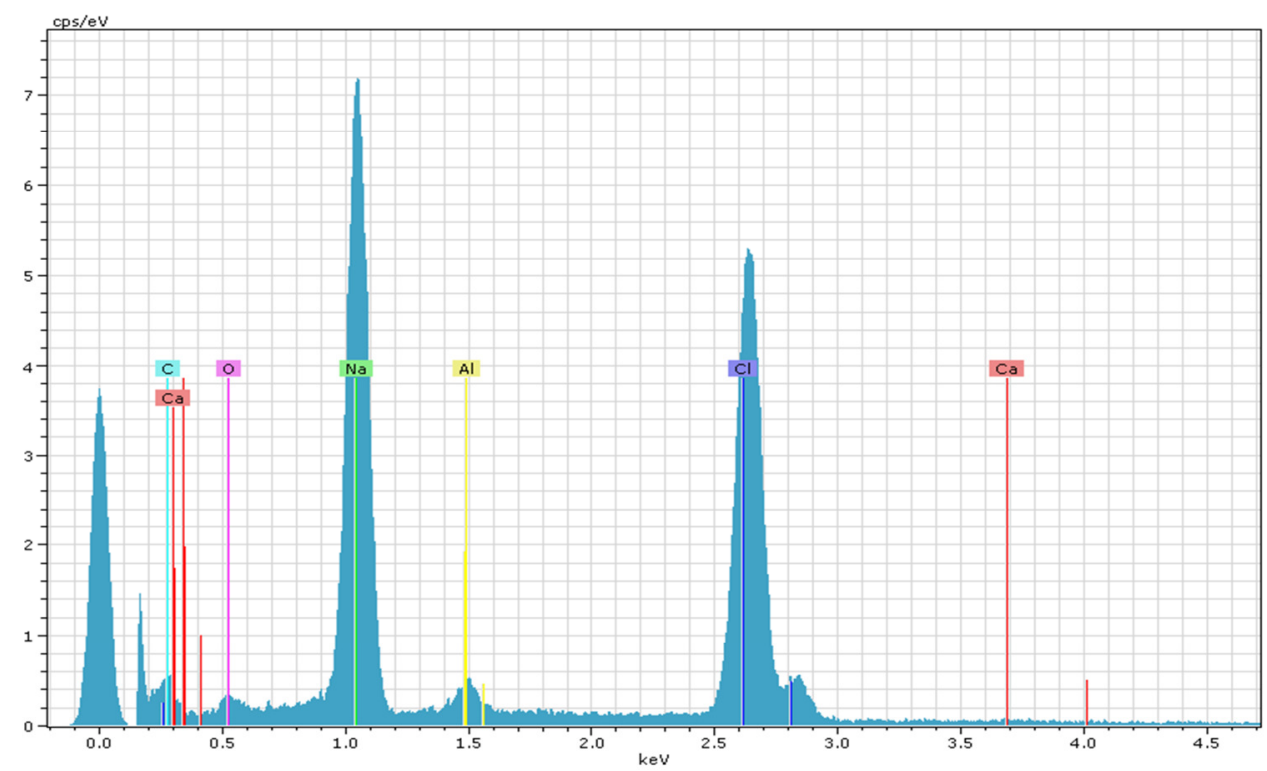

Figure 18: The EDX spectra of the crystals precipitated from solutions of 5.0 M ionic strength

${ }^{1} \mathrm{H}$ NMR spectra for the $\mathrm{Ca}^{2+} / \mathrm{Gluc}^{-}$system could only be recorded at $1.0 \mathrm{M}$ ionic strength, however, the variation in the ${ }^{1} \mathrm{H}$ NMR chemical shifts was too small, it was not suitable to get 
reliable formation constants. Therefore, only the ${ }^{13} \mathrm{C}$ NMR spectra were used for deriving stability constants.

\subsubsection{Determination of the formation constants of CaGluc ${ }^{+}$}

In the ${ }^{13} \mathrm{C}$ NMR spectra of Gluc ${ }^{-}$significant variations were seen as a result of $\mathrm{Ca}^{2+}$ complexation (page 37 Table 10 and Figure 19). To obtain formation constants and complex compositions, two kinds of fitting protocol are used: in one, only the variations $\mathrm{C} 1$ and $\mathrm{C} 3$ chemical shifts upon $\mathrm{Ca}^{2+}$ complexation are used and in the second, chemical shift changes for all 6 carbons were used together (Table 10) The limiting chemical shifts for the Gluc ${ }^{-}$ion are held constant during optimizations. The fitting parameters (that is: the agreement between the observed and calculated chemical shifts) have been found to be excellent for the first protocol and reasonable for the second one and the formation constants obtained for both protocols are practically identical. (Note that in some cases, no convergence could be achieved by using the second protocol, see Table 10).

Assuming the formation of the $\mathrm{CaGluc}^{+}$complex was only sufficient to the reasonable descriptions of all the experimental data points obtained with chemically meaningful $\log \mathrm{K}_{1,1}$ values and acceptable standard deviations. However, small but systematic differences between the observed and calculated values are seen (Figure 19) at the highest $\left[\mathrm{Ca}^{2+}\right]_{\mathrm{T}}:\left[\mathrm{Gluc}^{-}\right]_{\mathrm{T}}$ ratios, i.e., where the formation of the $\mathrm{Ca}(\mathrm{Gluc})_{2}{ }^{0}$ complex (if it exits) would be the most favoured. The three sets of data at $1.0 \mathrm{M}$ ionic strength but different $\mathrm{pHs}$ $(\sim 6, \sim 8$ and $\sim 11)$ have also been fitted also together (Table 10) to increase the confidence level of the results. Similar behavior was observed suggesting the presence of the $\mathrm{Ca}(\mathrm{Gluc})_{2}{ }^{0}$ complex. The extent of this deviation, however, was too small to make the extraction of log $\mathrm{K}_{1,2}$ possible from our ${ }^{13} \mathrm{C}$ NMR data, nevertheless, the existence of these effects indicate the possible formation of $\mathrm{Ca}(\mathrm{Gluc})_{2}{ }^{0}$ complex already suggested in a paper, ${ }^{36}$ but ignored elsewhere. $^{31}$ 


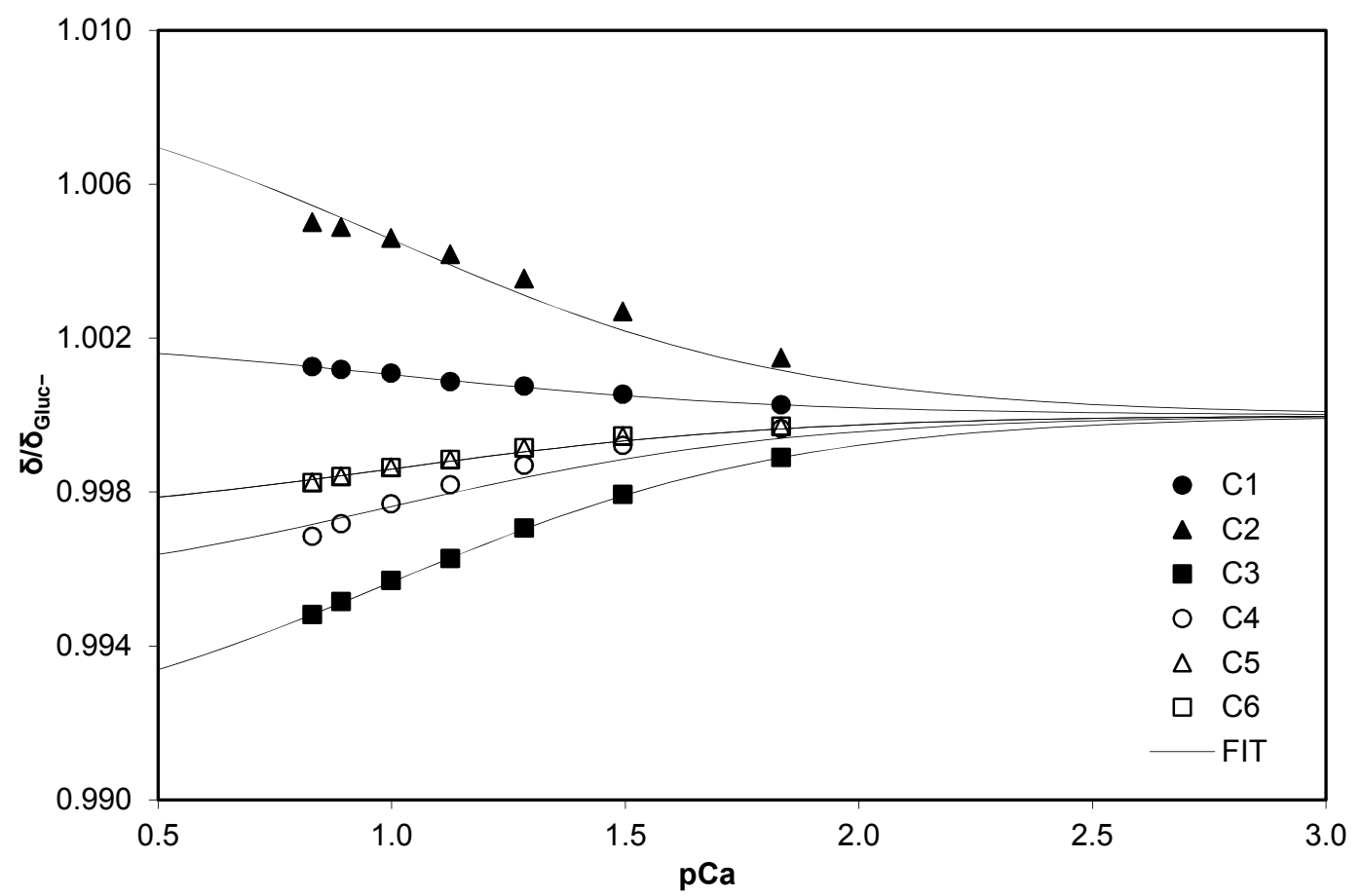

Figure 19: The observed and calculated chemical shifts on each carbon atom as the function of pCa (i.e., $-\log _{10}\left[\mathrm{Ca}^{2+}\right]$ ) at $1.0 \mathrm{M}$ ionic strength, assuming only 1:1 complex in the system; for better visualization the limiting chemical shifts for the carbons of gluconate were set to

$$
1.00 \mathrm{ppm}
$$

The $\log \mathrm{K}_{1,1}$ vs. I curve passes through a smooth minimum (Figure 20). Including data from other literature sources obtained at ionic strengths $<1 \mathrm{M}$, an extended Debye-Hückel treatment ${ }^{67}$ is used with the equation

$$
\log K_{1,1}=\log K_{1,1}^{0}-A \frac{\sqrt{I}}{1+1.5 \sqrt{I}}+B I
$$

From this calculation, $\log \mathrm{K}_{1,1}^{0}=1.5 \pm 0.4$ has been obtained, with reasonable agreement with other values from the literature. ${ }^{29,41,42}$

On the basis of the data in Table 10, it is striking that the ${ }^{13} \mathrm{C}$ NMR limiting chemical shifts $\left(\delta \mathrm{Ci}\right.$ ) observed for Gluc ${ }^{-}$and calculated for $\mathrm{CaGluc}^{+}$show systematic downfield variation with increasing ionic strength. The extent and direction of this shift is similar to that reported by Zhang et al. ${ }^{24}$ for solutions of $\mathrm{pH}>12$ and with increasing $\mathrm{pH}$. Zhang et al. argued that such variations were due to deprotonation of the aliphatic alcohol of Gluc ${ }^{-}$. However, on the basis of the present data it seems that such variations in ${ }^{13} \mathrm{C}$ NMR chemical shifts can be caused by interactions with $\mathrm{Na}^{+}$ions (i.e., breaking of the inter-molecular $\mathrm{H}-$ bonding of Gluc $^{-}$), as suggested in ref 68 . 


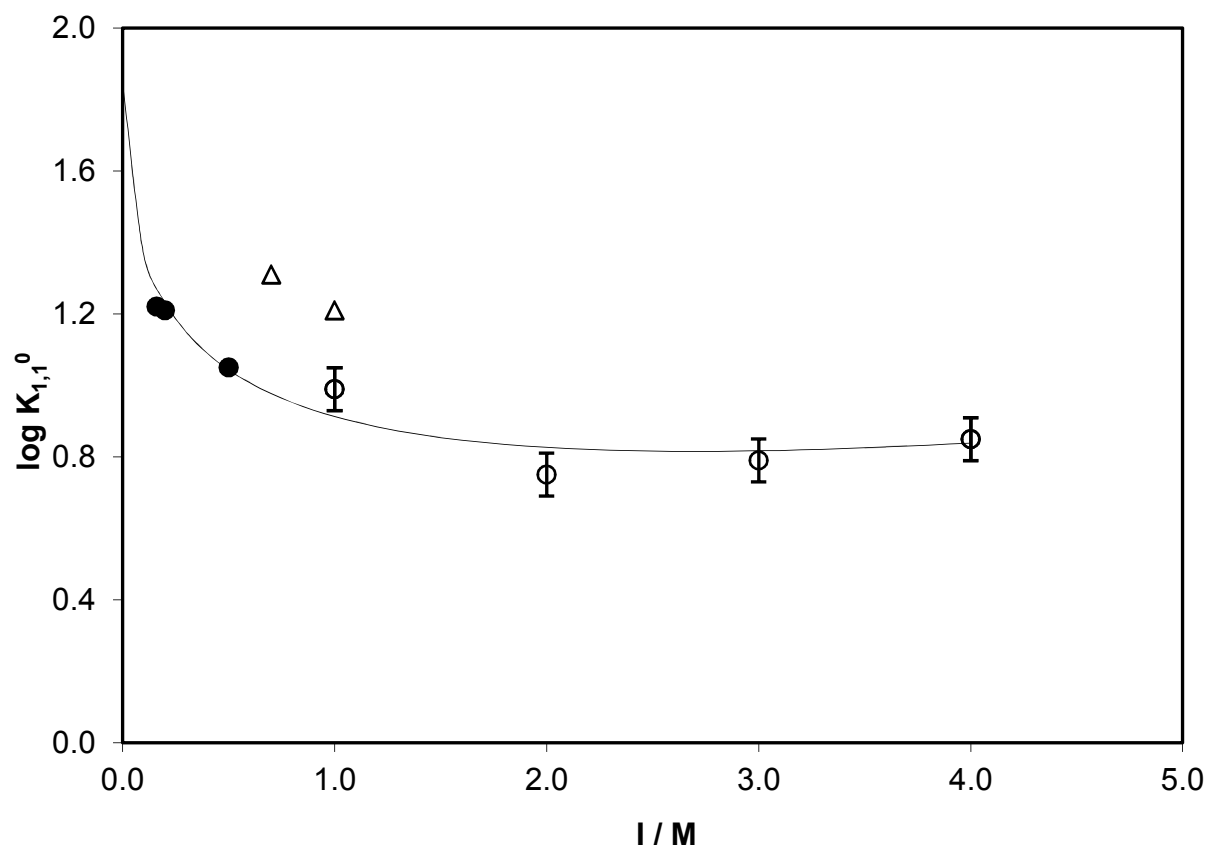

Figure 20: The formation constant of the CaGluc complex as a function of the ionic strength

$(\mathrm{NaCl})$. o: present work; $\Delta$ : values from references 4 and 10 - not included in the optimization; : values from refs 7, 8 and 9. Solid line: calculated on the basis of the extended Debye-Hückel treatment, with $\log K_{1,1}{ }^{0}=1.8$.

The differences between the limiting chemical shifts of Gluc ${ }^{-}$and HGluc, i.e.

$$
\Delta \delta=\delta_{H G l u c}-\delta_{G^{\prime l u c}}
$$

for the carbon atoms $\mathrm{C} 1-\mathrm{C} 6$ in Table 10 are all of the same sign (that is, the displacement of the ${ }^{13} \mathrm{C}$ NMR chemical shifts are directed towards the lower frequency with decreasing $\mathrm{pH}$ ). However, the $\Delta \delta$ values do not change monotonously with the distance from $\mathrm{C} 1$ of the carboxylate group undergoing protonation. This is most likely to be due to differences in conformational changes caused by protonation on $\mathrm{C} 1$, which are the most pronounced at $\mathrm{C} 4$.

The situation is more complex with regard to the $\Delta \delta$ values of $\mathrm{Gluc}^{-}$and $\mathrm{CaGluc}^{+}$. The displacements are towards the higher frequencies for $\mathrm{C} 1$ and $\mathrm{C} 2$, and towards the lower frequencies for $\mathrm{C} 3-\mathrm{C} 6 . \Delta \delta$ is the largest for $\mathrm{C} 2$ at each ionic strength. The $\Delta \delta$ on $\mathrm{C} 3$ upon $\mathrm{Ca}^{2+}$ binding is larger than that upon protonation. From these subtle variations, which are resultants of several coexisting and (sometimes) opposite effects, the structure of the CaGluc ${ }^{+}$ complex, that is, the binding site of $\mathrm{Ca}^{2+}$ from such NMR measurements cannot be unambiguously deduced. 


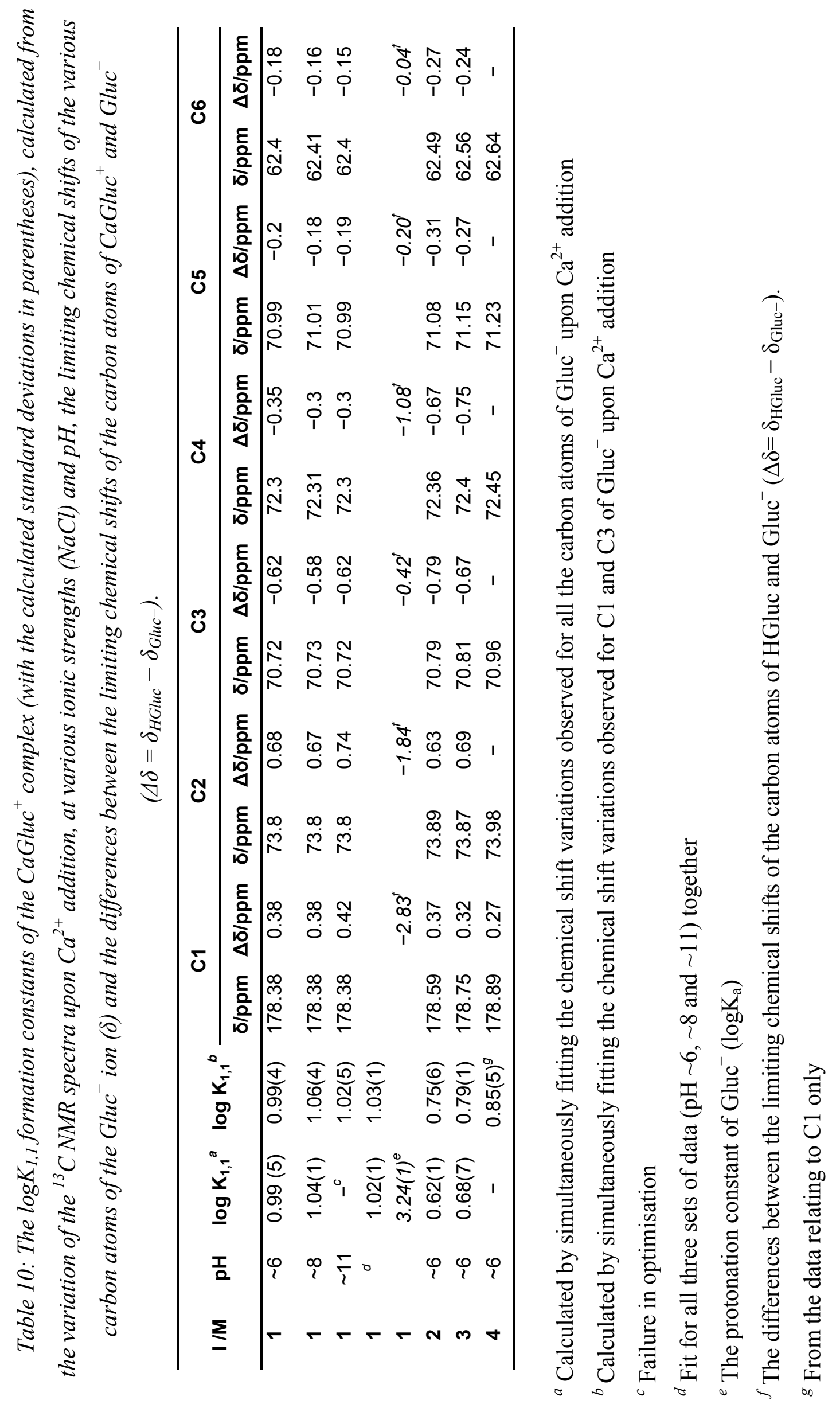




\subsubsection{The structure of the $\mathrm{CaGluc}^{+}$complex}

The identification of the binding sites has been approached experimentally via two-dimensional ${ }^{1} \mathrm{H}^{-}{ }^{43} \mathrm{Ca}$ NMR measurements. For this, first the ${ }^{43} \mathrm{Ca} \mathrm{NMR}$ spectra of solutions containing $\mathrm{CaCl}_{2}(0.200 \mathrm{M})$ and various amounts of NaGluc $(0.100-0.400 \mathrm{M})$ were recorded. Because of the low abundance of the ${ }^{43} \mathrm{Ca}$ isotope $(0.135 \mathrm{at} \%)$, acquisition of each spectra took several days (64000 scans), therefore these experiment were restricted to a few selected samples. Upon addition of Gluc ${ }^{-}$, the peak of the hydrated $\mathrm{Ca}^{2+}$ ion gradually moved towards the lower frequencies and significantly broadened (Figure 21), i.e., the full width at half-height (FWHH) increased from $1.2 \mathrm{~Hz}$ to $13.1 \mathrm{~Hz}$. On the basis of ${ }^{43} \mathrm{Ca}$ chemical shift variation and taking into consideration the formation constants shown in Table 10 the limiting chemical shift of $\mathrm{Ca}^{2+}$ in the $\mathrm{CaGluc}^{+}$complex can be approximated as $\sim-4.4 \mathrm{ppm}$ (relative to the hydrated $\mathrm{Ca}^{2+}$ ion).

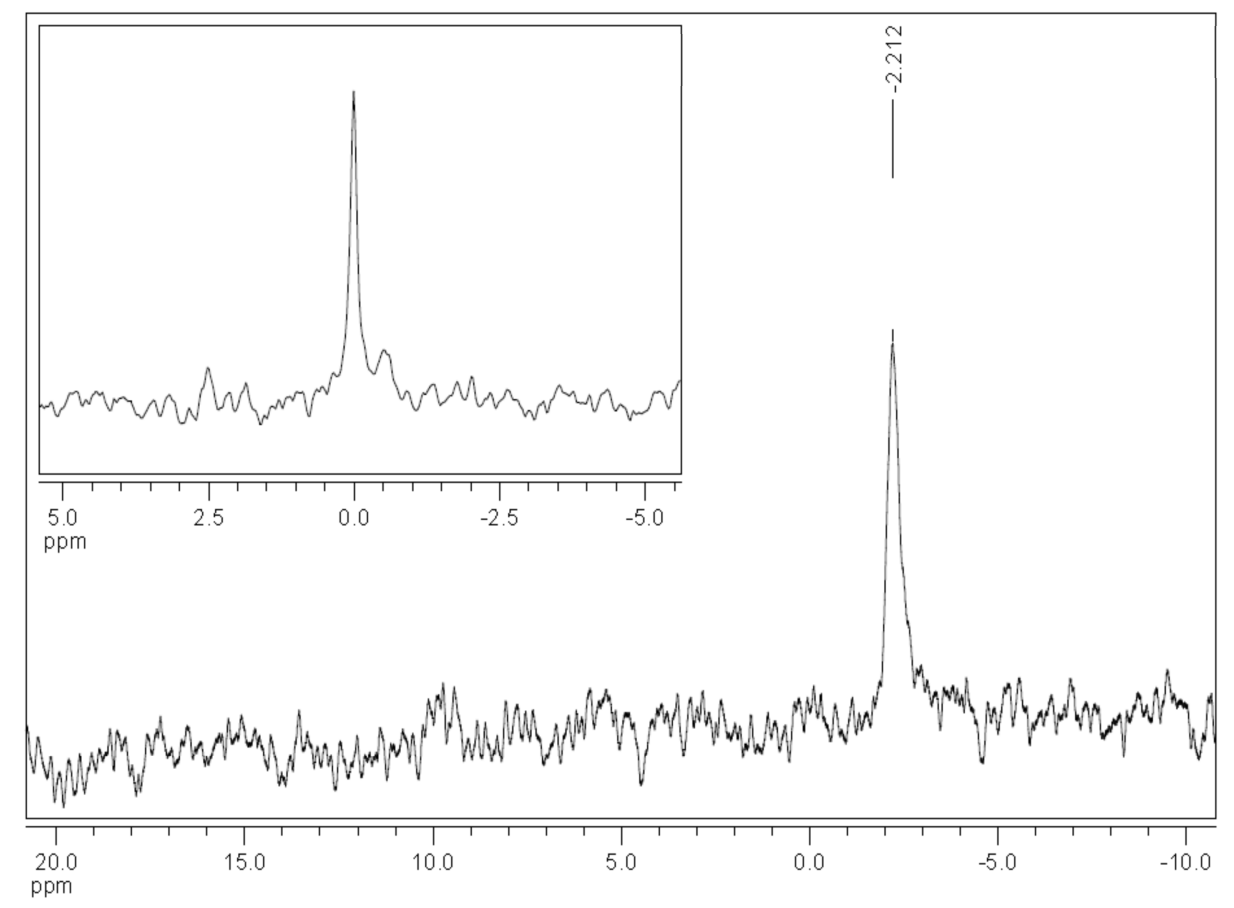

Figure 21: The ${ }^{43} \mathrm{Ca}$ NMR spectrum of a $\mathrm{Ca}^{2+} / \mathrm{Gluc}^{-}$system $\left(\left[\mathrm{Gluc}^{-}\right]_{T}=\left[\mathrm{Ca}^{2+}\right]_{T}=0.2000 \mathrm{M}\right)$ Insert: $\mathrm{CaCl}_{2}$ only $\left(\left[\mathrm{Ca}^{2+}\right]_{T}=8.0 \mathrm{M}\right)$

The two-dimensional ${ }^{1} \mathrm{H}-{ }^{43} \mathrm{Ca}$ NMR spectrum of a solution containing $\left[\mathrm{CaCl}_{2}\right]_{\mathrm{T}}=$ $[\mathrm{NaGluc}]_{\mathrm{T}}=0.200 \mathrm{M}$ is shown in Figure 22 . The ${ }^{1} \mathrm{H}-{ }^{43} \mathrm{Ca}$ correlations were detected by twodimensional HMQC Heteronuclear Multiple Quantum Coherence (HMQC) ${ }^{69}$ experiment (via heteronuclear zero and double quantum coherence). For creation of the anti-phase 
magnetisation, the $1 /\left(2 * J_{\mathrm{CaH}}\right)$ delay was optimized and a final $250 \mathrm{~ms}$ was used, which corresponds to a ${ }^{1} \mathrm{H}-{ }^{43} \mathrm{Ca}$ coupling constant of $2 \mathrm{~Hz}$. Spectra were acquired with 128 increments in the indirect dimension and with 256 scans and using a recycle delay of $2 \mathrm{~s}$. No decoupling was applied during acquisition.

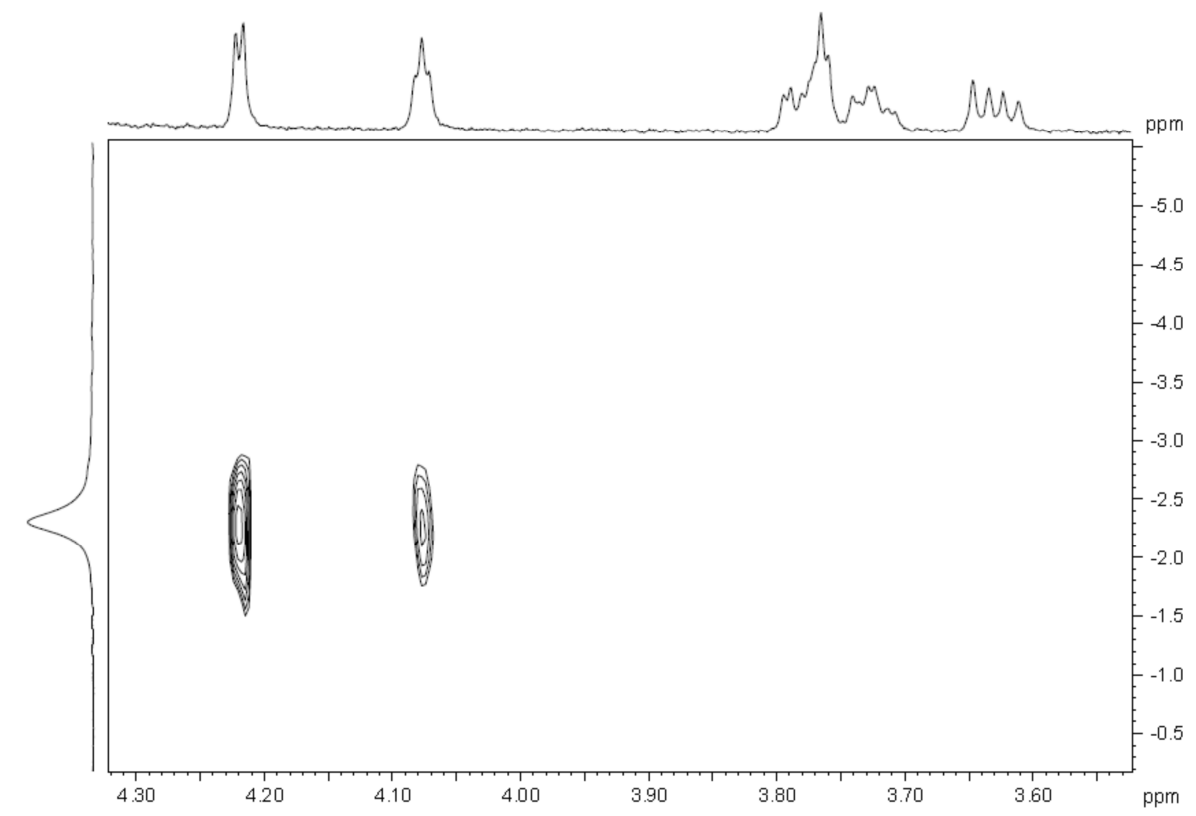

Figure 22: The two dimensional ${ }^{1} \mathrm{H}^{-43} \mathrm{Ca}$ NMR spectrum of a Ca-gluconate solution

$$
\left(\left[\mathrm{Gluc}^{-}\right]_{T}=\left[\mathrm{Ca}^{2+}\right]_{T}=0.2000 \mathrm{M} ; \mathrm{T}=25.0^{\circ} \mathrm{C}\right)
$$

From this spectrum it seems plausible that the $\mathrm{Ca}^{2+}$ ion interacts with the $\mathrm{OH}$ groups on $\mathrm{C} 2$ and $\mathrm{C} 3$ simultaneously. Since the interaction with the carboxylate oxygen (on C1) is plausible, two possible scenarios may be suggested. In one, bonding isomerism takes place according to Figure 23. By this model two isomers of calcium gluconate complex are formed in aqueous solution as a five- and a six-membered chelate structure and they are in equilibrium. On the basis of qualitatively examining the two-dimensional ${ }^{1} \mathrm{H}-{ }^{43} \mathrm{Ca} \mathrm{NMR}$ spectrum the predominant structure is the five-membered chelate structure of the two bonding isomers.

In the second scenario Gluc ${ }^{-}$acts as a tri-dentate ligand binding via the carboxylate and the aliphatic alcohols at both $\mathrm{C} 2$ and $\mathrm{C} 3$. 
<smiles>O=C1O[CH]O[C@H](C(O)[C@H](O)CO)[C@H]1O</smiles><smiles>O=C1O[GeH]OC1C(O)C(O)C(O)CO</smiles>

Figure 23: The suggested structures for the two bonding isomers of the calcium gluconate complex forming in aqueous solution

For clarifying the structure of $\mathrm{CaGluc}^{+}$complexes (forming in neutral or slightly alkaline solutions), all structure types were modeled as isolated ions as well as in aqueous solutions applying explicit water molecules (PM3 semiempirical calculations). The optimum geometry was found to be a multidentate bonding isomer, with $\mathrm{Ca}^{2+}$ entered into bonding interactions with $\mathrm{O}(\mathrm{C} 1), \mathrm{O}(\mathrm{C} 2), \mathrm{O}(\mathrm{C} 3)$ and $\mathrm{O}(\mathrm{C} 6)$ five-membered chelate (Figure 24), or with $\mathrm{O}(\mathrm{C} 1)$, $\mathrm{O}(\mathrm{C} 3)$ and $\mathrm{O}(\mathrm{C} 5)$ as six-membered chelate (Figure 25) at the same time, respectively.
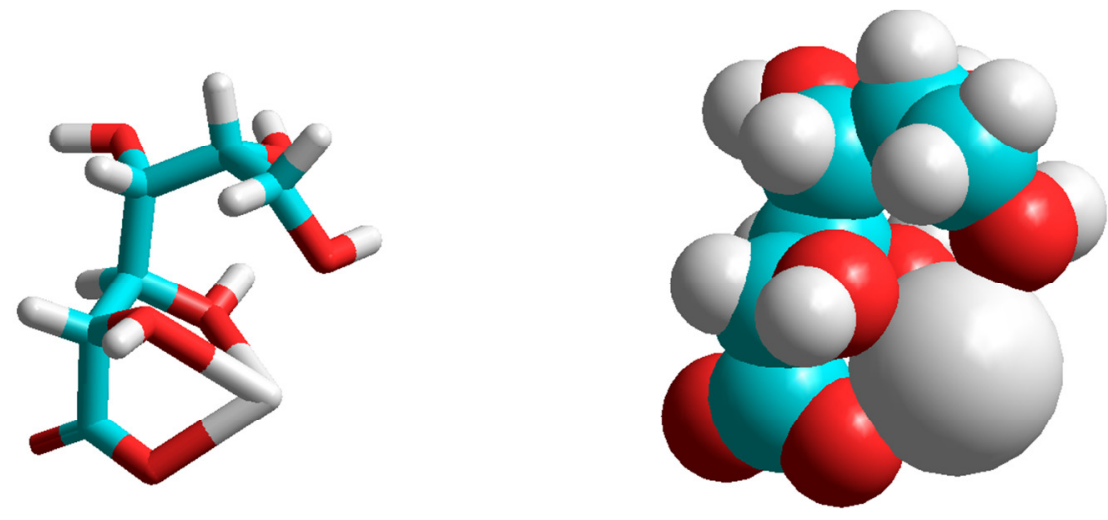

Figure 24: The optimum geometry found to five-membered chelate
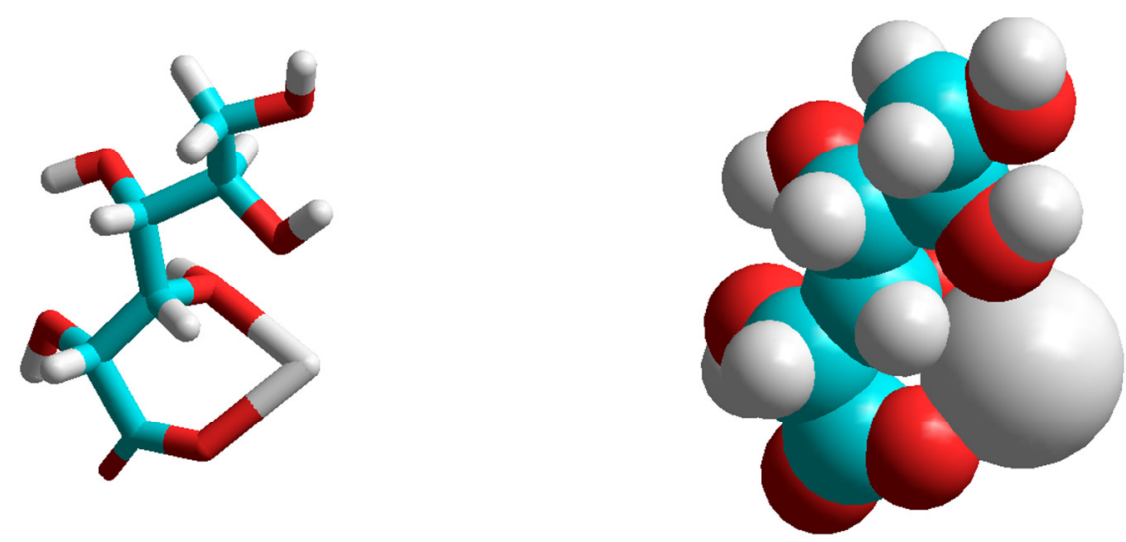

Figure 25: The optimum geometry found to six-membered chelate 


\subsection{Binary systems containing other sugar derivatives}

A set of sugar derivatives has been selected for further studies along various lines. One of the selection criteria is altering the oxidation states of the terminal groups and keeping the chain length of Gluc ${ }^{-}$and the other is keeping the oxidation states of the terminal group but increasing or decreasing the chain length. The list of the selected sugar derivatives is presented in the Table 11 .

Table 11: Selected carbohydrates under investigation

Arabic acid

\subsubsection{Complexation of $\mathrm{Ca}^{2+}$ with D-glucose (Glu)}

$\mathrm{Ca}^{2}$ complexation of Glu has been investigated with the aid of multinuclear $\left({ }^{1} \mathrm{H},{ }^{13} \mathrm{C}\right.$ and $\left.{ }^{43} \mathrm{Ca}\right)$ NMR spectroscopy and $a b$ initio quantum chemical calculations. The analytical concentration of Glu in the test solutions was $0.200 \mathrm{M}$. In the calcium-containing systems, the concentration of calcium chloride was systematically raised from $0.020 \mathrm{M}$ to $0.320 \mathrm{M}$, and the ionic strength was set with sodium chloride to $1.00 \mathrm{M}$. 
Assignation of the carbon atoms was done on the basis of $2 \mathrm{D}{ }^{1} \mathrm{H}^{-13} \mathrm{C}$ NMR spectra Figure 26.

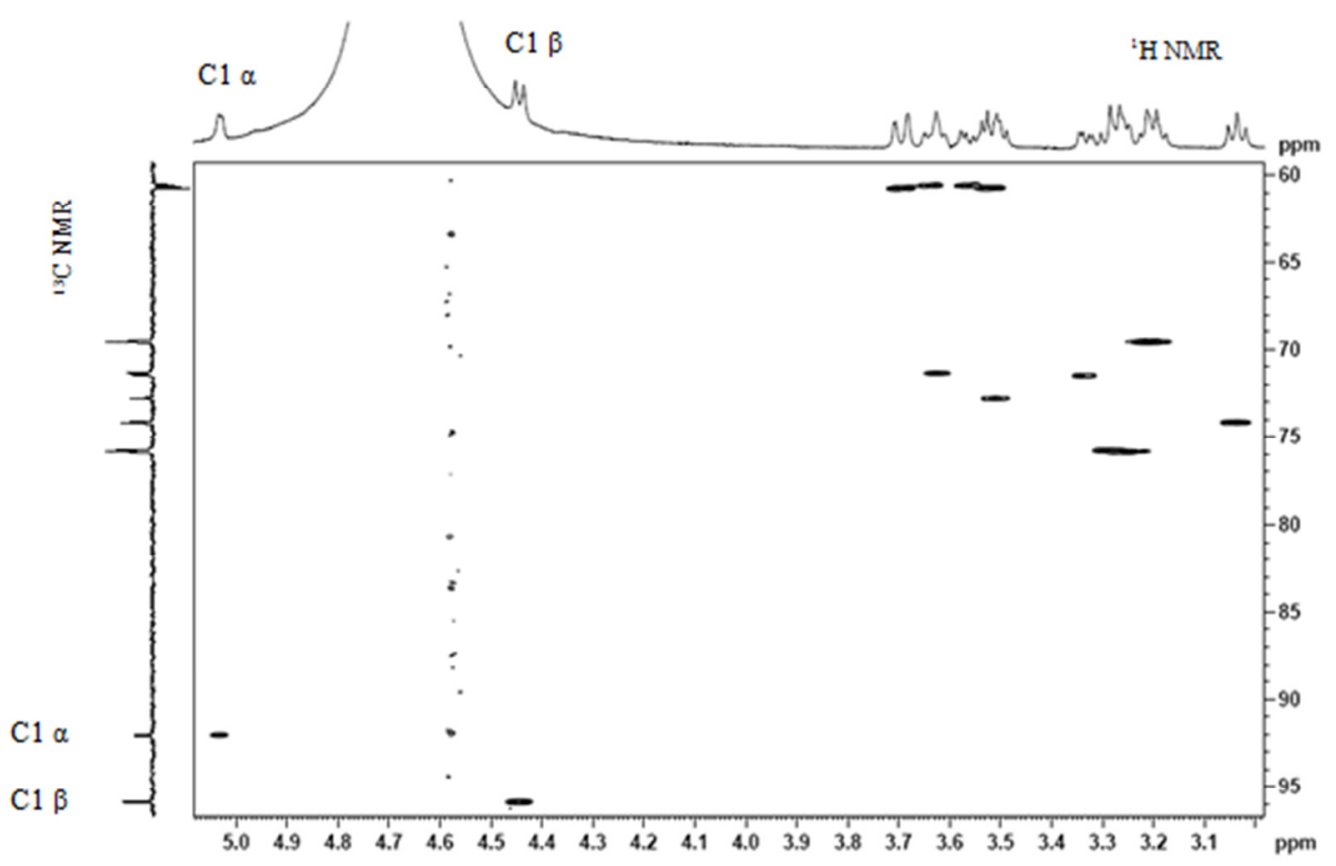

Figure 26: The $2 D^{1} \mathrm{H}^{-13} \mathrm{C}$ NMR spectrum of an aqueous solution of Glu. $\left([\mathrm{Glu}]_{T}=0.200 \mathrm{M}\right)$

Upon addition of calcium ions to the solution, the multiplicity of the signals did not change but the position of the NMR signals gradually, systematically and significantly moved towards lower chemical shifts (Figure 27). Due to the presence of both the $\alpha$ and $\beta$ anomeric forms of Glu in aqueous solutions, 12 distinct signals were observed in the ${ }^{13} \mathrm{C}$ NMR spectrum of an aqueous glucose solution. From the ${ }^{1} \mathrm{H}$ NMR spectra, the ratio between the $\alpha$ and $\beta$ forms is $36: 64$ in the absence of calcium ions, however, this equilibrium is shifted towards the formation of the $\alpha$ anomeric form with increasing metal ion concentration. Evaluations were performed assuming that either only the $\alpha$ or the $\beta$ form is present in the system, yielding an upper estimate for the formation constants. They are found to be practically identical for the two anomeric forms $\left(\mathrm{K}_{1,1}=1.5\right.$ and $\left.1.7 \mathrm{dm}^{3} \mathrm{~mol}^{-1}\right)$ indicating that the binding mode of $\mathrm{Ca}^{2+}$ is the same for the two anomers. From the ${ }^{1} \mathrm{H}^{-}{ }^{43} \mathrm{Ca}$ NMR spectrum participation of the $\mathrm{O}$ atom in the glycosidic hydroxide can be suggested for both anomers. 

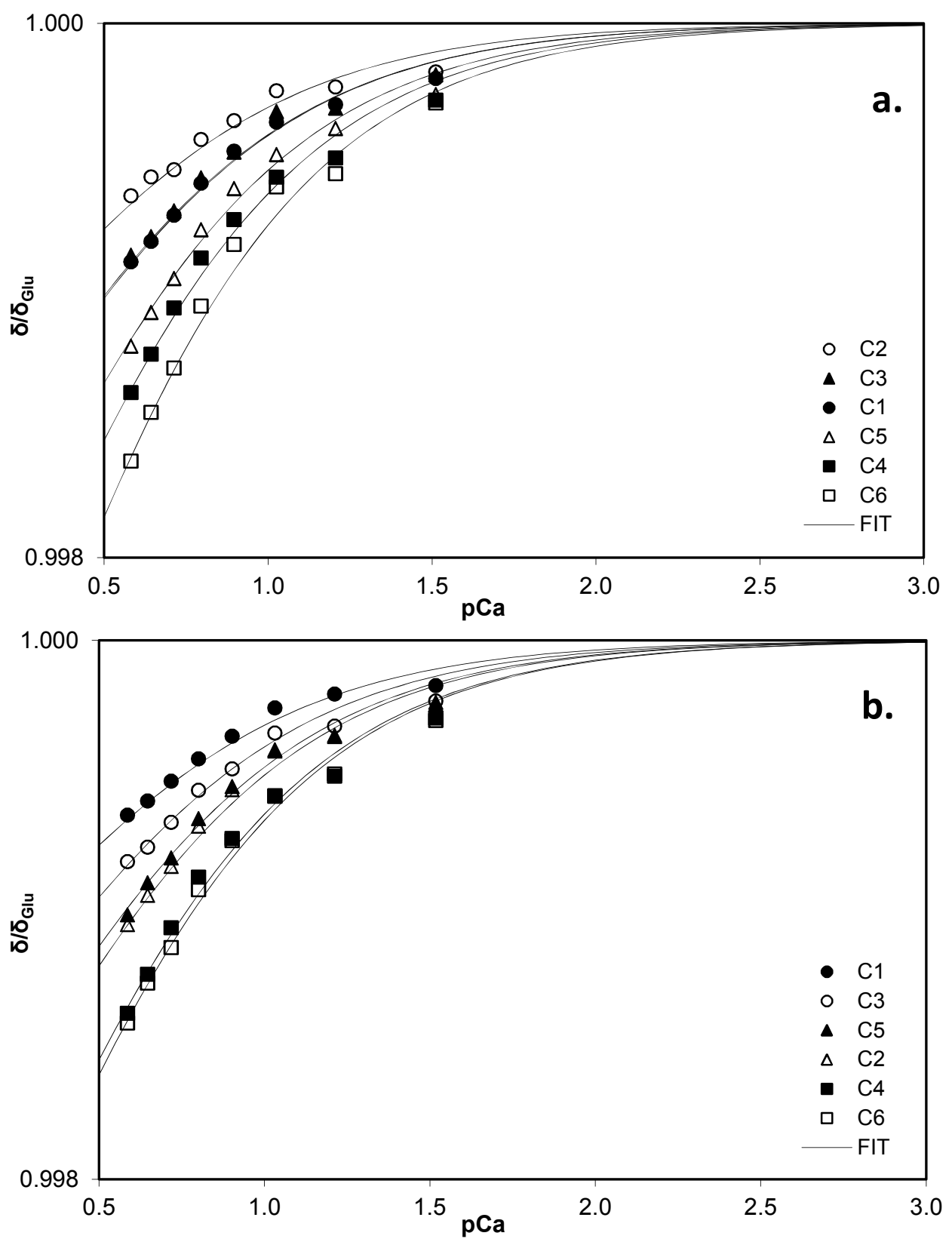

Figure 27: The observed and calculated ${ }^{13} C N M R$ chemical shifts on each carbon atom of Glu as a function of $p C a$ of the $\alpha-(a)$ and $\beta$ - (b) anomers of Glu. For better visualisation, observed chemical shifts were normalised with the limiting chemical shifts for the carbons of uncomplexed Glu.

In the ${ }^{43} \mathrm{Ca}$ NMR spectrum, a downfield shift is seen upon binding to Glu (Figure 28). From this spectrum of a solution containing $\left[\mathrm{Ca}^{2+}\right]_{\mathrm{T}}=0.200 \mathrm{M}$ and $[\mathrm{Glu}]_{\mathrm{T}}=0.200 \mathrm{M}$ participation of the $\mathrm{O}$ atom of the glycosidic hydroxide can be suggested for both anomers. As no other $\mathrm{OH}$ moieties are seen to directly participate in the complex formation from this twodimensional NMR spectra, it is highly probable, that the ethereal oxygen is also bound to the 
metal ion in the solution complex. (The possibility of monodentate $\mathrm{OH}$ binding can be excluded on common chemical sense.)

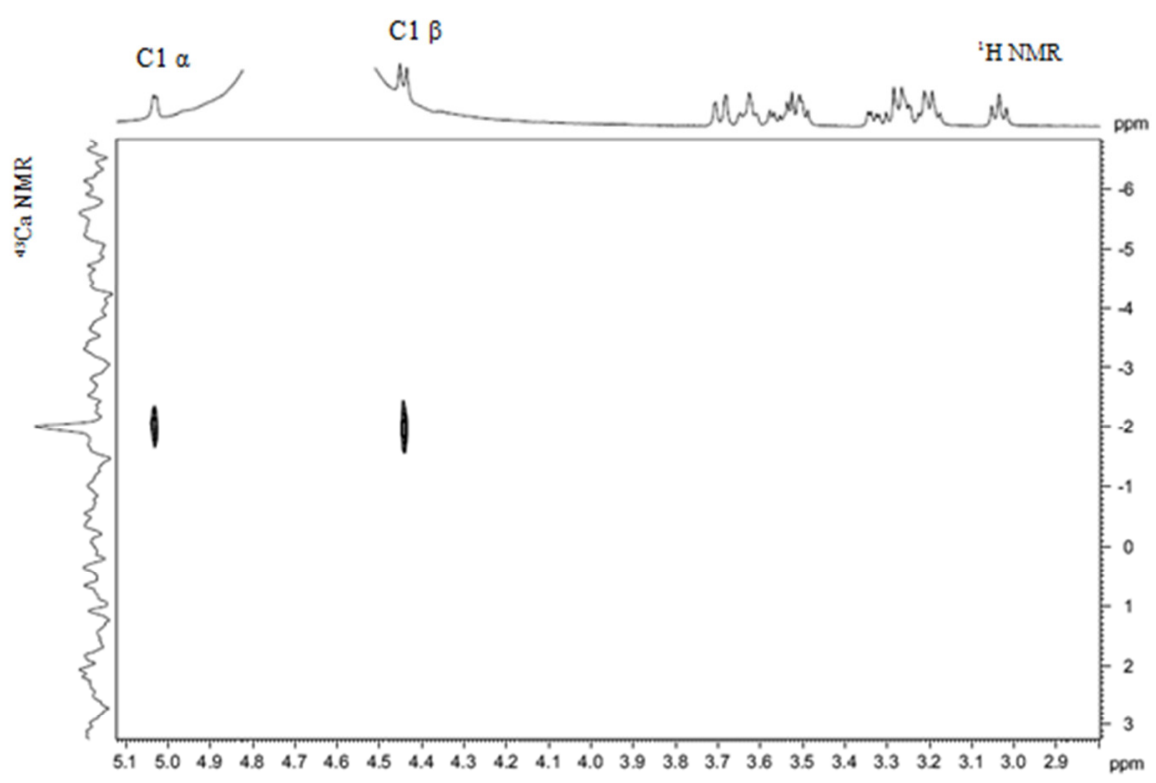

Figure 28: The $2 \mathrm{D}^{1} \mathrm{H}_{-}{ }^{43} \mathrm{Ca}$ NMR spectrum of an aqueous solution containing $\left[\mathrm{Ca}^{2+}\right]_{T}=$ $0.200 \mathrm{M}$ and $[\mathrm{Glu}]_{T}=0.200 \mathrm{M}$.

Geometry optimisation without constraints at the HF $6-31 \mathrm{G}^{* *}$ level, beside the above indicated binding sites, suggested the coordination of the oxygen at the terminal carbon as well for both isomers. The optimum geometries of the $\mathrm{Ca}^{2+}$ ion complexed with the $\alpha$ or the $\beta$ anomers together with bond distance data are seen in Figure 29.

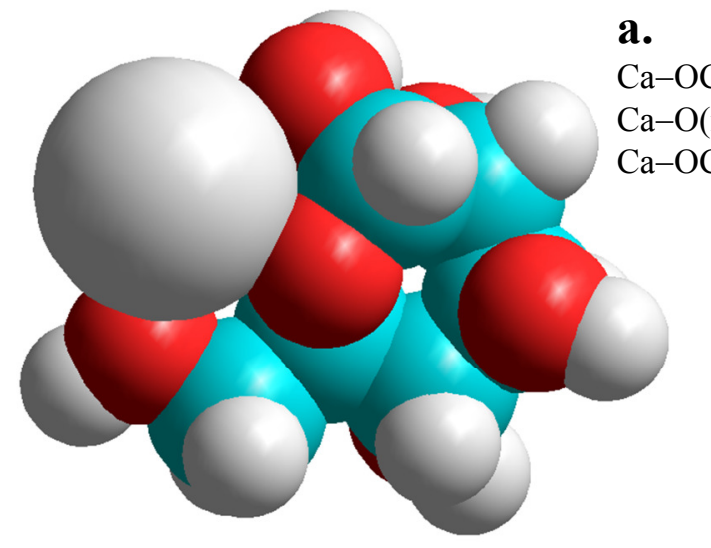

a.

$\mathrm{Ca}-\mathrm{OC} 1: 236 \mathrm{pm}$

$\mathrm{Ca}-\mathrm{O}$ (ring): $232 \mathrm{pm}$

Ca-OC6: $230 \mathrm{pm}$

Figure 29: The HF 6-31G** optimised structures of the $\mathrm{Ca}^{2+}$-complexes with Glu; (a) the $\alpha$ anomer and (b) the $\beta$ anomer as ligand. 


\subsubsection{Complexation of $\mathrm{Ca}^{2+}$ with sorbitol (Sor)}

In Sor-containing solutions 6 distinct signals were observed in the ${ }^{13} \mathrm{C}$ NMR spectra. Assignment of the carbon atoms of Sor was done on the basis of the $2 \mathrm{D}{ }^{1} \mathrm{H}-{ }^{13} \mathrm{C}$ NMR spectra (Figure 30). Similarly to that observed for Gluc - and Glu-containing solutions, the multiplicity of the signals did not change upon complexation, again suggesting a rapid chemical exchange on the NMR time scale between the species present.

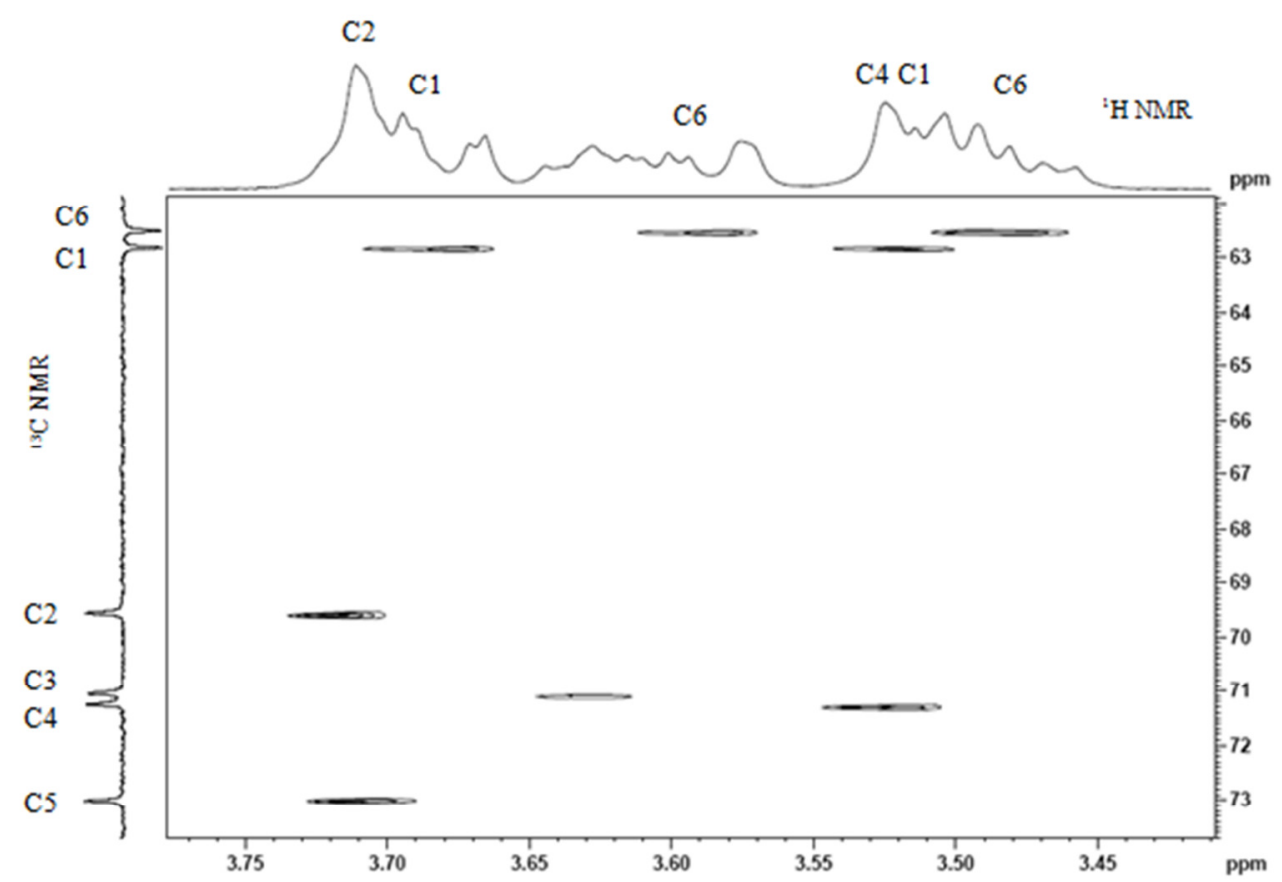

Figure 30: The $2 D^{1} \mathrm{H}^{-13} \mathrm{C} N \mathrm{NMR}$ spectrum of an aqueous solution of Sor $\left([\mathrm{Sor}]_{\mathrm{T}}=0.200 \mathrm{M}\right)$.

Both downfield (C4) and upfield (C1-C3, C5, and C6) variations in the ${ }^{13} \mathrm{C} \mathrm{NMR}$ chemical shifts could be observed for Sor upon $\mathrm{Ca}^{2+}$ complexation (Figure 31). The (upfield) shifts in the signal of $\mathrm{C} 1$ and $\mathrm{C} 5$ are not sufficiently large for formation constant determination, while the chemical shift of $\mathrm{C} 2$ remains practically constant within $\pm 0.01 \mathrm{ppm}$, which is commensurable with the error of chemical shift determinations.

Formation constant of the 1:1 complex of $\mathrm{Ca}^{2+}$ and Sor is calculated from the $\mathrm{C} 3, \mathrm{C} 4$ and C6 signals and has been found to be $\mathrm{K}_{1,1}=1.6 \pm 0.2 \mathrm{dm}^{3} \mathrm{~mol}^{-1}$. The ${ }^{13} \mathrm{C}$ NMR measurements in themselves are not sufficient to unambiguously identify the binding site of these ligands. 


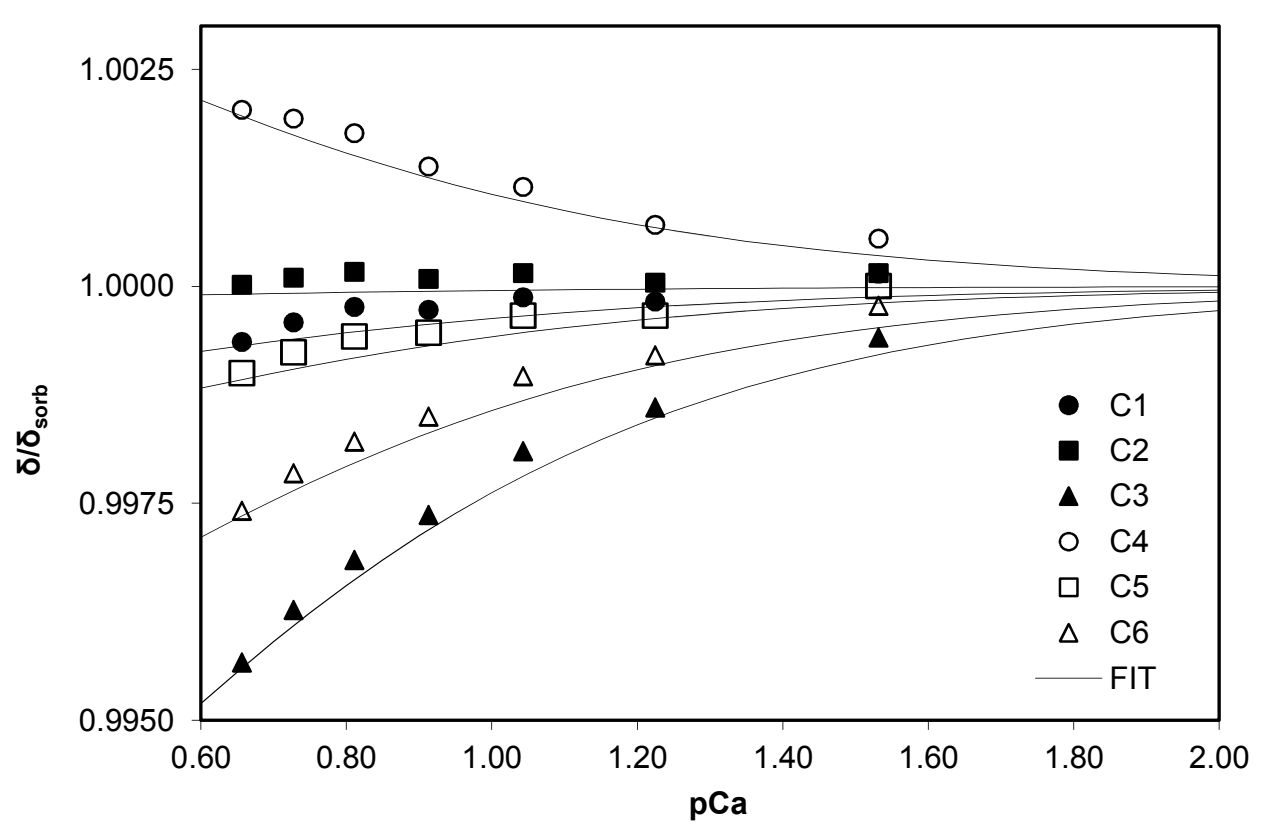

Figure 31: The observed and calculated ${ }^{13}$ C NMR chemical shifts on each carbon atom of Sor as a function of $p C a$. For better visualisation, observed chemical shifts were normalised with the limiting chemical shifts for the carbons of uncomplexed Sor.

However, 2D ${ }^{1} \mathrm{H}^{-}{ }^{43} \mathrm{Ca}$ NMR measurements suggest binding of Sor to $\mathrm{Ca}^{2+}$ through the alcoholic $\mathrm{OH}$ moieties on $\mathrm{C} 1, \mathrm{C} 2, \mathrm{C} 4$ and $\mathrm{C} 6$ (Figure 32). To check, whether such multidentate binding is geometrically possible, $a b$ initio quantum chemical calculations were performed.

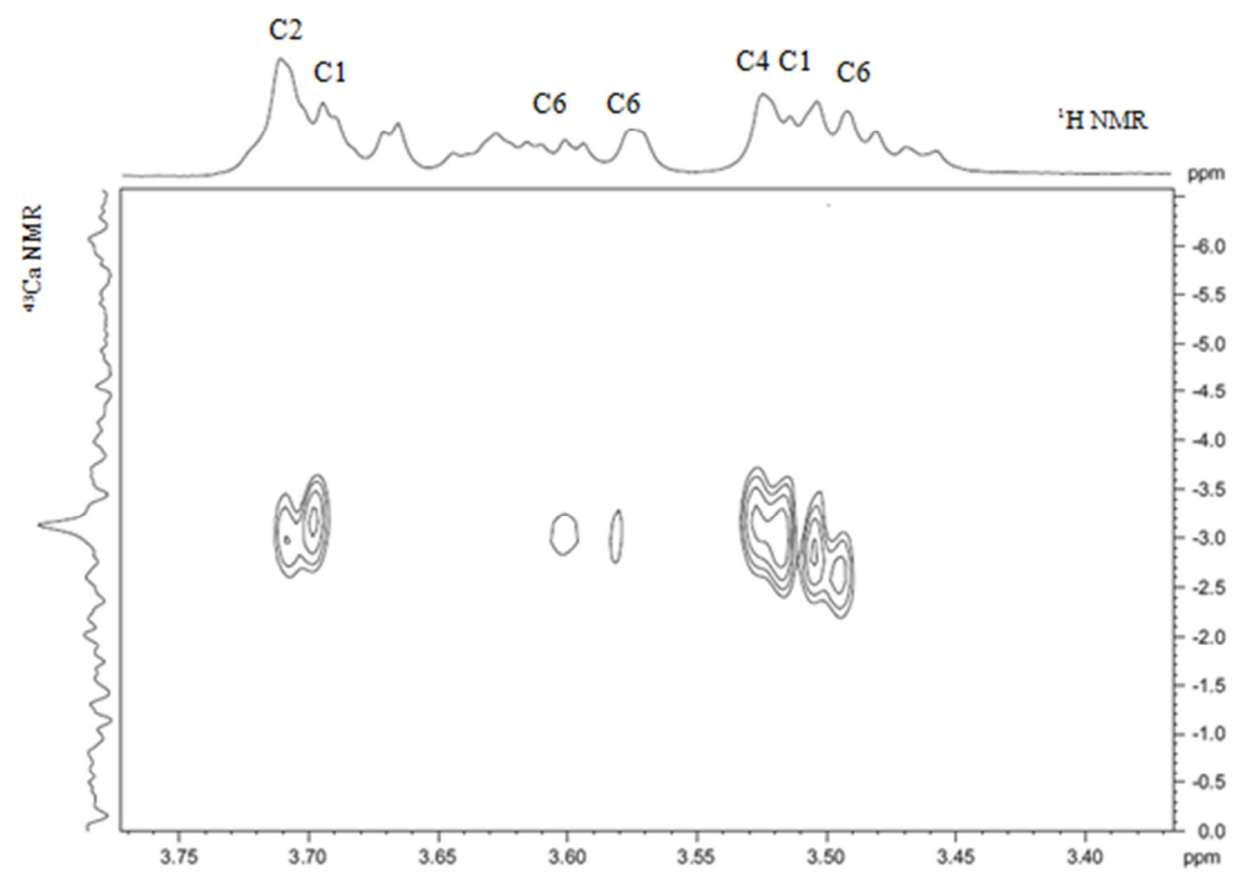

Figure 32: The $2 \mathrm{D}^{1} \mathrm{H}-{ }^{43} \mathrm{Ca}$ NMR spectrum of an aqueous solution containing $\left[\mathrm{Ca}^{2+}\right]_{T}=$ $0.200 \mathrm{M}$ and $[\mathrm{Sor}]_{T}=0.200 \mathrm{M}$. 
Geometry optimisation without constraints at the HF $6-31 \mathrm{G}^{* *}$ level indicated four binding sites in the Sor ligand with very similar $\mathrm{Ca}-\mathrm{O}$ bond distances (Figure 33). The ligand has high flexibility and it can conveniently embrace the $\mathrm{Ca}^{2+}$ ion coordinating to the oxygens bonded to the carbon atoms indicated by the 2D NMR measurements.

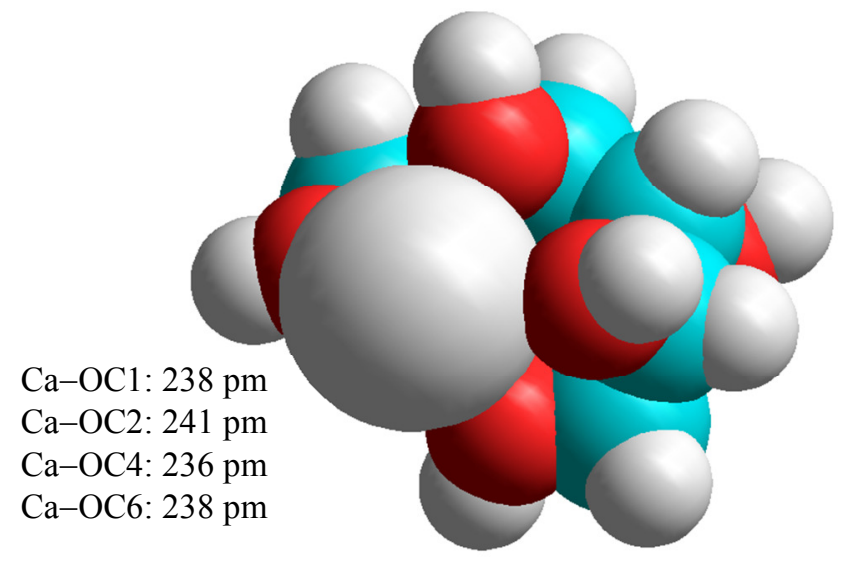

Figure 33: The HF 6-31G** optimised structure of the $\mathrm{Ca}^{2+}-$ Sor complex.

\subsubsection{Protonation of muconate $\left(\mathrm{Muc}^{2-}\right)$ and interaction with $\mathrm{Ca}^{2+}$}

The protonation of the $\mathrm{Muc}^{2-}$ containing systems have been investigated via ${ }^{1} \mathrm{H}$ and ${ }^{13} \mathrm{C}$ NMR measurements. In this series the concentration of $\mathrm{Muc}^{2-}$ is held constant at $0.0125 \mathrm{M}$, the ratio of the $\mathrm{HCl}$ is systematically raised from 0.00 to 1.00 . The ionic strength is set to 1.0 $\mathrm{M}$ with $\mathrm{NaCl}$, and the $\mathrm{pH}$ of the solutions has been determined with a calibrated $\mathrm{pH}-$ sensitive glass electrode (similarly to the series containing Gluc ${ }^{-}$).

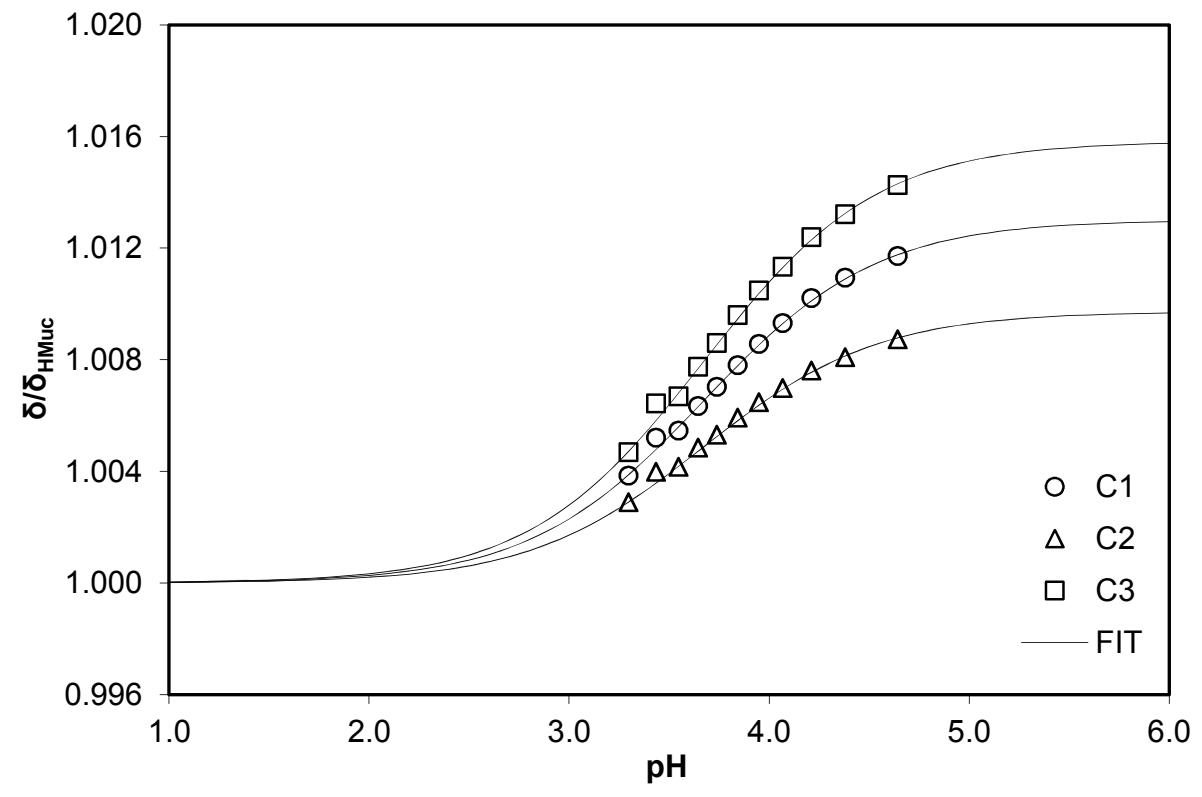

Figure 34: The observed and calculated chemical shifts on each carbon as a function of the pH for the $H^{+}+$Muc $^{2-}$ system 
$\mathrm{Muc}^{2-}$ is a centrosymmetrical meso compound, therefore three signals can be detected in its ${ }^{13} \mathrm{C}$ NMR spectrum. The chemical shifts as a function of $\mathrm{pH}$ fall on a sigmoid curve for each carbon atom (Figure 34), the acidity constant calculated using the chemical shifts of all carbon atoms has been found to be $\log \mathrm{K}_{\mathrm{a}}=3.67 \pm 0.05$ (the value found in the literature ${ }^{70}$ is $\log \mathrm{K}_{\mathrm{a}}=3.88$ at $\mathrm{I}=0.2 \mathrm{M}, \mathrm{KCl}$ and $25^{\circ} \mathrm{C}$ ).

On adding calcium chloride to solutions containing $\mathrm{Muc}^{2-}$ a solid material was precipitated. EDX measurement confirmed that the precipitated solid was CaMuc (Figure 35), therefore further experiments have not been performed.

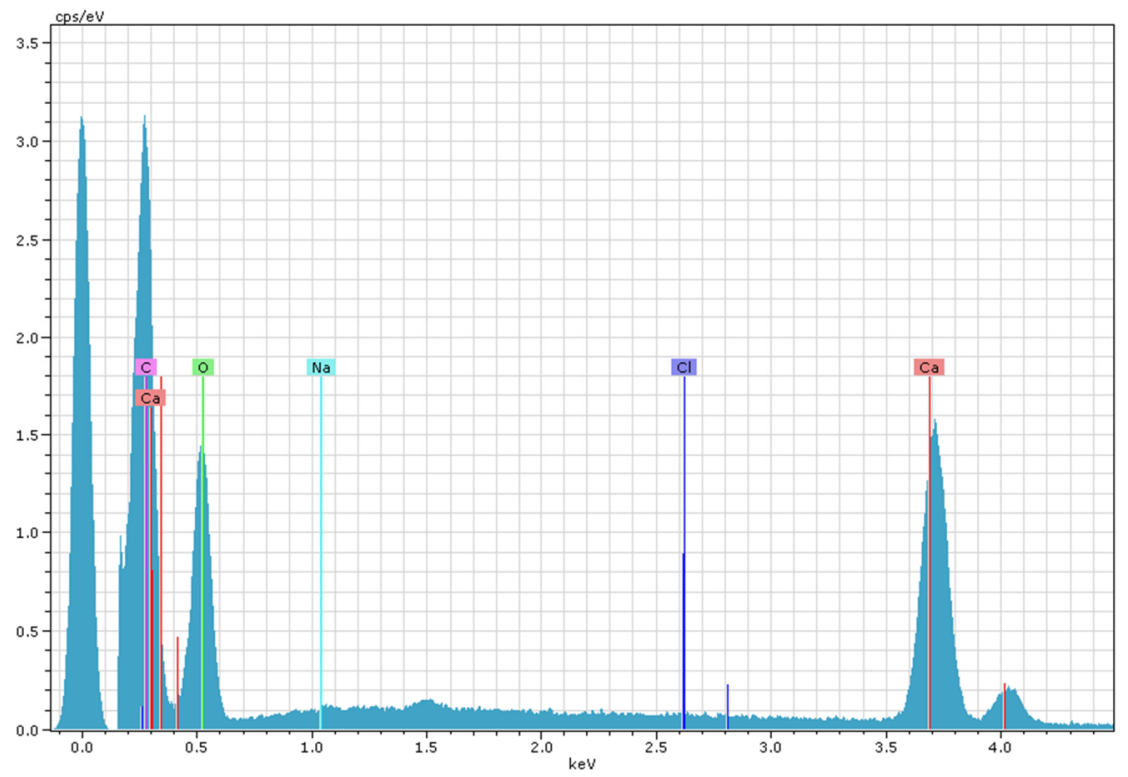

Figure 35: The EDX spectra of the material precipitated in the $\mathrm{Ca}^{2+}+\mathrm{Muc}^{2-}$ system

\subsubsection{Complexation of $\mathrm{Ca}^{2+}$ with arabinate (Ara)}

In order to study the effect of chain-length in carbohydrate derivatives on complexing to $\mathrm{Ca}^{2+}$ ion, we have commenced the investigations of the protonation and $\mathrm{Ca}^{2+}$ binding of arabic acid (HAra), a Gluc ${ }^{-}$analogue containing five carbon atoms. These experiments are particularly interesting, as from quantum mechanical calculations the $\mathrm{OH}$ on $\mathrm{C} 6$ of the Gluc ${ }^{-}$ was found to interact with $\mathrm{Ca}^{2+}$ in the $\mathrm{CaGluc}^{+}$complex.

In the first series, the concentration of NaAra was held constant at $0.1000 \mathrm{M}$, the ratio of the hydrogen chloride (to NaAra) was systematically raised from 0.00 to 1.00 , and the ionic strength was set to $1.0 \mathrm{M}$ with sodium chloride. The investigation of Ara ${ }^{-}$using multinuclear NMR measurements is quite complicated. ${ }^{13} \mathrm{C}$ NMR signals of this sugar carboxylate cannot be detected. The possible reason is the fast relaxation of the carbon atoms in such a high electrolyte background solutions (1.0M, $\mathrm{NaCl})$. 
Geometry optimisation applying explicit water molecules the model system approaches reality to a great extent. However, the size of the system increased considerably, and now, semiempirical calculations could only be used. The initial geometries of the naked cations were taken from the ab initio (HF 6-31 G* basis set) calculations previously performed on the isolated cations. After optimisation applying explicit water molecules the water molecules were removed.

The structure of the $\mathrm{CaAra}^{+}$complex ion after full geometry optimisation in aqueous solution is presented in Figure 36. Calculations result in a somewhat different scorpionate complex than for the isolated complex. However, four bonding distances are listed in the Figure 36, the $\mathrm{Ara}^{-}$acts as a tridentate ligand. The $\mathrm{Ca}-\mathrm{O}(\mathrm{C} 2)$ bond distance is too long for a bond.

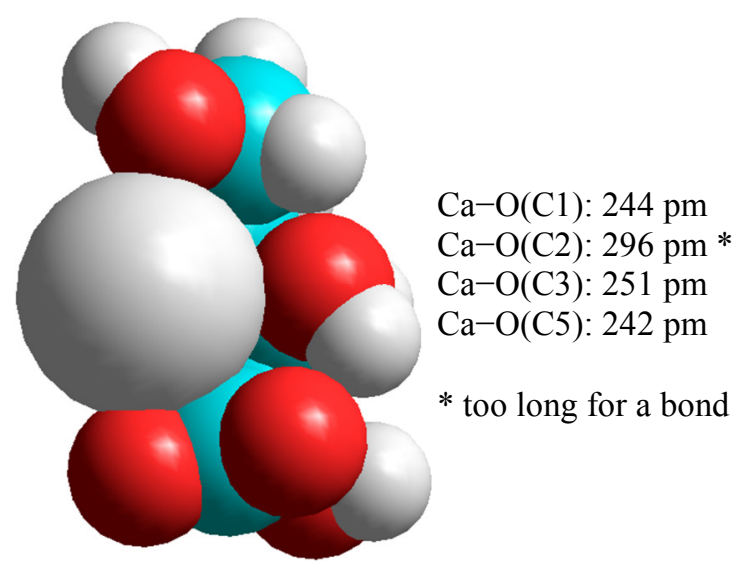

Figure 36: Structure of the CaAra ${ }^{+}$complex ion after full geometry optimisation in aqueous solution applying explicit water molecules with PM3 semiempirical quantum chemical calculations using the ab initio structure related to the scorpionate complex as initial geometry.

\subsubsection{Complexation of $\mathrm{Ca}^{2+}$ with heptagluconate (Hglu $\left.{ }^{-}\right)$}

For comparison with analogous Gluc ${ }^{-}$-containing systems, the interactions between $\mathrm{Ca}^{2+}$ and $\mathrm{Hglu}^{-}$(a sugar carboxylate structurally related to Gluc ${ }^{-}$) have been investigated. The ${ }^{1} \mathrm{H}$ NMR spectra of the $0.200 \mathrm{M} \mathrm{Hglu}^{-}$and $0.100 \mathrm{M} \mathrm{Ca}^{2+}$ containing systems in the presence of different $\mathrm{NaOH}$ concentrations $(0.010 \mathrm{M}$ and $1.0 \mathrm{M} \mathrm{NaOH})$ have been recorded in the $5-55^{\circ} \mathrm{C}$ temperature range. Beside the downfield shift of every proton signal, there is no variation with the temperature in the ${ }^{1} \mathrm{H}$ NMR spectra (Figure 37) in the solution containing $0.01 \mathrm{M} \mathrm{NaOH}$. At these conditions the temperature study of the $\mathrm{Ca}^{2+} / \mathrm{Hlgu}^{-}$system is not informative enough, as the coordination sites of the $\mathrm{Hglu}^{-}$cannot be determined. This result 
shows that at this concentration of $\mathrm{NaOH}$ high-pH complex (analogous to that with Gluc $^{-}$; see chapter 5.4.1.) is not formed with $\mathrm{Hglu}^{-}$.

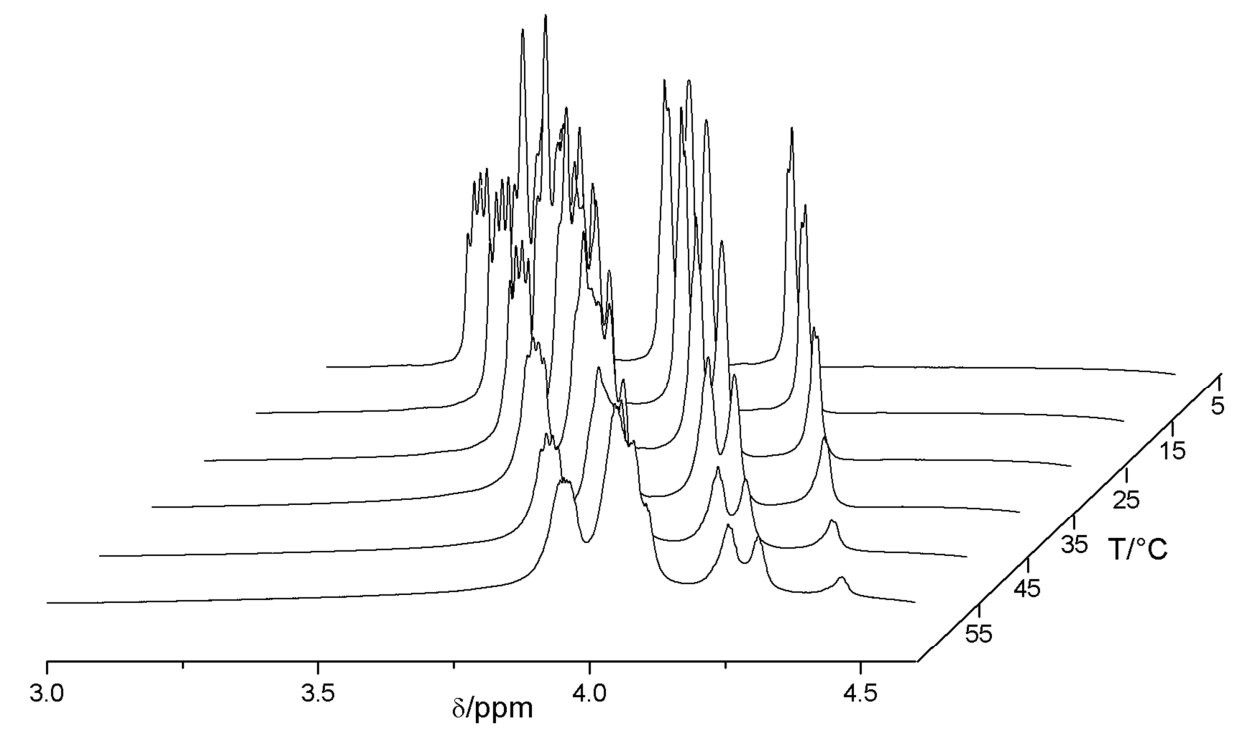

Figure 37: Temperature dependent ${ }^{1} \mathrm{H}$ NMR spectra of a system with $\mathrm{Hglu}^{-}(0.200 \mathrm{M})$ and $\mathrm{CaCl}_{2}(0.100 \mathrm{M})$ in the presence of $0.01 \mathrm{M} \mathrm{NaOH}$.

From the ${ }^{1} \mathrm{H}$ NMR spectra recorded for the $\mathrm{Ca}^{2+} / \mathrm{Hglu}^{-}$systems in $1.00 \mathrm{M} \mathrm{NaOH}$ media (Figure 38), at $5{ }^{\circ} \mathrm{C}$ the chemical exchange between the various forms of $\mathrm{Hglu}^{-}$ (uncomplexed and complexed) becomes slow enough on the NMR time scale. The signal of the $\mathrm{H} 2$ proton of $\mathrm{Hglu}^{-}$and that of the $\mathrm{Ca}^{2+}$ complex (e.g., $\mathrm{CaHglu}^{-}$) appear separately in the 3.7-4.0 ppm range (Figure 38). This can reflect the deprotonation of the alcoholic $\mathrm{OH}$ group(s) of the $\mathrm{Hglu}^{-}$upon $\mathrm{Ca}^{2+}$ binding, especially the deprotonation of the $\mathrm{OH}$ group binding to the $\mathrm{C} 2$ carbon atom of the sugar derivative. At $55{ }^{\circ} \mathrm{C}$ the chemical exchange between the two types of heptagluconate becomes fast enough on the NMR time scale and they appear together on the spectrum (see the peak marked with black arrow in Figure 38).

It is interesting to note that the NMR spectra observed for this system is much simpler than those of $\mathrm{Gluc}^{-}$and $\mathrm{Ca}^{2+}$, as only one additional $\mathrm{Ca}^{2+}$ binding site can be plausibly suggested beside the carboxylate oxygens (see chapter 5.4.1.1) 


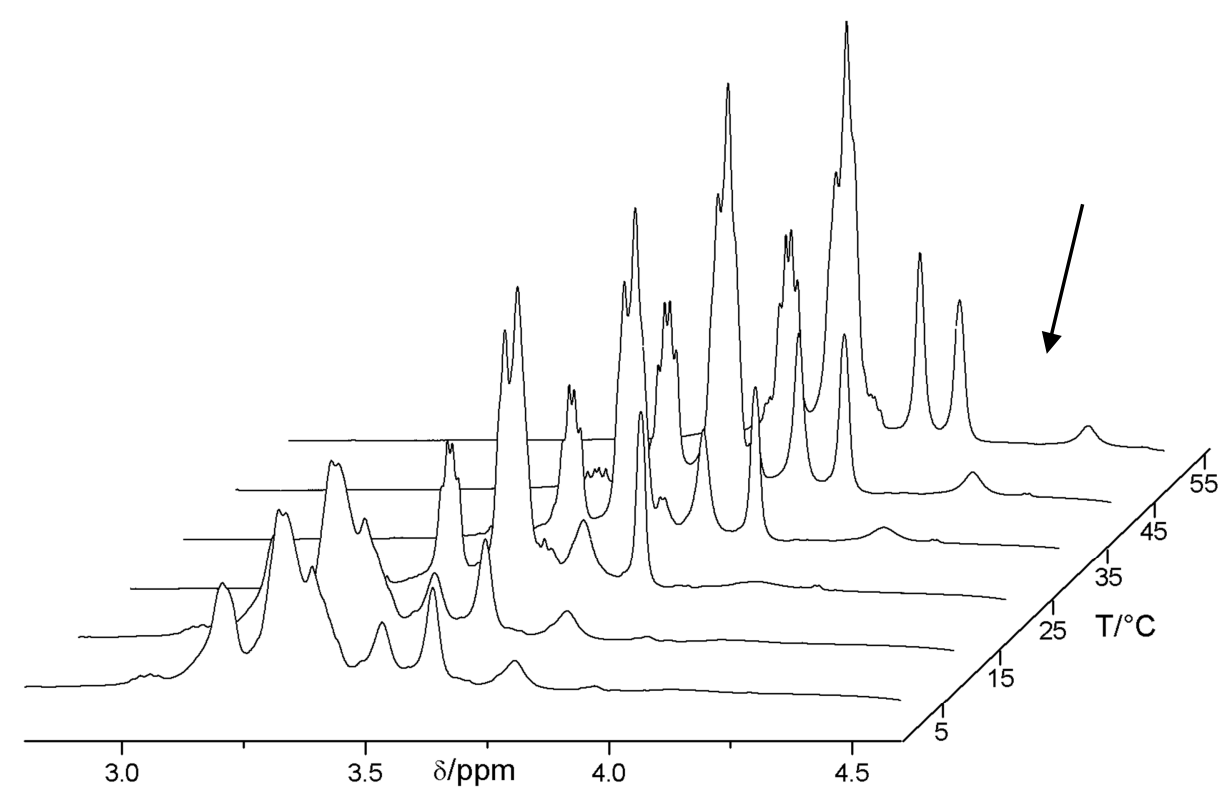

Figure 38: Temperature dependent ${ }^{1} \mathrm{H}$ NMR spectra of a system with $\mathrm{Hglu}^{-}(0.200 \mathrm{M})$ and $\mathrm{CaCl}_{2}(0.100 \mathrm{M})$ in the presence of $1.00 \mathrm{M} \mathrm{NaOH}$.

The structure of the $\mathrm{CaHglu}^{+}$complex ion after full geometry optimisation in aqueous solution is presented in Figure 39. The initial geometries of the naked cations were taken from the ab initio (HF 6-31 G** basis set) calculations previously performed on the isolated cations. After optimisation applying explicit water molecules the water molecules were removed.

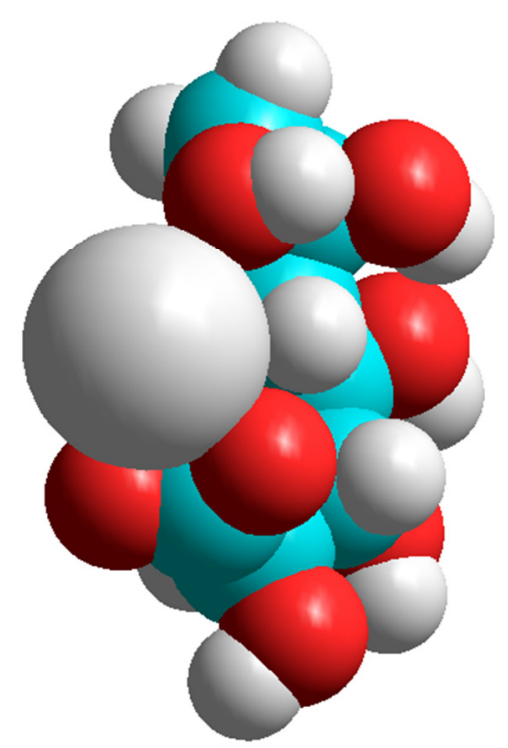

Figure 39: The optimum geometry found to CaHglu ${ }^{+}$scorpionate type complex ion after full geometry optimisation in aqueous solution applying explicit water molecules with PM3 semiempirical quantum chemical calculations using the ab initio structure as initial geometry. 
Calculations resulted in a scorpionate type complex (about the term scorpionate see chapter 5.2.6). The $\mathrm{Hlgu}^{-}$binds to the $\mathrm{Ca}^{2+}$ via two carboxylic oxygen on the $\mathrm{C} 1$ and the alcoholic $\mathrm{OH}$ group on the $\mathrm{C} 7$ forming a novel class of scorpionate complexes. However, the formation is these scorpionate type complexes has to be supplemented by other techniques the presence of these complexes is expected in aqueous solutions.

\subsubsection{Scorpionate type complexes}

The term scorpionate comes from the fact that the ligand can bind to a metal ion with (at least) three donor sites. Two of the donor sites bind like the pincers of a scorpion. The third (the terminal donor site of a ligand) binds to the metal over the plane formed by the metal and the other two donor atoms. The binding can be thought of as the scorpion grabs the prey with two pincers before stinging it.

A set of sugar derivatives has been selected to compare their properties with Gluc ${ }^{-}$. One of the selection criteria is keeping the oxidation states of the terminal group but increasing or decreasing the chain length and the other is altering the oxidation states of the terminal groups and keeping the chain length of the Gluc ${ }^{-}$.

However, the formation of the scopionate type complexes are mainly supported via molecular modeling calculations, the coordination of the $\mathrm{OH}$ group on the terminal carbon atom is confirmed by two dimensional ${ }^{1} \mathrm{H}-{ }^{43} \mathrm{Ca}$ NMR spectra in some cases (e.g. Ara ${ }^{-}$). Investigation of the $\mathrm{Ca}^{2+}$ complexation of sugar derivatives resulted in a novel class of scorpionate type complexes and we suppose that by supplementing the molecular calculations with further experimental studies (e.g. two dimensional NMR measurements, EXAFS) these findings can be considered for publication. 


\subsection{Solubility of $\mathrm{Ca}(\mathrm{OH})_{2}$ and the role of the Gluc}

In order to study the solubility of calcium oxide $(\mathrm{CaO})$ in sodium hydroxide solutions, first a concentrated $(19.78 \mathrm{M}) \mathrm{NaOH}$ stock solution has been prepared, the purity of which is monitored by ICP-OES spectrometer described previously. After appropriate dilution (1 to 50), the alkaline/alkaline earth metals content has been found to be under the detection limit (K: $0.2 \mathrm{mg} / \mathrm{dm}^{3}$; Ca: $0.1 \mathrm{mg} / \mathrm{dm}^{3} ; \mathrm{Mg}: 0.2 \mathrm{mg} / \mathrm{dm}^{3}$ ).

To eliminate the carbonate content of the solid material to be equilibrated, $\mathrm{CaO}$ sample (Reanal product, analytical grade) was heated at $\sim 900^{\circ} \mathrm{C}$ overnight. The $\mathrm{XRD}$ of the $\mathrm{CaO}$ before and after heating can be seen in Figure 40. The sample off the shelf is most probably $\mathrm{CaCO}_{3}$. The observed XRD peaks of the heat-treated $\mathrm{CaO}$ agree with those given in the literature for pure, anhydrous $\mathrm{CaO} .{ }^{71}$ The carbonate-free $\mathrm{CaO}$ sample is kept in a desiccator and the exposure to open air is kept in the minimum.

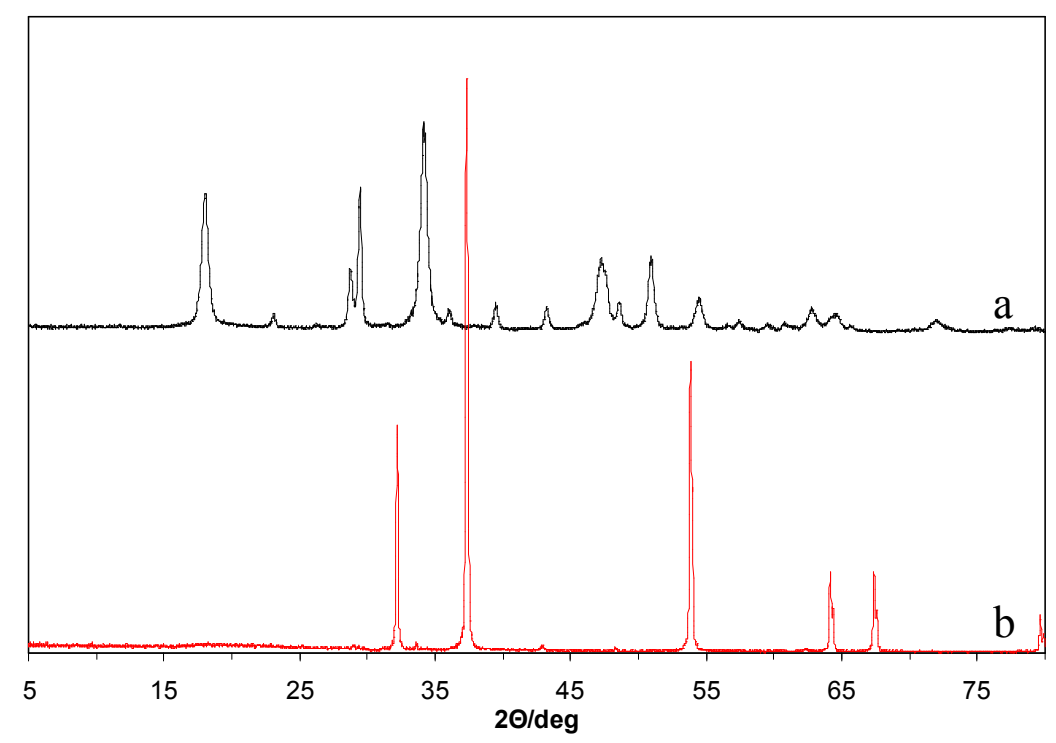

Figure 40: Powder XRD of the CaO before (a) and after (b) heating at $900^{\circ} \mathrm{C}$

\subsubsection{Solubility measurements at $25^{\circ} \mathrm{C}$}

\subsubsection{Solubility of $\mathrm{Ca}(\mathrm{OH})_{2}$ in caustic solutions at $25{ }^{\circ} \mathrm{C}$}

Solubility test measurements at $25.00 \pm 0.03{ }^{\circ} \mathrm{C}$ were performed in the usual way (described above), by saturating the target solutions with pure and baked $\mathrm{CaO}$ for at least two hours.

The concentration of the $\mathrm{Ca}^{2+}$ in the supernatant as a function of $\mathrm{NaOH}$ concentration is presented in Figure 41. A systematic difference between our experimental data and those 
found in the literature ${ }^{4}$ can be seen. To reveal the origin of this difference the following control experiments have been done:

verification the composition of the $\mathrm{NaOH}$ solution (in particular the presence of carbonate),

- determination of the composition of the solid phase before and after the experiments,

- verification of the ICP.

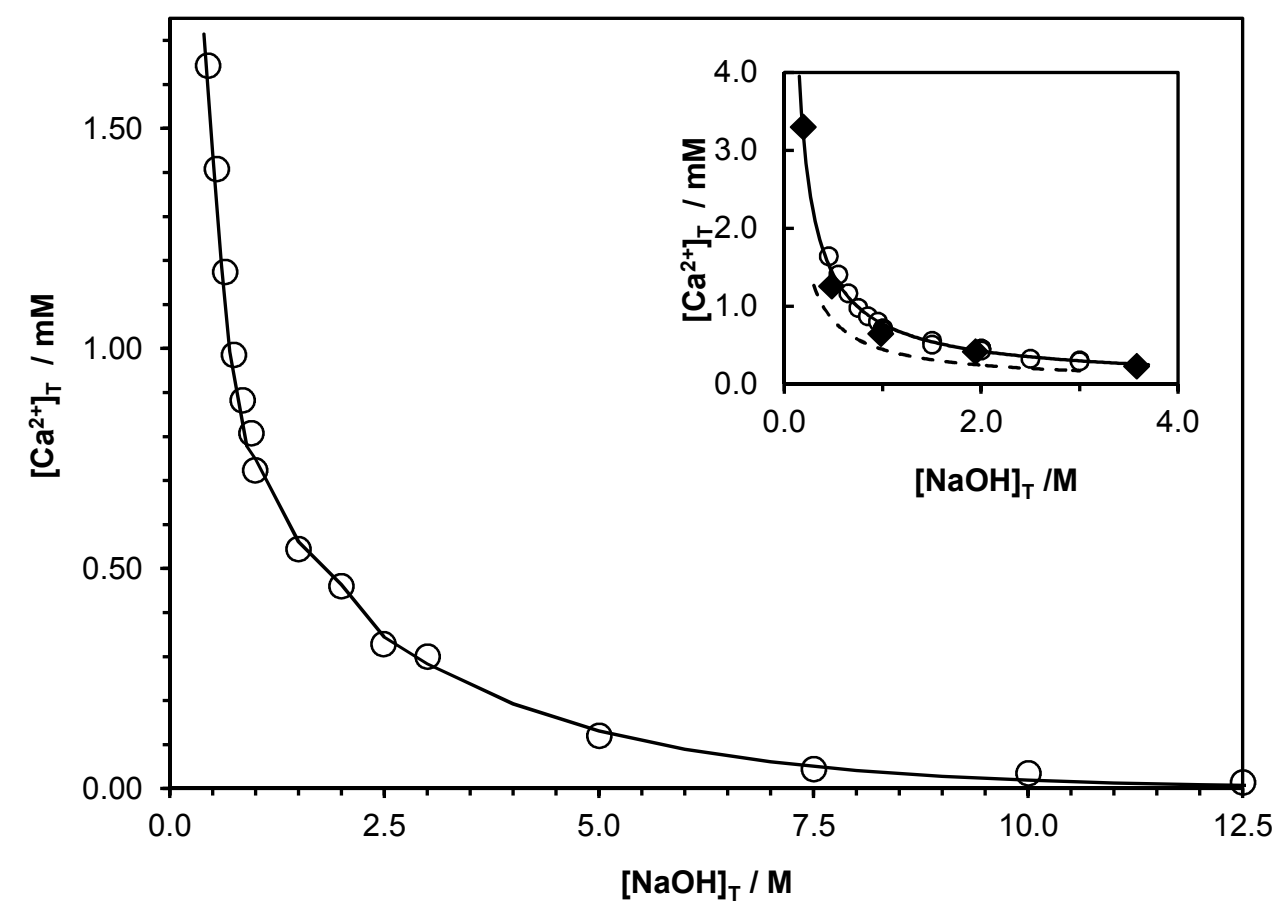

Figure 41: Variation of the $\mathrm{Ca}^{2+}$ concentration in a solution saturated with $\mathrm{Ca}(\mathrm{OH})_{2}(\mathrm{~s})$ as a function of the $[\mathrm{NaOH}]_{T}$ at $25^{\circ} \mathrm{C}$ (o: experimental data; : ref. 72 ; ---: ref. 4)

The results of these control measurements demonstrate that the protocol employed by us results in reasonably precise (reproducible that is) and accurate solubility data. Therefore, we have every reason to assume that the data published by Konno et al. ${ }^{4}$ contain some systematic error. (We tried to find the reason) of this difference and it seems to be that Konno et al. ${ }^{4}$ did not use the correct stoichiometry in their calculations.)

5.3.1.2. The solubility product of $\mathrm{Ca}(\mathrm{OH})_{2}$ and the stability constant of $\mathrm{CaOH}^{+}$at $25^{\circ} \mathrm{C}$

In the systems containing $\mathrm{NaOH}$ solution and $\mathrm{CaO}$ as solid phase the following chemical equilibria are valid:

$$
\begin{aligned}
& \mathrm{CaO}(\mathrm{s})+\mathrm{H}_{2} \mathrm{O} \rightleftharpoons \mathrm{Ca}(\mathrm{OH})_{2}(\mathrm{~s}) \\
& \mathrm{Ca}(\mathrm{OH})_{2}(\mathrm{~s}) \rightleftharpoons \mathrm{Ca}^{2+}+2 \mathrm{OH}^{-}
\end{aligned}
$$




$$
\mathrm{Ca}^{2+}+\mathrm{OH}^{-} \rightleftharpoons \mathrm{CaOH}^{+}
$$

On the basis of the XRD of the equilibrium solid phase after a one-day run, $\mathrm{CaO}$ is fully converted to $\mathrm{Ca}(\mathrm{OH})_{2}$. Because $\left[\mathrm{Ca}^{2+}\right]<<\left[\mathrm{OH}^{-}\right]_{\mathrm{T}}$, the solubility product of the $\mathrm{Ca}(\mathrm{OH})_{2}$ is

$$
L_{\mathrm{Ca}(\mathrm{OH})_{2}}=\left[\mathrm{Ca}^{2+}\right] \cdot\left[\mathrm{OH}^{-}\right]_{T}^{2}
$$

and the stability constant of the complex $\mathrm{CaOH}^{+}$is:

$$
K_{\mathrm{CaOH}^{+}}=\frac{\left[\mathrm{CaOH}^{+}\right]}{\left[\mathrm{Ca}^{2+}\right] \cdot\left[\mathrm{OH}^{-}\right]_{T}} .
$$

The solubility product of $\mathrm{Ca}(\mathrm{OH})_{2}$ and the stability constant of $\mathrm{CaOH}^{+}$have been calculated and depicted in Figure 42 using the following linearized equation (obtained via combining the equilibrium expressions and the mass balance equations.

$$
\mathrm{C}_{\mathrm{Ca}} \cdot\left[\mathrm{OH}^{-}\right]_{T}^{2}={\mathrm{LCa(OH})_{2}}+\mathrm{K}_{\mathrm{CaOH}^{+}} \cdot L_{\mathrm{Ca}(\mathrm{OH})_{2}}\left[\mathrm{OH}^{-}\right]_{T}
$$

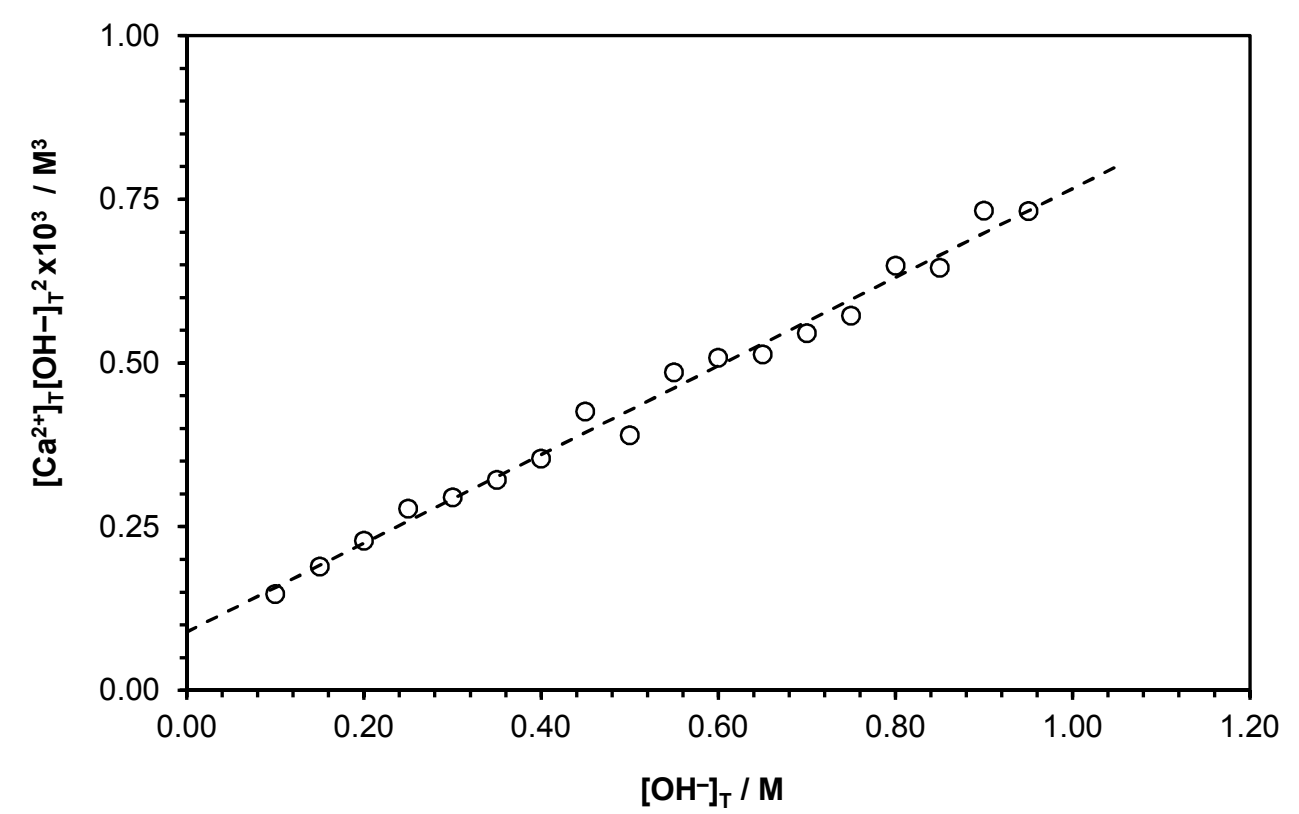

Figure 42: The variation of the total calcium ion concentration multiplied with the square of the total $\mathrm{OH}^{-}$concentration as a function of the total $\mathrm{OH}^{-}$concentration; the intercept gives $L_{\mathrm{Ca}(\mathrm{OH}) 2}$ and the slope is equal to $\mathrm{L}_{\mathrm{Ca}(\mathrm{OH}) 2} \times \mathrm{K}_{\mathrm{CaOH}}+$

From these, the solubility product and of the stability constant are as follows: $\log \mathrm{L}\left(\mathrm{Ca}(\mathrm{OH})_{2}\right)=-3.97 \pm 0.20$ and $\log \mathrm{K}\left(\mathrm{CaOH}^{+}\right)=0.78 \pm 0.10$. These results are reasonably close to the data found in the literature, ${ }^{73}$ the values published by Sruth et al. are $\log L_{\mathrm{Ca}(\mathrm{OH}) 2}$ $=-5.19 \pm 0.2(\mathrm{I}=0 \mathrm{M}) ; \log L_{\mathrm{CaOH}}{ }^{+}=0.64 \pm 0.1(\mathrm{I}=3 \mathrm{M}), 1.30(\mathrm{I}=0 \mathrm{M})$. 
Solubility data have also been processed with the aid of the ZITA suite of computer programs to evaluate the experiments by nonlinear parameter estimation. ${ }^{74}$ The results of these calculations are shown on Figure 43. The data set has been attempted to be fitted with assuming $\mathrm{Ca}^{2+}(\mathrm{aq})$ as the only water soluble calcium species present. As seen in Figure 43, this assumption fails to describe the experimental points (see green line in Figure 43). However, when the formation of the complex $\mathrm{CaOH}^{+}(\mathrm{aq})$ is included in the model as well, excellent fit is obtained (solid line). The average relative difference between the observed and calculated data points is $0.8 \%$. The formation constant of the $\mathrm{CaOH}^{+}(\mathrm{aq})$ species is found to be $\log \mathrm{K}\left(\mathrm{CaOH}^{+}\right)=0.97 \pm 0.03$ and the solubility product of $\mathrm{Ca}(\mathrm{OH})_{2}$ was computed as $\log$ $\mathrm{L}\left(\mathrm{Ca}(\mathrm{OH})_{2}\right)=-4.10 \pm 0.02$. Inclusion of $\mathrm{Ca}(\mathrm{OH})_{2}(\mathrm{aq})$ in the model does not improve the fit further and using this species in place of the $\mathrm{CaOH}^{+}$(aq) yields unacceptable fit (dashed line). From this it seems unlikely, that $\mathrm{Ca}(\mathrm{OH})_{2}(\mathrm{aq})$ is formed in reasonable quantities in these systems.

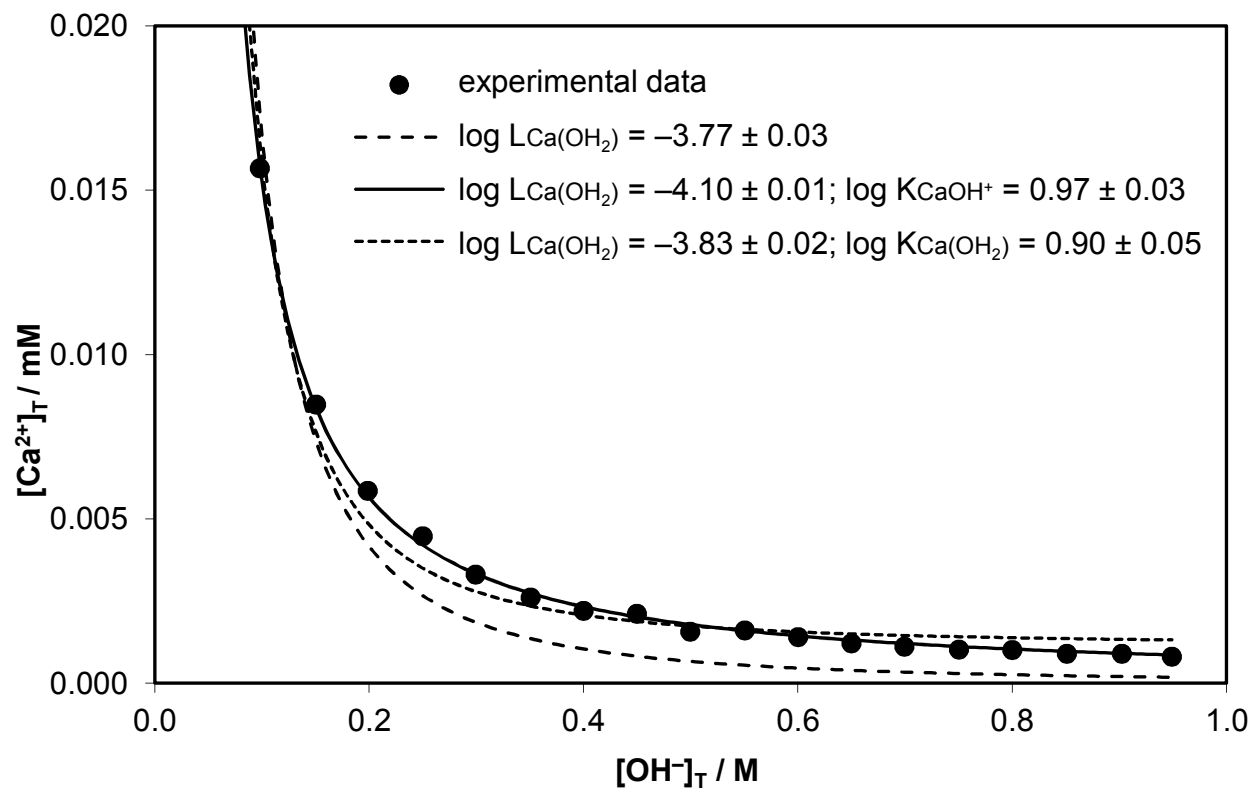

Figure 43: The total concentration of $\mathrm{Ca}^{2+}$ in solutions in equilibrium with $\mathrm{Ca}(\mathrm{OH})_{2}(\mathrm{~s})$ in $\mathrm{Na}(\mathrm{Cl}, \mathrm{OH})$ mixtures with constant ionic strength $(1.00 \mathrm{M})$ and at $25.00 \pm 0.02{ }^{\circ} \mathrm{C}$, as a function of the total [OH] and the various calculated data from the models indicated in the text. 
5.3.1.3. The conditional stability constant of the high-pH calcium gluconate complex at room temperature

Here, the working hypothesis is that the equilibrium concentration of the $\mathrm{Ca}^{2+}$ in caustic solutions containing solid $\mathrm{Ca}(\mathrm{OH})_{2}(\mathrm{~s})$ must increase with increasing Gluc ${ }^{-}$concentration, if complex formation takes place between the metal ion and the sugar carboxylate. Accordingly, solubility measurements have been performed, which (in principle) are suitable to determine the stability constant(s) of the complex(es) forming in these solutions. The concentration of Gluc $^{-}$in $1.00 \mathrm{M} \mathrm{NaOH}$ is systematically raised from $0.00 \mathrm{mM}$ to $1.60 \mathrm{mM}$. To check whether significant adsorption of Gluc ${ }^{-}$takes place on the surface of the solid, different amounts of $\mathrm{CaO}$ are added to the sample bottles $\left(40-120 \mathrm{mg}\right.$ to $25 \mathrm{~cm}^{3}$ sample). As the equilibrium calcium concentration in the samples containing the same concentration of $\mathrm{Gluc}^{-}$does not vary with the amount of the solid $\mathrm{CaO}$, the adsorption of $\mathrm{Gluc}^{-}$on the $\mathrm{Ca}(\mathrm{OH})_{2}$ surface can reasonably be considered insignificant.

In order to describe our system, the equations referring to the $\mathrm{CaO}$ containing $\mathrm{NaOH}$ solutions has to be combined with the stability constant of the calcium gluconate complex, the mass balance of total Gluc ${ }^{-}$and with the equilibrium concentration of the complex. The mass balance equations referring to the $\mathrm{Ca}^{2+}$ and $\mathrm{Gluc}^{-}$, respectively, are as follows (assuming only 1:1 complex, the charge of which is now omitted):

$$
\begin{gathered}
C_{C a}=\left[\mathrm{Ca}^{2+}\right]+\left[\mathrm{CaOH}^{+}\right]+[\mathrm{CaGluc}], \\
C_{\text {Gluc }}=\left[\text { Gluc }^{-}\right]+[\text {CaGluc }] .
\end{gathered}
$$

The solubility product of the $\mathrm{Ca}(\mathrm{OH})_{2}$ and the formation constant of $\mathrm{CaOH}^{+}$have already been known (see above).

The calcium concentration increases linearly with raising the Gluc $^{-}$concentration (Figure 44), therefore, the $\mathrm{Ca}^{2+}$ :Gluc ${ }^{-}$ratio in the complex forming in this concentration range is $1: 1$. The conditional stability constant can be determined using the following equation:

$$
K_{\text {CaGluc }}=\frac{[\text { CaGluc }]}{\left[\mathrm{Ca}^{2+}\right] \cdot\left[\text { Gluc }^{-}\right]}
$$

The same calculated conditional stability constants at different points refer to the formation of the complex with 1:1 ratio. The conditional stability constant of calcium gluconate in $1.00 \mathrm{M} \mathrm{NaOH}$ media is $\log \mathrm{K}_{\mathrm{CaGluc}}=4.02 \pm 0.06$ 


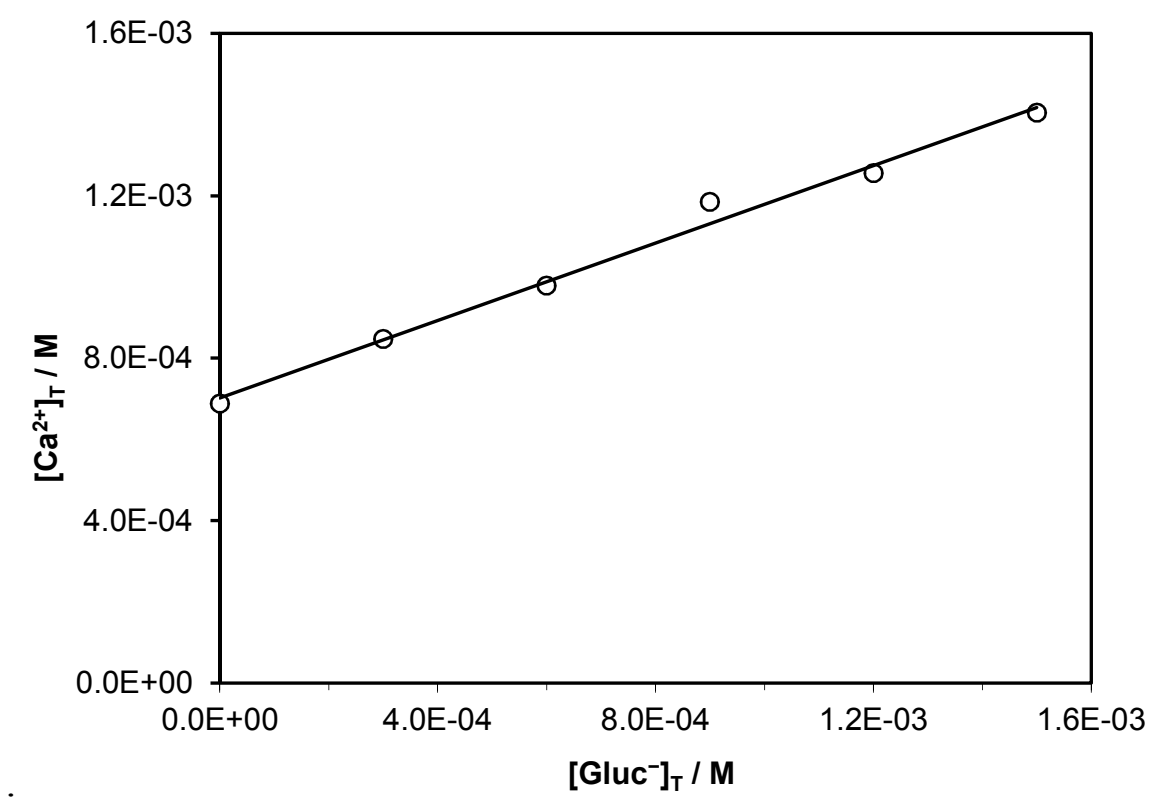

Figure 44: The variation of the total calcium concentration as a function of the total Gluc concentration in solutions with $1.00 \mathrm{M} \mathrm{NaOH}$ in equilibrium with $\mathrm{Ca}(\mathrm{OH})_{2}(\mathrm{~s})$ at $25.00^{\circ} \mathrm{C}$

Table 12: The calculated equilibrium concentrations and the conditional stability constants

\begin{tabular}{ccccccc}
\hline $\mathbf{C}_{\text {Gluc }}{ }^{-} / \mathbf{m M}$ & $\mathbf{c}_{\mathrm{Ca}} / \mathbf{m M}$ & {$[$ CaGluc] $/ \mathbf{m M}$} & {$\left[\mathrm{Gluc}^{-}\right] / \mathbf{m M}$} & {$\left[\mathrm{Ca}^{2+}\right] / \mathbf{m M}$} & $\mathrm{K}_{\text {CaGluc }}$ & log $\mathrm{K}_{\text {CaGluc }}$ \\
\hline 0.300 & 0.847 & 0.160 & 1.40 & 9.78 & 11570 & 4.06 \\
0.600 & 0.979 & 0.290 & 3.10 & 9.78 & 9600 & 3.98 \\
0.900 & 0.190 & 0.497 & 4.00 & 9.78 & 12620 & 4.10 \\
1.200 & 1.260 & 0.674 & 6.30 & 9.78 & 9180 & 3.96 \\
1.500 & 1.400 & 0.160 & 7.80 & 9.78 & 9340 & 3.97 \\
\hline
\end{tabular}

Due to the acceptable linearity suggested on Figure 44, this relatively simple equilibrium system has seemed to be plausible. Further potentiometric measurements, however, do indicate more species having significant concentration making the linearization impossible (see chapter 5.4.1.2 in detail for the further results on page 54).

\subsubsection{Solubility measurements under superambient conditions}

Solubility measurements have also been performed at $50.00 \pm 0.04{ }^{\circ} \mathrm{C}$ and $75.00 \pm 0.07^{\circ} \mathrm{C}$ (in the usual way) by saturating the target solutions with pure and baked $\mathrm{CaO}$. In the first series the concentration of the $\mathrm{NaOH}$ is systematically raised up to $15 \mathrm{M}$. In these solutions the ionic strength is not set. The total concentration of the $\mathrm{Ca}^{2+}$ in the supernatant as a function of the $\mathrm{NaOH}$ concentration is presented in Figure 45. 


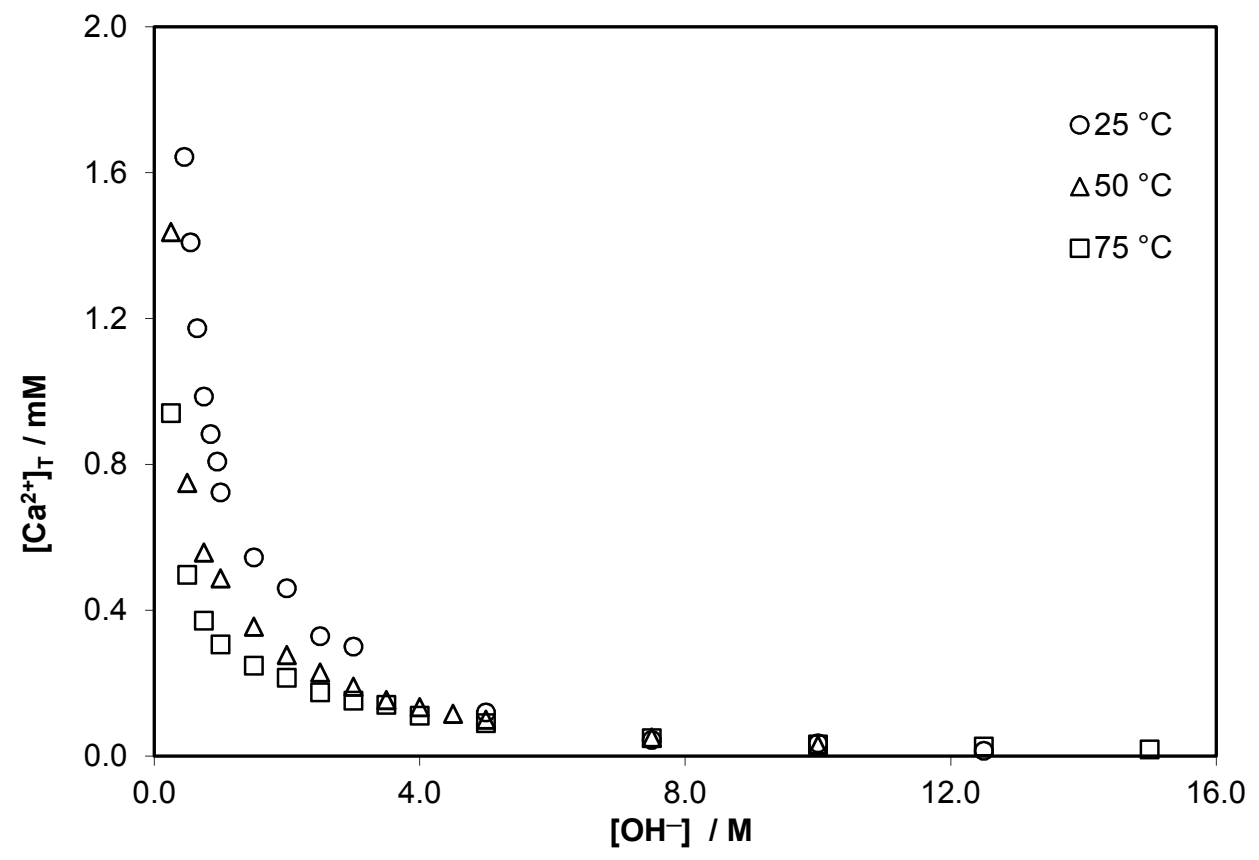

Figure 45: The variation $\mathrm{Ca}^{2+}$ concentration in the supernatant with the concentration of $\mathrm{NaOH}$ at $25^{\circ} \mathrm{C}, 50^{\circ} \mathrm{C}$ and $75^{\circ} \mathrm{C}$

The concentration of $\left[\mathrm{Ca}^{2+}\right]_{\mathrm{T}}$ decreases with increasing the concentration of the $\mathrm{OH}^{-}$. In the solutions with $\left[\mathrm{OH}^{-}\right]>12 \mathrm{M},\left[\mathrm{Ca}^{2+}\right]_{\mathrm{T}}$ can be estimated in the range of less than $0.3 \mathrm{ppm}$ $(10 \mu \mathrm{M})$. The $\left[\mathrm{Ca}^{2+}\right]_{\mathrm{T}}$ decreases by raising the temperature. The effect of the temperature on the $\mathrm{Ca}^{2+}$ solubility decreases by the increasing $\left[\mathrm{OH}^{-}\right]$. Under these conditions and $\left[\mathrm{OH}^{-}\right]>6 \mathrm{M}$, the temperature has a minor effect on the solubility of $\mathrm{Ca}^{2+}$.

The solubility products of the $\mathrm{Ca}(\mathrm{OH})_{2}$ and the stability constant of the $\mathrm{CaOH}^{+}$was determined at $50.00 \pm 0.04{ }^{\circ} \mathrm{C}$ and $75.00 \pm 0.07{ }^{\circ} \mathrm{C}$ by saturating the $\mathrm{NaOH}$ solutions with pure and baked $\mathrm{CaO}$. In these solutions the concentration of the $\mathrm{NaOH}$ systematically varied between 0.10 and $1.00 \mathrm{M}$, and the ionic strength was held constant at $1.00 \mathrm{M}$ with $\mathrm{NaCl}$.

The numeric values of the solubility product of $\mathrm{Ca}(\mathrm{OH})_{2}$ and the stability constant of the $\mathrm{CaOH}^{+}$at 25.0, 50.0 and $75.0{ }^{\circ} \mathrm{C}$ are summarized in Table 13. The solubility product of $\mathrm{Ca}(\mathrm{OH})_{2}$ decreases by raising the temperature. The stability constant of $\mathrm{CaOH}^{+}$increases by raising the temperature reaching $\log \mathrm{KCaOH}^{+}=1.95$. 
Table 13: The solubility product of $\mathrm{Ca}(\mathrm{OH})_{2}$ and the stability constant of $\mathrm{CaOH}^{+}$ at $25.0,50.0$ and $75.0^{\circ} \mathrm{C}$

\begin{tabular}{ccc}
\hline $\mathrm{T} /{ }^{\circ} \mathrm{C}$ & $\log \mathrm{LCa}(\mathrm{OH})_{2}$ & $\log \mathrm{KCaOH}^{+}$ \\
\hline $\mathbf{2 5 . 0}$ & $-4.10 \pm 0.01$ & $0.97 \pm 0.03$ \\
$\mathbf{5 0 . 0}$ & $-4.79 \pm 0.02$ & $1.28 \pm 0.04$ \\
$\mathbf{7 5 . 0}$ & $-5.51 \pm 0.09$ & $1.95 \pm 0.10$ \\
\hline
\end{tabular}

\subsection{Equilibria in solutions approaching real Bayer conditions}

\subsubsection{Complexation of $\mathrm{Gluc}^{-}$with $\mathrm{Ca}^{2+}$ in caustic solutions}

5.4.1.1. Multinuclear NMR measurements on the $\mathrm{Ca}^{2+} / \mathrm{Gluc}^{-}$binary systems in caustic solutions

The behavior of the gluconate ion in strongly alkaline solution has been studied to detect, if deprotonation of any alcoholic $\mathrm{OH}$ is possible to be observed. (Note, that in solutions of $\mathrm{pH}>6$, the carboxylic group is fully deprotonated.) In these calcium-free systems the concentration of the gluconate is kept constant $(0.2000 \mathrm{M})$ and the concentration of $\mathrm{NaOH}$ was raised from $0.1000 \mathrm{M}$ to $4.000 \mathrm{M}$.

The carbon signals exhibited downfield shift and can be described with saturation curves with increasing $\mathrm{NaOH}$ concentration $(\Delta \delta=0.20-2.45 \mathrm{ppm})$. An opposite variation of the proton signals is found (upfield shift) with the increasing $\mathrm{NaOH}$ concentration $(\Delta \delta=$ $0.25-0.35 \mathrm{ppm})$. These changes in the chemical shifts on icreasing $\mathrm{NaOH}$ concentration indicate that depronation of the alcoholic $\mathrm{OH}$ groups are likely to take place.

The investigation of the of the Gluc ${ }^{-}+\mathrm{Ca}^{2+}$ system has been continued with collection of further data in the presence of $1.00 \mathrm{M} \mathrm{NaOH}$ : the Gluc ${ }^{-}$concentration is held constant $0.0500 \mathrm{M}$ and the concentration of $\mathrm{CaCl}_{2}$ is systematically raised from $0.0000 \mathrm{M}$ to $0.2000 \mathrm{M}$. In these solutions solid material precipitated at $[\mathrm{NaGluc}]_{\mathrm{T}} /\left[\mathrm{CaCl}_{2}\right]_{\mathrm{T}}<1.25$. In solutions containing $0.0500 \mathrm{M} \mathrm{Gluc}^{-}$and various amount of $\mathrm{CaCl}_{2}(0.0000-0.0500 \mathrm{M})$ in $1.00 \mathrm{M}$ $\mathrm{NaOH}$ solid material precipitated at $[\mathrm{NaGluc}]_{\mathrm{T}} /\left[\mathrm{CaCl}_{2}\right]_{\mathrm{T}}<2$. The EDX spectrum of this material is seen in Figure 46. It is assumed that the precipitated material is primarily calcium hydroxide and contains some adsorbed gluconate or some sort of crystallized gluconate salt. 


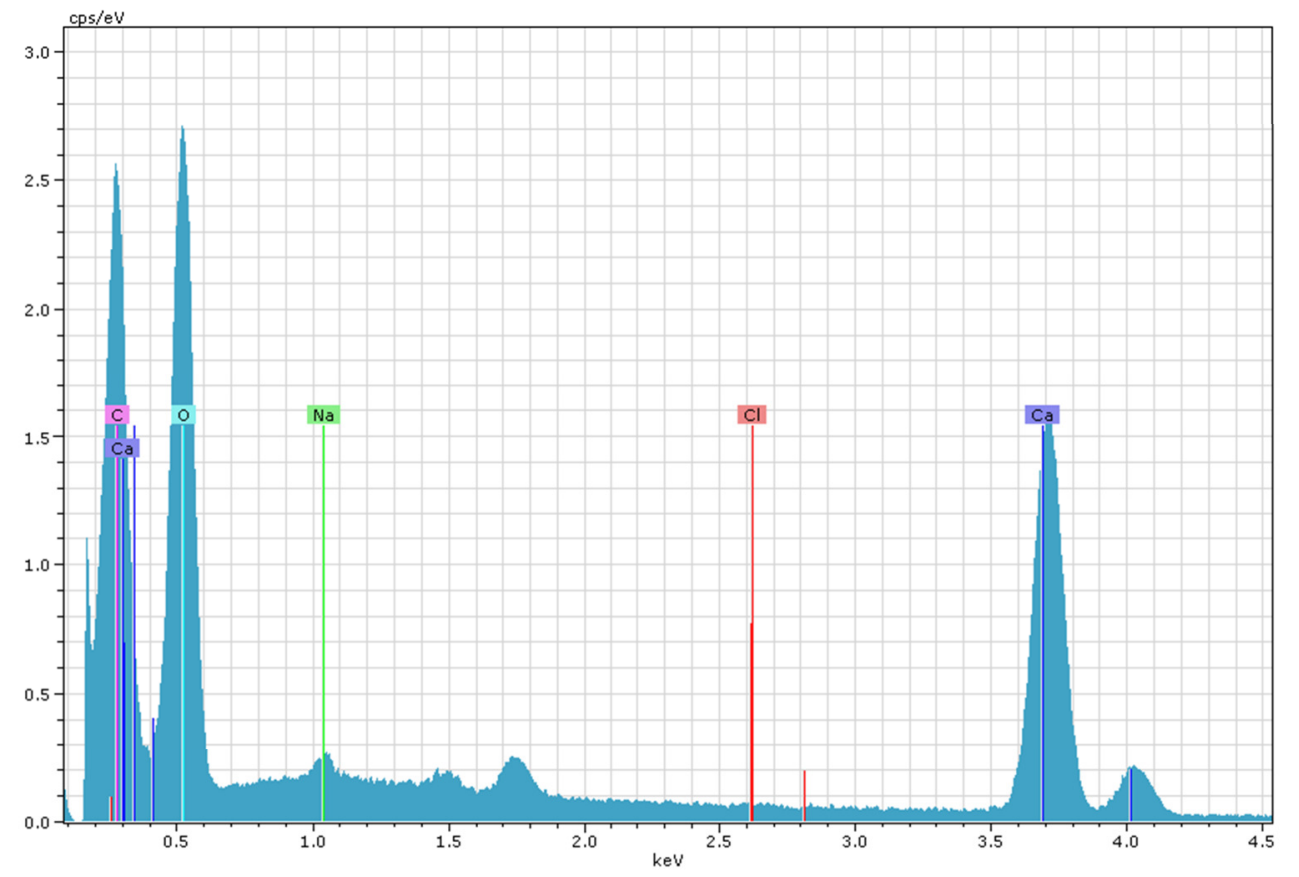

Figure 46: The EDX spectrum of the crystals precipitated from $[\mathrm{NaGluc}]_{T} /\left[\mathrm{CaCl}_{2}\right]_{T}<2$ systems at $[\mathrm{NaOH}]_{T}=1.00 \mathrm{M}$.

In the ${ }^{13} \mathrm{C}$ NMR spectra of these samples useful peaks cannot be detected, not even when the number of scans is increased from 256 to $4-8000$. In the ${ }^{43} \mathrm{Ca}$ NMR spectra no peaks are found. It is possible that the signal disappearance is due to extreme line broadening in the latter case.

With increasing calcium concentration significant downfield shift is seen in every proton signal (Figure 47). The downfield shifts for the $\mathrm{H} 2$ and $\mathrm{H} 3$ protons are small and rather uniform (from $\sim 4.04 \mathrm{ppm}$ to $\sim 4.08 \mathrm{ppm}$ and from $\sim 3.88 \mathrm{ppm}$ to $\sim 3.91 \mathrm{ppm}$, respectively), and (although the signals are quite congested) the same seems to be valid for protons H4-H6. Much more pronounced is the line broadening of each signal, in particular those of $\mathrm{H} 2$ and $\mathrm{H} 3$, i.e., $[\mathrm{NaGluc}]_{\mathrm{T}} /\left[\mathrm{CaCl}_{2}\right]_{\mathrm{T}}<2.00$ no $\mathrm{H} 3$ signal can be detected and a very broad feature is seen for $\mathrm{H} 2$. With increasing $\mathrm{Ca}^{2+}$ concentration, a broad feature at $\sim 4.25 \mathrm{ppm}$ emerges, most probably it belongs to the calcium-gluconate complex(es) at high $\mathrm{pH}$, which is in slow chemical exchange with the uncomplexed ligand. On the basis of the spectra collected so far, it is likely that the two binding sites for the $\mathrm{Ca}^{2+}$ ion are the alcoholates on $\mathrm{C} 2$ and $\mathrm{C} 3$ chelating the metal ion forming a highly stable complex compound. 


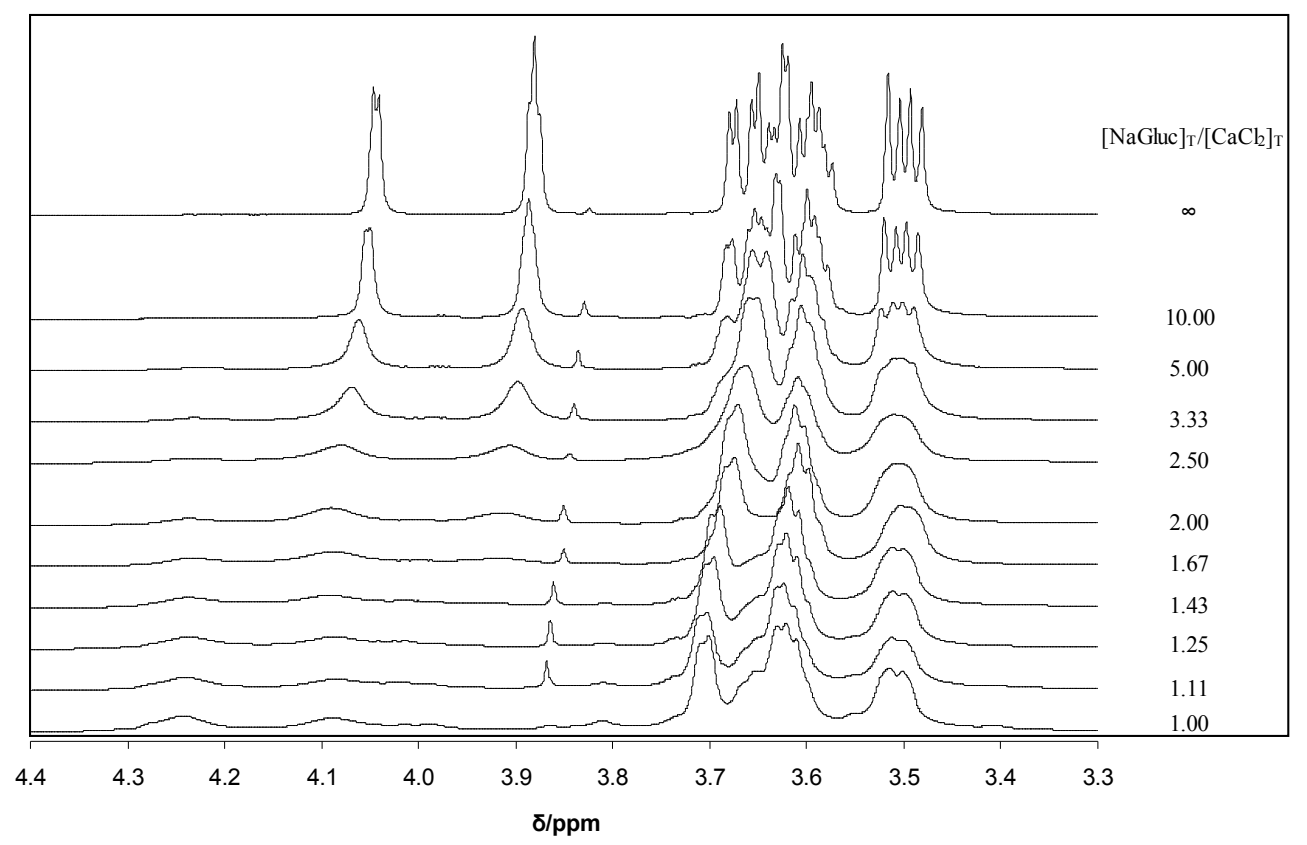

Figure 47: The variation in the ${ }^{1} \mathrm{H}$ NMR spectrum of $\mathrm{Gluc}^{-}$at various $[\mathrm{NaGluc}]_{T} /\left[\mathrm{CaCl}_{2}\right]_{T}$ ratios in solutions with $[\mathrm{NaOH}]_{T}=1.00 \mathrm{M}$ and $\left[\mathrm{Gluc}^{-}\right]_{T}=0.100 \mathrm{M}$ at $25^{\circ} \mathrm{C}$.

The temperature dependence study of this system in caustic solutions is presented in Figure 48. Data were collected in Gluc ${ }^{-}+\mathrm{Ca}^{2+}$ containing solutions in the presence of $1.00 \mathrm{M}$ $\mathrm{NaOH}$ of solution containing $0.2000 \mathrm{M} \mathrm{Gluc}^{-}$and $0.0800 \mathrm{M} \mathrm{CaCl}_{2}$ in the temperature range of $0-65{ }^{\circ} \mathrm{C}$.

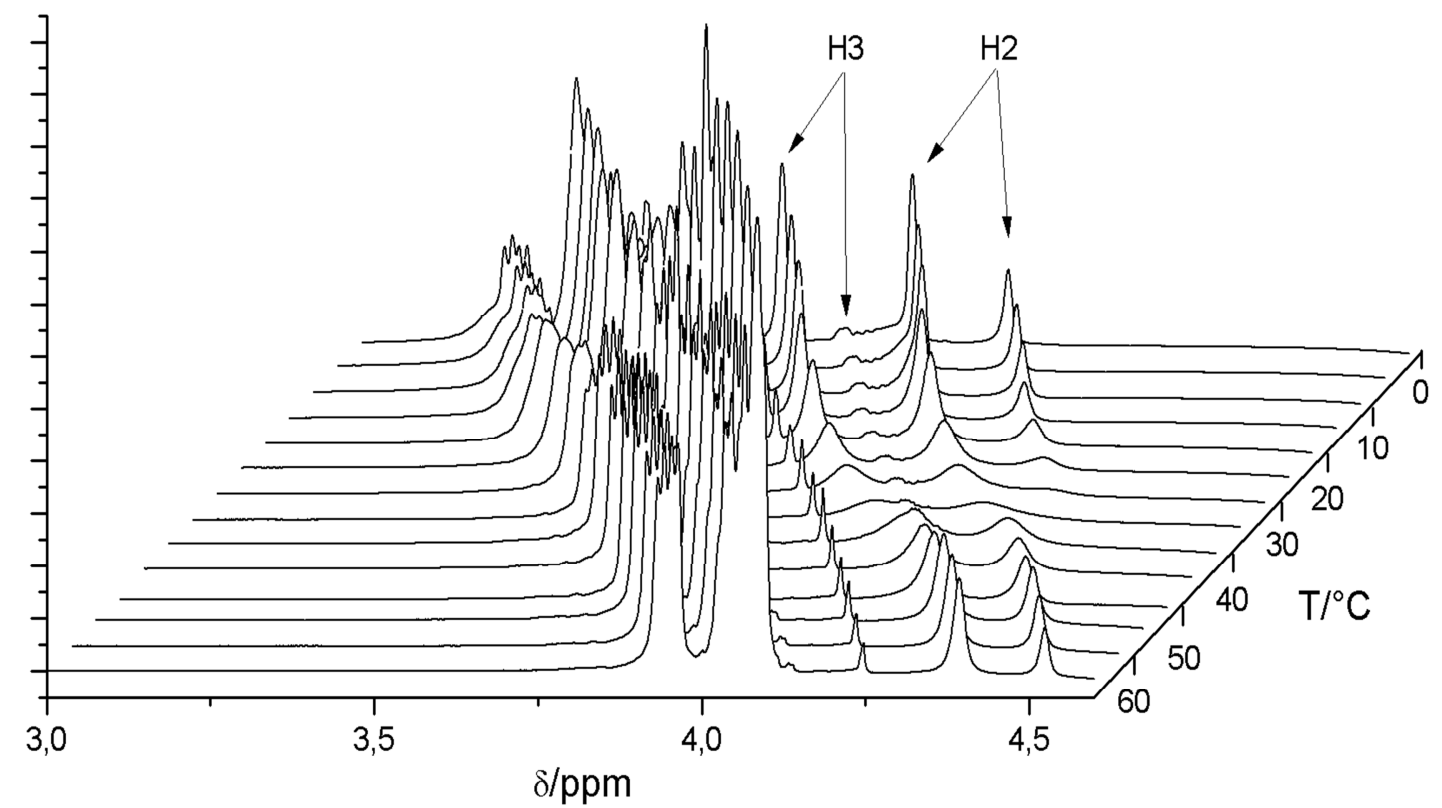

Figure 48: The ${ }^{1} \mathrm{H}$ NMR spectra of the solution containing $0.200 \mathrm{M} \mathrm{Gluc}^{-}$and $0.080 \mathrm{M} \mathrm{Ca}^{2+}$ in the presence of $1.000 \mathrm{MNaOH}$ at different temperatures 
The chemical exchange between the various forms of Gluc ${ }^{-}$at low temperatures $\left(0-15^{\circ} \mathrm{C}\right)$ is slow on the NMR time scale, therefore the signals of the $\mathrm{H} 2$ and $\mathrm{H} 3$ protons of Gluc ${ }^{-}$and that of the $\mathrm{Ca}$ complex (e.g., $\mathrm{CaGluc}^{-}$) appear separately. By raising the temperature the signals of both protons melt into the baseline $\left(25-35^{\circ} \mathrm{C}\right)$, and above $40-45^{\circ} \mathrm{C}$ the chemical exchange between the two types of gluconate became fast enough on the NMR time scale. This means that NMR spectroscopy can be useful to determine the stability constants of the complexes formed at temperatures relevant to Bayer liquors (that is: measurements at $\mathrm{I}=$ const. $\left[\mathrm{Gluc}^{-}\right]_{\mathrm{T}}=$ const. $\mathrm{T}=$ const. and varying $\left.\left[\mathrm{Ca}^{2+}\right]_{\mathrm{T}} /\left[\mathrm{Gluc}^{-}\right]_{\mathrm{T}}\right)$.

Regarding the structure of the high-pH calcium gluconate complex, these results strongly indicate, that the alcoholate groups on both the $\mathrm{C} 2$ and $\mathrm{C} 3$ carbons participate in $\mathrm{Ca}^{2+}$ binding. When 1:1 complex is only formed, the most likely structure is $\mathrm{CaGluc}^{+}$in which the metal ion is coordinated in a four-dentate manner via one carboxylate and two alcoholate. A similar structure has been observed in analogous systems with neutral and slightly alkaline $\mathrm{pH}$ (see Figure 23 on page 40$)$.

An interesting "side-product" of the work is that for the calcium-free sample very wellresolved ${ }^{1} \mathrm{H}$ NMR spectrum has been obtained in alkaline solutions (Figure 11 on page 27). For solutions of $\mathrm{pH}<11$, the double doublet of $\mathrm{H} 6$, and the $\mathrm{H} 4$ and $\mathrm{H} 5$ peaks of gluconate at $\sim 3.6 \mathrm{ppm}$ are usually unresolved. The well-resolved spectrum has been used for determining the proton-coupling constants of gluconate listed in Table 14.

Table 14: The average coupling constants for the gluconate protons in $\mathrm{Hz}$

\begin{tabular}{lllllll}
\hline & \multicolumn{6}{c}{$\mathrm{J} / \mathrm{Hz}$} \\
\cline { 2 - 7 } & H2 & H3 & H4 & H5 & H6 & H6' $^{*}$ \\
\hline H2 & & 3.1 & & & & \\
H3 & 3.1 & & 2.7 & & & \\
H4 & & 2.7 & & 6.9 & & \\
H5 & & & 6.9 & & 3.9 & 6.1 \\
H6 & & & 3.9 & & 11.4 \\
H6' & & & & 6.1 & 11.4 & \\
\hline
\end{tabular}

*H6 proton: 3.58-3.62 ppm; H6' proton: 3.41-3.45 ppm 


\subsubsection{Potentiometric titrations on the $\mathrm{Ca}^{2+} / \mathrm{Gluc}^{-}$binary systems}

For the $\mathrm{Ca}^{2+} / \mathrm{Gluc}^{-}$binary system seven titration curves have been fitted simultaneously. They can be divided into three groups on the basis of initial $\mathrm{Ca}^{2+}$ concentration, $\left[\mathrm{Ca}^{2+}\right]_{\mathrm{T}}$. In the first two (Figure 49, black and blue dots) the $\left[\mathrm{Ca}^{2+}\right]_{\mathrm{T}}:\left[\mathrm{Gluc}^{-}\right]_{\mathrm{T}}$ ratio is varied from 1:1.2 to $1: 3$ and $\left[\mathrm{Ca}^{2+}\right]_{\mathrm{T}}$ is equal to $0.0625 \mathrm{M}$ and $0.125 \mathrm{M}$, respectively. In the last (Figure 49, red dots) $\left[\mathrm{Ca}^{2+}\right]_{\mathrm{T}}$ is equal to $0.185 \mathrm{M}$ and the $\left[\mathrm{Ca}^{2+}\right]_{\mathrm{T}}:\left[\mathrm{Gluc}^{-}\right]_{\mathrm{T}}$ ratio is $1: 2$.

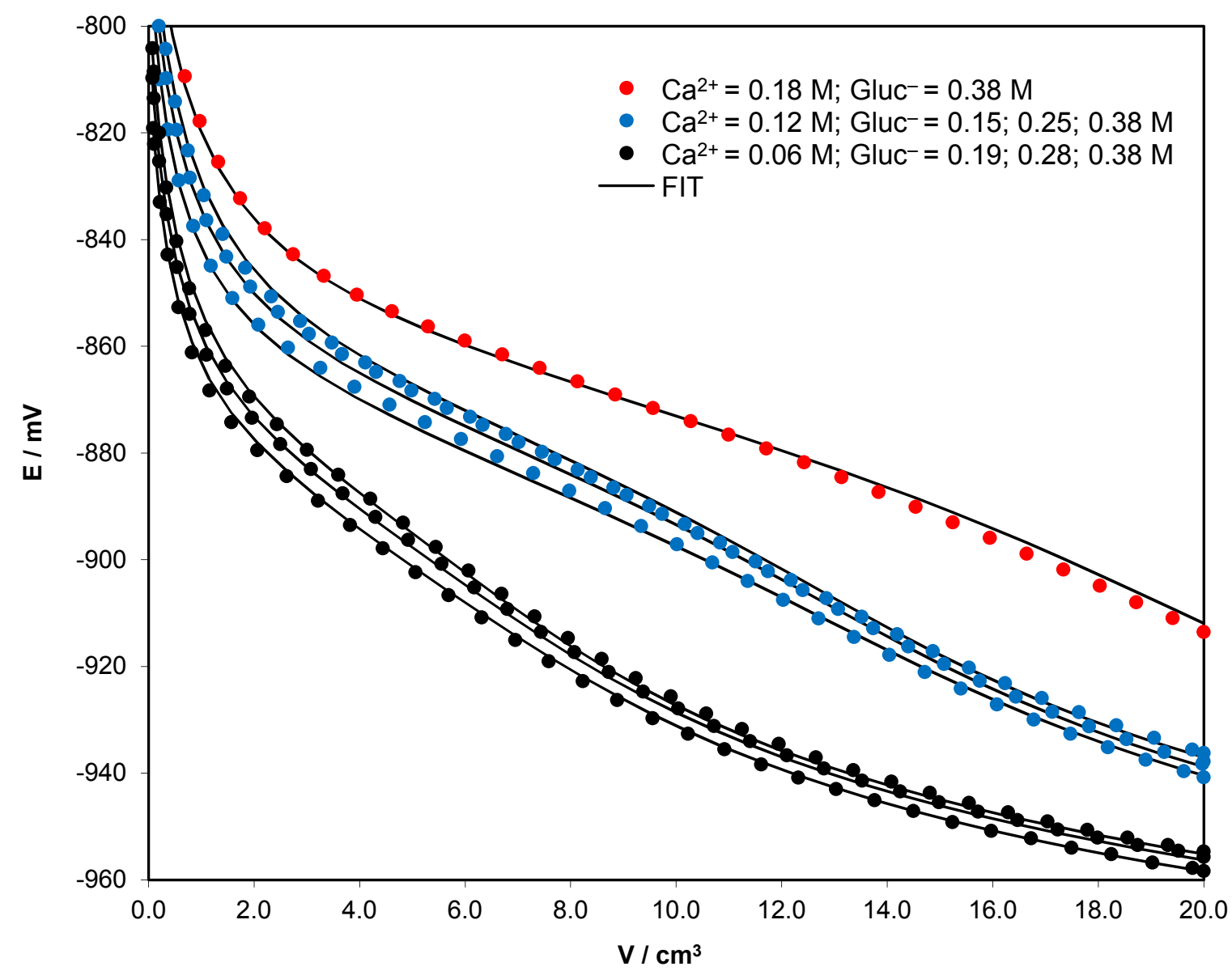

Figure 49: $\mathrm{H}_{2} / \mathrm{Pt}$-electrode potentiometric titration curves of the $\mathrm{Ca}^{2+} / \mathrm{Gluc}^{-}$binary systems. Dots represent observed EMF values, solid lines were fitted on the basis of the model discussed in the text. (Titrant: $1.00 \mathrm{NaOH} ; \mathrm{T}=25^{\circ} \mathrm{C}$ )

For the adequate fitting of the observed EMF values, 7 particles are needed to be simultaneously considered during the calculation. The stability constants of four particles $\left(\mathrm{GlucH}_{-1}{ }^{2-}, \mathrm{OH}^{-}, \mathrm{CaOH}^{+}, \mathrm{GlucH}_{-1}{ }^{2-}\right)$ are held constant and the stability constants of the other four particles are determined using the PSEQUAD software package. ${ }^{65}$ Beside the two mononuclear complexes $\left(\mathrm{CaGluc}^{+}\right.$and $\left.\mathrm{CaGlucH}_{-1}{ }^{0}\right)$ two further multinuclear complexes are needed for the model. The best agreement between the observed and the calculated data is 
achieved, when the $\left[\mathrm{Ca}_{2} \mathrm{Gluc}_{2} \mathrm{H}_{-3}\right]^{0}$ bi- and the $\left[\mathrm{Ca}_{3} \mathrm{Gluc}_{2} \mathrm{H}_{-4}\right]^{0}$ trinuclear complexes are included in the model. The calculations results in a good fit $(0.97 \mathrm{mV})$, and the stability constants are:

$$
\begin{array}{ll} 
& \mathrm{pKw}=13.76 \pm 0.01 \\
\mathrm{CaGluc}^{+} & \log \mathrm{K}_{110}=0.34 \pm 0.03 \\
\mathrm{CaGlucH}_{-1}{ }^{0} & \log \beta_{11-1}=-10.97 \pm 0.01(=2.79-13.76) \\
{\left[\mathrm{Ca}_{2} \mathrm{GlucH}_{-3}\right]^{0}} & \log \beta_{22-3}=-33.25 \pm 0.02(=8.03-3 \cdot 13.76) \\
{\left[\mathrm{Ca}_{3} \mathrm{Gluc}_{2} \mathrm{H}_{-4}\right]^{0}} & \log \beta_{32-4}=-42.65 \pm 0.04(=12.39-4 \cdot 13.76)
\end{array}
$$

The distribution of these $\mathrm{Ca}^{2+}$ containing species as a function of $\mathrm{pH}$ is presented in Figure 50.

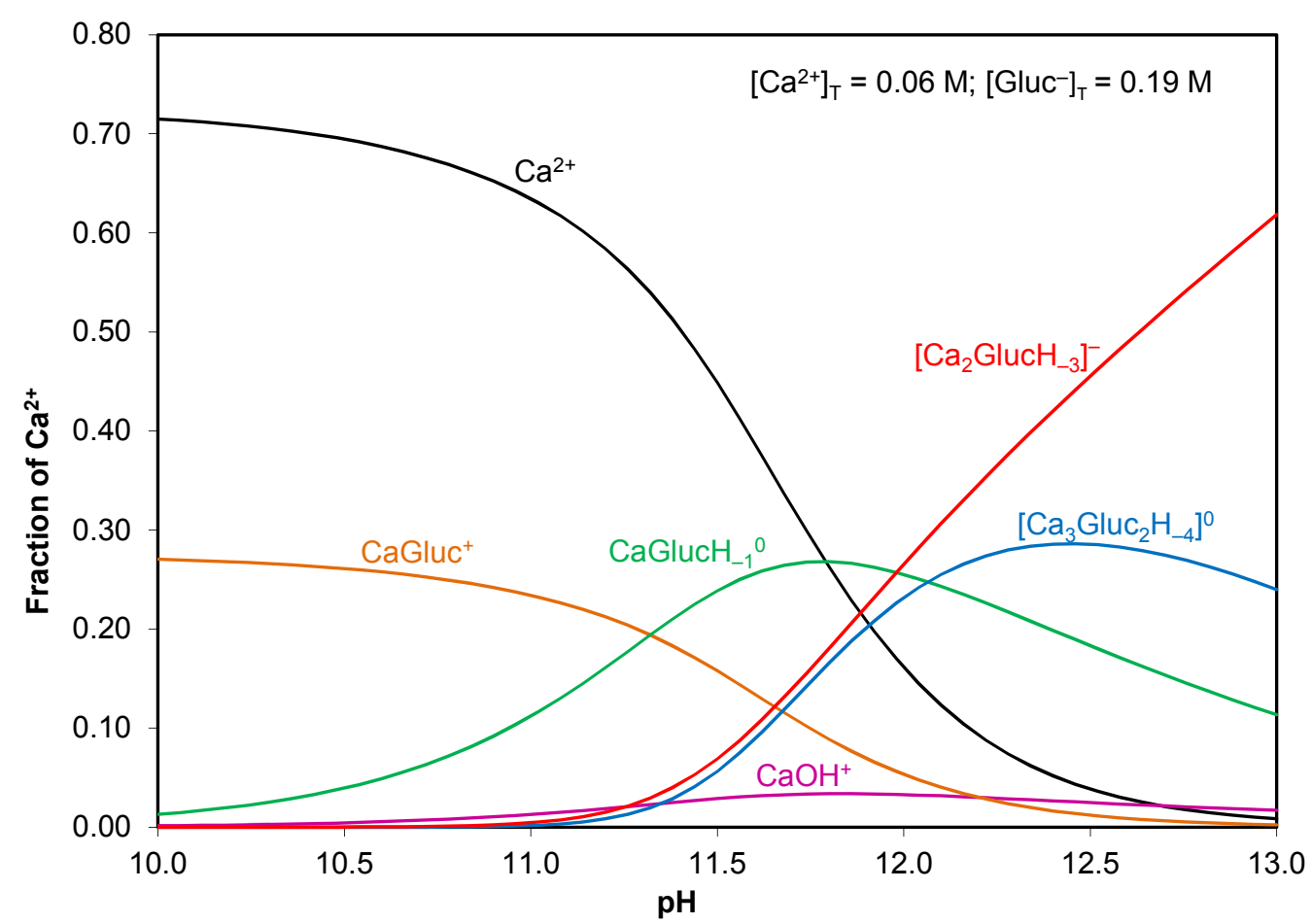

Figure 50: Distribution diagram of the $\mathrm{Ca}^{2+}$ containing species in the binary $\mathrm{Ca}^{2+} \mathrm{Gluc}^{-}$ system as a function of $\mathrm{pH}$

The stability constant of the $\mathrm{CaGluc}^{+}$described before $\left(\log \mathrm{K}_{110}=0.34 \pm 0.03\right)$ is different from that determined from the ${ }^{13} \mathrm{C}$ NMR measurements $\left(\log \mathrm{K}_{110}=0.99 \pm 0.05\right)$. The revision of the NMR measurements and of the relevant open literature $e^{29,31,35,37,38,41}$ revealed that from such type of measurements the stability constant of the $\mathrm{CaGluc}^{+}$could not be determined accurately and only a broad interval can reasonably be derived. The stability 
constant of this 1:1 complex is in the range of $\log \mathrm{K}_{110}=0.30-2.00$. We assume that the stability constant of $\mathrm{CaGluc}^{+}$can be refined by $\mathrm{Ca}-\mathrm{ISE}$ titrations.

\subsubsection{ESI-MS measurements on the high-pH $\mathrm{Ca}^{2+} / \mathrm{Gluc}^{-}$binary systems}

ESI-MS measurements on the $\mathrm{Ca}^{2+} / \mathrm{Gluc}^{-}$binary systems have been performed to confirm the formation of any of the polynuclear complexes $\left(\left[\mathrm{Ca}_{2} \mathrm{GlucH}_{3}\right]^{0}\right.$ and $\left[\mathrm{Ca}_{3} \mathrm{Gluc}_{2} \mathrm{H}_{-4}\right]^{0}$ ) that are required to have an adequate description of the potentiometric data points.

Two samples containing both $\mathrm{Ca}^{2+}$ and $\mathrm{Gluc}^{-}$have been analyzed using an ESI-MS apparatus. The concentration of the Gluc ${ }^{-}$is $0.005 \mathrm{M}$ and that of $\mathrm{Ca}^{2+}$ is set to $0.010 \mathrm{M}$ in both samples. In the first one the $\mathrm{pH}$ is raised above 12 using $25 \% \mathrm{NH}_{3}$ solution, and in the second the concentration of the $\mathrm{NaOH}$ is $0.065 \mathrm{M}$. Small concentrations like these are needed, because the salt concentration of the samples should not exceed $0.1 \mathrm{M}$ using when one uses ESI-MS.

The ESI-MS spectrum of the solution containing $0.005 \mathrm{M} \mathrm{Gluc}^{-}$and $0.010 \mathrm{M} \mathrm{Ca}^{2+}$ in $0.065 \mathrm{M} \mathrm{NaOH}$ medium and in negative ion mode is presented in Figure 51.

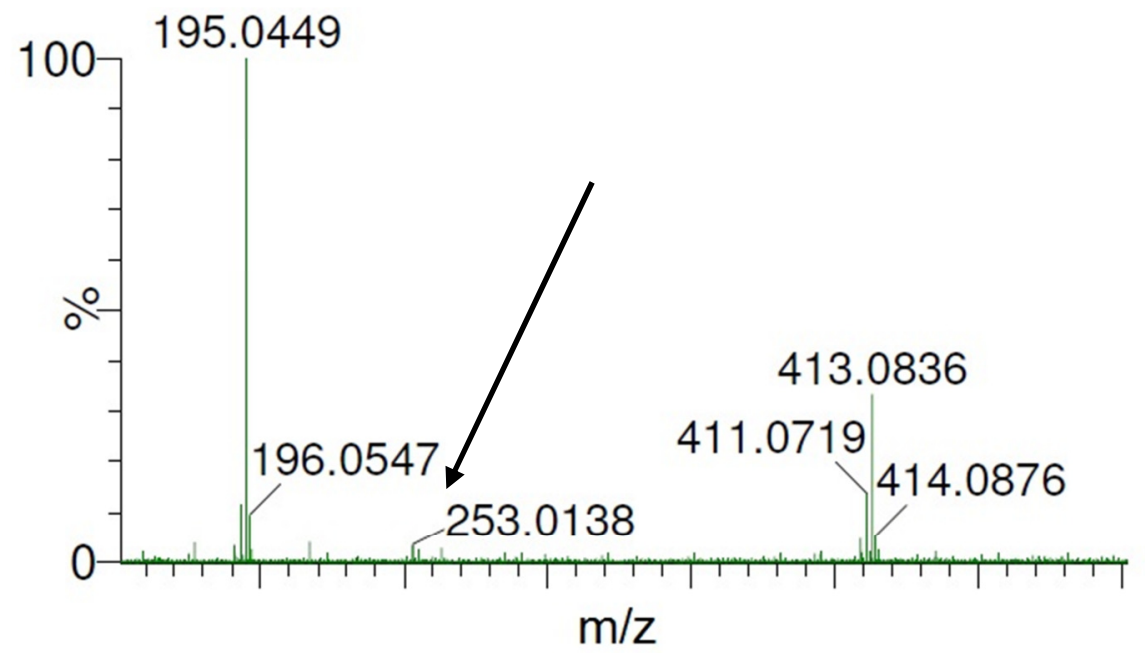

Figure 51: The ESI-MS spectrum of the solution containing $0.005 \mathrm{M} \mathrm{Gluc}^{-}$and $0.010 \mathrm{M}$ $\mathrm{Ca}^{2+}$ in $0.065 \mathrm{M} \mathrm{NaOH}$ medium; negative ion mode. The peak marked with black arrow refers to the $\left[\mathrm{Ca}_{3} \mathrm{Gluc}_{2} \mathrm{H}_{-4}\right]^{0}$ trinuclear complex.

The first signal, located at $195 \mathrm{~m} / \mathrm{z}$ value refers to the $\mathrm{Gluc}^{-}$and the ion at $413 \mathrm{~m} / \mathrm{z}$ signal can be built up from two Gluc ${ }^{-}$molecules and a $\mathrm{Na}^{+}$atom. Further peaks in Figure 51 which may belong to some polynuclear complex (e.g., $\left(\left[\mathrm{Ca}_{2} \mathrm{GlucH}_{-3}\right]^{0}\right.$ or $\left.\left[\mathrm{Ca}_{3} \mathrm{Gluc}_{2} \mathrm{H}_{-4}\right]^{0}\right)$ are located around $253 \mathrm{~m} / \mathrm{z}$ value. Since the molecular weight of the trinuclear complex 
$\left(\left[\mathrm{Ca}_{3} \mathrm{Gluc}_{2} \mathrm{H}_{-4}\right]^{0}\right)$ is $506 \mathrm{~g} \cdot \mathrm{mol}^{-1}$ and it is exactly twice of the value found in the MS spectra, it may be assumed, that the peak belongs to this trinuclear complex with two negative charges, which may easily form under the conditions of the measurements. This suggests that the formation of the $\left[\mathrm{Ca}_{3} \mathrm{Gluc}_{2} \mathrm{H}_{-4}\right]^{0}$ trinuclear complex in the $\mathrm{Ca}^{2+} / \mathrm{Gluc}^{-}$binary system is possible.

Structural model for the $\left[\mathrm{Ca}_{3} \mathrm{Gluc}_{2} \mathrm{H}_{-4}\right]^{0}$ trinuclear complex has also been built. The possible binding sites were chosen on the basis of NMR data (i.e., five- and six-membered chelate rings). Full geometric optimisation has been performed by Hartree-Fock $a b$ initio calculations applying the $6-31 \mathrm{G}^{* *}$ basis set.

The optimum geometry found for the $\left[\mathrm{Ca}_{3} \mathrm{Gluc}_{2} \mathrm{H}_{-4}\right]^{0}$ trinuclear complex is presented in Figure 52. The central $\mathrm{Ca}^{2+}$ is in bonding interactions with $\mathrm{O}(\mathrm{C} 1)$ and $\mathrm{O}(\mathrm{C} 2)$ of both $\mathrm{Gluc}^{-}$ molecules. The $\mathrm{Ca}-\mathrm{O}(\mathrm{C} 1)$ bonding distances are found to be equal for the two Gluc ${ }^{-}$ molecules $(240 \mathrm{pm})$ and the $\mathrm{Ca}-\mathrm{O}(\mathrm{C} 2)$ distances are $225 \mathrm{pm}$ and $230 \mathrm{pm}$. Each of the remaining two $\mathrm{Ca}^{2+}$ ions forms six-membered chelate with the $\mathrm{Gluc}^{-}$, entering into bonding interactions with $\mathrm{O}(\mathrm{C} 3)$ and the other carboxylic oxygen $\left(\mathrm{O}^{\prime}(\mathrm{C} 1)\right)$. The $\mathrm{Ca}-\mathrm{O}(\mathrm{C} 3)$ bonding distances are $218-219 \mathrm{pm}$, and the $\mathrm{Ca}-\mathrm{O}^{\prime}(\mathrm{C} 1)$ distance is found to be $229 \mathrm{pm}$.
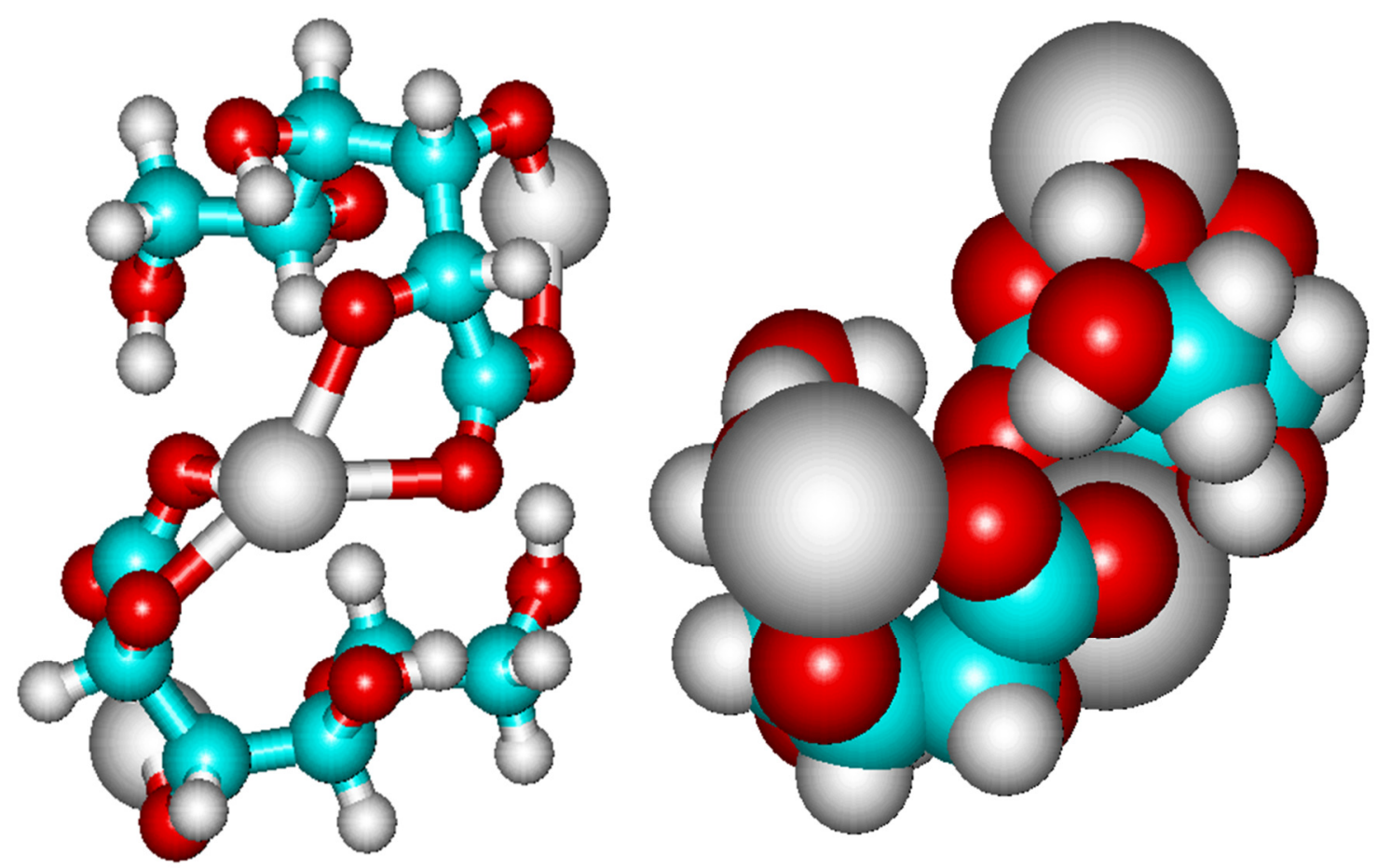

Figure 52: The optimum geometry of the $\left[\mathrm{Ca}_{3} \mathrm{Gluc}_{2} \mathrm{H}_{-4}\right]^{0}$ trinuclear complex applying two rendering types (ball-and-stick and spacefilling models)

It is to be noted, that this structure is in full agreement with the ${ }^{1} \mathrm{H}$ NMR findings. From those measurements, the extent of $\mathrm{Ca}^{2+}$ binding to alcoholates on $\mathrm{C} 2$ and $\mathrm{C} 3$ is different. This 
means that when only mononuclear complexes are formed, two binding isomers are most likely to coexist in solution. At reasonably high concentrations of both the metal ion and the ligand, the $\mathrm{Ca}^{2+}$ ion binds the two mononuclear complexes via forming a bridge and releasing two protons:

$$
2 \mathrm{CaGlucH}_{-1}^{0}+\mathrm{Ca}^{2+} \rightleftharpoons\left[\mathrm{Ca}_{3} \mathrm{Gluc}_{2} \mathrm{H}_{-4}\right]^{0}+2 \mathrm{H}^{+}
$$

5.4.1.4. X-ray absorption (XAS) measurements on the $\mathrm{Ca}^{2+} / \mathrm{Gluc}^{-}$binary system

Ca K-edge X-ray absorption spectra of an aqueous $\mathrm{CaCl}_{2}$ solution without added ligand at $\mathrm{pH}=7$ and two others with added $\mathrm{NaGluc}$ and $\mathrm{NaHglu}$ at $\mathrm{pH}=13$ were recorded. From such measurements the coordination environment of $\mathrm{Ca}^{2+}$ (that is, the coordination number and bond lengths) can be extracted.

For pure $\mathrm{CaCl}_{2}$, a coordination number of 8 and a square antiprism structure resulted in the best fit (Figure 53), and structural parameters, presented in Table 15, are in good agreement with literature data.

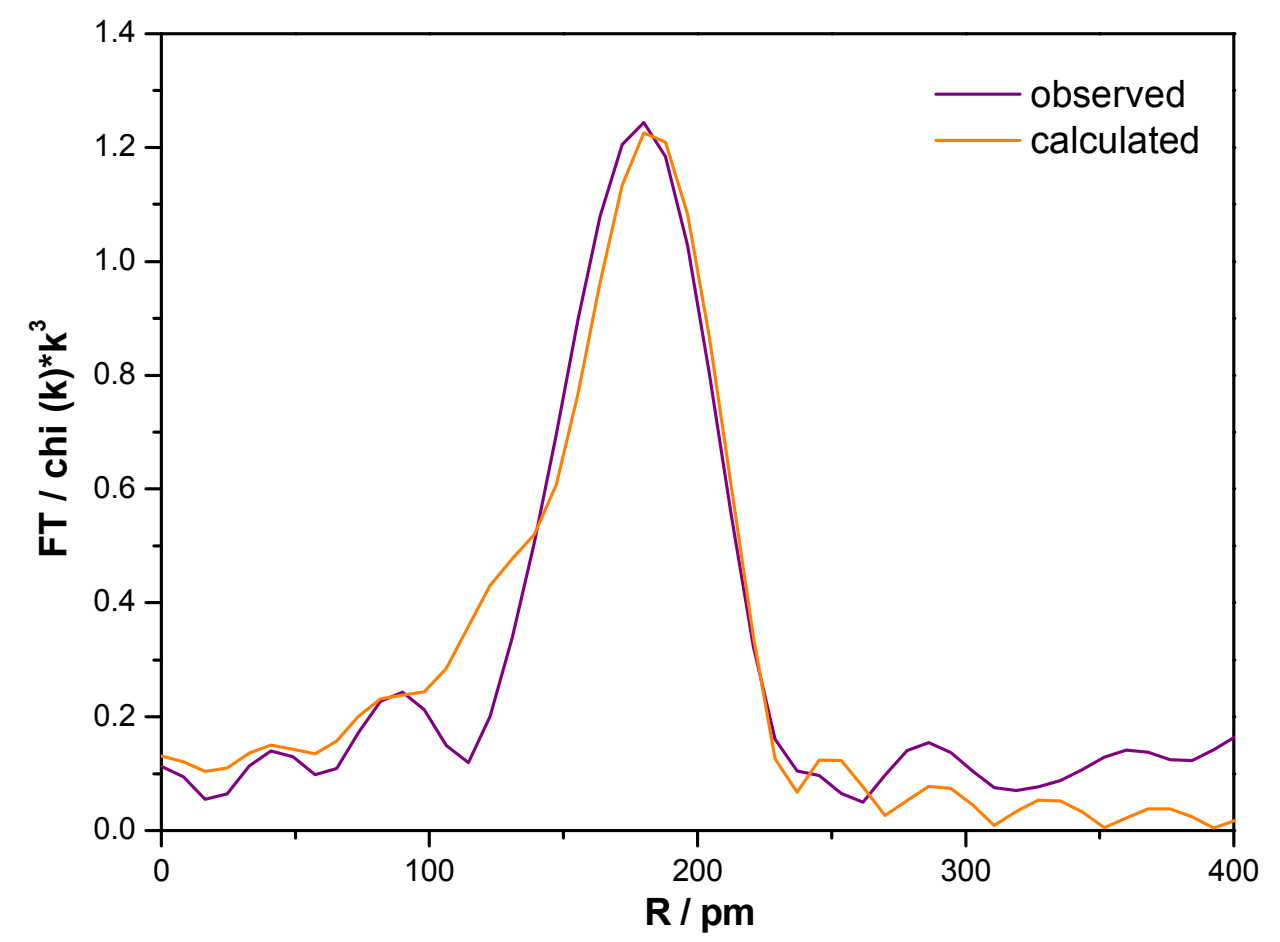

Figure 53: The pseudo-radial distribution function derived from the EXAFS spectrum of an aqueous solution containing $0.200 \mathrm{M} \mathrm{CaCl}_{2}$. 
Table 15: The structural parameters obtained for the $0.2 \mathrm{M} \mathrm{CaCl}_{2}$ solution

$N$ : coordination number; $R$ : bond length; $\sigma^{2}$ : Debye-Waller factor

\begin{tabular}{cccc}
\hline & $\mathbf{N}$ & $\mathbf{R} / \mathbf{p m}$ & $\boldsymbol{\sigma}^{2}$ \\
\hline $\mathbf{C a}-\mathbf{O}$ & 7.2 & 240 & 0.00962 \\
\hline
\end{tabular}

In the solution containing $0.200 \mathrm{M} \mathrm{CaCl}_{2}$ and $0.500 \mathrm{M} \mathrm{NaGluc}$ at $\mathrm{pH} \sim 13$, peaks stemming from the second coordination sphere of calcium can also be seen (Figure 54). As the scattering power of $\mathrm{O}$ and $\mathrm{C}$ atoms is far too low to cause an effect like this, it is suggested that under these experimental conditions multinuclear complexes are formed (hence the $\mathrm{Ca}-\mathrm{Ca}$ interactions are around $370 \mathrm{pm}$ in Table 16.) These findings appear to corroborate the conclusions of the potentiometric titrations in the binary $\mathrm{Ca}^{2+} / \mathrm{Gluc}^{-}$system (see above) and suggest, that XAS spectroscopy can be a powerful tool in elucidating the exact structure of the high-pH CaGluc solutions species. (It is to be noted here, however, that analogous $\mathrm{Ca}-\mathrm{Ca}$ pair interactions are not seen on the pseudo-radial distribution function of the solution with $0.200 \mathrm{M} \mathrm{CaCl}_{2}$ and $0.500 \mathrm{M} \mathrm{NaHglu}$ at $\mathrm{pH} 13$; since that at this stage we do not know too much about the high $\mathrm{pH}-\mathrm{CaHglu}$ complex, the relevance of this observation cannot be judged.)

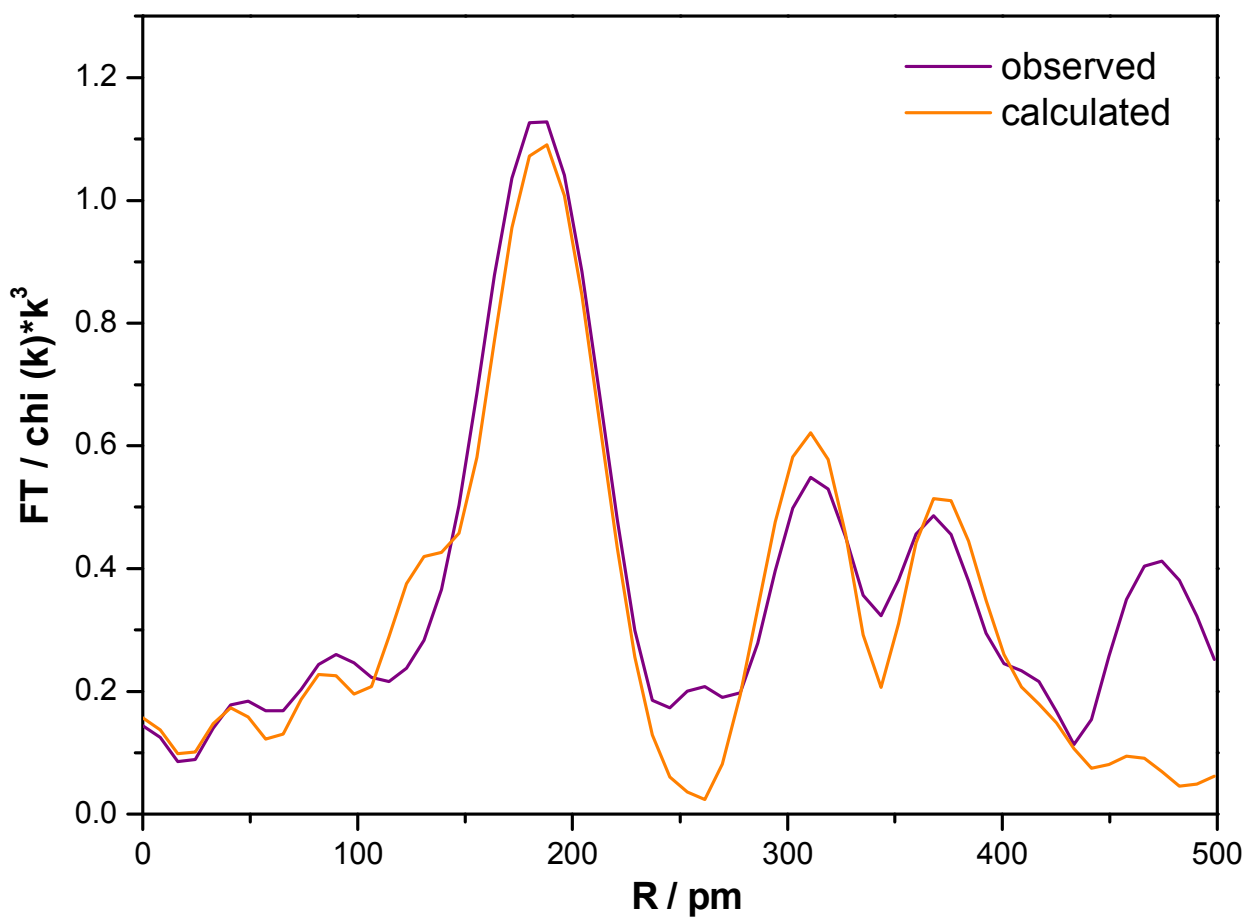

Figure 54: The pseudo-radial distribution function derived from the EXAFS spectrum of a solution containing $0.200 \mathrm{M} \mathrm{CaCl}_{2}$ and $0.500 \mathrm{M} \mathrm{NaGluc} \mathrm{at} \mathrm{pH} 13$ 
Table 16: The structural parameters of the solution containing $0.200 \mathrm{M} \mathrm{CaCl}_{2}$ and $0.500 \mathrm{M}$ NaGluc at $p H \sim 13$

N: coordination number; $R$ : bond length; $\sigma^{2}$ : Debye-Waller factor

\begin{tabular}{cccc}
\hline & $\mathbf{N}$ & $\mathbf{R} / \mathbf{p m}$ & $\boldsymbol{\sigma}^{2}$ \\
\hline $\mathbf{C a}-\mathbf{O}$ & 6.22 & 244 & 0.00952 \\
$\mathbf{C a}-\mathbf{C a}$ & 1.31 & 369 & 0.00016 \\
$\mathbf{C a}-\mathbf{O}$ & 4.73 & 431 & 0.00195 \\
\hline
\end{tabular}

\subsubsection{Complexation of $\mathrm{Gluc}^{-}$with $\mathrm{Al}(\mathrm{OH})_{4}^{-}$}

Two types of measurements were performed with the system containing both $\mathrm{Al}(\mathrm{OH})_{4}{ }^{-}$ and Gluc ${ }^{-}$. In the first one, the concentration of $\mathrm{Gluc}^{-}$was systematically raised (from 0.000 to $0.500 \mathrm{M}$ ) and the $\mathrm{Al}(\mathrm{OH})_{4}{ }^{-}$concentration was held constant at $0.100 \mathrm{M}$, while in the second, the Gluc ${ }^{-}$concentration was held constant at $0.1000 \mathrm{M}$ and the concentration of $\mathrm{Al}(\mathrm{OH})_{4}{ }^{-}$was systematically raised from zero to $0.500 \mathrm{M}$. In both series the $[\mathrm{NaOH}]_{\mathrm{T}}:[\mathrm{Al}(\mathrm{III})]_{\mathrm{T}}=2$ (constant).

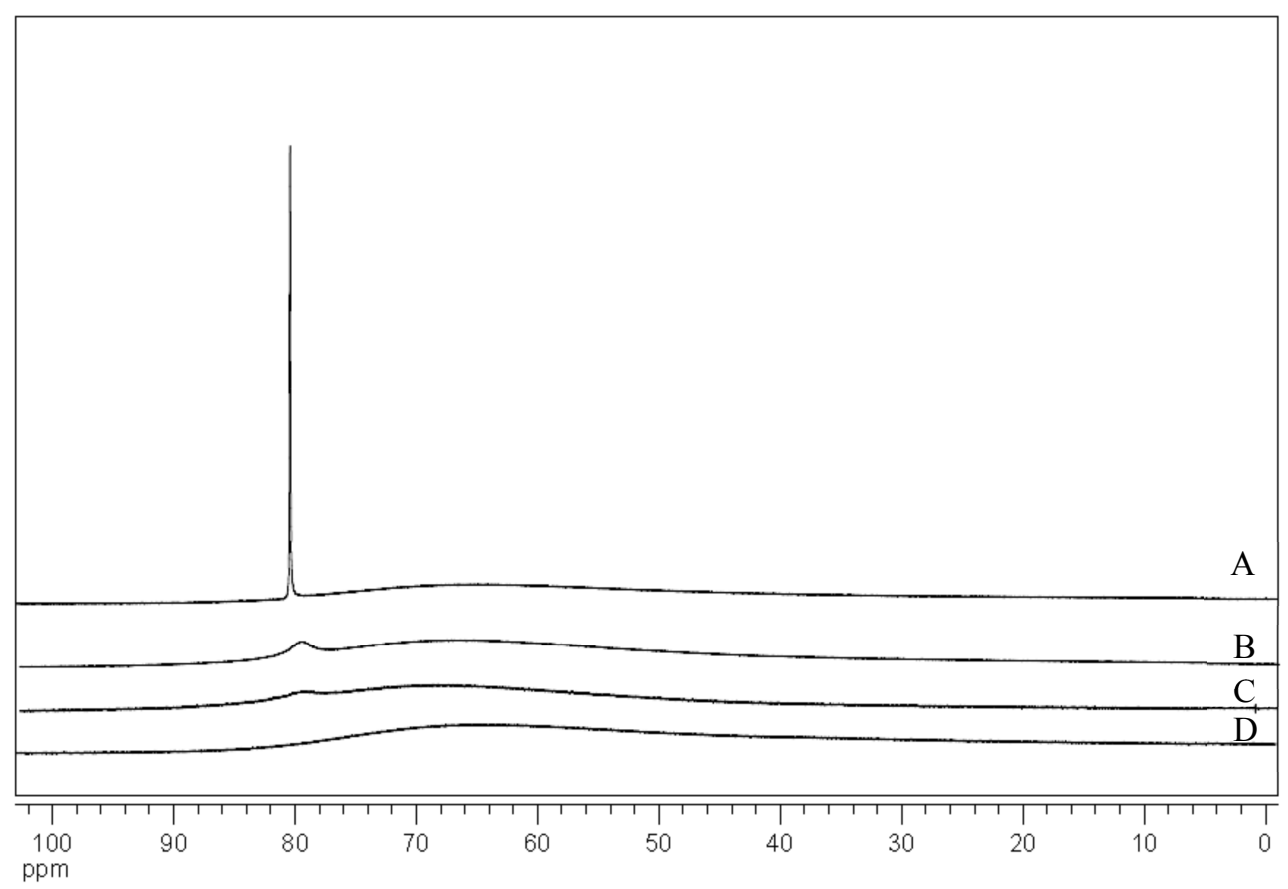

Figure 55: The ${ }^{27} \mathrm{Al} \mathrm{NMR} \mathrm{spectrum} \mathrm{of} \mathrm{a} 0.100 \mathrm{M} \mathrm{Al}(\mathrm{OH})_{4}{ }^{-}$in $0.200 \mathrm{M} \mathrm{NaOH}$ at various $\left[\mathrm{Gluc}^{-}\right]_{T} /\left[\mathrm{Al}(\mathrm{OH})_{4}^{-}\right]_{T}$ ratio $\left[\mathrm{Gluc}^{-}\right]_{T} /\left[\mathrm{Al}(\mathrm{OH})_{4}{ }^{-}\right]_{T}=0.0(\mathrm{~A}) ; 1.0(\mathrm{~B}) ; 2.0(\mathrm{C}) ; 5.0(\mathrm{D})$ 
The first ${ }^{27} \mathrm{Al}$ NMR spectrum series obtained at constant concentration of $\mathrm{Al}(\mathrm{OH})_{4}{ }^{-}$can be seen in Figure 55. Only one (if any) signal is detected, proving that the chemical exchange between the various forms of $\mathrm{Al}(\mathrm{III})$ is fast on the NMR timescale. The very broad feature between 50 and $80 \mathrm{ppm}$ is associated with the Al-content of the sample holder. This baseline needs to be subtracted from each spectrum before peak integration can be performed. Regarding the position of the aluminate peak, a small but significant upfield shift ( $\sim 1 \mathrm{ppm})$ is seen with increasing Gluc ${ }^{-}$concentration. More importantly, substantial line broadening can be detected, and at $\left[\mathrm{Gluc}^{-}\right]_{\mathrm{T}} /\left[\mathrm{Al}(\mathrm{OH})_{4}{ }_{\mathrm{T}}>2.00\right.$, the signal melts into the baseline.

${ }^{1} \mathrm{H}$ and ${ }^{13} \mathrm{C}$ NMR spectra of these samples were also recorded. In the ${ }^{13} \mathrm{C}$ NMR spectra no carbon signals were detected even after 8192 scans (approx. 7.5 hours). ${ }^{13} \mathrm{C}$ NMR spectra of $\mathrm{Al}(\mathrm{OH})^{-}$and $\mathrm{Gluc}^{-}$containing solutions have been recorded on a Bruker Avance $600 \mathrm{NMR}$ spectrometer too. Similarly to the first series, no carbon signals can be detected in the spectra.

One of the typical ${ }^{1} \mathrm{H}$ NMR spectra is presented in Figure 56. The ${ }^{1} \mathrm{H}$ NMR spectrum reveals that upon $\mathrm{Al}(\mathrm{III})$ addition, both the multiplicity and the shape of the multiplets change significantly.

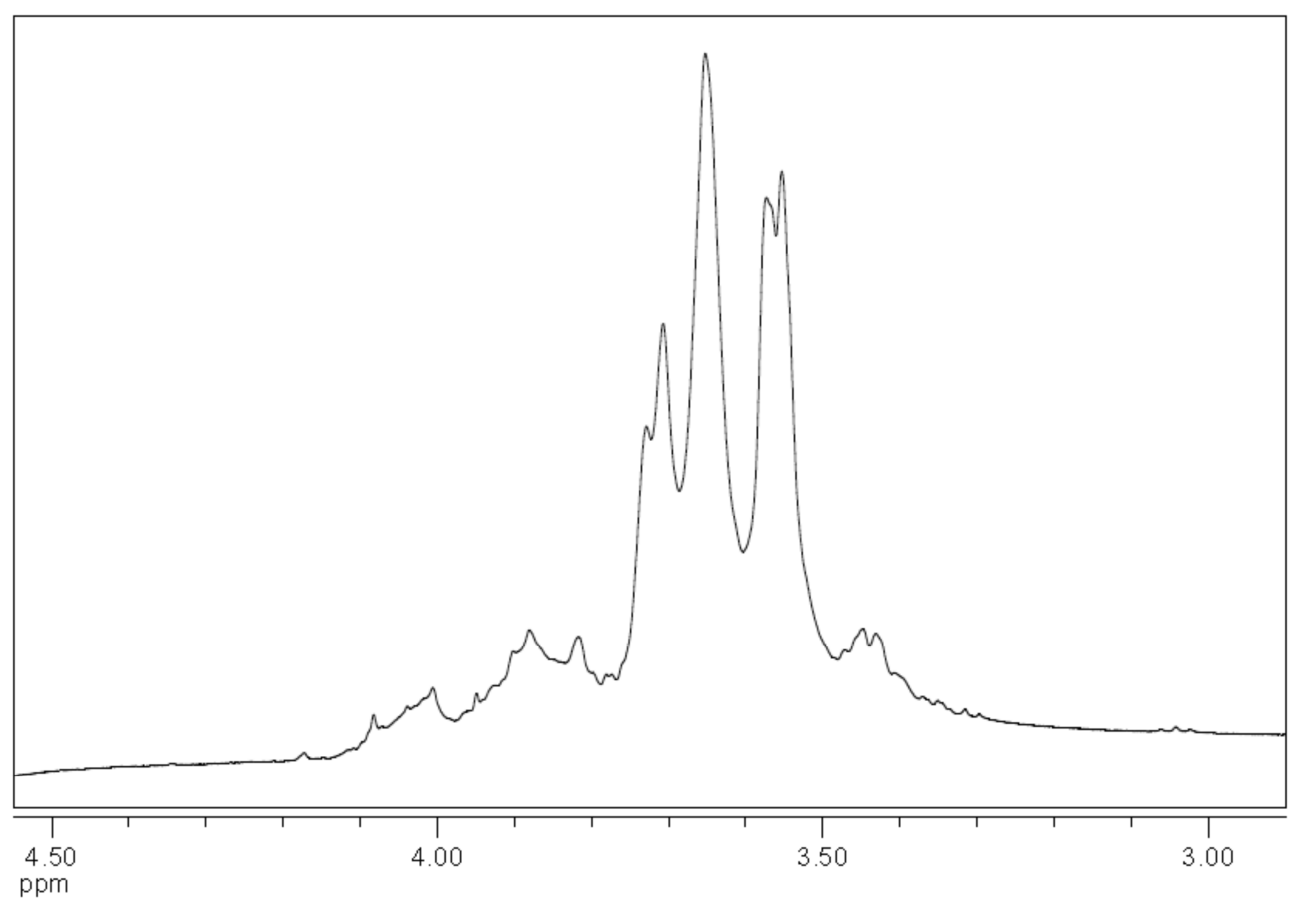

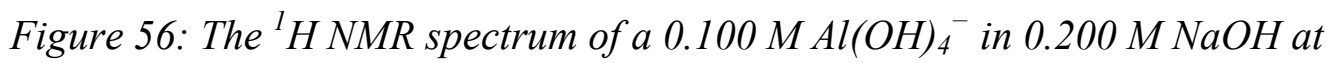
$\left[\mathrm{Gluc}^{-}\right]_{T} /\left[\mathrm{Al}(\mathrm{OH})_{4}^{-}\right]_{T}=1.0$ (Compare with spectrum presented in Figure 11 on the page 27).

From these NMR experiments, its seems plausible that (in spite of strong indications published in the literature ${ }^{47}$ ) $\mathrm{Al}(\mathrm{III})$ ions do form solution complex(es) with the $\mathrm{Gluc}^{-}$ion, even in strongly alkaline solutions. 
In order to study the interaction between $\mathrm{Al}(\mathrm{OH})^{-}$and $\mathrm{Gluc}^{-}$, a new series of solutions was prepared. In this series the Gluc concentration was systematically raised from zero to $0.400 \mathrm{M}$, and the analytical concentration of $\mathrm{Al}(\mathrm{OH})_{4}{ }^{-}$and $\mathrm{NaOH}$ was held constant at $0.200 \mathrm{M}$ and $0.400 \mathrm{M}$, respectively.

Complexation can (in principle) be followed by the ${ }^{27} \mathrm{Al}$ NMR spectra. The very broad feature between 50 and $80 \mathrm{ppm}$, associated with the Al-content of the sample holder, is subtracted from each ${ }^{27} \mathrm{Al}$ NMR spectra recorded using the software 'SpinWorks 3'. In these baseline-corrected spectra, by raising the $\mathrm{Gluc}^{-}$concentration the variation of the Full Width at the Half-Height (FWHH) systematically increases (Figure 57). There are indications in the literature $^{75}$ that (under well-defined circumstances) variations like these can be used to obtain stability constants. This is, however, complicated by the fact that viscosity variations also cause change in the FWHH of the ${ }^{27} \mathrm{Al}$ NMR lines, which must be corrected for.

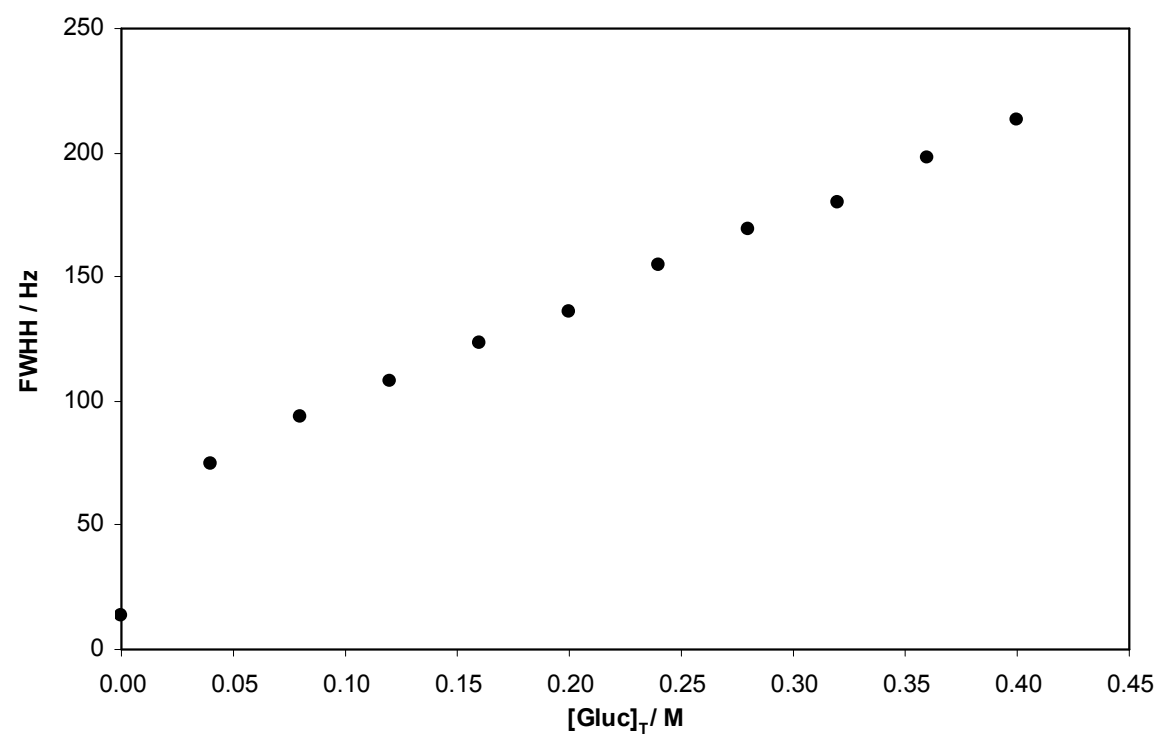

Figure 57: The variation of the FWHH of Al on the ${ }^{27} \mathrm{Al}$ NMR spectra with rising Gluc concentration in solutions of $\left[\mathrm{Al}(\mathrm{OH})_{4}{ }^{-}\right]_{T}=0.200 \mathrm{M}$ and $[\mathrm{NaOH}]_{T}=0.400 \mathrm{M}$

${ }^{1} \mathrm{H}$ NMR spectra of a solution containing $0.200 \mathrm{M} \mathrm{Gluc}^{-}, 0.200 \mathrm{Al}(\mathrm{OH})_{4}^{-}$and $0.400 \mathrm{M}$ $\mathrm{NaOH}$ have been recorded in the temperature range of $0-60{ }^{\circ} \mathrm{C}$ (Figure 58). The results show that the chemical exchange between the various types of Gluc ${ }^{-}$above $40-45^{\circ} \mathrm{C}$ is fast on the NMR time scale. 


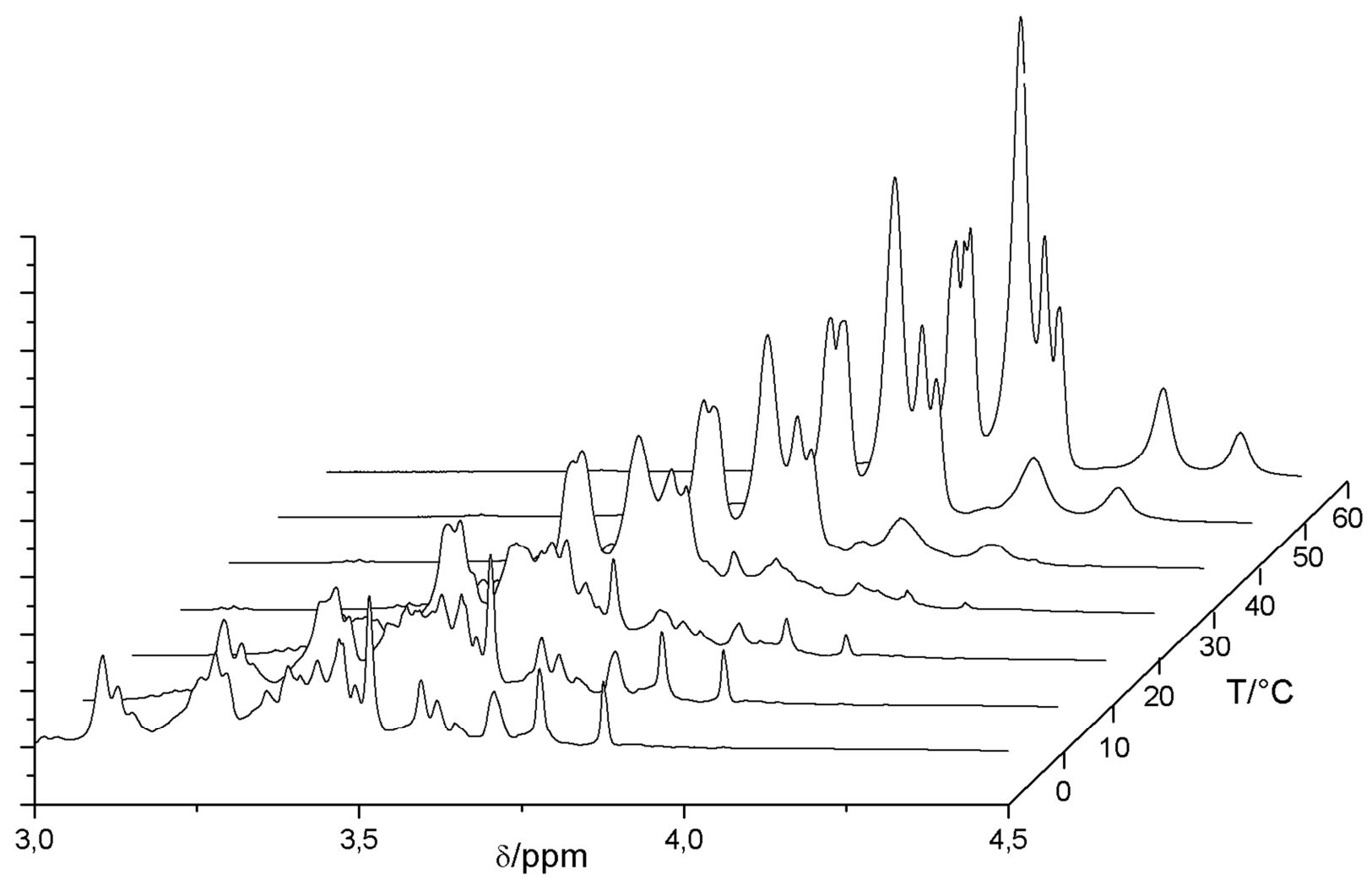

Figure 58: The ${ }^{1} \mathrm{H}$ NMR spectra of the solution containing 0.200 $\mathrm{M} \mathrm{Gluc}^{-}, 0.200 \mathrm{M} \mathrm{Al}(\mathrm{OH})_{4}^{-}$ and $0.400 \mathrm{MNaOH}$ at different temperatures

In alkaline solutions containing $\mathrm{Gluc}^{-}$and $\mathrm{Al}(\mathrm{OH})_{4}{ }^{-}$the chemical exchange is slow between the free and complexed ligand on the NMR timescale up to $50{ }^{\circ} \mathrm{C}$ (Figure 58); at temperatures close to ambient, the spectra are very complex and difficult to resolve to the peaks of the complexed and uncomplexed ligands. Formation constants for the complexes can be extracted from data collected at temperatures $\geq 50{ }^{\circ} \mathrm{C}$ (fast-exchange region), noting that here, the variations in the chemical shifts upon complexation are not very large (i.e. these measurements may not be suitable to provide accurate thermodynamic data).

For assigning the ${ }^{1} \mathrm{H}$ NMR signals of Gluc ${ }^{-}$in solution containing $\mathrm{Al}(\mathrm{OH})_{4}{ }^{-}$four types of two-dimensional spectra have been recorded. These methods were COSY (Correlation Spectroscopy), NOESY (Nuclear Overhauser Effect Spectroscopy), HSQC (Heteronuclear Single Quantum Coherence) and HMBC (Heteronuclear Multiple Bond Correlation). Unfortunately, they have not proved to be informative.

As a next step, room-temperature ${ }^{1} \mathrm{H}$ NMR spectra at various $\mathrm{Al}(\mathrm{OH})_{4}{ }^{-}$concentrations $(0-0.20 \mathrm{M})$ and constant $\left[\mathrm{Gluc}^{-}\right]_{\mathrm{T}}(0.20 \mathrm{M})$ and $\left[\mathrm{OH}^{-}\right]_{\mathrm{T}}(0.20 \mathrm{M})$ have been recorded. From Figure 59 it can be seen, that several new spectral features emerge with increasing aluminate concentration (the most prominent are those at 4.13, 4.05, 3.92 and 3.78 ppm, marked by 
squares in Figure 59): these peaks are very much likely to be associated with the complexed ligands as they are absent in the spectra of the uncomplexed Gluc ${ }^{-}$. Quantitative data can only be obtained, if these peaks were accurately integrated (as peak areas are linearly proportional to the concentration of the complexed ligand). However, accurate integration is hampered by the ill-defined baseline for the 4.05, 3.92 and 3.78 ppm peaks, and accuracy is questionable for the one at $4.13 \mathrm{ppm}$ due to its small intensity.

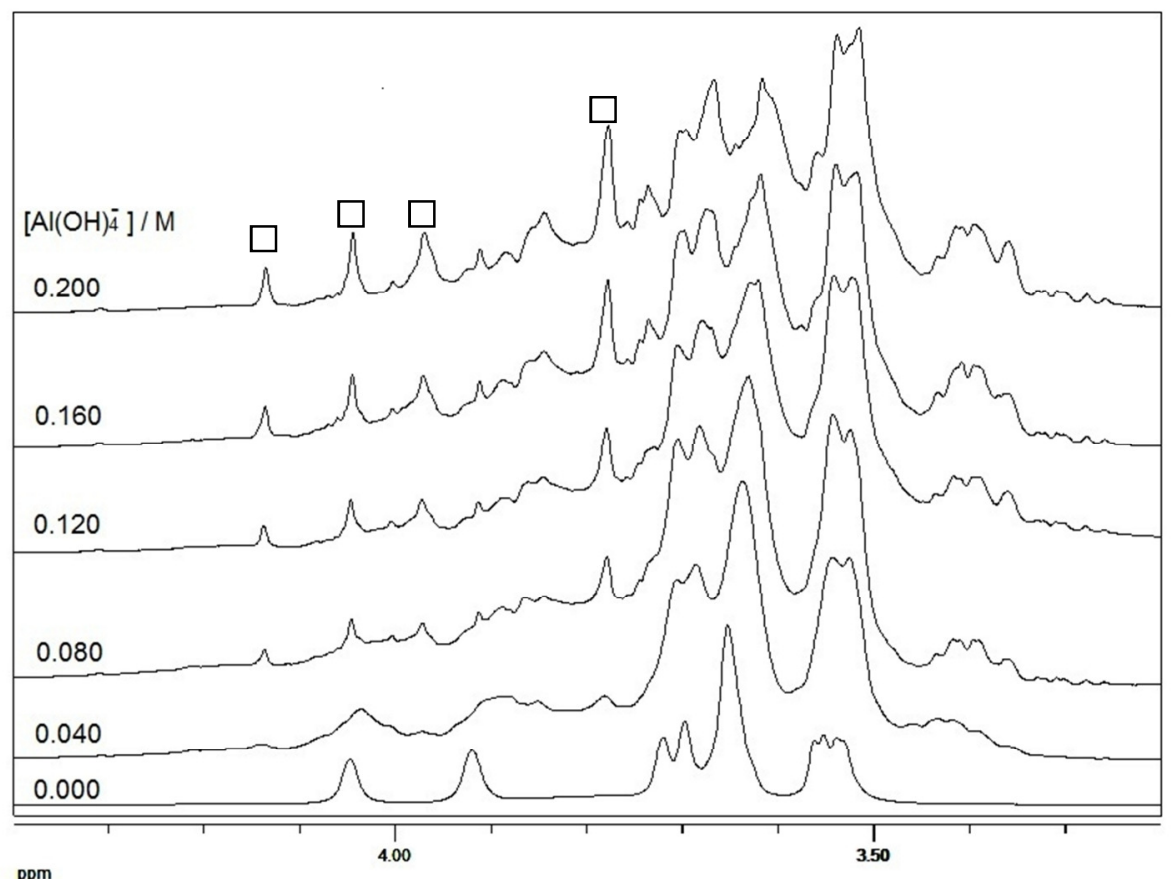

Figure 59: One-dimensional ${ }^{1} \mathrm{H}$ NMR spectra of solutions with constant $\left[\mathrm{Gluc}^{-}\right]_{T}(0.20 \mathrm{M})$ and $\left[\mathrm{OH}^{-}\right](0.20 \mathrm{M})$ and varying $\left[\mathrm{Al}(\mathrm{OH})_{4}^{-}\right]_{T}$ (from the bottom to top, from 0 to $0.20 \mathrm{M}$, in 0.04 M increments)

Further ${ }^{1} \mathrm{H}$ NMR measurements at various $\mathrm{Al}(\mathrm{OH})_{4}{ }^{-}$concentrations $(0.00-0.40 \mathrm{M})$ and constant $\left[\mathrm{Gluc}^{-}\right]_{\mathrm{T}}(0.20 \mathrm{M})$ and $\left[\mathrm{OH}^{-}\right]_{\mathrm{T}}(1.00 \mathrm{M})$ have been recorded. The ${ }^{1} \mathrm{H}$ NMR protocol is set that the integration of the peaks associated with the complexed ligands can accurately be performed. Because of the intense ${ }^{1} \mathrm{H}$ NMR signal of water using this protocol, the accurate integration of the aforementioned peaks is difficult. The baseline of the analyzed peaks is determined by fitting four baseline anchor points. The area of the integrated ${ }^{1} \mathrm{H}$ NMR signal at $\sim 4.05 \mathrm{ppm}$ as a function of the $\mathrm{Al}(\mathrm{OH})_{4}{ }^{-}$concentration is presented in Figure 60 . 


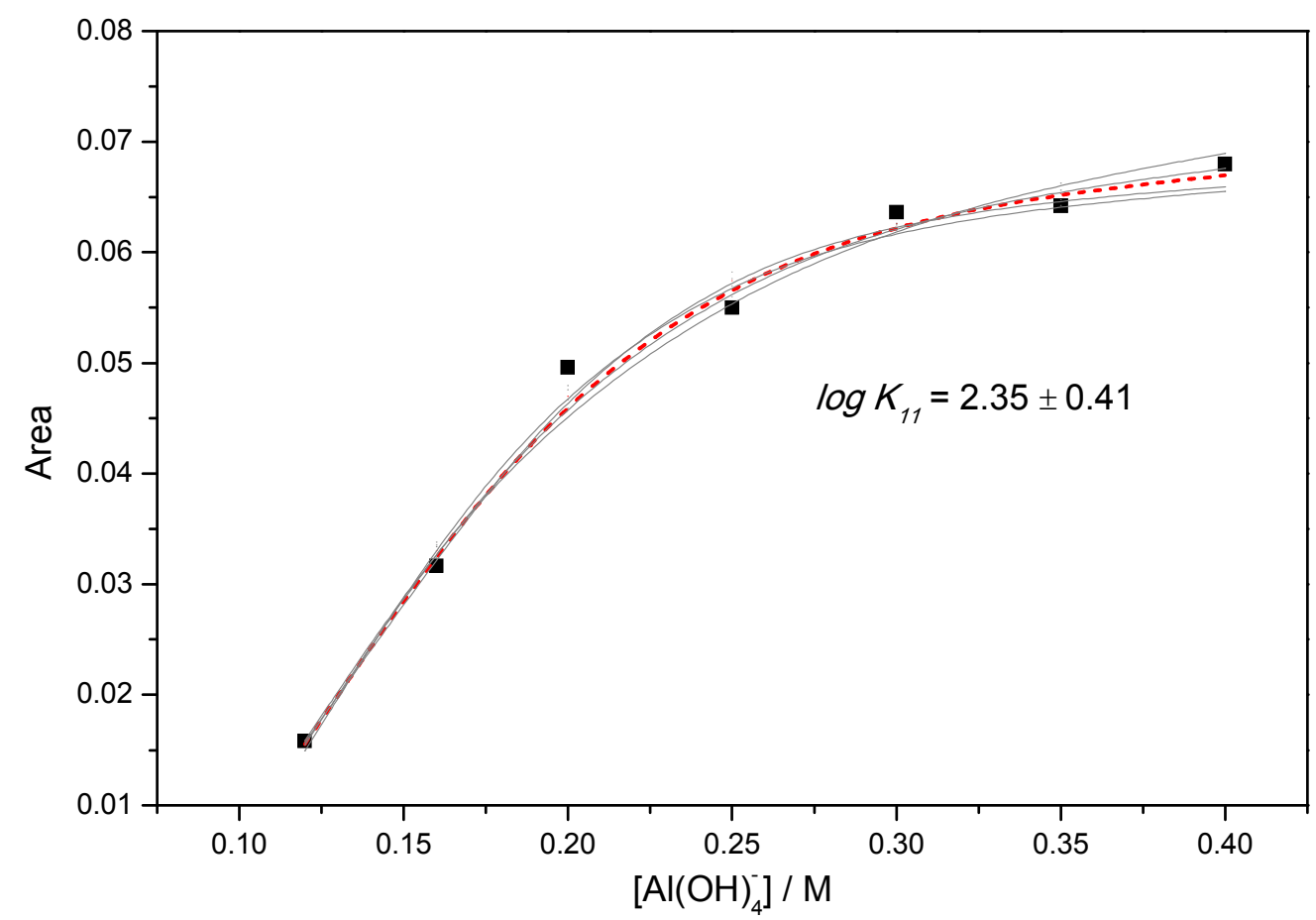

Figure 60: The area of the ${ }^{1} H$ NMR signal at $\sim 4.05 \mathrm{ppm}$ in the function of the total concentration of $\mathrm{Al}(\mathrm{OH})_{4}{ }^{-}$

From the $\left[\mathrm{Al}(\mathrm{OH})_{4}{ }^{-}\right] v s$. area curves, the stability constant has been estimated using the PSEQUAD software package. ${ }^{65}$ The area of the ${ }^{1} \mathrm{H}$ NMR peak at $0.00 \mathrm{M} \mathrm{Al}(\mathrm{OH})_{4}{ }^{-}$cannot be fixed, because the baseline determined does not coincide with the absolute baseline of the ${ }^{1} \mathrm{H}$ NMR spectra. The area of the $\sim 4.05 \mathrm{ppm}$ proton signal can be described with a saturation curve with increasing $\mathrm{Al}(\mathrm{OH})_{4}{ }^{-}$concentration. Calculations have been performed by holding the saturation value of the peak area at different constant values, to provide upper and lower limit of the stability constant. The average of stability constants from the different calculations is found to be $\log \mathrm{K}_{11}=2.3 \pm 0.4$. The stability constants of the complex forming in alkaline solutions at $\left[\mathrm{OH}^{-}\right]_{\mathrm{T}}=0.50 \mathrm{M}$ and $\left[\mathrm{OH}^{-}\right]_{\mathrm{T}}=1.67 \mathrm{M}$ have also been determined. Calculations have been performed without holding the saturation value of the peak area at this time. The ${ }^{1} \mathrm{H}$ NMR peaks selected are $\sim 3.92 \mathrm{ppm}\left(\left[\mathrm{OH}^{-}\right]_{\mathrm{T}}=0.50 \mathrm{M}\right)$ and $\sim 3.84 \mathrm{ppm}\left(\left[\mathrm{OH}^{-}\right]_{\mathrm{T}}\right.$ $=1.67 \mathrm{M})$. The stability constants are $\log \mathrm{K}_{11}=2.4 \pm 0.5$ and $\log \mathrm{K}_{11}=2.7 \pm 0.4$ in systems with $\left[\mathrm{OH}^{-}\right]_{\mathrm{T}}=0.50 \mathrm{M}$ and $\left[\mathrm{OH}^{-}\right]_{\mathrm{T}}=1.67 \mathrm{M}$, respectively, indicating that binding of aluminate to gluconate in alkaline solutions is a $\mathrm{pH}$ independent process.

Potentiometric measurements on the $\mathrm{Al}(\mathrm{OH})_{4}{ }^{-} / \mathrm{Gluc}^{-}$binary systems have also been performed. The titration curves of the solutions containing $\mathrm{Al}(\mathrm{OH})_{4}{ }^{-} / \mathrm{Gluc}^{-}$are almost perfectly superimposable with those of the identical, but Gluc ${ }^{-}$only (aluminate free) systems in the relevant $\mathrm{pH}$ range $(\mathrm{pH}>12)$. Although the validity, reproducibility and the possible 
time dependence of this observation has to be double checked, it suggests, that binding of aluminate to gluconate in these strongly alkaline solutions is a $\mathrm{pH}$ independent process. In other words, the (simplified) condensation reaction

$$
\mathrm{R}-\mathrm{OH}+\mathrm{Al}(\mathrm{OH})_{4}{ }^{-} \rightleftharpoons \mathrm{R}-\mathrm{O}-\mathrm{Al}(\mathrm{OH})_{3}{ }^{-}+\mathrm{H}_{2} \mathrm{O}
$$

is likely to take place, which does not involve release of proton. This observation explains why other researchers (like Martell and Motekaitis ${ }^{47}$ ) from pH-potentiometry arise at the conclusion, that there is no reaction between aluminate and gluconate in strongly alkaline systems. Another consequence is, that $\mathrm{pH}$-potentiometry will have to be supplemented with some other experimental means (i.e., multinuclear NMR or, more probably, Raman spectroscopy, see above) to reveal the thermodynamics of other systems.

Scoping Raman measurements have been performed, to see if Raman could be more useful, than ${ }^{1} \mathrm{H}$ NMR spectroscopy. The experiments have been carried out using an Ocean-Optics benchtop Raman instrument.

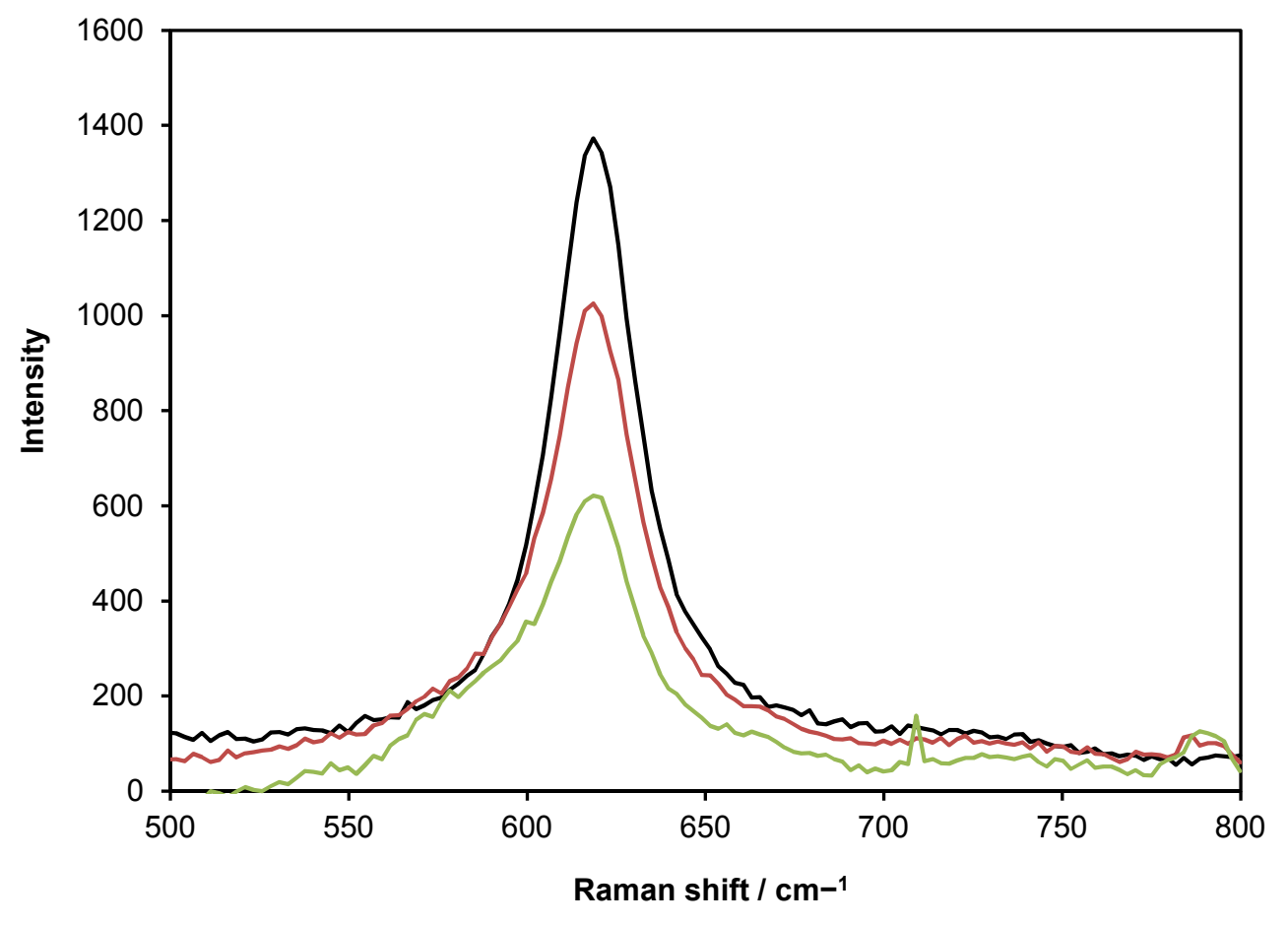

Figure 61: Background corrected Raman spectra of aluminate solutions $\left(\left[\mathrm{NaAl}(\mathrm{OH})_{4}\right]_{T}=0.4\right.$ $\left.\mathrm{M} ;[\mathrm{NaOH}]_{\text {excess }}=0.4 \mathrm{M}\right)$ with various added gluconate concentrations

$$
\text { (一: } 0 \mathrm{M} ;-: 0.2 \mathrm{M} ;-: 0.4 \mathrm{M})
$$

The intensity of the symmetrical stretching of the monomeric aluminate (around $620 \mathrm{~cm}^{-1}$ in Figure 61) systematically decreases by raising the Gluc $^{-}$concentration. This is a sure sign 
of complexation. Note, that even under equimolar conditions (green curve in Figure 61), still a lot of aluminate ( $c a .30 \%$ of the total) is uncomplexed. This means that the stability constant of the aluminate-gluconate complex is not very large. The emerging shoulder around $570 \mathrm{~cm}^{-1}$ surely corresponds to the complex - a further tool to monitor complexation. The Raman spectrum of the Gluc is relatively empty in this $550-700 \mathrm{~cm}^{-1}$ range, allowing relatively accurate aluminate peak integration to be performed.

\subsubsection{The role of the carbonate ion: Does it interact with $\mathrm{Al}(\mathrm{OH})_{4}{ }^{-}$or Gluc $^{-}$?}

The possibility of some interaction between the $\mathrm{Al}(\mathrm{OH})_{4}{ }^{-}$and $\mathrm{CO}_{3}{ }^{2-}$ was followed using ${ }^{27} \mathrm{Al}$ NMR spectroscopy. In these three solutions the concentration of $\mathrm{Al}(\mathrm{OH})_{4}{ }^{-}$was held constant at $0.01 \mathrm{M}$ and $\left[\mathrm{CO}_{3}{ }^{2-}\right]_{\mathrm{T}}$ concentration was systematically raised up to $1.0 \mathrm{M}$ in the presence of $1.0 \mathrm{M} \mathrm{NaOH}$.

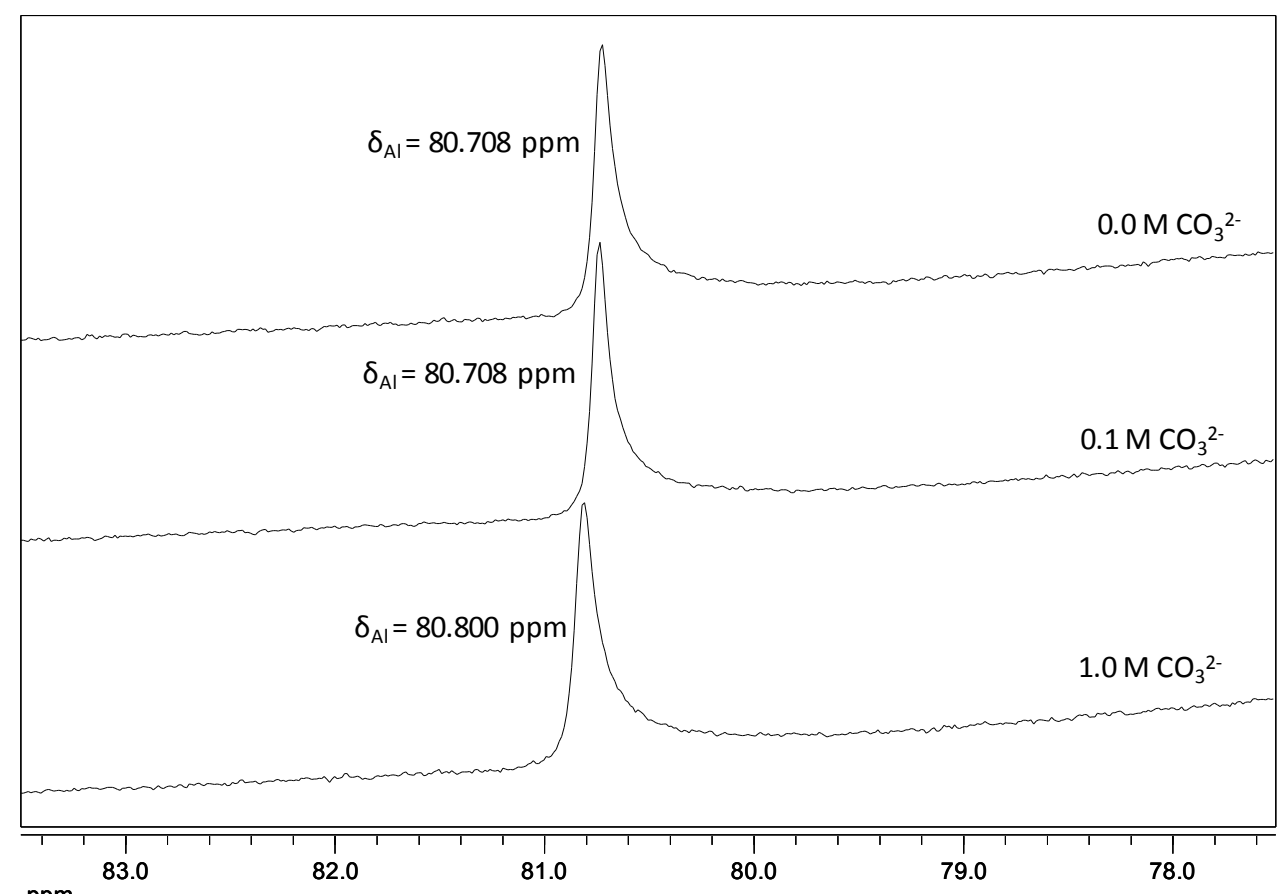

Figure 62: The effect of the $\mathrm{CO}_{3}{ }^{2-}$ on the ${ }^{27} \mathrm{Al} \mathrm{NMR} \mathrm{signal} \mathrm{of} \mathrm{Al}(\mathrm{OH})_{4}{ }^{-}$ $\left.\left[\mathrm{Al}(\mathrm{OH})_{4}{ }^{-}\right]=0.01 \mathrm{M} ; \mathrm{OH}^{-}\right]_{T}=1.0 \mathrm{M}$

The ${ }^{27} \mathrm{Al}$ NMR spectra of these solutions are presented in Figure 62. Beside a minor downfield shift there is no variation in the spectra with rising $\mathrm{CO}_{3}{ }^{2-}$ concentration - it does not exceed $0.1 \mathrm{ppm}$ at $1.0 \mathrm{M} \mathrm{CO}_{3}{ }^{2-}$ concentration (100 fold excess relative to $\mathrm{Al}(\mathrm{OH})_{4}{ }^{-}$). 


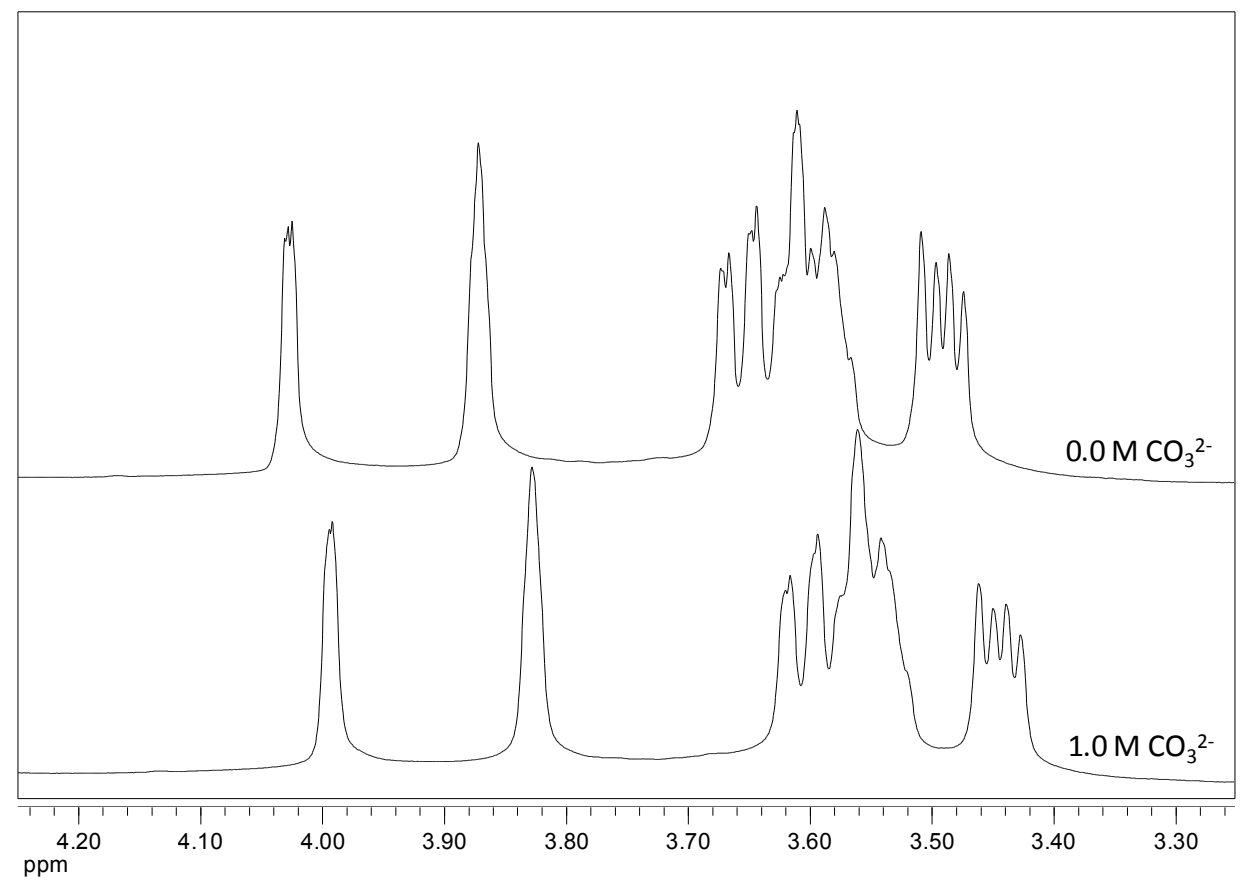

Figure 63: The effect of the $\mathrm{CO}_{3}{ }^{2-}$ on the ${ }^{1} \mathrm{H}$ NMR signal of Gluc

$\left.\left[\mathrm{Gluc}^{-}\right]=0.10 \mathrm{M} ; \mathrm{OH}^{-}\right]_{T}=1.0 \mathrm{M}$

The ${ }^{1} \mathrm{H}$ NMR spectra of Gluc ${ }^{-}$in the absence and presence of the $\mathrm{CO}_{3}{ }^{2-}$ are presented in Figure 63. In these solutions the concentration of the $\mathrm{Gluc}^{-}$is fixed to $0.100 \mathrm{M}$ and the $\mathrm{CO}_{3}{ }^{2-}$ is raised to $1.0 \mathrm{M}$. No interaction can be observed between the two molecules. The $0.05 \mathrm{ppm}$ upfield shift is most probably associated with the drastic change of the medium (its susceptibility) as $\mathrm{CO}_{3}{ }^{2-}$ is added to the solution.

These control experiments demonstrate that (in accordance with the expectations) in solutions relevant to the Bayer process, $\mathrm{CO}_{3}{ }^{2-}$ does not form binary solution species with aluminate or gluconate.

\subsubsection{Ternary system containing $\mathrm{Ca}^{2+}, \mathrm{Al}(\mathrm{OH})_{4}{ }^{-}$and $\mathrm{Gluc}^{-}$}

Interaction between the $\mathrm{Ca}^{2+}$, $\mathrm{Gluc}^{-}$and $\mathrm{Al}(\mathrm{OH})_{4}{ }^{-}$was investigated with the aid of NMR spectroscopy and potentiometric titrations.

${ }^{1} \mathrm{H}$ NMR spectra have been recorded in $1.0 \mathrm{M} \mathrm{NaOH}$ medium. The concentrations of the constituents are as follows: $\left[\mathrm{Ca}^{2+}\right]=0.05 \mathrm{M} ;\left[\mathrm{Al}(\mathrm{OH})_{4}{ }^{-}\right]=0.05 \mathrm{M}$ and $\left[\mathrm{Gluc}^{-}\right]=0.20 \mathrm{M}$. The variation in the ${ }^{1} \mathrm{H}$ NMR spectra of Gluc ${ }^{-}$by adding $\mathrm{Ca}^{2+}$ and/or $\mathrm{Al}(\mathrm{OH})_{4}^{-}$to the system is presented in Figure 64. The formation of $\mathrm{Ca}^{2+}$ or $\mathrm{Al}(\mathrm{OH})_{4}{ }^{-}$containing $\mathrm{Gluc}^{-}$complex can be easily observed when $\mathrm{Ca}^{2+}$ or $\mathrm{Al}(\mathrm{OH})_{4}^{-}$is added to the Gluc containing solution (Figure 64). In the ${ }^{1} \mathrm{H}$ NMR spectra of the ternary system new signals appear in the spectrum (at $c a .3 .80-$ $3.85 \mathrm{ppm})$. This spectrum is not the combination of the two binary spectra $\left(\mathrm{Ca}^{2+} / \mathrm{Gluc}^{-}\right.$and 
$\left.\mathrm{Al}(\mathrm{OH})_{4}{ }^{-} / \mathrm{Gluc}^{-}\right)$. This proves that in $1.0 \mathrm{M} \mathrm{NaOH}$ medium, a $\mathrm{Ca}^{2+} / \mathrm{Al}(\mathrm{OH})_{4}{ }^{-} / \mathrm{Gluc}^{-}$containing ternary complex is formed.

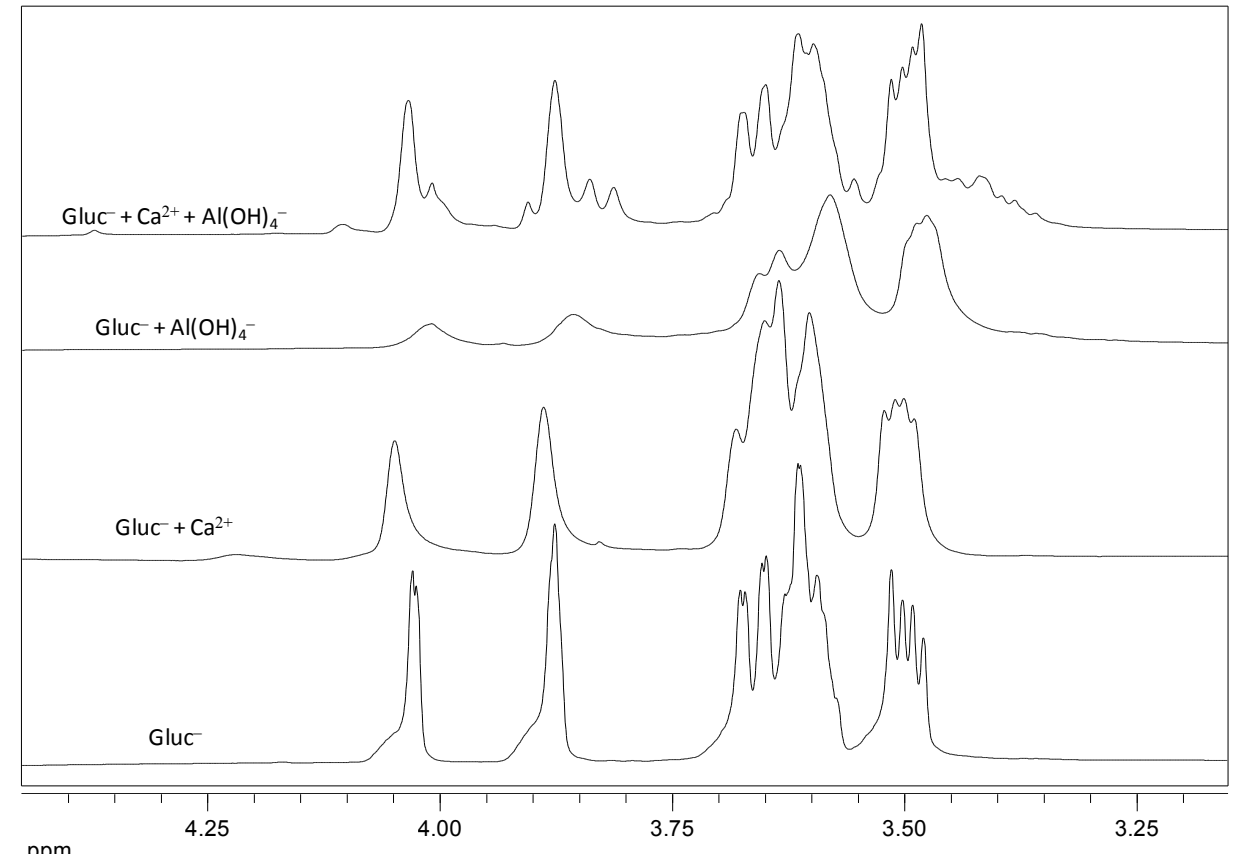

Figure 64: The variation of the ${ }^{1} H$ NMR spectra of Gluc ${ }^{-}$during the preparation of the $\mathrm{Ca}^{2+} / \mathrm{Al}(\mathrm{OH})_{4}^{-} / \mathrm{Gluc}^{-}$ternary system at $25.0^{\circ} \mathrm{C} ;\left[\mathrm{Ca}^{2+}\right]=0.05 \mathrm{M} ;\left[\mathrm{Al}(\mathrm{OH})_{4}{ }^{-}\right]=0.05 \mathrm{M}$; $\left[\mathrm{Gluc}^{-}\right]=0.20 \mathrm{M} ;\left[\mathrm{OH}^{-}\right]_{T}=1.0 \mathrm{M}$

Variation of the ${ }^{1} \mathrm{H}$ NMR spectra of the ternary system described above by adding $\mathrm{CO}_{3}{ }^{2-}$ $(1.0 \mathrm{M})$ to the solution is presented in Figure 65.

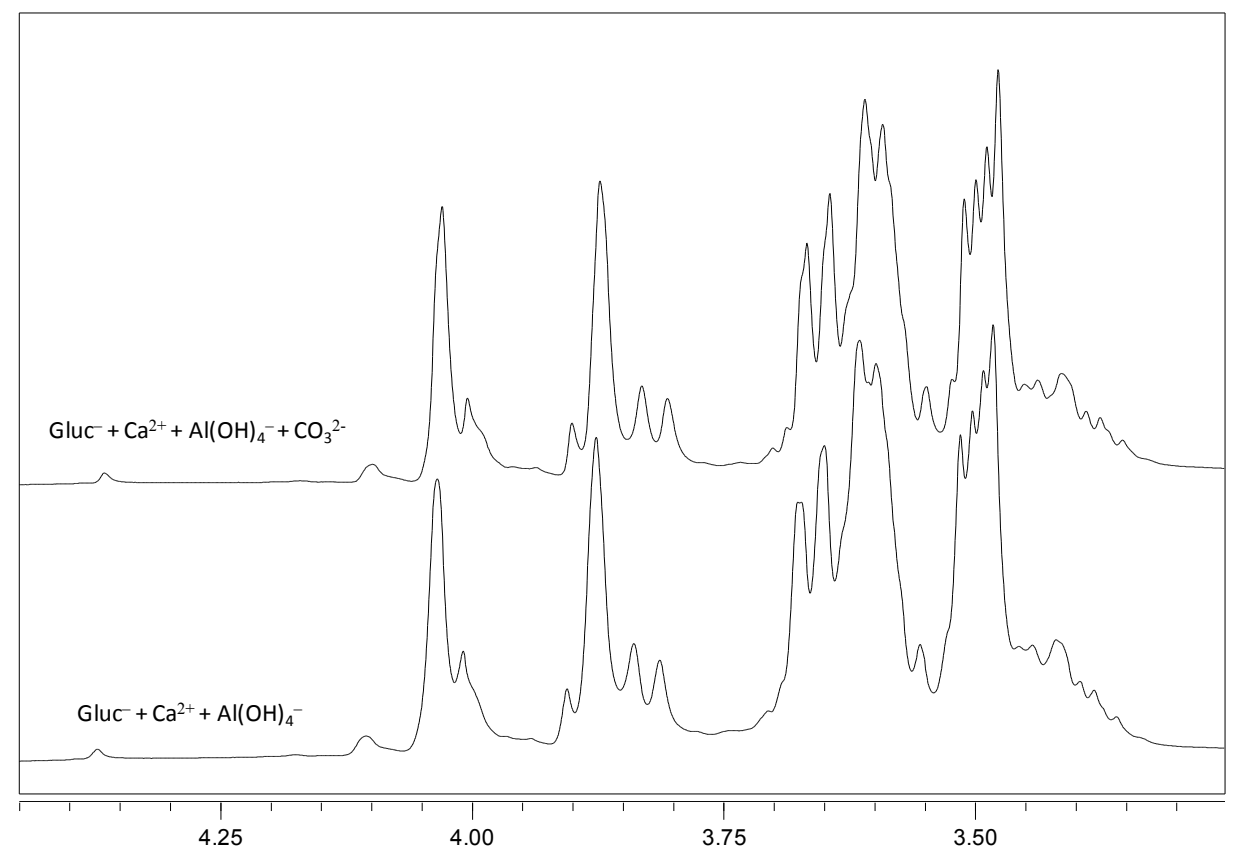

ppm

Figure 65: The effect of the $\mathrm{CO}_{3}{ }^{2-}$ on the $\mathrm{Ca}^{2+} / \mathrm{Al}(\mathrm{OH})_{4}{ }^{-} / \mathrm{Gluc} c^{-}$ternary system at $25.0{ }^{\circ} \mathrm{C}$ $\left[\mathrm{Ca}^{2+}\right]=0.05 \mathrm{M} ;\left[\mathrm{Al}(\mathrm{OH})_{4}{ }^{-}\right]=0.05 \mathrm{M} ;\left[\mathrm{Gluc}^{-}\right]=0.20 \mathrm{M} ;\left[\mathrm{OH}^{-}\right]_{T}=1.0 \mathrm{M} ;\left[\mathrm{CO}_{3}{ }^{2-}\right]=1.0 \mathrm{M}$ 
The addition of the $\mathrm{CO}_{3}{ }^{2-}$ has no effect on the NMR spectra even at these very high carbonate concentration $(1.0 \mathrm{M})$. This means that the ternary solution complex formed remains unchanged even in the presence of large amounts of $\mathrm{CO}_{3}{ }^{2-}$. Furthermore, no other visible changes (e.g., solid precipitation) are observed in this solution.

Temperature dependence of the ${ }^{1} \mathrm{H}$ NMR spectrum of the solution containing the ternary solution complex (described above) has been determined The temperature of the $\mathrm{Ca}^{2+} / \mathrm{Al}(\mathrm{OH})_{4}{ }^{-} / \mathrm{Gluc}^{-}$containing system $(0.05 \mathrm{M}, 0.05 \mathrm{M}$ and $0.20 \mathrm{M}$, respectively) in $1.0 \mathrm{M}$ $\mathrm{NaOH}$ media has been systematically raised from $5{ }^{\circ} \mathrm{C}$ up to $65{ }^{\circ} \mathrm{C}$ and the ${ }^{1} \mathrm{H}$ NMR spectra has been recorded (Figure 66). The solution is stable in this temperature range, i.e., no precipitation or any other variation has occurred. In the ${ }^{1} \mathrm{H}$ NMR spectra beside a $\sim 0.6 \mathrm{ppm}$ downfield shift a new signal appears on raising the temperature (Figure 66: $4.07 \mathrm{ppm}$ at $55^{\circ} \mathrm{C} ; 4.17 \mathrm{ppm}$ at $65^{\circ} \mathrm{C}$ ). This indicates that the increasing temperature has a profound effect on the interactions in these ternary systems and the equilibrium distribution of the solution complexes at room temperature is likely to be different from that at elevated ones.

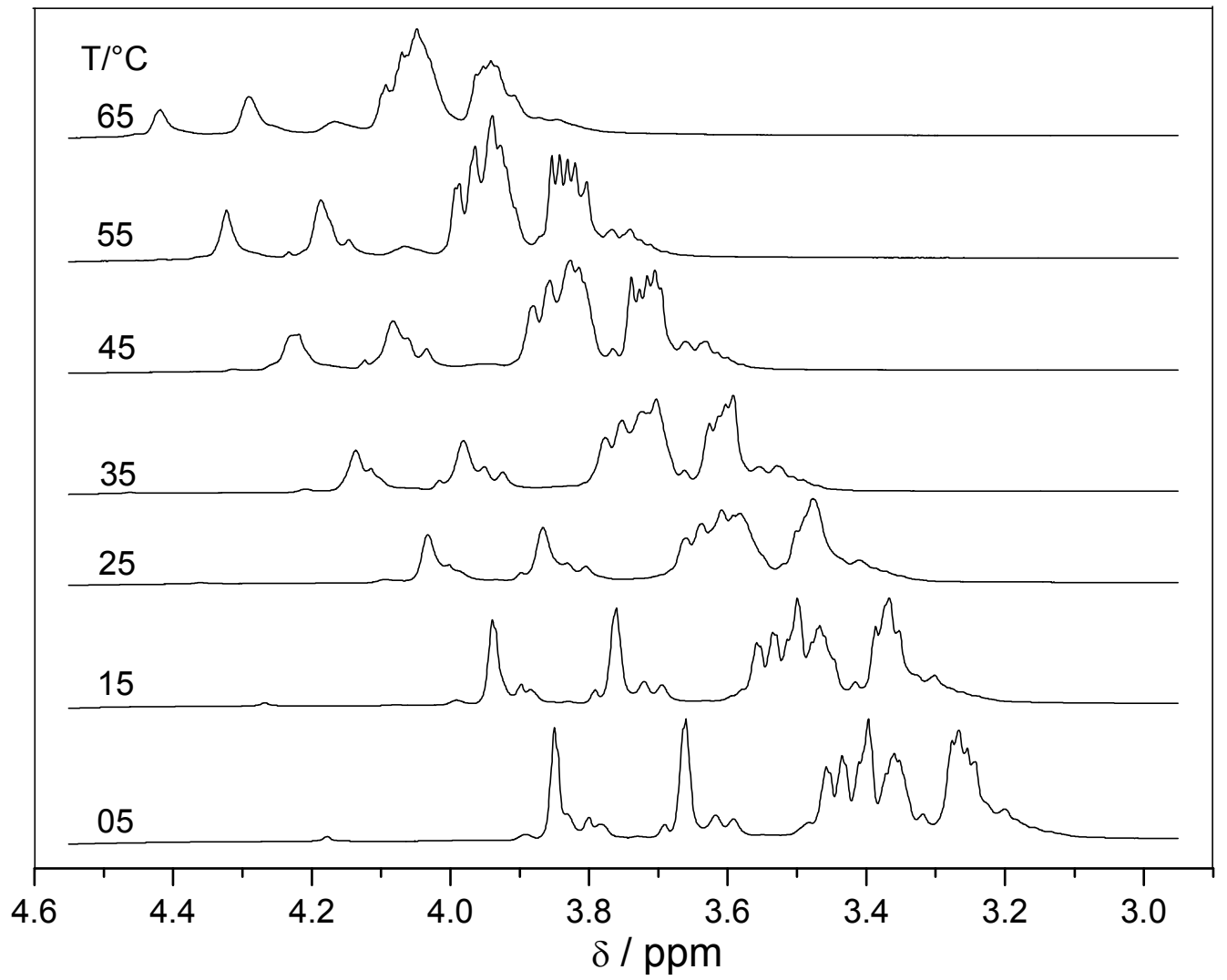

Figure 66: Variation of the ${ }^{1} \mathrm{H}$ NMR spectra of the $\mathrm{Ca}^{2+} / \mathrm{Al}(\mathrm{OH})_{4}^{-} / \mathrm{Gluc}^{-}$ternary system on raising the temperature

Potentiometric titrations were performed in the $\mathrm{Ca}^{2+} / \mathrm{Al}(\mathrm{OH})_{4}{ }^{-} / \mathrm{Gluc}^{-}$ternary system at $25.0{ }^{\circ} \mathrm{C}$. In these systems the $\mathrm{Ca}^{2+}: \mathrm{Gluc}^{-}: \mathrm{Al}(\mathrm{OH})_{4}{ }^{-}$ratio was systematically varied and the 
concentration range of the initial concentrations were as follows: $\left[\mathrm{Ca}^{2+}\right]_{\mathrm{T}}=0.025-0.100 \mathrm{M}$; $\left[\mathrm{Gluc}^{-}\right]_{\mathrm{T}}=0.0625-0.250 \mathrm{M} ;\left[\mathrm{Al}(\mathrm{OH})_{4}^{-}\right]_{\mathrm{T}}=\left[\mathrm{OH}^{-}\right]_{\mathrm{T}}=0.025-0.100 \mathrm{M}$ (here $\left[\mathrm{OH}^{-}\right]_{\mathrm{T}}$ denotes the total concentration of the excess hydroxide). Two parallel titrations were performed at each composition; the potential differences between the parallel measurements were in the range of $1 \mathrm{mV}$ in the well-buffered potential range. The possible formation of inert complexes (that is slowly establishing equilibria) was also checked in an independent set of measurements and it was found that (under the experimental conditions employed) all the equilibria are established rapidly.

The titrant was $1.00 \mathrm{M} \mathrm{HCl}$ solution and during these titrations the $4<\mathrm{pH}<12 \mathrm{pH}$ range was covered (see Figure 67). The starting pH of the solutions with these initial concentrations was rather low, indicating that extensive proton releasing processes take place upon the reaction of these three components.

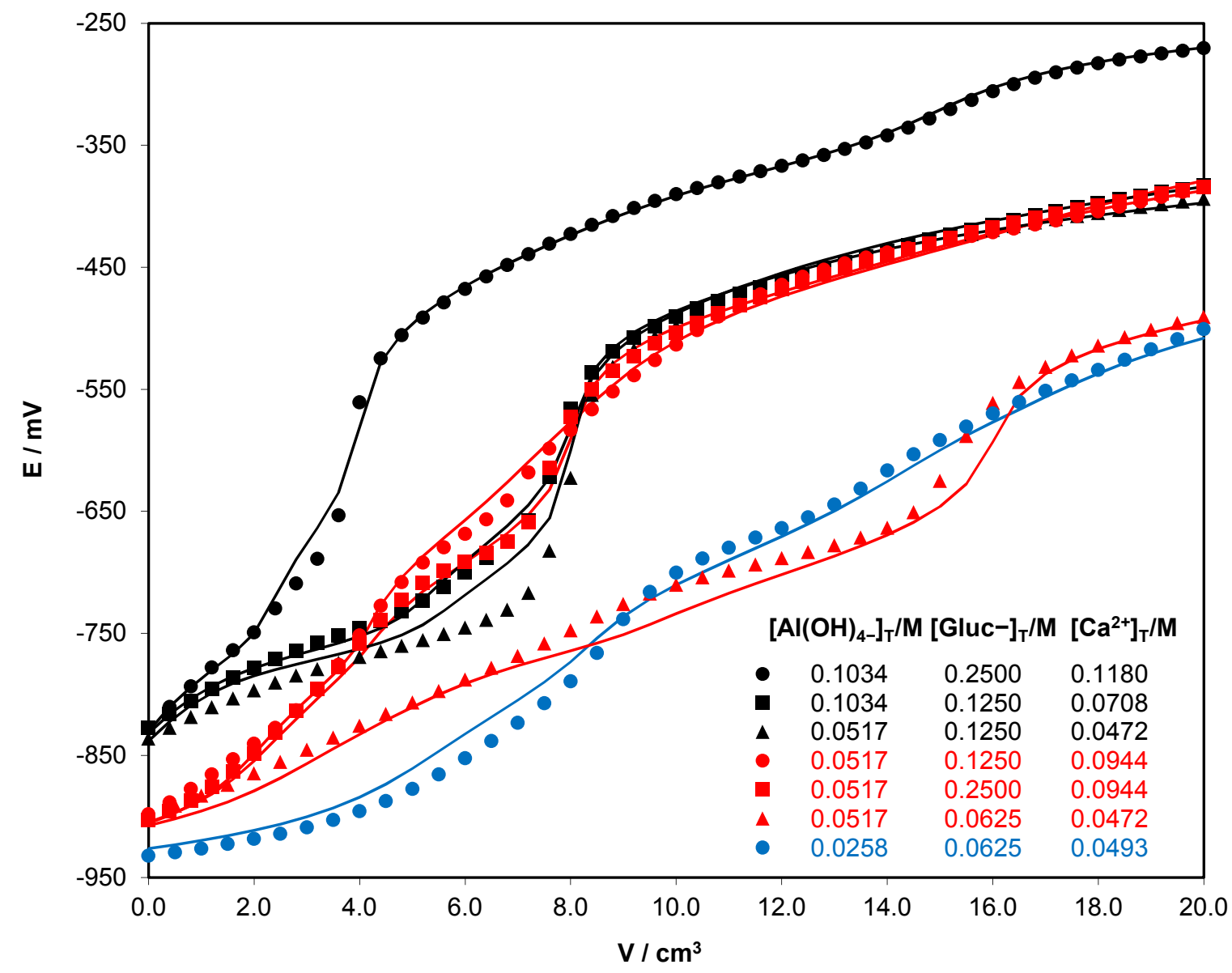

Figure 67: Potentiometric titration curves of the $\mathrm{Al}(\mathrm{OH})_{4}{ }_{4}^{-} / \mathrm{Ca}^{2+} / \mathrm{Gluc}^{-}$ternary systems. Symbols represent observed EMF values, solid lines were fitted on the basis of the model discussed in the text. 
The evaluation of the observed titration curves has been done using the PSEQUAD software package. ${ }^{65}$ In these calculations the fundamental solution species are as follows: $\mathrm{H}^{+}$, $\mathrm{Na}^{+}, \mathrm{Ca}^{2+}$, Gluc ${ }^{-}$and $\mathrm{Al}(\mathrm{OH})_{4}^{-}$. All of the particles listed above are systematically included in the calculations to reach the best available fit. The stability constants of the complexes describing the binary systems were held constant (see chapters 5.1.1.2 and 5.4.1.2). These species were as follows: $\mathrm{OH}^{-}, \mathrm{GlucH}_{-1}{ }^{2-}, \mathrm{CaOH}^{+}, \mathrm{GlucH}_{-1}{ }^{2-},\left[\mathrm{CaGlucH}_{-1}\right]^{0},\left[\mathrm{Ca}_{2} \mathrm{Gluc}_{2} \mathrm{H}_{-3}\right]^{0}$ and $\left[\mathrm{Ca}_{3} \mathrm{Gluc}_{2} \mathrm{H}_{-}\right]^{0}$. For the adequate fitting of the observed EMF more than 80 derived solution species were systematically included and checked. The best fit obtained on this system was $6.83 \mathrm{mV}$. However, this fitting parameter is higher than expected, the fitting is primarily affected by the two titration curves at higher Gluc concentrations $\left(\left[\mathrm{Gluc}^{-}\right]_{\mathrm{T}}=\right.$ $0.250 \mathrm{M}$; Figure 67, black and red triangles). Omitting these two curves from the calculations resulted in a $4.30 \mathrm{mV}$ fitting parameter. The stability constants are listed below:

$\begin{array}{ll} & \mathrm{pK}_{\mathrm{w}}=13.76 \pm 0.01 \\ \mathrm{CaGluc}^{+} & \log \mathrm{K}_{1010}=1.08 \pm 0.14 \\ \mathrm{Al}(\mathrm{OH})_{2}{ }^{+} & \log \mathrm{K}_{010-2}=12.89 \pm 0.11 \\ \mathrm{Al}^{3+} & \log \mathrm{K}_{0100}=20.94 \pm 0.08 \\ {\left[\mathrm{Al}(\mathrm{OH})_{3} \mathrm{Gluc}\right]^{-}} & \log \beta_{011-1}=9.89 \pm 0.04 \\ {\left[\mathrm{Al}(\mathrm{OH})_{2} \mathrm{Gluc}\right]^{0}} & \log \beta_{011-2}=15.01 \pm 0.07 \\ {[\mathrm{Al}(\mathrm{OH}) \mathrm{Gluc}]^{+}} & \log \beta_{011-1}=19.54 \pm 0.06 \\ {\left[\mathrm{CaAl}(\mathrm{OH})_{4} \mathrm{Gluc}^{0}\right.} & \log \beta_{111-4}=3.76 \pm 0.08 \\ {\left[\mathrm{Ca}_{3} \mathrm{Al}(\mathrm{OH})_{6} \mathrm{Gluc}_{2}\right]^{+}} & \log \beta_{312-6}=-11.22 \pm 0.20 \\ {\left[\mathrm{Ca}_{3} \mathrm{Al}(\mathrm{OH})_{3} \mathrm{Gluc}_{3}\right]^{3+}} & \log \beta_{313-3}=18.59 \pm 0.18\end{array}$

The distribution of the Gluc ${ }^{-}$or $\mathrm{Al}(\mathrm{III})$ containing solution species as a function of the $\mathrm{pH}$ are presented on the Figure 68 and Figure 69 , respectively.

The solution species used to describe the titration curves are in good agreement with those published by Lakatos et al. ${ }^{46}$ to describe their Al(III)/Gluc ${ }^{-}$system under $\mathrm{pH} 10$, but the 1:2 metal-ligand ratio complexes did not fit in our model.

Beside the three $\left(\left[\mathrm{Al}(\mathrm{OH})_{3} \mathrm{Gluc}\right]^{-}, \quad\left[\mathrm{Al}(\mathrm{OH})_{2} \mathrm{Gluc}\right]^{0}\right.$ and $\left.[\mathrm{Al}(\mathrm{OH}) \mathrm{Gluc}]^{+}\right) \quad 1: 1$ $\mathrm{Al}(\mathrm{III})$-gluconate complexes, the presence of the high-pH aluminate-gluconate complex (see chapter 5.4.2; page 70) cannot be confirmed indirectly as the complex does not participate in any proton binding or releasing processes. Beside these complexes, three others containing both $\mathrm{Ca}^{2+}$ and $\mathrm{Al}(\mathrm{OH})_{4}^{-}$must be included in the model to describe the titration curves. These are the $\left[\mathrm{CaAl}(\mathrm{OH})_{4} \mathrm{Gluc}\right]^{0}$, the $\left[\mathrm{Ca}_{3} \mathrm{Al}(\mathrm{OH})_{6} \mathrm{Gluc}_{2}\right]^{+}$and the $\left[\mathrm{Ca}_{3} \mathrm{Al}(\mathrm{OH})_{3} \mathrm{Gluc}_{3}\right]^{3+}$, the latter 
was suggested by Rosenberg et al. to be present in solutions containing $\mathrm{Ca}^{2+}, \mathrm{Al}(\mathrm{OH})_{4}{ }^{-}$and Gluc $^{-}$in a very different concentration range and temperature. ${ }^{2}$

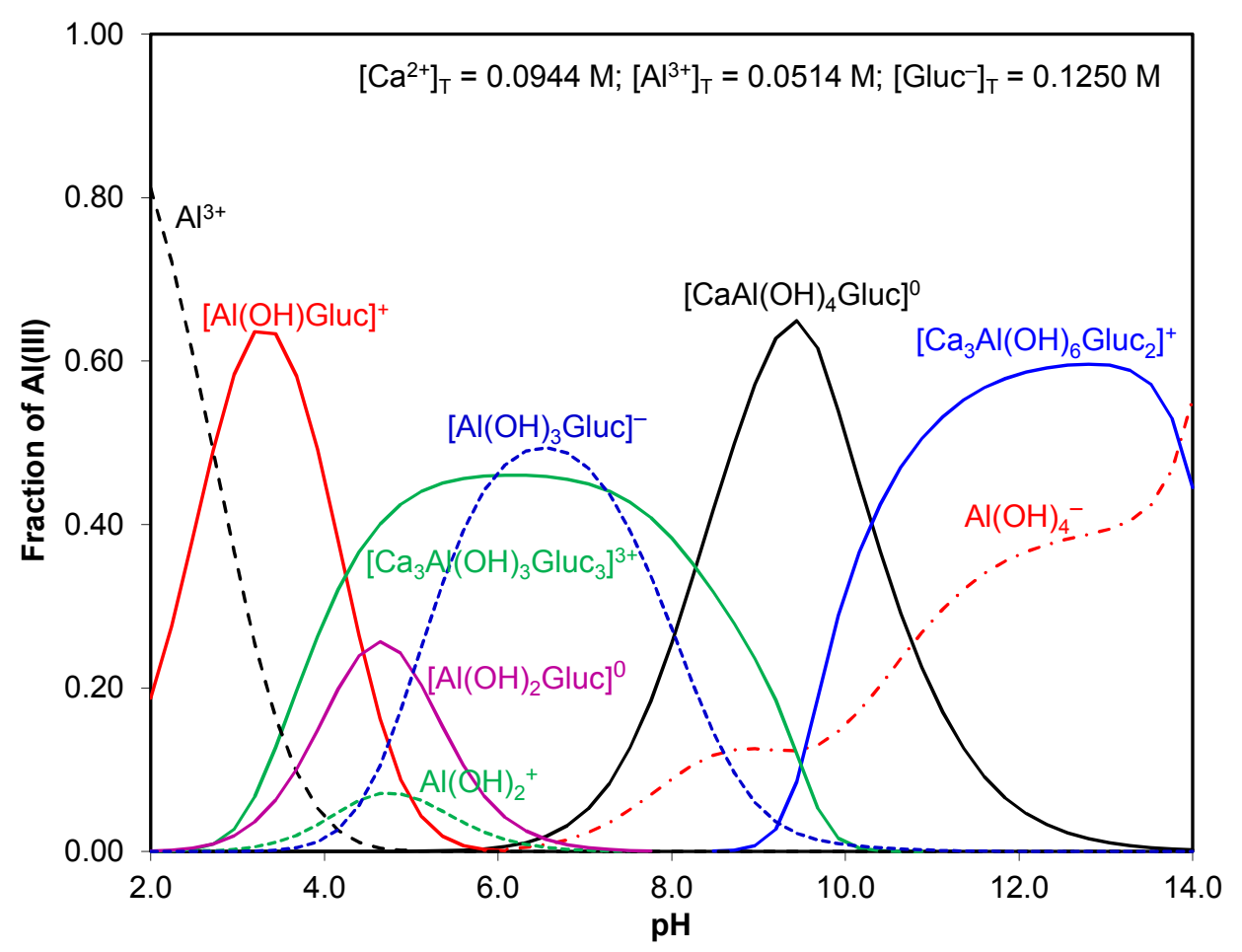

Figure 68: Distribution diagram of the Al(III) containing particles in the $\mathrm{Ca}^{2+} / \mathrm{Al}(\mathrm{OH})_{4}{ }^{-} / \mathrm{Gluc}^{-}$ternary system as a function of $\mathrm{pH}$ at $25.0^{\circ} \mathrm{C}$

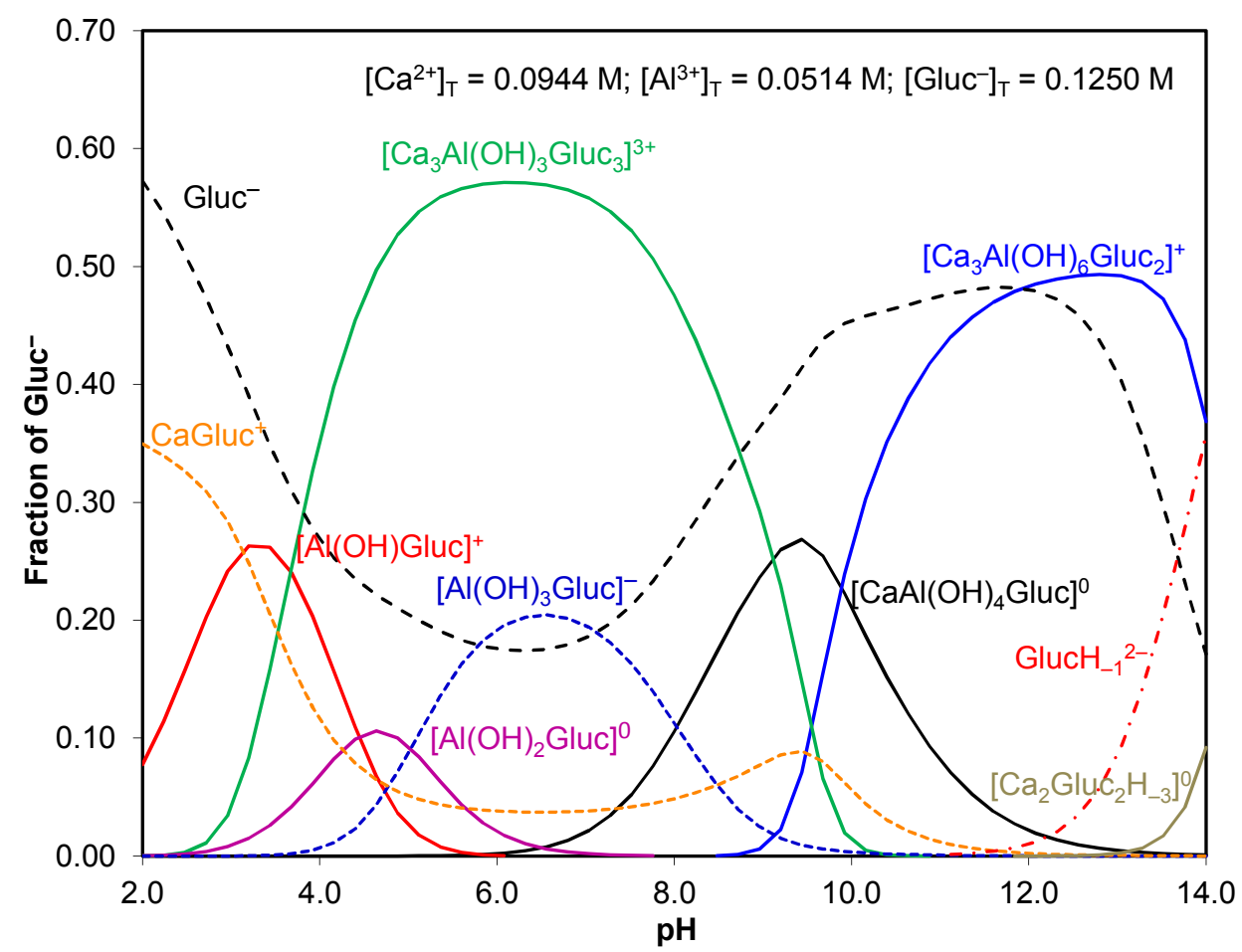

Figure 69: Distribution diagram of the Gluc containing complex species in the $\mathrm{Ca}^{2+} / \mathrm{Al}(\mathrm{OH})_{4}^{-} / \mathrm{Gluc}^{-}$ternary system as a function of $\mathrm{pH}$ at $25.0^{\circ} \mathrm{C}$ 
The distribution of the $\mathrm{Ca}^{2+}$ containing solution species was extrapolated to the concentrations used by Rosenberg et al. ${ }^{2}$ (Figure 70 ). Note, that this extrapolation cannot describe accurately those solutions because of the enormous difference in the concentrations and temperature.

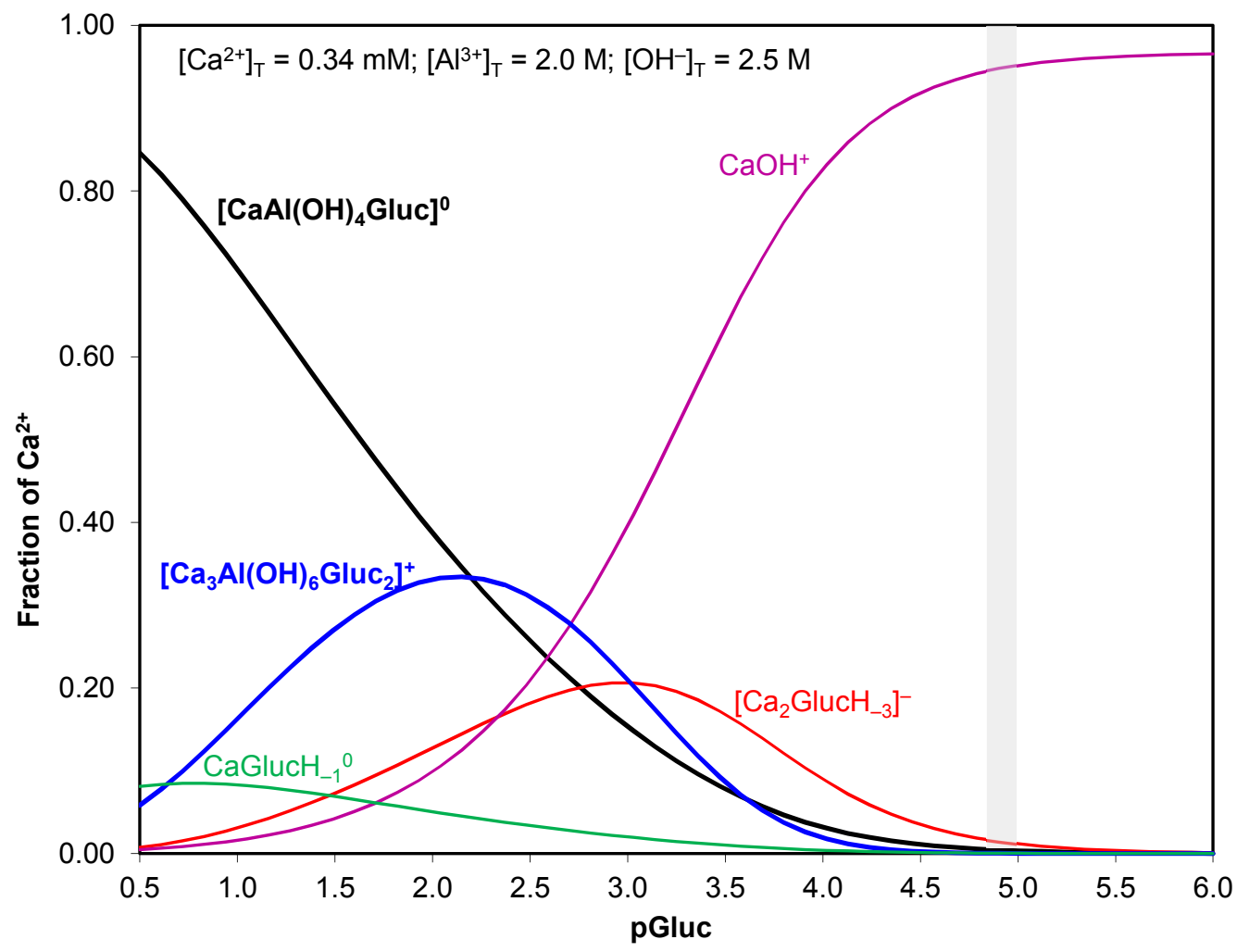

Figure 70: Distribution diagram of the $\mathrm{Ca}^{2+}$ containing complex species in the $\mathrm{Ca}^{2+} / \mathrm{Al}(\mathrm{OH})_{4}^{-} / \mathrm{Gluc}^{-}$ternary system as a function of $p$ Gluc.

The grey band refers to the $\left[\mathrm{Gluc}^{-}\right]_{T}=1 \mathrm{~g} / \mathrm{dm}^{3}$.

Regarding the concentrations used by Rosenberg et al. ${ }^{2}$ the concentration of the compounds were as follows: $\left[\mathrm{OH}^{-}\right]_{\mathrm{T}}=2.5 \mathrm{M},\left[\mathrm{Al}(\mathrm{OH})_{4}{ }^{-}\right]_{\mathrm{T}}=2.0 \mathrm{M}$ and $\left[\mathrm{Ca}^{2+}\right]_{\mathrm{T}}=0.34 \mathrm{mM}$. Since the concentration of the free Gluc ${ }^{-}$varies between $0.3 \mathrm{M}$ and $10^{-6} \mathrm{M}$ (pGluc $=0.5-6$ ) the presence of the $\mathrm{CaGlucH}_{-1}{ }^{0},\left[\mathrm{CaAl}(\mathrm{OH})_{4} \mathrm{Gluc}\right]^{0},\left[\mathrm{Ca}_{3} \mathrm{Al}(\mathrm{OH})_{6} \mathrm{Gluc}_{2}\right]^{+}, \mathrm{Ca}_{2} \mathrm{GlucH}_{-3}{ }^{-}$and $\mathrm{CaOH}^{+}$can be predicted (see also Figure 70). Extrapolation of our results shows regarding the calcium the major solution species is $\mathrm{CaOH}^{+}$(with a possible formation of $\mathrm{Ca}_{2} \mathrm{GlucH}_{-3}{ }^{-}$) at $\left[\text { Gluc }^{-}\right]_{\mathrm{T}}=1 \mathrm{~g} / \mathrm{dm}^{3}$. The formation of the $\left[\mathrm{Ca}_{3} \mathrm{Al}(\mathrm{OH})_{3} \mathrm{Gluc}_{3}\right]^{3+}$ complex species suggested in the open literature ${ }^{2}$ (where the Gluc ${ }^{-}$anion could equally be some other organic or the hydroxyl ion) cannot be confirmed. The presence of this complex can be predicted in solutions of $\mathrm{pH} 2-10$. 


\section{Conclusions}

The calcium ion (particularly in the form of lime) is one of the most useful processing aids available to alumina refinery operators. In some cases the benefits provided arises through the actions of some soluble form of the calcium cation. Sugar derivatives increase the concentration of the calcium in the liquor phase, therefore investigating their complexation with compounds relevant to the Bayer process $\left(i\right.$ e e. $\left.\mathrm{Ca}^{2+}, \mathrm{Al}(\mathrm{OH})_{4}{ }^{-}\right)$is important to the industry.

Investigating the $\mathrm{H}^{+} / \mathrm{Gluc}^{-}$system shows that NMR spectroscopy is suitable to derive precise stability constants $\left(\log \mathrm{K}_{\mathrm{a}}=3.23 \pm 0.01\right)$, accordingly the $\mathrm{Ca}^{2+} / \mathrm{Gluc}^{-}$system has been treated analogously. The complex formation equilibria between $\mathrm{Ca}^{2+}$ and $\mathrm{Gluc}^{-}$has been characterized via multinuclear NMR $\left({ }^{1} \mathrm{H},{ }^{13} \mathrm{C}\right.$ and $\left.{ }^{43} \mathrm{Ca}\right)$ measurements and the formation constants of the 1:1 complex as a function of the ionic strength $(1 \mathrm{M} \leq \mathrm{I} \leq 4 \mathrm{M})$ and $\mathrm{pH}<11$ have been determined. The structure of the complex species has been identified via twodimensional NMR spectra and the existence of a peculiar binding isomerism (carboxylate- $\mathrm{C} 2$ alcoholic $\mathrm{OH} \rightleftharpoons$ carboxylate $-\mathrm{C} 3$ alcoholic $\mathrm{OH}$ ) has been established.

The complexation of $\mathrm{Ca}^{2+}$ with a set of sugar derivatives has also been investigated. These were the glucose, sorbitol and the anions of mucic acid, arabic acid and the heptagluconic acid. The complexes were characterized (formation constant and structure) via multinuclear NMR measurements supplemented with molecular modeling calculations. Structural investigation of these complexes revealed a novel class of scorpionate complexes.

A home-made apparatus suitable to establish equilibrium solubilities over a wide temperature range $\left(20-80^{\circ} \mathrm{C}\right)$ has been constructed and tested. An experimental protocol to accurately determine $\mathrm{Ca}^{2+}$ concentrations via ICP-AES has been elaborated. Using the apparatus, the solubility of the $\mathrm{CaO}$ in $\mathrm{NaOH}$ (up to $\sim 15 \mathrm{M}$ ) was determined at various temperatures $\left(25.0,50.0\right.$ and $\left.75.0^{\circ} \mathrm{C}\right)$. The solubility product of $\mathrm{Ca}(\mathrm{OH})_{2}$ and the stability constant of $\mathrm{CaOH}^{+}$have been determined. Processing the solubility data with the aid of the ZITA suite of computer programs showed that beside $\mathrm{Ca}^{2+}, \mathrm{CaOH}^{+}$is the only water soluble species present in these systems. The conditional stability constant of the high-pH calcium gluconate complex was determined via solubility measurements in $1.00 \mathrm{M} \mathrm{NaOH}$ medium and was found to be $\log \mathrm{K}_{\mathrm{CaGluc}}=4.02 \pm 0.06$

The $\mathrm{Ca}^{2+} / \mathrm{Gluc}^{-}$system in caustic solutions was studied by various techniques. The temperature dependence study of this system showed that chemical exchange between the various forms of Gluc is slow at low temperatures $\left(0-15^{\circ} \mathrm{C}\right)$, but above $40-45^{\circ} \mathrm{C}$ it becomes 
relatively fast on the NMR time scale. Regarding the structure of the high-pH calcium gluconate complex, results strongly indicate that the alcoholate groups on both the $\mathrm{C} 2$ and the $\mathrm{C} 3$ carbon atoms participate in $\mathrm{Ca}^{2+}$ binding. Potentiometric titrations were done using a home-built platinized-platinum hydrogen electrode. The evaluation of the titrations showed, that beside the $\mathrm{CaGluc}^{+}$and $\mathrm{CaGlucH}_{-1}{ }^{0}$ mononuclear complexes (and the $\mathrm{GlucH}_{-1}{ }^{2-}$ as well) the $\mathrm{Ca}_{2} \mathrm{Gluc}_{2} \mathrm{H}_{-3}{ }^{0}$ bi- and the $\mathrm{Ca}_{3} \mathrm{Gluc}_{2} \mathrm{H}_{-4}{ }^{0}$ trinuclear complexes are present in these systems. The geometry of the $\mathrm{Ca}_{3} \mathrm{Gluc}_{2} \mathrm{H}_{-4}{ }^{0}$ polynuclear complex was optimized by molecular modeling calculations.

The ${ }^{1} \mathrm{H}$ and ${ }^{27} \mathrm{Al}$ NMR measurements confirm the complexation between $\mathrm{Al}(\mathrm{OH}){ }_{4}{ }^{-}$and Gluc $^{-}$unambiguously. The $\mathrm{pH}$ potentiometric titration curves are practically identical to those performed in solutions containing Gluc ${ }^{-}$only. This fact suggests that the binding of aluminate to gluconate in these strongly alkaline solutions $(\mathrm{pH}>12)$ is a $\mathrm{pH}$-independent process. The stability constant of the complex was estimated from NMR spectroscopic measurements as new peaks emerge on the ${ }^{1} \mathrm{H}$ NMR spectra of the Gluc ${ }^{-}$with increasing $\mathrm{Al}(\mathrm{OH})_{4}{ }^{-}$ concentration.

The $\mathrm{Ca}^{2+} / \mathrm{Al}(\mathrm{OH})_{4}{ }^{-} / \mathrm{Gluc}^{-}$ternary system was studied by multinuclear NMR spectroscopy and potentiometric titrations. NMR measurements showed that the presence of the $\mathrm{CO}_{3}{ }^{2-}$ had no effect on the $\mathrm{Ca}^{2+} / \mathrm{Al}(\mathrm{OH})_{4}{ }^{-} / \mathrm{Gluc}^{-}$ternary system even at high carbonate concentrations. To describe the titration curves of the ternary systems containing $\mathrm{Ca}^{2+}, \mathrm{Al}(\mathrm{III})$ and $\mathrm{Gluc}^{-}$, the stability constants of the particles describing the $\mathrm{Ca}^{2+} / \mathrm{Gluc}^{-}$binary systems were held constant. The solution species containing $\mathrm{Al}(\mathrm{III})$ only were $\mathrm{Al}(\mathrm{OH})_{2}{ }^{+}$and $\mathrm{Al}^{3+}$. Beside the $\left[\mathrm{Al}(\mathrm{OH})_{3} \mathrm{Gluc}\right]^{-},\left[\mathrm{Al}(\mathrm{OH})_{2} \mathrm{Gluc}\right]^{0}$ and $[\mathrm{Al}(\mathrm{OH}) \mathrm{Gluc}]^{+}$binary complexes the formation of the $\left[\mathrm{CaAl}(\mathrm{OH})_{4} \mathrm{Gluc}\right]^{0},\left[\mathrm{Ca}_{3} \mathrm{Al}(\mathrm{OH})_{6} \mathrm{Gluc}_{2}\right]^{+}$and $\left[\mathrm{Ca}_{3} \mathrm{Al}(\mathrm{OH})_{3} \mathrm{Gluc}_{3}\right]^{3+}$ ternary complexes has been established. 


\section{References}

${ }^{1}$ BAYER KJ, Process of making alumina, US Patent 515895 (1894).

${ }^{2}$ Rosenberg SP, Wilson DJ, HeAth CA, Light Metals (2001) 19-25.

${ }^{3}$ The PJ, SivaKumar TJ, Light Metals (1985) 209-222.

${ }^{4}$ Konno H, Nanri Y, Kitamura M, Powder Technology 123 (2002) 33-39.

${ }^{5}$ Gyurcsik B, Nagy L, Coord. Chem. Rev. 203 (2000) 81-149.

${ }^{6}$ Symons MC, Benbow JA, Pelmore H, J. Chem. Soc. Faraday Trans. I 78 (1982) 36713677.

${ }^{7}$ Symons MC, Benbow JA, Pelmore H, J. Chem. Soc., Faraday Trans. I 89 (1984) 19992016.

${ }^{8}$ Zhuo KL, LiU HX, Zhang HH, LiU YH, Wang JJ, J. Chem. Thermodyn. 40 (2008) 889896.

${ }^{9}$ ZhUo KL, LiU HX, ZhANG XK, LiU YH, WANG JJ, Carbohydr. Res. 343 (2008) 2428-2432.

${ }^{10}$ Burgess J, Raven E, Prog. Inorg. Chem. 61 (2009) 251-366.

${ }^{11}$ Angyal SJ, Pure Appl. Chem. 1973, 35 (1973) 131-146.

12 Angyal SJ, Davies KP, Chem. Commun. (1971) 500-502.

${ }^{13}$ Morel JP, Lhermet C, Morel-Desrosiers N, J. Chem. Soc. Faraday Trans. I 84 (1988) 2567-2571.

${ }^{14}$ Grebennikov VN, Vyskrebtsov BV, Budarin LI, Russ. J. Inorg. Chem. 29 (1984) $27-$ 30.

${ }^{15}$ Beattie JK, Kelso MT, Aust. J. Chem. 34 (1981) 2563-2568.

${ }^{16}$ Moulik SP, Khan DP, Carbohydr. Res. 36 (1974) 147-157.

${ }^{17}$ Kieboom APG, BuUrmans HMA, van LeEuwen LK, van Benschop HJ, Rec. Trav. Chim. Pays-Bas 98 (1979) 393-394.

${ }^{18}$ MÄKINEN KK, SÖDERLING E, Calcified Tissue Int. 36 (1984) 64-71.

${ }^{19}$ TAJMIR-RIAHI HA, Carbohydr. Res. 183 (1988) 35.

${ }^{20}$ LU Y, DENG G, MiAO F, Li Z, Journal of Inorganic Biochemistry 96 (2003) 487-492.

${ }^{21}$ YANG L, SU Y, LIU W, JIN X, WU J, Carbohydrate Research 337 (2002) 1485 -1493.

${ }^{22}$ EsCANDAR GM, SALA LF, Can. J. Chem. 70 (1992) 2053.

${ }^{23}$ SAladini M, Menabue L, FERRARI E, Carbohydrate Research 336 (2001) 55-61.

${ }^{24}$ Zhang Z, Gibson P, Clark SB, Tian G, Zanonato PL, Rao L, J Solution Chem 36 (2007) 1187-1200. 
${ }^{25}$ SAWYER DT, BRANNAN JR, Inorg. Chem. 4 (1965) 1070.

${ }^{26}$ Escandar GM, Olivieri AC, GonzÁlez-Sierra M, Frutos AA, SAla LF, J. Chem. Soc. Dalton Trans. (1995) 799.

${ }^{27}$ Escandar M, Olivieri AC, GonzÁlez-Sierra M, Sala LF, J. Chem. Soc. Dalton Trans. (1994) 1189.

${ }^{28}$ NIST, Standard Reference Database 46, Critically Selected Stability Constants, version 5.

${ }^{29}$ VAn Loon LR, Glaus MA, Vercammen K, Acta Chem. Scand. 53 (1999) 235-240.

${ }^{30}$ Rhai D, Hess NJ, Xia Y, Rao L, Cho HM, Moore RC, VAn LoOn LR, J. Solution Chem. 32 (2003) 665-689.

${ }^{31}$ HaAs J Jr, Marine Chem. 19 (1986) 299-304.

32 Daniele PG, Foti C, Gianguzza A, Prenesti E, Sammartano S, Coord. Chem.Rev. 252 (2008) 1093-1107.

${ }^{33}$ SHERIDAN RL, RyAn CM, QuinBy WC JR, BLAIR J, TOMPKInS RG, BURKE JF, Burns 21(1) (1995) 62-64.

34 Kono K, Watanabe T, Dote T, Usuda K, Hishiura H, Tagawa T, Tominaga M, Higuchi Y, ONNDA M, International Archives of Occupational and Environmental Health, 73 (2000) S93-S97.

${ }^{35}$ CAnnan RK, Kibrick A, J. Am. Chem. Soc. 60 (1938) 2314-2320.

${ }^{36}$ Masone M, Vicedomini M, Ann.Chim.(Rome) 71 (1981) 517.

${ }^{37}$ SCHubert J, LindenBAum A, J.Am.Chem.Soc 74 (1952) 3529.

${ }^{38}$ Zhang Z, Bottenus B, Clark SB, Tian G, Zanonato PL, Rao L, J. Alloys Compd. 444 (2007) 470-476.

${ }^{39}$ SAwyer DT, Bagger JB, J. Am. Chem. Soc. 81 (1959) 5302-5306.

${ }^{40}$ Combes CL, Birch GG, Food Chem. 27 (1988) 283-298.

${ }^{41}$ Vercammen K, Glaus MA, Van Loon LR, Acta Chem. Scand. 53 (1999) 241-246.

42 Duro L, Grivé M, Domenech C, Gaona X, Colás E, Montoya V, Bruno J, Development of the ThermoChimie Thermodynamic Data Base, ANDRA Report C.RP.0ENQ.07.0001, 2007.

${ }^{43}$ Martell AE, Smith RM, Critical Stability Constants; Plenum Press: New York and London, 1974.

${ }^{44}$ TAJMIR-RIAHI HA, Carbohydr. Res. 122 (1983) 241-248.

${ }^{45}$ Kiss T, Farkas E, Perspect. Bioinorg. Chem. 3 (1996) 199. 
${ }^{46}$ Lakatos A, Kiss T, Bertani R, Venzo A, Di Marco VB, Polyhedron 27 (2008) 118-124.

${ }^{47}$ Motekaitis RJ, Martell AE, Inorg. Chem. 23 (1984) 18.

${ }^{48}$ Giroux S. Rubini P, Henry B,Aury S, Polyhedron 19 (2000) 1567.

${ }^{49}$ Giroux S, Aury S, Henry B, Rubini P, Eur. J. Inorg. Chem. (2002) 1162.

${ }^{50}$ Bechtold T, Burtscher E, Turcanu A, J. Chem. Soc., Dalton Trans. (2002) 2683.

${ }^{51}$ Williams PAM, Barrio DA, EtcheVerry SB, BARAn EJ, J. Inorg. Biochem. 98 (2004) 333.

52 Rossiter DS, Fawell PD, Ilievski D, PARKInson GM, Journal of Crystal Growth 191 (1998) 525-536.

${ }^{53}$ Rossiter DS, Illevski D, SMith PG, Parkinson GM, Chem. Eng. Res. Des. 74 (1996) A7, 828.

${ }^{54}$ Gadna X, Montoya V, Colàs E, Grivé M, Duro L, Journal of Contaminant Hydrology $102(2008) 217$.

${ }^{55}$ Venema A, Peters JA, Van Bekkum H. Recl. Trav. Chim., Pays-Bas 112 (1993) 445.

${ }^{56}$ Sipos P, Hefter G, MAY PM, The Analyst 125 (2000) 955.

${ }^{57}$ Sipos P, Hefter G, May PM, J. Chem. Eng. Data 45 (2000) 613.

${ }^{58}$ Sipos P, Hefter G, May PM, Aust. J. Chem. 51 (1998) 445.

59 May PM, Hefter G, Mershall S, Kron I, Sipos P, Fundamentals of Alumina Precipitations, Report Submitted to AMIRA, September 1993, Page: 17.

${ }^{60}$ Hyperchem 8.0, Hypercube, Inc., Gainesville, Florida, 2007.

${ }^{61}$ Jalilehvand F, SpÅngberg D, Lindqvist-Reis P, Hermansson K, Persson I, Magnus SAndSTRÖM, J. Am. Chem. Soc. 123 (2001) 431-441.

62 Nelson BC, Uden PC, Rockwell GF, Gorski KM, Aguilera ZB, Journal of Chromatography A 771 (1997) 285-299.

${ }^{63}$ Windholz M (Editor), The Merck Index, Merck and Co., Rahway, NJ, 10th ed., 1983

${ }^{64}$ Lakatos A, Schrantz K, Enyedi EA, Dombi A: Mennyiségi analitikai gyakorlatok, Szegedi Egyetemi kiadó, Szeged, 2008.

${ }^{65}$ ZÉKÁNy L, NAGYPÁl I, Peintler G, PSEQUAD for Chemical Equilibria, Update 5.01, 2002.

${ }^{66}$ SipOs P, J. Mol. Liq. 143 (2008) 13.

${ }^{67}$ NANCOLLAS GH, Interactions in Electrolyte Solutions; Elsevier: New York, 1966.

${ }^{68}$ Cho HM, Rai D, Hess NJ, Rao L, J. Solution Chem. 32 (2003) 691-702. 
${ }^{69}$ BAX A, GRIFFEy RH, HAwKIns BL, J. Magn. Reson. 55 (1983) 301.

${ }^{70}$ Dörnyei A, GARribBa E, JAKUSCh T, Forgó P, Micera G, Kiss T, Dalton Trans 12 (2004) 1882-1891.

${ }^{71}$ Huang Q, Chmaissem O, Capponi JJ, Chaillout C, Marezio M, Tholence JL, Santoro A, Physica C: Superconductivity 227 (1994) 1.

${ }^{72}$ Duchesne J, Reardon EJ, Cement Concr. Res. 25 (1995) 1043.

${ }^{73}$ SRuth RA, Rostell AE, Critical Stability Constants, Plenum Press, New York, 1976

74 PEINTLER G: ZITA, A Comprehensive Program Package for Fitting Parameters of Chemical Reaction Mechanisms, Versions 2.1-5.0 (Department of Physical Chemistry, University of Szeged, Szeged, Hungary, 1989-2001).

75 JT Gerig, J. Am. Chem. Soc. 1968, 90, 2681. 